\title{
St. Thomas' hospital cardioplegia versus intermittent aortic cross-clamping in aorto-coronary bypass surgery
}

Citation for published version (APA):

van der Veen, F. H. (1985). St. Thomas' hospital cardioplegia versus intermittent aortic cross-clamping in aorto-coronary bypass surgery. [Doctoral Thesis, Maastricht University]. Rijksuniversiteit Limburg. https://doi.org/10.26481/dis.19850404fv

Document status and date:

Published: 01/01/1985

DOI:

10.26481/dis.19850404fv

Document Version:

Publisher's PDF, also known as Version of record

\section{Please check the document version of this publication:}

- A submitted manuscript is the version of the article upon submission and before peer-review. There can be important differences between the submitted version and the official published version of record.

People interested in the research are advised to contact the author for the final version of the publication, or visit the DOI to the publisher's website.

- The final author version and the galley proof are versions of the publication after peer review.

- The final published version features the final layout of the paper including the volume, issue and page numbers.

Link to publication

\footnotetext{
General rights rights.

- You may freely distribute the URL identifying the publication in the public portal. please follow below link for the End User Agreement:

www.umlib.nl/taverne-license

Take down policy

If you believe that this document breaches copyright please contact us at:

repository@maastrichtuniversity.nl

providing details and we will investigate your claim.
}

Copyright and moral rights for the publications made accessible in the public portal are retained by the authors and/or other copyright owners and it is a condition of accessing publications that users recognise and abide by the legal requirements associated with these

- Users may download and print one copy of any publication from the public portal for the purpose of private study or research.

- You may not further distribute the material or use it for any profit-making activity or commercial gain

If the publication is distributed under the terms of Article $25 \mathrm{fa}$ of the Dutch Copyright Act, indicated by the "Taverne" license above, 
ST. THOMAS" HOSPITAL CARDIOPLEGIA VERSUS INTERMITTENT AORTIC CROSS-CLAMPING IN AORTO-CORONARY BYPASS SURGERY 
Druk: Srichting Grafische Werkplats Maastricht 
ST. THOMAS' HOSPITAL CARDIOPLEGIA VERSUS INTERMITTENT ADRTIC CROSS-CLAMPING IN AORTO-CORONARY BYPASS SURGERY

PROEFSCHRIFT

ter verkrijging wan de graad van doctor in de geneeskunde aan de Rijksuniversiteit Limburg te Maastricht, op gezag van de Rector Magnificus, Prof. Dr. F.I.M. Bonke, volgens het besluit wan het college wan Dekanen, in het openbaar te verdedigen op donderdag 4 aprit 1985, om 16.00 uur

door

Frederik Hendrik wan der Veen

geboren te 's-Gravenhage in 1950. 
Promotor : Prof. dr. R.S. Reneman, Rijksuniversiteit Limburg, Maastricht Ca-pramotor: Dr. G.J. Van der Vusse, Rijksuniversiteit Limburg, Mastricht Referenten: Prof. dr. H.J.J. Wellens, Rijksumiwersiteit Limburg, Maastricht Prof. dr. H.A. Huysmans, Rijksuniversiteit Leiden, Leiden Prof. dr. W. Flameng, Katholieke Uniwersiteit Leuven, Leuven, Belgite

Financial support by the Netherlands Heart Foundation for the publication of this thesis is gratefully acknowledged. 
aan mijm ouder's, voor Astrid, Nina en Lara. 


\section{CONTENT}

Symbols and abbreviations.

1. INTRODUCTION

1.1 Open-heart surgery

1.2 The need for myocardial protection

1.3 Techniques for myocardial protection

1.4 Evaluation of the clinical outcome

1.5 unsalved clinical problems

1.6 Aim of the present study

\subsection{Myocardial protection}

2.1.1 Introduction

2.1.2 Aorto-coronary bypass surgery

2.1.3 Hypothermia

2.1.4 Techniques of myocardial protection

2.2 The myocardium during aorto-coronary bypass surgery

2.2.1 Hemodynamic function

2.2.2 Coronary artery blood flow

2.2.3 Mechanical function

2.2.4 Tissue metabolism

2.2 .5 U1 trastructure 
3.1 Patient situdy 33

3.1.1 Patients, anesthesia and instrumentation 33

3.1 .2 Surgical technique 36

3.1.3 Hemodynamic assessment 37

3.1.4 Sampling of tissue 37

3.1 .5 Sampling of blood 38

3.1 .6 ultrastructural anatysis $\quad 39$

3.1.7 Biochemical analysis of tissue 41

3.1.8 Biochemical analysis of blood $\quad 42$

3.1.9 Mathematical analysis of enzyme activity data 43

3.2 Animal experiments 47

3.2.1 Animals and anesthesia 47

3.2 .2 Instrumentation 48

3.2.3 Design of the experiments 50

3.2.4 Cardiopulmonary bypass 57

3.2 .5 Hemodynamic measurements $\quad 60$

3.2.6 Sampling of tissue $\quad 61$

3.2.7 Sampling of blood 62

3.2.8 Biochemical analysis of tissue and blood 63

3.2.9 Plasma volume determimation and cumulative enzyme 64 release

3.2.10 Microsphere technique 67

3.2.11 Myocardial mechanical function 72

3.3 Technical notes $\quad 76$

3.4 Statistical analysis $\quad 77$ 
4.1 Patient study $\quad 79$

4.1.1 Clinical outcame $\quad 79$

4.1.2 Hemadynamics 81

4.1.3 Brochemical analysis $\quad 86$

4.1.3.1 Plasma catecholamine concentrations 86

4.1.3.2 Postoperat lve enzyme release 88

4.1.3.3 Tissue content of ATP, creatine phosphate 91 and glycogen

4.1.3.4 Plasma levels of lactate, inorganic 96 phosphate, potassium, and oxygen content

4.1.4 Mitochondrial ultrastructural findings 104

4.2 Animal experiments 106

4.2.1 Introduction 106

$\begin{array}{ll}4.2 .2 \text { Hemodynamics } & 106\end{array}$

4.2.3 Myocardial blood flow 108

4.2.4 Myocardial mechanical performance 111

4.2.5 Biochemical analysis 111

4.2.5.1 Release and uptake of lactate, inorganic 111 phosphate and potassium, and uptake of oxygen

4.2.5.2 Tissue content of metabolic substances 122

4.2.6 Hemodynamic and biochemicall changes during the 129 initial period of cardiopulmonary bypass

4.2.7 Enzyme release 133

4.2.8 Plasma vol ume $\quad 136$ 
5.1 General topics

5.1.1 $\mathrm{CT}$ inical outcome and hemodynamic recovery

5.1.2 Biochemical variables in arterial blood

5.1.3 Arterial-coronary sinus differences of biochemical variables in blood

5.1.4 Biochemical variables in tissue

5.1.4.1 Tissue high-energy phosphates and glycogen in patients

5.1.4.2 Tissue content of ATP and glycogen in dog hearts. Comparison with the human situation

5.1.4.3 Tissue content of creatine phosphate in dog hearts

5.1.4.4 Tissue content of inorganic phosphate in relation to high-energy phosphate content. and inorganic phosphate rellease

5.1.4.5 Tissue lactate in relation to glycogen release of lactate in the caronary sinus

5.1.4.6 Variations in the high-energy phosphate and

glycogen contents in preischemic myocardial biopsies.

5.1.4.7 Summary of biochemical findings in tissue

5.2.1 Hemodynamic and biochemical changes in the initial period of cardiopulmonary bypass

5.2.2 Coronary artery blood flow cardioplegic techniques in open-heart surgery. 
1. Body weight and left wentricular weight 165

2 Rectal temperature 166

3 Septal temperature $\quad 166$

4 Hemodynamic vartables 167

5 Perfusion pressure and pump flow during cardiopumonary 168 bypass

6 Coronary blood flow $\quad 170$

7 Regional shartening $\quad 171$

8 Blood gas walues $\left(\mathrm{pH}, \mathrm{PCO}_{2}\right.$ and $\left.\mathrm{O}_{2}\right) \quad 172$

9 Arterial concentration of lactate, inorganic phosphate, $\quad 175$ potassium and glucose

10 Arterial-coronary sinus differences of lactate, inorganic 179 phasphate, potassium and oxygen

11 Uptake and release of lactate, inorganic phosphate, potassium and oxygen

12 Plasma enzyme activity, hematocrit and free hemoglobin 

SYMBOLS AHD ABBREWIATIOHS

$A C$

$A=C S$

ACT

ALT

AST

ATP

$\mathrm{CCad}^{2+}$

$\mathrm{Cl}$

CK-MB

$\mathrm{CPB}$

dPT v/dt max, pos

d.w.

ECG

$e^{e}$

$e_{z}$

$e_{Z C}$

endo, est

FCR

$\mathrm{Hb}$

$\mathrm{HBDH}$

$\mathrm{Ht}$

i.m.

i.v.

$\mathrm{k}_{\mathrm{d}}$

LAICA

LCCA

LWSW:

MDH

MFGC

min

n

Pao, sys

Pao,dia
Aortic cross-clamping

Arterial-coronary sinus (difference)

Actual clotting time

Alanine aminotransferase

Aspartate aminotransferase

Adenosine triphosphate

Ionized calcium

Cardiac index

Creatine kinase isoenzyme MB

Cardiopulmonary bypass

Positive, maximum first derivative of

left ventricular pressure

dry weight

Electrocardiogram

Natural tangential strain

Natural axial strain

Shear angle

Estimated subendocardial fiber shortening

Fractional catabolic rate constant

Hernoglobin

$\alpha$-hydroxybutyrate dehydrogenase

Henatocrit

intramuscular

intravenous

Apparent enzyme disappearance constant

Left anterior interventricular coronary artery

Left circumflex coronary artery

Left ventricular stroke work index

Malate dehydrogenase

Magnetic field generating coil

minutes

number of observations

Systolic aortic blood pressure

Diastolic aortic blood pressure 


\begin{tabular}{|c|c|}
\hline Pao, zimea & Mean aortic blood pressure \\
\hline Plv & Systolic left ventricular blood pressure \\
\hline Ply,ed & end-diastolic left ventricular blood pressure \\
\hline $\mathrm{PCO}_{2}$ & Partial carbon dioxide tension \\
\hline PLV & Plasma volume \\
\hline $\mathrm{PO}_{2}$ & Partial axygen tension \\
\hline Php & Pulmonary artery wedge pressure \\
\hline$s$ & seconds \\
\hline 50 & Sensor coil \\
\hline SD & Standard deviation \\
\hline SEM & Standard error of the mean \\
\hline TER & Tramscapillary escape rate constant. \\
\hline
\end{tabular}




\section{Patient groups}

Hormothentia $\left(34^{\circ} \mathrm{C}\right)$ and internittent aortic cross-clamping.

4 Hypothemia $\left(25^{\circ} \mathrm{C}\right)$ and intermittent aortic cross-clamping

c. Cardiopllegia using continuous aortic cross-clamping in combination with icemcold st. Thomas Hospital cardioplegia

\section{Animal groups}

Nomothemia $\left(34^{\circ} \mathrm{C}\right)$ and intermittent aortic cross-clamping (4 times 10 minutes)

H Hypothermia $\left(25^{\circ} \mathrm{C}\right)$ and intermittent aortic cmoss-clamping (4 times 10 minutes)

c Hypothermic potassium cardioplegia (st Thomas Hospital) with continuous aortic cross-clanping $(60 \mathrm{~min})$

NB Nomothermia with intermittent aortic cross-clanping and multiple left ventricular biopsies

$\mathrm{HB}$ Hypothermia with intermittent aortic cross-clamping and multiple left ventricular biopsies

NC Normothersia without intermittent aortic cross-clamping

HC Hypothemia without intermittent aartic cross-clamping

CON Cantrol group with complete instrumentation, but without cardiopulmonary bypass

EC Enzyme release during control conditions without cardiac manipulation

HPLV Hypothermia with intermittent aortic cross-clamping and multiple plasma volume determinations 


\section{INTRODUCTION}

\subsection{Open-heart surgery}

Congenital and acquired heart diseases have been known for a long time, but it was not until about 30 years ago that the combined efforts of clinicians, surgeoms, biochemists and engineers enabled the performance of a successful open-heart operation. Intracardiac operations are complex because of the requirement of circulatory arrest during the performance of the correction. Initialiy short periods of systemic circulatory arrest have been used for minor interventions, but in this procedure the time available for surgery is 8-10 min and therefore of limited use. Adequate correction of most cardiac diseases requires a quiet and bloodless heart for surgical reasons. Numerous efforts and subsequent discoveries in the past, as sumarized in table 1.1, finally resulted in the knowledge and experience necessary to sustain the patients systemic blood circulation during the course of the operation. This was achieved with cardiopuimonary bypass (CPB), using an oxygenator and an artificial pump (fig 1.1). After connection of the extracorporeal circuit to the patient, a flow of 3 to 5 liters per min can be maintained, which is adequate to suppart the peripheral circulation.

The highly important oxygenator was designed to exchange oxygen and carbon dioxide in the venous blood of the extracorporeal circuit. From the many types of oxygenators constructed, nowadays the bubble axygenator, supplied with a heat exchanger, is commonly used in open-heart surgery. Membrane oxygenators are used in pediatric patients and during long lasting operations.

Once the heart-lung machine could replace heart and lung function, it became possible to arrest the heart and to stop the blood circulation within the heart after crass-clamping of the aorta. Meanwhile peripheral circulation was artifactually maintained. Cross-clamping of the aorta, however, induces periods of global ischemia, limiting the time available for cardiac repair. Extention of the ischemic period was found to be allowed when cardioprotective measures were taken.

starting with the repair of congenital heart and valvular diseases in the early years of cardiac surgery, we are now facing the widespread incidence of 
Table 1.1 Historical events in cardiopulmonary bypass (After Ream and Fogdall, 1982).

1928 Pulsatile perfusion of dag s head, using piston pump.

1930 organ perfusion, bacterial filtering.

1934 Roller pump for blood infusion (Debakey).

1948 Invention of disc oxygenator.

1950 First modern bubble oxygenator, first application of effective defoaming (Clark and coworkers).

1951 Successful organ bypass in man: direct bubble oxygenation device (Dogliotti and Costantinil.

1951 First attempt of total bypass in man (Dennis and coworkers).

1953 Success in open heart surgery using only hypothermia (Lewis and Mansar).

1955 Successful bypass, using human lung in cross circulation

(Lillehei and coworkers).

1956. Invention of disposable bubble design (DeWall and coworkers).

1956 First clinical use of membrane oxygenator (Clowes and coworkers). 
coronary artery diseases, valve lesions and aneurysms of the left ventricle. Each of these heart abnormalities can be repaired with a low intraperative mortality risk and a good lomgtern surviwal. In combination with the adwanced diagnostic techmiques, this has lead towards an increasing demand for openheart surgery. For instance, in the Netherlands the number of open-heart operations nearly doubled within 3 years from a total of 3945 in 1979 to a total of 7112 in 1982. This data mainly nefers to cononary bypass surgery (5036), valve replacements (1195) and congenital heart surgery (648) (data from Begeleidingscomissie Hartchirurgie Mederland 1982). It is evident that the rapid development of open-heart surgery in different cllitical centres around the world has introduced variety of techniques and protocols for the perfomance of the aperation. This is especially true for the techniques to protect the heart during the critical ischemic period, when the heart is deprived from blaod for a longer period of time (see section 1.2). The need for protection, the protective techniques applied to minimize ischemic damage of heart tissue and the evaluation of their adequacy are dissussed in detail in the consecutive sections, at least when relevant to aorto-coronary bypass surgery and to the present stidy.

Protection includes reduction of the patient's blood temperature to $25^{\circ} \mathrm{C}$ (systemic temperature) and selective cooling of the heart to $15^{\circ} \mathrm{C}$ with a cardioplegic solution. A different protection technique is intermittent cross-clamping of the aorta and thus introducing repetitive, short periods of ischemia, each followed by a reperfusion (recovery) period. Development of protective techniques requires reliable evaluation of the clinical outcome. Beside the use of perioperative and postoperative mortality rates, for instance analysis of changes in ECG, henodynamic function and specific enzyme release during the postoperative period have shown to be valuable tools. By the development of accurate biochemical and ultrastructumal indices, a variety of parameters has become avallable to more specifically evaluate the clinical outcome. These parameters are discussed briefly in section 1.4 and in more detail in section 2.2. Desplte the fact that rellable variables to evaluate aorto-coronary bypass surgery are at hand, contradictory results of clinical and experimental research are still being reported (see section $1.5)$.

The final part of the Introduction (see section 1.6) reports on the set-up of the clinical and experimental parts of this study, which were 


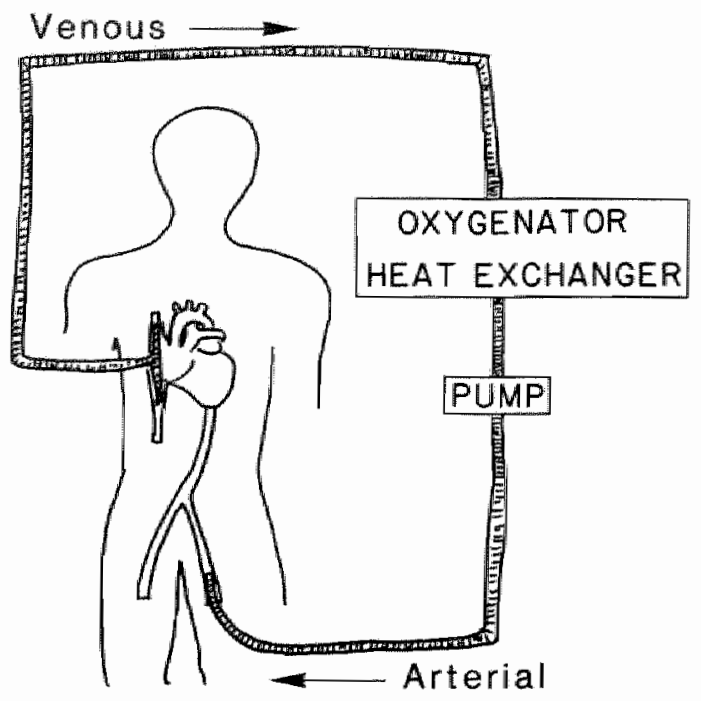

Fig 1.1 Schenatic design of a heart-7ung machine, including an oxygenator, a heat exchanger and a punp, to sustain the blood circuiation during open-heart surgery.

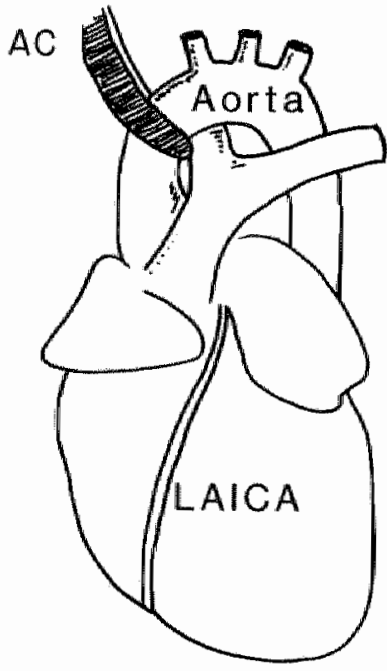

Fig 1.2 site of acclusion of the ascending aorta above the inflow opening of the left and right coronary arteries $(A C=$ aartic cross-cl amping). 
primarily designed to:

- analyse the clinical and experimental course of three techniques routinely used for myocardial protection during aorto-coronary bypass surgery.

- provide hemodynamic and biochemical parameters to evaluate the behavior of the heart during and immediately after open-heart surgery.

\subsection{The need for myocardial protection}

When replacing heart and lung function by means of a heart-lung machine the heart becomes unioaded. To perform surgical repair, it is necessary that coronary blood flow is diminished. In particular during aorto-coromary bypass operations a quiet and bloodless operating field is required to perform the bypasses between the ascending aorta and the affected coronary artery. With sustained coronary perfusion incision of the coronary arteries would calise excessive bleeding. A standstill of coronary flow is routinely obtained by occlusion of the ascending aorta, just above the inflow opening of the coronary vessels (fig 1.2 ).

The duration of aortic cross-clamping during aorto-coronary bypass surm gery is in general detemined by the total number of aorta to coronary artery grafts. Routinely the perfomance of one bypass takes $6-15 \mathrm{~min}$. During the period of aortic cross-clamping, when coronary flow is zero (globali ischemia), axygen and substrates will not be delivered to the myocardium and breakdown products will accumulate in this tissue. Because oxygen supply has ceased, and the oxygen reserve is limited within the myocardial cells, the cells immediately change from aerobic to anaerabic metabolism. Endogenous glycogen, which is available in Targe quantities, will be used for lactate production and the energy delivered should maintatn the content of high-energy phosphates at physiological levels. Because meanwhile the removal of breakdown products is hampered, $\mathrm{CO}_{2}$ and such harmful products as $H^{*}$ ions and lactate will accunulate. When ischenia lasts for longer periods of turne, the amount of high energy phosphates finally diminishes and cell metabolism deteriorates. Consequently membrane integrity changes and intracellular macromolecules enter the intercellular (interstitial) space.

In order to reduce the metabolic activity of the heart during the critical periad of ischemia the myocardium is usually coaled to $15-25^{\circ} \mathrm{C}$. This can 
be achieved by infusion of cardioplegic solutions or through topical coolling with ice-water or a combination of these techniques. These procedures may reduce the oxygen consimption to $50 \%$ at temperatures of $26^{\circ} \mathrm{C}$ (Badeer, 1956) and to $0.33 \mathrm{ml} 0_{2}$ per min per $100 \mathrm{~g}$ left ventricular tissue at $15^{\circ} \mathrm{C}$ (Chitwood et al, 1979). This amounts to $6 \%$ of the values observed in the empty beating heart ent $37^{\circ} \mathrm{C}$.

Animal experiments have shown that upto $30 \mathrm{~min}$, global ischemia has no irreversible influence on myocardial ultrastructural appearence (Nohara, 1983; Taylor et al, 1984), while after $60 \mathrm{~min}$ ischemia at $37^{\circ} \mathrm{C}$ the myocardium becomes firreversibly injured (Flameng et a1, 1981a).

In between these extremes there is a transition from reversible to irreversible changes of the myocardial cellis. The technique of myocardial protection should particularly ain at the extension of the onset of irreversible tissue damage.

\subsection{Techniques for myocardial protection}

The development of techniques for myocardial protection during open-heart surgery, was initially related to congenital heart abnormalities and walve lesions. Therefore, these techniques had to protect the heart during relatively long, uninterrupted periods of ischemia due to aortic cross-clamping. Since the introduction of aorto-coronary bypass surgery in 1967 (Favaloro), the earlier developed techniques were adapted to this procedure. In myocardial protection two important aims have to be addressed. Firstly, the duration of amaerobic metabolism should be limited and secondly, the intensity of anaerobic metabolism should be reduced. Most of the techniques used nowadays are dealing with one or bath of these aspects. In aarto-coronary bypass surgery reduction of the duration af anaerobic metabolism can be achieved by intemittently cross-clamping the aorta (Delva et al, 1978). During each ischemic period the distal anastomosis (coronary artery connection) of the graft cam be performed, while during the succeeding reperfusion phase the proximal anastomosis (aortic connection) will be made. The number of crossclanpings mostly equals the number of distal anastomoses uniess the "snake" method is applied (multiple distal anastomosis to one graft). The duration of one ischemic period is commoniy reduced to $6-15 \mathrm{~min}$ and metabolic recovery 
during the subsequent reperfusion period $(10-20 \mathrm{~min})$ precedes the next ischenic phase. Initially this technique was carried out at a systemic tensperature of $34^{\circ} \mathrm{C}$ (nomothermia), but was abandonned because of postoperative complications. Good clinical results were obtained by lowering systemic temperature to $25^{\circ} \mathrm{C}$ (hypothermia) and combining this method with hypothermia became the technique of choice (Koster et al, 1977; Baur et al, 1979).

Nowadays a different approach to myocardial preservation, known as cardioplegia, is applied in mearly all centres for open-heart surgery (Weisel et. a), 1983). Cardioplegia, or cardiac arrest due to selective perfusion of the coronary arteries during aortic cross-clamping with a variety of artificial solutions, primarily aimes at reducing the intensity of anaerobic metabolism, and has recently been reviewed by Hearse and his colleagues (1981). In general, cessation of electromechanical activity is achieved by low temperature and a relatively high potassium content of the solution. The composition of the various cardioplegic solutions as described in literature differs enormously and even today the concept, on which the composition is based, varies. Experimental results are not uniform in respect to the optimum combination of constituents. In search of this optimun composition several criteria can be mentioned. The cardioplegic solution should:

- stop heart activity

- minimize anaerobic metabolic activity

- preserve membrane integrity

- have an optimal oxygen capacity

- act as a buffer

- prevent $t$ issue edema

- not contain toxic substances or particles.

Beside the composition of the solution, such factors as temperature, $\mathrm{pH}_{\text {, }}$ volume infused and intervals between the infusions can be manipulated. Inprovement of the technique of cardioplegia is still being reported from many labaratories and it seems to take still some time before the final and llost ideal cardioplegic solution has been developed and accepted. 


\subsection{Evaluation of the clinical outcome}

The evaluation of a patient after an open-heart operation can be based upon two different approaches. Firstly, during the operation intensive monitoring in the operating room provides information about the systemic circulation, the blood gas values, the pump function of the heart and the ECG. Correct anesthetic policy sustains the patient at the onset of weaning from cardiopulmonary bypass and detemines whether prolonged support of the heart is needed. During the first hours after CPB heart rate, ECG, blood pressure and cardiac output are routinely monitored. Complications as for instance an unacceptable low cardiac output or evolved myocardial infarction can be detected innediately. Within the first days after the operation, repetitive cardiac output and ejection fraction determinations can be perfomed. This policy takes care of the optimum condition of the patient and the parameters mentioned are in general applied to determine the patient's clinical outcome and recovery in the intensive care unit.

Secondly, comparison of the different surgical and/or protective techniques should involve examination of more specific variables beside the hemodynamic and clinical recovery. Especially the asessment of heart function (i.e. left ventricular pressure and its maximum positive first derivative) is useful when values as obtained following CPB, are compared to the values before CPB. However, these parameters are influenced by multiple interventions and are therefore not solely indicative for damage due to an ischemic insult. Different from the hemodynamic measurements immediately after CPB is the analysis of enzyme release, which is essentially initiated during the operation, but effectuated only after hours or days following the operation. The rellability of the measurement of the activity of one or a set of heart. specific enzymes for the detection of myocardial tissue damage has improved during the past years. This is caused by the development of seperation techniques to determine isoenzymes and by the application of mathematical models which allow multienzyme analysis.

Detailed information about the myocardium can be derived from myocardial blopsies and coronary sinus blood samples during the period of CPB. To evaluate the effects of ischemia biopsies for studying heart metabolism and ultrastructural examinations can be taken in the inmediate postischemic 


\subsection{Unsolved clinical problems}

In interpreting the results from clinical studies in which different groups of patients are compared, patient selection and history, and overall treatment during the preoperative period have to be considered. Great diversity of these factors may influence the final clinical outcone and even hamper adequate interpretation of the results. Especially the hearts of patients submitted to aorto-coronary bypass surgery may be subject to previous myocardial infarction or less well perfused areas. Also during surgery, (even when the operation protocols are ment to be standardized) individual anesthetic policies, to maintain adequate hemodynamic function, may differ between patients.

Another aspect of clinical studies deserves full attention. When the protective technique has been replaced in time, the groups are treated serially and not in a randomized parallel way. The validity of serial observations is debatable because other factors beside myocardial protection may change in time and affect the clinical outcome (Davids, 1982).

Although a variety of studies have been performed on myocandial protection during global ischemia, several aspects need to be clarified. Firstly, the question whether hypothermia should be preferred above normothemia. Deleterious influences of hypothernic ventricular fibrillation as compared to the normothermic empty beating heart, have been reported (Grover et al, 1977; Vinas et al, 1979). On the other hand hypothermia has shown to reduce metabolic demands and hence may be beneficial to the ischemic myocardium. Selective cooling of the heart to $15^{\circ} \mathrm{C}$ is routinely used and may result in cold damage to cells or more specifically membranes. Whether this type of damage occurs in heart tissue is still subject of discussion.

secondly, as was mentioned in section 1.3 myocardial protection has evolved to a number of cardioplegic solutions all of which are advocated as being excellent. However, comparison of the cardioplegic solutions used, has only been rarely reported in a climical trial.

Thirdly, beside the deleterious influence of global ischemia during: aorta-coronary bypass operations, other interventions which may be harnful to the myocardial tissue have been recognized. Especially reperfusion damage occurring after ischemia has been hypothetized to influence the state of the myocardial tissue. In this respect the application of different reperfusion 
techniques is worthy to note (Engeiman et al, 1977).

Fourthly, most of the aorto-coronary bypass operations are performed routinely today and the incidence of myocardial necrosis due to perioperative infarction is low, because of myocardial protection. To detect myocardial necrosis, if any, wery sensitive parameters are required. At the same time it will be desirable to select parameters which will discriminate between reversible and irreversible injury as well.

\subsection{Aim of the present study}

- Cinicar set-up

Before this study was started cardiac surgeons from the st. Raphael Clinics in Leuven performed aorto-coronary bypass operations routinely by combining intermittent aortic cross-clamping and nomothermia $\left(34^{\circ} \mathrm{C}\right)$ or hypothermia $\left(25^{\circ} \mathrm{C}\right)$ with good clinical results. Since comparable good results were abtained in patients undergoing extensive aorto-coronary bypass surgery combined with hypothermic St. Thomas Hospital cardioplegia and continuous aortic cross-clamping, this study was designed to evaluate these three techniques in a randomized way. The main question of the study was whether these surgicall techniques were different as far as the myocardial changes induced by global ischemia during aortic crass-clamping ars concerned. It was abserved in the literature that several surgeons operate with the use of one or more of these techniques (Koster et al, 1977; Baur et al, 1979), while evaluation of these techniques within a clinical trial was nat reported so far.

Table 1.2 shows the three patient groups including the type of cardioprotective protocol employed (see section 3.1 for detailed information). All patients included in the study were mandomly allotted to one of the three groups and they were all subjected to assessment of the parameters listed in table 1.3.

The values of the hemodynamic wariables after weaning fron CPB were compared with those measured prior to CPB, to obtatn insight into the effects of the surgical procedure on systemic circulation. Tissue metabolites were deterimined to assess the preservation of high-energy phosphates and glycogen stores, and the release of inorganic phosphate into the coronary sinus effluent as an index of high-energy phosphate breakdown. Simultaneously, in 
Table 1.2 Three groups of patients with thefr respective technique of myocardial protection.

Group

Technique of myocardial protection

Normothermi a

24

Normothermic intermittent aortic crassclamping $\left(34^{\circ} \mathrm{C}\right)$

Hypothermia

23

Hypothermic intermittent aortic crossclamping $\left(25^{\circ} \mathrm{C}\right)$

Cardioplegia

25

Continuous aortic cross-clamping combined with St. Thomas Hospital Cardioplegia

Table 1.3 Parameters and variables used to evaluate the efficacy of the three protective techniques under investigation.

Hemodymanic variables

Metabolic substances

Tissue metabolites

Tissue ultrastructure

Catechol anines

Plasma enzyme activity
Cardiac output, arterial pressure, left ventricular pressure (and its maximum positive first derivative), heart rate, pulmonary wedge pressure.

Lactate, inorganic phosphate, potassium and oxygen in arterial and coronary sinus blood.

High energy phosphates and glycogen in myocardial biopsies.

Mitochondrial appearance in myocardial biopstes.

Epinephrine, norepinephrine and dopamine in systemic venous blood.

AST, creatine kinase, $C K-M B$ and $H B D H$ in systemic wenous blood upto $36 \mathrm{hrs}$ after cardiopulmonary bypass. 
coronary sinus effluent we determined lactate as a measure of anaerobic glycolysis during myocardial ischemia, potassium as a marker of transsarcolenmal ion transport, and the arterial-coronary sinus difference of the oxygen content to assess tissue axygen consumption.

Suberido and subepicardial tissue specimens were obtained from the left ventricular free wall to determine ultrastructural changes in mitochondria, as measure of reversible and irreversible tissue injury. The serum content of catecholamines was assayed to estimate the possible correlation with changes in the hernodynamic performance. Up to 36 hours after CPB serial measurements of plasma enzyme activity of aspartate aminotransferase (AST), creatine kinase, its isoenzyme CK-MB and al pha-hydroxybutyrate dehydrogenase (HBDH) were used to quantitate irreversibly damaged cardiac tissue.

The combination of parameters and variables (Table 1.3) was selected to distinguish between changes from reversible (for instance moderate metabolic disturbances occurring after a short ischemic periad) and irreversible cell damage (for instance massive enzyme release in the circulation associlated with cell necrosis due to long lasting ischemia).

\section{- Animal experiments}

Although a lot of information about the efficacy of protective measures could be obtained from the clinical study, additional animal experiments were performed to investigate aspects, which could not be studied in patients. Therefore, an animal model, resembling the clinical situation, was developed. The animal madel allows the investigation of

- quantitative myocardial metabolism enabled by the measurement of myocardial blood flow with radioactive microspheres and an electromagnetic flow probe.

- transmural distribution of myocardial blood flow to assess whether subendocardial regions are preferentially underperfused after cardiopulmonary bypass.

- nyocardial metabolism in more detail because of the larger number of biopsies that can be taken. Biopsies just prior to ischemia and at the end of ischemic periods were obtained to differentiate between changes induced by ischemia and by reperfusion.

- the effect of cardiopulmonary bypass per se on the variables and para- 
meters measured, because aortic cross-clamping could be deleted. - the effect of anesthesia and instrumentation on the parameters measured. Besides, in the animal model we inwestigated the rapid changes in hematocrit using plasma volume measurements before and after cardiopulmonary bypass. 


\section{SURVEY OF THE LITERATURE}

\subsection{Myocardial protection}

\subsubsection{Introduction}

In the early days the clinical outcome after open-heart surgery was nat always adequate and in particular perioperative infarction was frequentily observed in association with postoperative low cardiac output (see for reviews Bedard et al, 1977; Davfds, 1982). Recognition of these complications has been a strong impetus for investigations aiming at the development of techniques to protect the heart during the surgical procedure.

To position the methods of protection presently available in perspective of their development, some important changes in attitude towards myocardial protection will be discussed. Since the first 25 years of myacardial protection have already extensively been reviewed by Hearse and coworkers (1981), and Conahan (1982), three selected topics will be discussed in this chapter.

The first part includes the specific conditions of the heart during the procedure of aorto-coronary bypass surgery. These conditions are the enpty beating, fibrillating and flaccid heart as well as the global ischemia of the myocardium due to aortic crass-clamping. Secondly, the effect of the aforementioned conditions of the heart on the tolerance to ischemia as a function of temperature will be discussed. Finally, protective techniques which have been developed from experimental and clinical investigations will be considered, in particular the techniques of intemittent aortic crossclamping and cardioplegia.

The choice of these topics closely relates to the type of surgery used in the present study. Aorto-coronary bypass surgery differs froin other openheart surgical procedures, mainly because of the duration of aartic crossclamping and the necessity to operate upon coronary arteries. These differences have resulted in adaptations of the myocardial protection policy. In general, valve replacement and correction of left ventricular aneurysms or congenital heart abnomalities require a continuous period of relatively long-lasting aortic cross-clamping (Flameng et al, 1980). The concomitant axygen deprivation of the heart is tolerable if profound myocardial cooling, commoniy in 
combination with cardioplegic solutions, will be applied. In contrast, during aorto-coronary bypass surgery the instalment of each single graft can be succeeded by a reperfusion period allowing the myocardiun to recover from a relatively short ischemic period, comonly lasting from 6 to 15 min.

\subsubsection{Aarta-coronary bypass surgery}

An essential requirement during aorto-coronary bypass surgery is a quiet and bloodless aperation field. After instalment of cardiopulmonary bypass the heart is empty beating. This can be changed into a flaccid heart (cardioplegia) or a fibrillating heart. (induced electrically or by hypothermil). Next, cessation of coronary artery flow is achieved by cross-clamping the ascending aorta permitting incission of coronary arteries for the perfomance of distal anastomoses without excessive loss of blood for details see conahan, 1982).

The initial employement of a fibrillating state during open-heart surgery offered many practical advantages. However, it has been subject of continuous debate whether fibrillation during this type of surgery is detrimental to the heart in itself. In an experimental model Senning (1952) abserved no change in the rate of oxygen consumption during fibrillation as compared to the empty beating heart. In contrast decreased oxygen consumption in the fibrilllating heart, as cormpared with the working heart, was reported by paul and coworkers (1954). An increased oxygen consumption as compared to the nonworking heart, was found by other investigators (Jardetzky, 1956). The functional recowery after proionged periods of induced fibrillation was reported to be adequate in both dogs and patients (Race et al, 1964).

More recently fibrillation during cardiopulmonary bypass was found to cause an increase in myocardial oxygen consumption and redistribution of coronary blood flow within the left ventricular wall, preferentially to the subepicardial layers (Ghidoni et al, 1969; Hottenrot et al, 1974; Buckberg and Hottenrot, 1975; Brazier et a1, 1975; Vinas et a1, 1979). These changes indicate that the fibrillating state may cause an imbalance between myocardial metabolic demand and supply resulting in a shortage of oxygen in the subendocardial layers. Under mild hypothermia the supposed deleterious effects of fibrillation were found to be reduced (Ninas et al, 1979). Other expe- 
rimental studies did not confin the negative effects of fibrillation. For

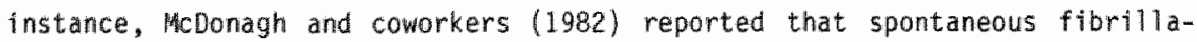
tion during 20 min did not increase myocardial oxygen consumption. Besides, Is om and colleagues (1973) were unable to detect redistribution of flow from the subendocardium towards the epicardium. Nowadays continuous, electrically induced ventricular fibrillation is used less frequentily in the clinical setting.

The ultimate effect of fibrillation on myocardial tissue is dependent on the model of investigation (Utley et 1, 1981). Vinas and coworkers (1979) and Hottenrot and collaborators (1974) employed continuous, electrically induced fibrillation under normothermic conditions in dogs on an extracorporeal circuit. They observed that during fibrilllation coronary flow was lower when electrical stimulation was applied continuously than when the heart was fibrillating without such a stimulus. This difference was especially pronounced after 60 min of fibrillation. Ventricular fibrillation will automatically occur when hypothermia is applied as part of the technique of myocardial protection unless cardioplegia is used (Malina et al, 1977). All reports mentioned so far were dealing with non-ischemic conditions of the heart.

Beside tha necessity of a quiet heart during aorto-coronary bypass surgery, cessation of coronary blood flow is also required which can be obtained by cross-clamping the aorta. This sitwation is referred to as global ischenia and its consequences for the myacardial tissue have been studied extensively. In clinical conditions ischemia affects the myocardial tissue depending on the efficacy of the technique for myocardial protection employed (Reul et al, 1975). The technique of protection should not anly reduce the reversible changes induced by ischemia, but should especially prevent irreversible damage to occur.

\subsubsection{Hypothermia}

One of the first papers on systemic moderate hypothermia in open-heart surgery in infants reports on the successful preservation of the myocardium and other organs after circulatory arrest of $8.5 \mathrm{~min}$ without the use of cardiopulmonary bypass (CPB; Swan et al, 1953). Earlier dog experiments had 
shown the reversal of changes in cardiodynamics and systeric circulation after cooling to $20^{\circ} \mathrm{C}$ for a short period of time and subsequent rewarming (Bigelow et al, 1950). The advantage of reduced metabolic demands at reduced body temperature has been applied during the first $C P B$ procedures. Cooling was initially performed by placing the body in a tub of crushed ice and water, which improved survival rate (King et al, 1958). Cooling of the core of the body became possible with the development of CPB equipment, and this technique subsequently replaced peripheral cooling (Galetti and Brechner, 1962). During systemic cooling by means of CPB the temperature of the heart will equal that of the body. An additional advantage of this technique is the fibrillating state of the heart offering a quiet operating field for the surgeon.

It is not practical to decrease body (systemic) temperature below $25^{\circ} \mathrm{C}$, but profound cooling of the heart has shown to improve protection during ischemia. External cooling of the heart using ice-cold saline solutions inside the pericardial cradle by addition of crushed ice, has initially been employed (Shumway et a1, 1959; Hurley et a1, 1964). From then on cold injury to the myocardium became subject of discussion (Speicher et al, 1962; Marco et al, 1977; Shragge et al, 1981). At the time coromary artery perfusion through separate 1 ines was introduced, more uniform cooling of the myocardium could be achieved (Bernhard et al, 1960; Van der Schaar et al, 1966), although inhomogenieties due ta pre-existing occlusions ar stenoses of the coronary arteries have to be considered (see final part of this section).

The possibility to adjust nyocardial temperature made it urgent to consider the optinum temperature. In 1979 Chitwood and coworkers reported a study in dogs, subjected to separate, uninterrupted perfusion during $C P B$, in which they varied myocardial temperature from $37^{\circ} \mathrm{C}$ to $15^{\circ} \mathrm{C}$ with the use of potas sium enriched cold blood. At this decrease in temperature they noticed a reduction of arterial-coronary sinus difference of oxygen content from 3.92 to 0.42 woll $\%$, and an increase in myocardial blood flow of $43 \%$. This may be benificial to patients, especially when underperfused myocardial areas aliready exist due to atherosclerotic lesions of the coronary arteries.

Profound levels of hypothermia $\left(6-18^{\circ} \mathrm{C}\right)$ were investigated by Balderman and coworkers (1983) in dogs on CPB. They found myocardial preservation during 120 min of global ischemia to be satisfactory at a myocardial temperature of $14^{\circ} \mathrm{C}$. Cooling to lower degrees impaired postoperative myocardial 
function. Kao and coworkers (1982) studied the preserwation of high-energy phosphates in the isolated working rat heart during and after one hour of ischemic potassium arrest at temperatures varying from 4 to $37^{\circ} \mathrm{C}$ with increments of 4 degrees. They observed optimum protection at temperatures of $12^{\circ} \mathrm{C}$ or lower, without the occurrence of cold injury to the heart. Despite some lack of agreement (Gays, 1980), the experimental and clinical findings ind cate that during ischemia the optimum temperature is in the range of 12 to $16^{\circ} \mathrm{C}$ (E11 is et al, 1979; Manners and Nielsen, 1981).

since hypothermia decreases oxygen demand of the tissue by slowing down metabollic activity, this aspect has been studied in detail in relation to its potential protective effect. Besides, other biochemical and biaphysical aspects should be considered as well. They include the increased solubility of oxygen in plasma and the reduced release of oxygen from hemoglobin for a given oxygen partial pressure. The reduced overall oxygen requirement and the increase in viscosity of blood with decreasing temperature makes hemodilution preferable. Hypothermia and hemodilution are rautinely combined in open-heart surgery.

\subsubsection{Techniques of myocardial protection}

Initially progress in open-heart surgery was dependent on the surgical skill and the adequacy of extracorporeal circulation (i.e. oxygenation, priming solution etc.). The application of aortic cross-clamping resulted in lang periods of coronary blood flow interruption and myocardial ischemia, associated with perioperative infarction and a thigh mortality rate (Favaloro, 1979). In the early years surgical repair mainly involved valve operations and congenital heart abnormalities. These surgical procedures were combined with several types of protective measures. The application of aortic crossclamping combined with selective coronary artery perfusion permits the uninterrupted delivery of blood to the myocardium. Aortic cross-clamping without coronary artery perfusion at normothermia or with moderate systemic hypothermia, implies no or only a small reduction in metabolic rate, but has the advantage of a short duration of operation and no complications from intracoronary catheters. Besides, local cooling of the heart could be used, resulting in diminished myocardial metabolic demands at the time of ischemia 
(Bernhard et al, 1960; Hurley et al, 1964).

Initially these techniques of myocardial protection were adapted to aartocoronary bypass surgery (Favaloro, 1967). Selective coronary artery perfusion was rarely used, because of coronary blood obfuscating the surgical field when the distal anastanoses (on the coronary artery) had to be made. However, aortic cross-claming at nomothermia, hypothermia, or with the use of profound local cooling of the myocardium were assumed to be appropriate in aorto-coronary bypass surgery (Baun et al, 1979).

A completely different technique is the local occlusion of the distal coronary artery. This techinique, however, has shown to be inferior to ischemic arrest as induced by aortic cross-clamping (Ell is et al, 1975), although this approach may be prefered under certain circumstances when aortic crossclamping is less desirable (Akins, 1984).

Especially after Levitsky and Feinberg (1975) reported the depletion of tissue high energy phosphate and glycogen stores after 60 min of continuous normothermic ischemic arrest, surgeons limited the duration of coronary flow obstruction by intermittently cross-clamping the aorta. Myocardial necrosis after prolonged normothermic ischemic cardiac arrest was established by other investigators (Buja et al, 1970; Merchant et a1, 1974). Intermittent reperfusion did not improve this situation (Lewitsky et $a 1,1977$ ). These experimental findings caused a shift from moderate hypothemia $\left(30-34^{\circ} \mathrm{C}\right)$ towards hypothermic $\left(25^{\circ} \mathrm{C}\right)$ intermittent aortic cross-clanping in combination with moderate hemodilution in the clinical setting (Delva et al, 1978). However, intermittent cross-clamping of the aorta was found to have a similar protective efficacy as continuous cross-clamping under profound local cardiac hypothermia (Koster et al, 1977).

As an alternative to intermittent aortic cross-cllamping, Melrose and colleagues (1955) and Berglund and coworkers (1957) introduced the so called "cardioplegia" technique. During continuous cross-clamping of the aorta the coronary arteries were perfused with cald solutions introduced via the clamped aartic root. Much research has been perforned to find the optimum composition and temperature of the cardioplegic solution. Bretschneider and associates (1975), for instance, adwocate solutions, the composition of which is essentialiy based on the concentration of crystalloids inside the myocardial cells. The most striking feature of their cardioplegic solution is the absence of calcium ions. 
In contrast, wher investigators proposed solutions related to the extracellular composition of the heart, supplemented with a relatively high concentration of potassium and magnesium (McFarland et al, 1960; Tyers et al, 1977; Hearse et a1, 1981). In our study we applied the St . Thomas hospital cardioplegic solution as proposed by Hearse and coworkers (1981). This solution has a high sodium chloride content $\left(110\right.$ mol. $\left.1^{-1}\right)$, and further includes potasstum chloride $\left(16\right.$ mol.1 $\left.1^{-1}\right)$, magnesium chloride $\left(16\right.$ mol. $\left.1^{-1}\right)$, calcium chloride $\left(1.2\right.$ mot. $\left.1^{-1}\right)$ and sodium bicarbonate $\left(10\right.$ mmol. $\left.7^{-1}\right)$. This solution has been studied during recent years with respect to the optimum potassium concentration (Hearse et al, 1976; Jellinek et al, 1981) and the addition of procalne (Hearse et al, 1981) and high-energy phosphates (Hearse et al, 1976; Robinson et ali, 1984). Both animal experinents (sink et al, 1979; Wugent et al, 1982) and clinical studies (Fisk et al, 1977; Tyers et al, 1977) have shown the beneficial effects of potassium cardioplegia, and its superiority as compared to Bretschneider"s cardioplegic solution (Jynge et al, 1978).

A different policy in cardioplegic composition was developed in the United States, where the group of Buckberg and Follette concluded that blood cardioplegia was more effective to protect the myocardium from ischemic damage than crystalloid cardioplegia (follette et al, 1978). The rationale behind blood cardioplegia is an enhanced delivery of axygen to the myacardial tissue during crass-clamping of the aorta (Hendriks et al, 1983) and an improved colloid osmolality of the cardioplegic solution. The observation of Singh and cowarkers (1982) that blood cardioplegia is superior to crystalloid cardioplegia in preserving myocardial ultrastructure and reducing the release of intraceilular enzymes, such as CK-MB, howewer, is at variance with the findings of, for instance, Engelman and coworkers (1981). They did not find differences in myocardial oxygen consumption, when crystalloid or blood cardiopiegla was evaluated. The latter results were in keeping with the findings of Shapira and coworkers (1980). An explanation for this discrepancy can not be offered at this moment. 


\subsection{The myocardium during aorto-coronary bypass surgery}

In this section aspects of hemodynamic function, coronary blood flow, local mechanical function, cellular metabolism and ultrastructumal appearance, and the loss of intracellular enzymes will be discussed as far as they are relevant to the clinical and experimental study in this thesis. Basic infamation an the myocardium can readily be obtained from text books (Mc Alpine, 1975; Guyton, 1976; Berne, 1979; Drake-Holland and Noble, 1983).

\subsubsection{Henodynamic function}

The early clinical reports on the status of the patient during and after aorto-coronary bypass surgery did not routinely include data on left ventricular function or hemodynamic recovery. More recentiy, functional parameters such as heart rate, central venous pressure, mean pulmonary artery pressure, mean left atrial pressure, mean radial artery pressure, cardiac index, stroke volume index, stroke work index, systemic vascular resistance and left ventricular mimute work index were used by Griepp and calleagues (1975). On the basis of these parameters, no substantial differences between surgical tech niques could be abserved, although postoperative enzyme release was significantily different in these techniques. It may therefore be concluded that the assessment of these hemodynamic variables is inadequate to discriminate between different techniques, which is in agreement with the findings of Sapsford and coworkers (1974).

Later studies, performed by Cunningham and coworkers (1979). Fennel and colleagules (1979) and Rasenkranz and Buckberg (1983), indicate that postoperative cardiac output and left wentricular end-diastolic pressure were useful parameters to evaluate the adequacy of myocardial protection during the sumgical procedure and that these variables correlated well with perioperative complications. Jalonen (1980) showed that the end-diastolic volume, rather than the end-diastolic pressure, was more reliable for the examination of individual patients than for groups of patients.

Although the first derivative of left ventricular pressure has shown to be a sensitive marker of myocardial contractility (Mason et al, 1964; 1969; Schaper et al, 1965), in particular to study the effect of regional (Szekeres 
and Udvary, 1983) and global 15chenia (Standeven et al, 1984), this parameter has been scarcely used in the surgical setting. Using hemodynamic parameters to evalute the patient outcome after aortocoronary bypass surgery, one should be aware of ariety of factors complicating the correct interpretation of these indices. Changes in hemodynamic function cannot solely be ascribed to inadequate measures against ischemia, but the responses to anesthesia and extracorporeal circulation should alsa be considered. Differences if the plasna concentration of catecholamines. substances known to influence the hemodynamic function, might occur (Regan et al, 1970; Sebell et al, 1981). Apart from the systemic effects of circulating catecholamines, local cardiac release has been described (Brown et al, 1981). Under circumstances, which are comparable to those observed in cardioplegia, a reduced myocardial epinephrine response may be expected from experimental findings using high potasslum solutions (Mamm et al, 1968). Besides, severe depression of myocardial sympathetic nerve activity, resulting in a decreased tissue content of norepinephrine, has been reported during hypothermia (Jones, 1981), which might result from a reduction in catecholamine uptake (Reves et al, 1984). For obvious reasons the policy af the anesthesiologist is aiming at a good hemodynamic condition of the patient throughout the operation. Deliberate patient-tomptient differences in the administration of anesthetics, and positive and negative inotropic agents as well as changes in blood volume and artificially adjustment of the filling pressure will influence the values of the memodynamic parameters. Hence, the effect of, for instance, inadequate protection against perioperative ischemia on these variables could be masked.

\subsubsection{Coronary artery blood fllow}

Bload flow through the coronary arteries during aorto-coronary bypass surgery has been subject of interest for two distinct reasons. Firstly, restoration of flow through the area distal to an occluded or stenosed artery is the ultinate goal of this type of operation. Measurement of the flow through the arto-coronary graft offers a reliable parameter to evaluate the success of the operation (Reneman and Spencer, 1972; 1975; Glock et al, 1981). secondly, sufficient nutritional flow should be maintained throughout the operation (Ghidoni et al, 1969; Hottenrot et al, 1974). 
In the initial phase of cardiopulmonary bypass, whem the heart is enpty beating in near nomothemic conditions, no signs of inpaired subendocardial blood flow could be found (Magrassi et al, 1981). Moreover, total blood fliow to the animal heart increased considerably as the result of CPB instalment (Lees et al, 1971; Vinas et al, 1979; Schuette et al, 1982). Adequate subendacardial flow was also observed at reduced perfusion pressures of $6.7 \mathrm{kPa}$ (Chitwood et a1, 1981). In contrast, when hypothermia was employed, leading to wentricular fibrillation, myocardial blood flow reached normal walues at perfusion pressures of $13.3 \mathrm{kPa}$, but significantly decreased at lower perfusion pressures particularly in the subendocandial layers (Mcconnell et al, 1977). The significance of these dog experiments might be important since decreased perfusion pressures are commonly present during the imitiali phase of aorto-coronary bypass surgery.

The effect of several interwentions on myocardial blood flow during aorta-coronary bypass surgery in patients was discussed by Gray and coworkers (1976). They measured cononary sinus flow during CPB, using mild hypothemia $\left(30-32^{\circ} \mathrm{C}\right)$ and hemodilution. Their findings indicate that during the initial phase of CPE reduced coronary blood flow may well be associated with a drop in perfusion pressure; increased coromary artery flow was observed after opening of the aorto-coronary bypasses

\subsubsection{Mechanical function}

In general, most of the variables mentioned in section 2.2.1 provide indirect information about the mechanical function of the heart. For technical reasons, direct measurement of the local mechanical activity of the different myocardial layers is not applied in the clinical setting In animal experiments, pairs of ultrasonic crystals have been implanted within the myocardial tissue to measure changes in fiber length and in left ventricular shape (Theroux et al, 1974; Weintraub et al, 1981). This technique provides information about local myocardial shortening (usually at the endocardial site) but is dependent on the orientation of the crystals in relation to the lacal fiber direction. Besides, this approach may influence fiber contractility through local tissue damage (Hattori et al, 1982).

In the animal study of the present thesis a different techmique was 
applied for the measurement of epicardial deformation using three electromagnetic inductive coils attached to the epicardial surface resulting in Thtte damage of the myocardium (Arts and Reneman, 1980). With this technique epicardial deformation can be described accurately (Arts et al, 1982). From this deformation subepi and subendocardial fiber shortening can be estimated (Prinzen et a], 1984).

Direct measurerisent of local shortening in the human heart has been described by Glock and cowarkers (1981), using angiographic techniques. Their study, perfomed sewaral months after the operation, showed that lacal myocardial function had been improved after aorto-coronary bypass surgery when the graft(s) were still patent. Brower and coworkers (1978; 1982) have studied the efficacy of $5 t$ Thomas Hospital cardioplegia versus topical nypothermia with intemittent aortic cross-clamping with the use of radiopaque markers sutured to the epicardium. Improved regional shortening in the cardioplegia group was found to correlate well with lower values of creatine kinase leakage.

\subsubsection{Tissue metabol11 $\mathrm{sm}$}

Under normaxic conditions, myocardial cells utilize exogenous substrates for energy production. Non-esterified fatty acids, lactate and, to a lesser extent, glucose are stepwise degradated to carbon dioxide and water in oxygen-depending processes to provide ATP for proper functioning of the cell. Endogenous substrate stores such as glycogen and triacylglycerol are present, but are not used in steady-ștate conditions (Van der Vusse and Reneman, 1982). However, when the cellular requirenents for energy exceed the supply by oxidative processes, anaerobic glycolysis will be accelerated (Opie, 1976). Via this escape mechanism only two molecules of ATP can be generated when one molecule of glucose is converted to lactate. Under circunstances of axygen deprivation by complete cessation of coronary artery blood flow, as is the case during aortic cross-clamping, breakdown of glycogen will readily occur and lactate will be formed, providing 3 molecules of ATP per glucose noiety. When the amount of glycolyticly generated high-energy phosphates is insufficient to meet cellular requirements, net consumption of ATP and creatine phosphate will occur. Beside the formation of creatine and inorganic 
phosphate, degradation products of ATP will accurnilate. Moreover, accumulation of potassium witl take place in the extracellular space probably caused by disturbances at the level of the meimbrane $\mathrm{Na}^{+}-\mathrm{K}^{+}$ATPase during energy shortage (Owen et a], 1970) or by a higher potassiun conductance during ischemia (Rau and Langer, 1978). The above described changes in myocardial metabolism do not necessarily reflect irreversible damage, but most likely reveai a physiological adaptation to a period of unbalance between energy requirements and supply.

Prolonged duration of this unbalance will ultimately lead to cell death. The mechanisms responsible for the transition of reversible to irreversible injury are not completely understood. Degradation of phospholipid moieties in myocardial membranes by enhanced phospholipase $A_{2}$ activity, resulting in impaired celluiar ion and fluid homeostasis, and loss of macromolecules likely enzymes, has been suggested to be involved (Katz and Messineo, 1981).

In aorto-coronary bypass surgery measures should be taken to minimize the number of cells irreversibly damaged die to periods of ischemia throughout the operation. Ischemia readily accurs during periods of low perfusion pressure (commonly seen during the initial phase of CPB), due to the low oxygen carrying capacity of the coromary artery perfusate (e.g. hemadilution) and during the period(s) of aortic cross-clamping. The safest approach is to minimize the unbalance between energy demand and supply during ischemia by reduction of the energy requirement. This can be achieved by reducing the workload of the heart. In this respect Kawachi and coworkers (1982) reported that myocardial oxygen consumption reduces by $60 \%$ when the heart is empty beating instead of working, whereas Badeer (1956) found an additional reduction of $26 \%$ when the heart is caoled to $28^{\circ} \mathrm{C}$. These measures appeared to be independent of perfusion pressure in the range from 7 to $13 \mathrm{kPa}$ (Mcconnell et al, 1977). Despite these precautions, Gray and coworkers (2976) found a significant change from uptake to release of lactate during the initial period of CPB (prior to the first aortic cross-clamping) in their study. This change was closely related to the occurrence of perioperative myocardial infarction.

During aortic cross-clamping oxygen delivery has almost completely ceased. Lewitsky and Feinberg (1975) reported a severe reduction of highenergy phosphates (52\%) and glycogen (63\%) associated with an increase in lactate content to $350 \%$ in the dog heart after one hour of normothermic 
ischenic arrest. The sustained metabolic activity over a period of 60 min of ischemia was clearly evident and confirmed by others (Merchant et a1, 1974; Opie, 1976; dones et a1, 1981; Reimer et al, 1981).

Employment of hypothermia has proved to reduce the rate of substrate breakdown (see section 2.1.3). In particular the use of ice-cold potassium cardioplegia reduces the rate of pH decrease during ischemia (Wilson et al, 1980), while in a clinical study depletion of ATP could completely be prevented when aortic cross-clamping lasted less than 90 min under these circumstances (Balderman et a1, 1981). During one hour of ischentic arrest in the isolated working rat heart, the degradation rate of ATP, creatine phosphate and glycogen was greatiy reduced when the temperature was lowered to $20^{\circ} \mathrm{C}$ or less (Tyers et al, 1977).

At reperfusion following unclamping of the aorta, accumulated metabolites will be released into the blood. A rapid regeneration of creatine phosphate occurred, whereas restoration of ATP content and glycogen stores required a prolanged period of recovery (Tyers et al, 1977; Salerno and Chiong, 1980; Balderman et al, 1981). Clinical studies reported lactate release after unclamping of the aorta (Goldschlager et al, 1972; 01 in et al, 1981). In particular St. Thomas Hospital cardioplegia proved to reduce the washout of lactate as compared to intermittent aortic cross-clamping with topical cooling (Jalonen et a1, 1981d).

Myocardial metabolism after weaning from $C P B$ has been exanined in a few studies and the results indicate rapid marmalization of oxygen and lactate extraction by the heart from the arterial blood (Wallace et al, 1961; Jalonen et al, 1981c; Edlund et al, 1982).

\subsubsection{U1trastructure}

Analysis by means of transmission electron microscopy offers the opportunity to study in detail typical cellular components and organelles, such as glycogen granules, mitochondria, nuclei, sarcomeres and sarcolenma in very sma11 myocardial tissue specimen (Jennings et a1, 1969; 1978; Buja et a), 1970; Schaper et al, 1977).

On the base of ultrastructural changes several grading systems have been developed to quantitate the severity of ischemic injury (Schaper, 1979; 
Apstein et a1, 1983; Lindal et al, 1983). In particular the ultrastructural appearance of the mitochondria has been cheracterized in detail to distinguish between reversible and irreversible ischenic damage. In 1980. Flameng and coworkers proposed a classification system which solely examines the mitochondrial appearance and is basically comparable to the one described by Schaper (1979). We adapted this approach for our patient study and the detaills are presented in section 3.1.6.

Within minutes after the onset of nomothermic ischenia, the specific, snall intramitochondrial granules will disappear. After approximately 30 minutes of ischemia fragmentation of cristae and large amounts of gray floccullent material can be observed. After 60 minutes of ischemia severe injury is found and numerous cristae are broken. The ultimate irreversible state of mitochondrial damage is characterized by the presence of large amorphous densities (Jennings et a], 1969). It is generally beljeved that reduction of the temperature of the ischemic tissue will substantially delay these ultrastructurall changes.

It should be emphazised that reperfusion of prewiously ischemic tissue will led to restoration of the ultrastructural features when the duration af ischemia remains within limits, but that exaggeration of the morphologilcal signs of injury most likely accur during restoration of flow after a prolonged period of ischemia. This notion is important to consider, because in most clinical studies biopsies for ultrastructural analysis were obtalned after variable periods of reperfusiton. For instance Balderian and coworkers. (1981) allowed 3 min of reperfusion before taking the postischemic biopsies, whereas Flamieng and coworkers (1980) allowed the heart to recover during 30 min. Lindal and coworkers (1983) reported that ultrastructural changes observed after more than one hour of aortic cross-clamping (i.e. fragmentation of mitochondrial cristae) had completely normalized after 60 anin of reperfusion. using ice-cold St Thomas Hospital cardioplegic solution for myocardal protection.

\subsubsection{Enzyme content and enzyme release}

Enzyme release after tissue damage can be established with the use of serial plasma enzyme activity measurements. Quantification of tissue injury 
can be done by assessing the peak plasma value and the time-delay between the damaging event and the appearance of the peak value in plasma, but more accurately the area under the release curve can be used to calculate cumulative release. Because of the catabolic remaval of enzymes from the plasma, and the extravascular return of enzymes during the time intervals of sampling, correcttons should be made using known circulatory parameters (Shell et a1, 1973; Willems et al, 1979).

Already in 1960 Baer and Blount correlated the AST pllasma activity and postoperative mortality. Also in myocardial revascularization studies peak values of plasma AST, ALT and LDH have initially been used to detect myocardial injury, and a positive correlation with the occurrence of ECG disturbances has been reported (Dietrich et al, 1968). These results were confirmed by Hultgren and coworkers (1971) who measured the plasma peak activity of creatine kinase, AST and LDH.

The introduction of isoenzymes of both creatine kinase and LDH rapidly led to numerous studies aiming at determination of the validity of cardiac specific enzyme measurements as a marker of cardiac tissue injury. Differences in the enzyme content of various tissues may well be used to discriminate between several sources of enzyme release (table 2.1). The assessment of the plasma enzyme activity of CK-MB after aorto-coromary bypass surgery is preferred above that of AST, creatine kinase and LDH, since the specific activity of $C K-M B$ is highest in cardiac tissue as was shown by Baur and coworkers (1979). They observed that the detection of myocardiali necrosis from changes in the ECG or by scintigraphy correlated best with CK-MB peak values. Similar findings showing the advantage of creatine kinase isoenzyme deteminations as compared to total creatine kinase detemination, were reported by Roe and coworkers (1979) and Sylven and colleagues (1982). The latter investigators applied the method developed by Shell and coworkers (1973) in a study on uncomplicated aorto-coronary bypass surgery and calculated that an equivalence of about $5 \mathrm{~g}$ of myocardial tissue became damaged. Such factors as the duration of aortic cross-clamping, the number of bypasses and the pump time carrelated mighly with the peak values of plasma CK-MB (01dham et al, 1973; Stron et al, 1979).

However, the complex nature of enzyme release after aorto-coronary bypass surgery being the resultant of cardiopulmonary bypass, surgical interventions. and anesthesia may easily lead to difficulties in interpretation of the 
results (Moore et a1, 1977; Lell et al, 1977; Davids, 1982). Thoracotony will damage skeletal muscle. Moreover, surgical dissection of saphenows veins will cause muscle and vessel wall injury, and insertion of cannulas, including those for CPB, is associated with heart and blood vessel wall injury. For example, release of $\mathrm{CK}$-isoenzymes from saphenous veins as a consequence of surgical manipulation was reported by Landas and coworkers (1981). Hence overestimation of ischemia induced cardiac injury will occur when cardiac damage through surgical manipulation contributes considerably. Besides. hemolysis due to extracorporeal circulation is frequently observed and will result in increased plasma LDH activity. The application of CPB combined with hemodilution results in a decrease of plasma enzyme activity.

Although release of enzymes has generaly been considered as a phenomenon related to loss of membrane integrity and hence cell death, Piper and coworkers (1984) have recently proposed that the extrusion of intracellular enzymes may occur in a reversible fashion. Since no data are available to conclude that loss of enzymes during apen-heart surgery can accur through a reversible process, we consider the appearance of cellular enzymes in the extravascular space as a sign of irreversible damage (Hermens et a1, 1982).

Table 2.1 Enzyme activity in human myocardial, liver and skeletal muscle tissue, and in erythrocytes $\left(\mathrm{U} . \mathrm{g}^{-1}\right.$; assay temperature of $\left.25^{\circ} \mathrm{C}\right)$. References: (a) - Siegenthaler, 1982; (b) - Hollaar and Van der Laarse, 1979; (c) - Van der Laarse et al, 1980; (d) Willems et al, $1982 \mathrm{~b}$.

AST

Heart

Liver

Skeletal muscle

Erythrocytes
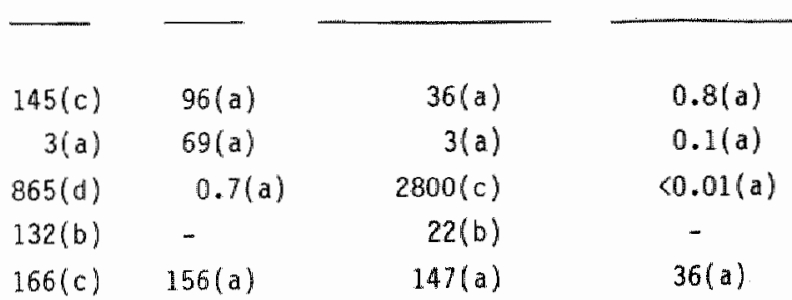

ALT

$145(c)$

$96(a)$

$36(a)$

0.8 (a)

3 (a)

69(a)

3 (a)

Creatine kinase

865 (d)

$0.7(a)$

$2800(\mathrm{c})$

22(b)

CK-MB

$132(\mathrm{~b})$

-

147 (a)

36(a) 
3. METHODS AWD TECHMLUUES

\subsection{Patient study}

\section{1 .1 Patients, anesthesia and instrumentation}

Seventy two patients undergoing aorto-coronary bypass surgery were assigned at randiom to three groups with a different cardioprotective technique: Group (nomothemia), intemittent aortic cross-clamping at $34^{\circ} \mathrm{C}$, Group $\mathrm{H}$ (hypothermia), intermittent aortic cross-clamping at $25^{\circ} \mathbb{C}$, and Group $C$ (cardioplegia) continuous aortic cross-clamping in combination with alultidase St. Thomas Hospital cardioplegia. All operations were performed in the St. Rafael Clinics, Leuven, Belgium, between November 1980 and October 1981. The two surgeons inwolwed, Dr. H. Flameng and Prof R. Suy, were already familiar with the three protective techniques before the start of the study. The anesthetic policy and the surgical procedures were standardized in the patients as described before (Flameng et al, 1984).

Selection of the patients to enter the study was based on the diagnosis of three vessel disease requiring at least four distal anastomoses. Patients with associated cardiac diseases, signs of acute myocardial infarction or an ejection fraction of less than $30 \%$ were not included. The profile of the patients is presented in table 3.1 .

The treatment of patients with nitrates and beta-blocking agents was discontinued on the evening before the operation. As night sedatian lorazepam ( $3 \mathrm{mg}$ orally) was given. Premedication, administered 60 min before induction, consisted of scopolamine $(0.5 \mathrm{mg})$, fentanyl $(75 \mathrm{ug})$ and droperidol $(3.75 \mathrm{mg})$ intramuscularly. Anesthesia was induced with pancuronium $\left(0.1 \mathrm{mg} \cdot \mathrm{kg}^{-1}\right)$, fentamyl (15 $\mu \mathrm{g} . \mathrm{kg}^{-1}$ ) and sodium thiopentone $\left(3 m g . \mathrm{kg}^{-1}\right)$ while the patients inspired 100\% oxygen by mask. Pancuronium was given before fentany administration to prevent the onset of truncal rigidity.

After endatracheal intubation, the lungs were wentilated with nitrous oxide and oxygen $\left(\mathrm{FIO}_{2}, 0.5\right)$. The ventilation was adjusted to maintain an arterial $\mathrm{PCO}_{2}$ of $4.7-5.3 \mathrm{kPa}$ corresponding to an endtidal $\mathrm{CO}_{2}$ of $4.5-5 \%$ (capnogram). A 7F Edwards balloon guided thermistor catheter was inserted through the right internal jugular vein into the pulmonary artery for cardiac 
Table 3.1. Profile of the patients in the three groups. Mean values and standard dewiations are presented.

\section{Group}

normothermia hypothermia cardioplegia

number of patients

24

23

25

age (years)

$52 \pm 9$

$54 \pm 6$

$53 \pm 7$

sex

$22 \mathrm{M}, 2 \mathrm{~F}$

$19 \mathrm{M}, 4 \mathrm{~F}$

$22 \mathrm{M}, 3 \mathrm{~F}$

body weight $(\mathrm{kg})$

$73 \pm 9$

$69 \pm 8$

$71 \pm 9$

preaperative

ejection fraction $(\%)$

$60 . \pm 17$

$59 \pm 16$

$64 \pm 15$

NYHA class

$2.3 \pm 0.7$

$2.3 \pm 0.7$

$2.5 \pm 0.8$

\section{Operation scheme:}

Normothermia $\left(34^{\circ} \mathrm{C}\right)$; Hypothermia $\left(25^{\circ} \mathrm{C}\right)$ :

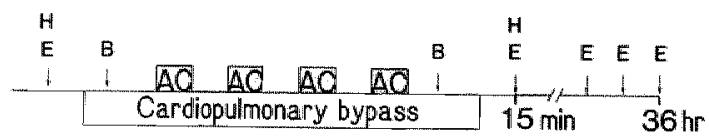

St Thomas hospital cardioplegia :

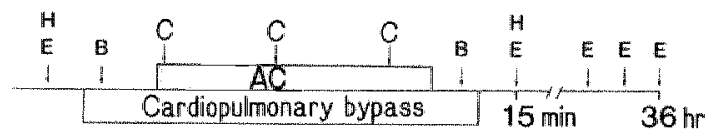

H. - Hemadynamics

E enzymes

B - biopsies

$$
\begin{array}{r}
C \text { - multidose cardioplegia } \\
A C \text { - aortic cross-clamping }
\end{array}
$$

Fig 3.1 Protocol as followed in the three groups. $A C=$ aortic cross $-\mathrm{cl}$ amping, $B=$ biopsies, $C=$ multidose cardioplegia, $E=$ enzymes, $\mathrm{H}=$ hemodynamics. (Note that both hemodynamics and enzymes were measered at more sample times; see for details section 3.1 .3 and 3.1 .5 ). 
output determinations and to measure pulmonary artery wedge pressure (PWP). The thorax was opened by a median sternotony, after the patients had recieved an extra dose of fentanyl $\left(60 \mu \mathrm{g} \cdot \mathrm{kg}^{-1}\right)$. During the preoperative period an isotonic solution of Nomosol ${ }^{R}$ composition see technical note in section 3.3) was administered aiming at a pkp value of at least $1.1 \mathrm{kPa}$. Initial meparinization (300 $\mathrm{WU} . \mathrm{kg}^{-1}$ ) before cardjopulmonary bypass (CPB) was followed by supplementary doses to obtain a three fold increase in actual clotting time, which was maintained until 15 min after CPB. Through the right atrium a $7 \mathrm{~F}$ catheter was inserted into the coronary sinus to collect blood samples. A 7F Millar or Philips catheter-tip micromanometer was placed in the left ventricle via the right pulmonary vein for monttoring left ventricular pressure and its maximum positive first derivative. The left ascending aorta was cannulated for the return of oxygenated blood from the oxygenator and usually two cannulas were placed in the superior and inferior caval veines for the drainage of blood to the oxygenator by gravity. Just prior to the start of $C P B$ an additional dose of pancuronium $\left(0.1 \mathrm{mg} \cdot \mathrm{kg}^{-1}\right)$ was given. During CPB a mean arterial pressure of 11-13 $\mathrm{kPa}$ was maintained, using droperidol or nitroglycerine. During CPB the lungs were not ventllated and were allowed to remain collapsed with a static inflation pressure of $0.7 \mathrm{kPa}$. Cardiopulmonary bypass was conducted using a Harvey H-1500, a Bentley Spiraflo BOS-10 or a Shiley 100A bubble oxygenator with heat exchanger. The oxygenator was primed with Nomosol $\mathrm{pH} 7.4,\left(25 \mathrm{ml} . \mathrm{kg}^{-1}\right)$, human albumin $(80-100 \mathrm{~g})$, fresh donor blood (500 $\mathrm{ml})$ and heparim (500 IU). This produced a hemodilution with an average minimum hematocrit of $25 \%$ during the bypass period. Using Sarns roller pumps, a non-pulsatile flow rate of $60-80 \mathrm{ml} . \mathrm{kg}^{-1}$. $\mathrm{min}^{-1}$ was maintailied. During CPB the left ventricle was wented through the left atrial appendage. Fresh blood and Normosol were supplemented when needed. Before weaning from $\mathrm{CPB}$ ventilation was started with oxygen in air $\left(F 10_{2}, 0.5\right)$. At the same time fresh blood or the remaining content of the oxygenator was slowly transfused to the patients to reach a final PWP of 1.1-1.3 kPa. After the pumps were stopped and the heart perfomed adequately, the cannulas were removed and the lungs were ventilated with mitrous axide in oxygen $\left(F I 0_{2} 0.5\right)$. Between 15 and 20 min after $C P B$, pratamine hydrochloride was given to counteract heparin. 


\subsubsection{Surgical technique}

The patients were randomized and allotted to the three groups $\mathrm{N}, \mathrm{H}$ and $\mathrm{C}$. The operation conditions were similar for all groups, with the exception of the myocardial protective technique used to minimize harmful influences of aortic cross-clamping during $C P B$. The protocols as followed in the groups are schematically shown in fig 3.1 .

- Group N (normothermia with intermittent aortic cross-clamping, $n=24$ ). The rectal temperature of the patients was maintained at $34^{\circ} \mathrm{C}$ throughout the CPB period. The aorta was cross-clamped intermittently to allow performance of the distali anastomosis. Meanwhile, the left ventricle was fibrillating. After each clamp the hearts were defibrillated, if necessary, and reperfused for $6-18 \mathrm{~min}$. The reperfusion period was used to perform the proximal anastomosis consisting of a vein graft connection to the ascending aorta. After the last. cross-clamp the patients were rewarmed to at least $36^{\circ} \mathrm{C}$ rectal tenperature, before weaning fron $\mathrm{CPB}$.

- Group $H$ (hypothermia with intermittent aortic cross-clamping, $n=23$ ). The patients were cooled to $25^{\circ} \mathrm{C}$ (rectal temperature) immediately after starting the extracorporeal circulation. Analoguously to group $N$ the aorta was intermittently cross-clamped for performance of the distal anastomosis. In contrast to group $N$ the hearts renained fibrillating during the periods of reperfusion due to the low temperature. The patients were rewarmed immediately after the last aortic cross-clamping and the hearts were defibrillated when rectal temperature had reached a value of $34^{\circ} \mathrm{C}$.

- Group $C$ (hypothermic cardioplegia with continuous aortic cross-clamping, $\mathrm{n}=25$ ). The patients were cooled to $25^{\circ} \mathrm{C}$ of rectal temperature after the onset. of $\mathrm{CPB}$. Unlike group $\mathrm{N}$ and group $H$ the aorta remained cross-clamped throughout the period needed to perform all distal anastomoses. During this period an ice-cald st. Thomas hospital cardioplegic solution (composition see technical note section 3.3) was infused into the artic root with a roller pump. Infusion pressure as measured in the aortic root was kept at about $7 \mathrm{kPa}$. Initially 700 anl of the cardioplegic solution were infused, which was suffi- 
cient to lower septal temperature to $8-15^{\circ} \mathrm{C}$. Infusion was repeated (with approximately $400 \mathrm{~m}$ of $\mathrm{St}$. Thomas solution) every 20 min to keep septal temperature below $18^{\circ} \mathrm{C}$. The patients were rewarmed after release of the aortic $\mathrm{clamp}$ and defibrillated at a rectal temperature of $34^{\circ} \mathrm{C}$.

Individual wariations were mainly caused by the number of aorto-coronary bypass grafts and, hence, the number of aortic cross-clampings in group $N$ and group $H$ and the duration of the single aortic cross-clamp period in group $C$.

\subsubsection{Hemodynamic assessment}

After all catheters and cannulas were installed, reference data was collected during a stable hemodynamic period preceding the start of CPB (pre CPB values). Hemodynamic variables included in this study were heart rate, systallic and diastalic arterial blood pressure, left ventricular pressure, pulmonary artery wedge pressure and cardiac output. Derived hemodymanic indices were calculated using standard formulas for the cardiac index (CI = cardiac output divided by body surface area; $1 . \mathrm{min}^{-1} . \mathrm{m}^{-2}$ ) and left ventricular stroke work index (LVSWI = cardiax index multiplied by mean arterial blood pressure minus pulmonary artery wedge pressure and divided by heart rate; $d \cdot m^{-2}$. beat ${ }^{-1}$ ). The variables were also measured 5,10 and 15 minutes after $C P B$. During CPB mean arterial perfusion pressure and pump flow were recorded at regular intervals.

Rectal and systemic blood temperature were measured routinely during the whole surgical procedure, and in group $C$ septal temperature was recorded during aortic cross-clamping.

\subsubsection{Sampling of tissue}

In each patient two transmural biopsies were taken from the anterior free wall of the left ventricle about $2 \mathrm{~cm}$ above the apex using a small biopsy needle (Tru-cut Travenol Laboratories, Inc. Deerfield, III, USA) as described by $\mathrm{Flameng}$ and coworkers (1980). Two preischemic biopsies were taken within 5 min after the start of $\mathbb{C P B}$, and a second pair of postischemic biopsies was obtalned approximately $20 \mathrm{~min}$ after release of the (last) aortic cross-clamp, or when rectal temperature was at least $32^{\circ} \mathrm{C}$. One of each pair of biopsies 
was used for electronmicroscopic evalluation, while the second ane was analysed for glycogen, ATP and creatine phosphate.

The biopsies for ultrastructural evaluation were immediately immersed in a cold fixative solution. The biopsies were divided into a subepi and a subendocardial part.

The biopsies for biochemical evaluation were immediately (within 3 seconds) frozen in liquid nitrogen and stored at $-80^{\circ} \mathrm{C}$ until analysis. Biopsies were subsequently freeze dried and any adherent blood was carefully removed. The dry weight of these biopsies amounted to $3.0 \mathrm{mg}(2.4-3.5 \mathrm{mg})$ (median value and $95 \%$ confidence 1 imits) for 21172 patients.

\subsubsection{Sampling of bliood}

Several chemical substances were measured in blood or plasma obtaimed before, during and after CPB.

- Lactate, inorganic phosphate, potassiula and oxygen were determined in arterial (radial artery; during CPB directly from the oxygenator content) and coronary sinus blood to evaluate myocardial metabolic activity. Blood was sampled at the following intervals: 1) prior to $C P B$, immediately after insertion of the coronary sinus catheter, 2) after onset of CPB when the heart was empty beating, 3) just before cross-clamping of the aorta when the heart was fibrillating, 4) during reperfusion after each period of aortic cross-clamping within $30 \mathrm{sec}$ and at $1,2,3,4,5,6,7.5$ and $10 \mathrm{~min}$ (shown as wash-out curves), 5) at 20, 30 and $40 \mathrm{~min}$ after release of the last aortic clamp and 6) during the post $C P B$ period at 5,10 and 15 min after weaning from $C P B$.

- Plasma catecholamines were measured to evaluate distinct anesthetic and surgical interventions during the course of the operation. Epinephrine, norepinephrine and dopamine were deternined $n$ venous blood samples at the following sample times: 1) before induction of the patient, 2) at the time of endotracheal intubation, 3) immediately following sternotomy, 4) just prifor to the start of CPB, but after cannulation of the aorta, 5) at the end of CPB when controlled ventilation of the lungs was started, 6) 5 min after cessation of $C P B$, and 7) 15 min after cessation of $C P B$ when the aorta was already 
decannulated.

- Plasma was assayed for creatine kinase, its isoenzyme CK-MB, AST and HBoH, enzymes known to mark myocardial muscle damage or hemolysis. The hematocrit and free hemoglobin values were determined simultaneously. For these purposes systematic venous biood samples $(10 \mathrm{ml})$ were collected priar to sternotomy and $15 \mathrm{~min}, 4,8,12,24$ as well as 36 hours after cessation of CPB.

\subsubsection{U1trastructural analysis}

Initial fixation of biopsies for electronmicroscopic analysis lasted for at least $24 \mathrm{hrs}$, using a cold $3 \%$ givtaraldehyde solution containing 90 mmol. $1^{-1}$ oxalate and adjusted to $\mathrm{pH} 7.4$ with $\mathrm{KOH}$. Next the tissue was rinsed in potassium oxalate buffer, containing $0.22 \mathrm{~mol} .1^{-1}$ sucrose, and subsequentIy pastfixation was achieved in $2 \% 1050_{4}$, buffered with $0.05 \mathrm{~mol} .1^{-1}$ veronal acetate to pi 7.4. The tissue was embedded in epoxy resin and ultrathin sections were cut. These sections were contrasted with uramyl acetate, followed by lead citrate, and pictures were taken on a Philips EM 300 electron microscope.

From the ultrathin sections of each subepi and subendocardial tissue specimen five photographs were made for semiquantitative evaluation of mitochondria. The procedure of evaluation as described by flameng and coworkers (1980), involved grading of twenty randomly chosen mitochondria per photograph, using a scale from 0 to 4 (see fig 3.2):

0 - nomal ultrastructure of the mitochondrion.

1 - nomal appearance of the crests and matrix, but absence of gramular deposits (small electron dense granules).

2 - loss of matrix granules and clarification of the matrix without breaking of crestis.

3 - Toss of matrix granules, uniform clarification of the matrix and disruption of crests (focal condensation may be seen: inclusions having at. least twice the diameter of nomal mitochondrial granules).

4 - loss of matrix granules, uniform disruption of crests and loss of integrity of mitochondrial inner and outer membranes. 


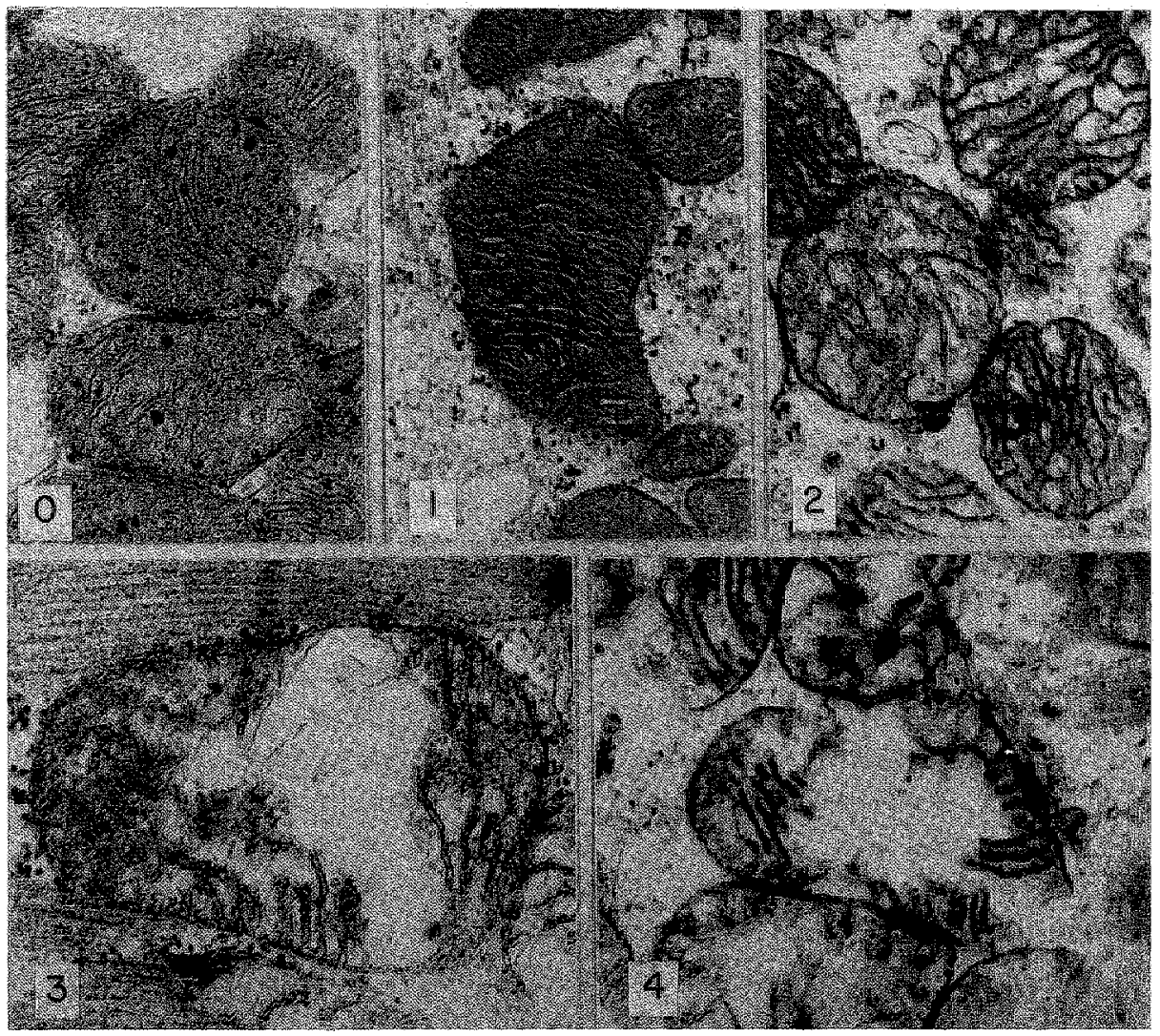

Fig 3.2 Five stages of ultrastructural appearance of mitochondria as used for the classification of tissue injury. Meaning of the five distinct classes of mitochondrial appearance. $0=$ normal ultrastructure, $1=$ absence of granular deposits, 2 = clarification of the matrix, $3=$ disruption of crests, 4 = loss of integrity of mitochondrial inner and outer membranes. 
The awerage score of 100 mitochondria per tissue sample was calculated. All micrographs were examined in a blind fashion.

\subsubsection{Biochemical analysis of tissue}

Analysis of ATP, creatine phosphate and glycogen was performed as described in detail by Van der Vusse and coworkers (1984). The dried tissue was crushed wth a glass rod in a $0.2 \mathrm{ml}$ water-acetone (1:1, W/w) nixture, containing 2 moll. $1^{-1}$ EDTA and 0.4 mol. $1^{-1}$ perchloric acid at a temperature of $-15^{\circ} \mathrm{C}$. This mixture was subsequenty neutralized with 0.1 mil ice-cold Tris$-\mathrm{KOH}$ and centrifuged for $10 \mathrm{~min}$ at $4^{\circ} \mathrm{C}$ with a relative centrifugal force of $1100 \mathrm{~g}$. The clear supermatant was carefully removed and alliquots were used for the detenination of ATP and creatine phosphate. The residue, containing iragments of tissue and insoluble satts was used for the determination of gl yoogen.

ATP and creatine phosphate were analyzed with a fluorometric technique (Lamprecht and Trautschold, 1974; Lamprecht et a1, 1974), modified by Drake and coworkers (1980). The composition of the reaction mixture per liter was: Tris buffer (55 mmol, $\mathrm{pH}=8.1), \mathrm{NADP}^{+}\left(1\right.$ mmol), glucose $(1 \mathrm{mmol}), \mathrm{MgCl}_{2}(1$ mol) and glucose 6-phosphate dehydrogenase $(160 \mathrm{U})$. After addition of 10 w1 tissue extract to $1.0 \mathrm{ml}$ of the reaction mixture, the reaction was started with hexokinase $(690 \mathrm{ml})$. The amount of ATP was calculated by comparison of the change in fluorescence in the test cuvet with the standard cuvet (standardized with $5 \times 10^{-9}$ mol NADPH $1 \mathrm{~m} 1.0 \mathrm{ml}$ buffer). From a subsequent addition of ADP (final concentration 0.05 mmol. $1^{-1}$ ) and creatine kinase ( 980 mu) the amount of creatine phosphate was determined in the same cuwet.

For glycogen analys is the residue mentioned before was incubated at $37^{\circ} \mathrm{C}$ for 3 hours, after addition of $1.0 \mathrm{ml}$ of $1.0 \mathrm{~mol} .1^{-1} \mathrm{NaOH}$. Subsequent $1 \mathrm{y}, 1.0$ mil 95\% ethanol was added and the whole mixture was heated for 10 min at $85^{\circ} \mathrm{C}$. After cooling to $4^{\circ} \mathrm{C}$, the mixture was stored at this temperature for 24 hours. Than the mixture was centrifuged at $4^{\circ} \mathrm{C}$ with $1100 \mathrm{~g}$ for 20 min. The clear supernatant was carefully removed with a pipette, and the residue was washed twice with $0.5 \mathrm{ml} 60 \%$ ethanol. After centrifugation at $4^{\circ} \mathrm{C}$ with $1100 \mathrm{~g}$ for $30 \mathrm{mim}$, the glycogen residue was hydrolyzed at $85^{\circ} \mathrm{C}$ for 3 hours, after the addition of $1.0 \mathrm{ml}$ of $1.0 \mathrm{~mol} .1^{-1} \mathrm{HCl}$ to the residue. The mixture was 
subsequently neutralized with $0.5 \mathrm{ml}$ Tris-KOH and al iquots were used for the fluorometric assay of the glucose moleties. Instead of glucose, AtP ( 1 mol. $1^{-1}$ ) was added to the afore mentioned reaction mixture. The reaction was started with hexokinase $(690 \mathrm{mu})$, using 10 ul of tissue extract. The deteminations were performed with a Zeiss ZFM4 Flurometer at $25^{\circ} \mathrm{C}$.

\subsubsection{Biochemical analysis of blood}

Lactate, inorganic phosphate and potassium were measured in plasma derived from arterial and coronary sinus blaod. Lactate and inorganic phosphate were analyzed with a Techmicon-autoanalyzer as described before Van der Vusse et al, 1979). Potassium was detemined with a Technicom Flame Photometer IV. The blood samples were also used to determine total hemogiobin content and oxygen saturation immediately after collection, using a Radiometer 0SM 2 hemoximeter. Oxygen content was estimated by multiplying venous hemoglobin content and the arterial-coronary sinus ( $A-C S$ ) differences in oxygen saturation.

The concentration of norepinephrine, epinephrine and dopamime was determined in venous blood plasma, using the method of simultameous single isotope radioenzyme assay as described by Peuler and Johnson (1977).

In pre and postoperative plasma samples the enzymatic activity of creatine kinase, its isoenzyme CK-MB, AST, HBDH and free hemoglobin were determined. Creatine kinase (EC 2.7.3.2) was measured with creatine phosphate as a substrate (Merck testkit 14111). The isoenzymes of creatime kinase (EC 2.7.3.2) were separated by fon exchange chromatography on DEAE-sephadex A50 (Pharmacia) into 3 isoenzyme fractions: CK-MM, CK-MB and CK-BB according to Mercer and Varat (1975). HBDH (EC 1.1.1.27) was measured with a-ketobutyrate as a substrate, as described by Rosalki and Wilkinson (1960), wsing a testkit (Boehringer 124818). AST (EC 2.6.1.1) was measured with a-ketoglutarate as a substrate according to Bergmeyer and Bernt (1974) (Boehringer testkit 124397). Al1 enzyme activities were assayed at $25^{\circ} \mathrm{C}$ using an Eppendorf Photometer 1101 in combination with a CKE calculator. Enzyme activities were expressed as units (IU), in which 1 IU of enzyme catalyses the conversion of 1 umol of substrate per min at $25^{\circ} \mathrm{C}$. Free hemoglobin in plasma was measured spectrophotometrically at 540 nin after addition of cyanide and ferricyanide 
according to Van Kampen and Zijustra (1961), with the use of a testkit (Boehringer 124729$)$.

\subsubsection{Mathematical analysis of enzyme activity data}

Recently Willems and coworkers (1982) described a method to calculate enzyme release due to cardiac injury, with the elimination of the contribution of non-cardiac enzyme sources. The mathematical method allows multi-enzyme analysis of plasma enzyme activity data. Using this method the plasma enzyme activity for creatine kinase, CK-MB, AST and $H B D H$ was measured before and at various intervals after $C P B$. upto and including $36 \mathrm{hrs}$. Postoperative data for enzyme activity was corrected for the mean value of the standard activity, found in control samples. These control values $\left(C_{s}\right)$ were determined for creatine kinase $\left(32.5 \mathrm{U} . \mathrm{1}^{-1}\right), \mathrm{CK}-\mathrm{MB}\left(5.6 \mathrm{U} . \mathrm{1}^{-1}\right)$, AST $\left(8.8 \mathrm{U} . \mathrm{1}^{-1}\right)$ and $\mathrm{HBDH}(80$ $U .1^{-1}$; Willems et al, 1982). Corrected values of enzyme activity $\left(C_{t}-C_{s}\right)$ are presented in this study, and subsequently used for the callculation of cumulative enzyme release $Q(t)$ (release as a function of time, expressed per liter of plasma). Analyses of $Q(t)$ values were based on a two compartment model (Willems et al, 1979). This two compartment distribution model consists of one intravascular (plasma pool) and one extravascular space as is illustrated in fig 3.3. Enzymes entering the circulation are subject to three processes:

- degradation from the plasma pool $P(t)$ at a rate $F C R \times P(t)$, where FCR is the fractional catabollic rate constant.

- escape from $P(t)$ to the extravascular pool $E(t)$ at a rate $T E R \times P(t)$, where TER is the transcapillary escape rate constant.

- return from $E(t)$ to $P(t)$ at a rate ERR $\times E(t)$, where ERR is the extravascular return rate constant.

Quantification of total plasma enzyme release follows from three equations:

$$
A(t)=P(t)+E(t)+F C R \int_{0}^{t} P(\tau) d \tau
$$




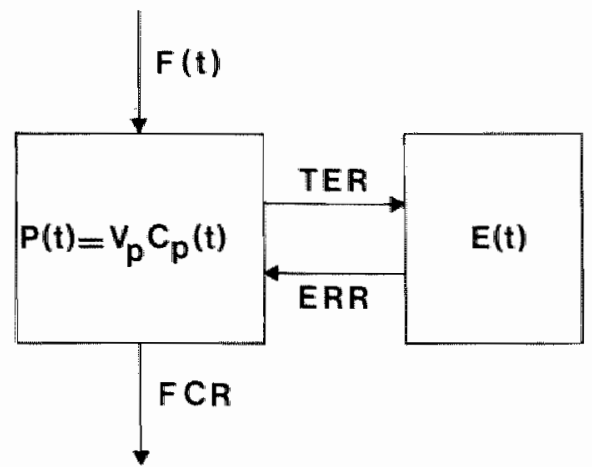

Fig 3.3 Two compartment model as reported by willems and coworkers (1982). $T E R=$ transcapillary escape rate constant, $E R R=$ extravascular return rate constant, $F C R=$ fractional catabol ic rate constant, $P(t)=$ plasma pool, $E(t)=$ extravascular pool, $F(t)=$ rate of input of enzyme into plasma, $V p(t)=$ plasma volume, $C p(t)=$ plasma enzyme activity. 
$E(t)=T E R \cdot \int_{0}^{t} \varphi(\tau) e^{-\operatorname{ERR}(t-\tau)} d \tau$

$P(t)=c(t) \times v_{p}$

where: $C(t)=$ piasma enzyme activity $\left(u .1^{-1}\right)$

$V p=p$ iasma volume

Since the actual plasma volume was not determined in the patients, the equations mentioned before were transformed to calculate the cunulative release expressed in units per liter of plasma:

$$
\begin{aligned}
& Q(t)=P(t)+E^{\prime}(t)+F C R \int_{0}^{t} P(\tau) d \tau \\
& E^{\prime \prime}(t)=\pi \operatorname{TER} \cdot \int_{0}^{t} P(\tau) e^{-E R R(t-\tau)} d \tau
\end{aligned}
$$

These processes determine the relation between (total) enzyme release and the plasma enzyme activity measured. The mathematical model mentioned before quantitates these processes, using parameter values from standard conditions for the enzymes involved, and finally results in cumulative values for enzyme release $Q(t)$.

It is obvious that the two compartment model and the derived $Q(t)$ values are useful in case of enzymes leaking from one specific tissue or argan. Under conditions of open heart surgery, calculations based on the measurement of AST and creatine kinase will overestimate the amount of damaged myocardial tissue because AST, creatine kinase and HBDH may also be released from noncardiac sources. To correct for hemolysis, the amount of HBDH released during $C P B$ was substracted from the $Q(t)$ values calculated over the total postoperative period of 24 to 36 hrs. Cumulative values of CK-MB were not corrected for release from non-cardiac sources, such as arterial and venous vascular structure and skeletal muscle, since their contribution has been assumed to be smal1. The two remaining marker enzymes, AST and creatine kinase, can be released from skeletal muscle $(S M)$ as well as from cardiac muscle $(H)$. 
Recently, a mathematical procedure was developed to discriminate between these two sources using the following equations:

$Q_{A S T}=I(A S T ; H) \cdot Q_{H}+I(A S T ; S M) \cdot Q_{S M}$

$Q_{C K}=I(C K ; H) \cdot Q_{H}+I(C K ; S M) \cdot Q_{S M}$

In equation 1, Q QST refers to the amount of AST meleased during the postoperative phase, assuming that only cytoplasmatic AST was released. I(AST;H) and I(AST;SM) refers to the content of cytoplasmatic AST in heart (H) and skeletal muscle (SM), respectively. These enzyme contents were reported to be 54 U. $\mathrm{g}^{-1}$ for heart tissue (Van der Laarse et al, 1980) and $32 \mathrm{U} . \mathrm{g}^{-1}$ for skeletal muscle tissue (Willems et al, 1982b). $Q_{C K}$, from equation 2 , refers to the anount of creatine kinase released during the postoperative period. $I(C K ; H)$ and $\mathrm{I}$ (AST;SM) refers to the content of creatine kinase in heart muscle (798 U. $\mathrm{g}^{-1}$ according to Willems et a1, 1979), and in skeletal muscle tissue (2800 U. $\mathrm{g}^{-1}$ according to Van der Laarse et al, 1980), respectively. Finally cumulative enzyne release from cardiac tissue $\left(Q_{H}\right)$ and from skeletal muscle $\left(a_{S M}\right)$ after cessation of $\mathrm{CPB}$ can be calculated from the equations 1 and 2 by conversion to:

$$
\begin{aligned}
& Q_{S M}=\frac{Q_{A S T} \cdot I(C K ; H)-Q_{C K} \cdot I(A S T ; H)}{I(A S T ; S M) \cdot I(C K ; H)-I(C K ; S M) \cdot I(A S T ; H)} \\
& Q H=\frac{Q_{A S T} \cdot I(C K ; S M)-Q_{C K} \cdot I(A S T ; S M)}{I(A S T ; H) \cdot I(C K ; S M)-I(C K ; H) \cdot I(A S T ; S M)}
\end{aligned}
$$

Substitution of the known tissue enzyme contents and of the calculated cumulative release values of these enzymes results in $Q_{S M}$ and $Q_{H}$ values, reflecting gramequivalents of tissue irreversibly damaged. 


\subsection{Animal experiments}

\subsubsection{Animals and anesthesia}

Investigations on hearts in situ implicate that one has to choose between pigs, calves and dogs, depending on the aim of the study. Dogs have generally been used in cardiopulmonary bypass (CPB) research during the past 30 years (Senning, 1952). Well documented information about anesthesia, CPB equipment and blood transfusion further stressed the preference of using the dog madel in this specific study (De Vries, 1976; Van der Wusse et a1, 1979; Jalonen, 1980; Prinzen, 1982).

Additional advantages of the use of dogs in this type of experiments, as compared to other species, are their seize and weight, making them suitable for handling. More specifically their vessels are strong and their heart is not very susceptible to surgical and anesthetic interventions. It should be emphasized that dogs allow the use of most of the clinical instrumentations, catheters and CPB devices, including oxygenators.

Comparing experimental and clinical models implies the consideration of differences in, for instance, anesthetic policy and blood constituents which may affect the hemodynamic and metabolic state. Another "important difference is that in patients with obstructions of the coronary arteries myocardial areas with inadequate perfusion have to be considered. On the other hand various fairly simillar canditions are observed in dogs and man, which validates most of the comparisons made in this study. The myocardial metabolism, the coronary vasculature (James, 1961), in particular the prescence of collaterals (Schaper, 1971), myocardial and systemic blood flow, hemodynamic function and gross anatony are comparable, which allows the extrapolation of data from animall experiments to the clinical situation.

Mongrel dogs of either sex and unknown age, ranging in weight from 18-36 $\mathrm{kg}$ were used in this study. Prior to the experiments the animals were housed individually for at least one week. The dogs were allowed to take water ad libitum and were fed with Doko dog food (Troum, Putten; composition see technical notes 3.3 ). Data on body weight and heart weight is shown in appendix 1 . 
The animals were premedicated with Hypnom $\left(1 \mathrm{mi} . \mathrm{kg}^{-1}\right)$, containing 10 mg fluanisone and $0.3 \mathrm{mg}$ fentanyl citrate per $\mathrm{ml}$, as described by Marsboom and coworkers (1964). Anesthesia was induced intravenously with at least 10 mg per $\mathrm{kg}$ body weight sodium pentobarbital (Narcovet) and, after endotracheal intubation, was maintained with oxygen/nitrous oxide and a continuous infusion of sodium pentobarbital $\left(2 \mathrm{mg} \cdot \mathrm{kg}^{-1} \cdot \mathrm{hr}^{-1}\right)$. The lungs were ventilated with a pasitive pressure respirator (Pulmamat). The inflation pressure was kept at 0.05-0.15 kPa and the respiratory volume at $10 \mathrm{ml}$ per $\mathrm{kg}$ body weight. The respiratory rate was maintained at 18 inflations per min. If necessary, ventilation was adjusted on the basis of the blood gas wallues, which were kept within physiological ranges, i.e. $\mathrm{PCO}_{2}: 4.7-6.0 \mathrm{kPa} ; \mathrm{pH}: 7.35-7.45$.

Prior to sternotomy, succinylcholime $\left(2 \mathrm{mg} \cdot \mathrm{kg}^{-1}\right.$ body weight $\mathrm{i} . \mathrm{m} . ;$; Curalest) was injected to prevent muscle movement induced by electrocaagulation. The sternum was spitt over its total length and the pericardium was opened completely. Throughout the experiments two heating mattresses were placed underneath the animal to regulate body temperature. During hypothermic perfwsions, fentanyl was administered at regular intervals (total amount of fentanyl not exceeding $0.5 \mathrm{mg})$. Just before cessation of CPB, the animals routinely received $500 \mathrm{mg}$ calcium gluconate. There was no support with inotropic drugs in the animal experiments. Anesthesia was standardized as much as possible to minimize influences of different anesthetic protacols on the parameters measured.

\subsubsection{Instrumentation}

The experimental protocol and the sample scheme for the assessment of most parameters and variables of the 10 groups in the experimental study is given in section 3.2.3. The devices were installed in the following order:

- A Braunulle was placed in the right brachial vein for compound administration.

- ECG cables were connected to the animals (1 imb leads).

- A polyethylene catheter was inserted into the left femoral artery and connected to an external pressure transducer to measure arterial pressure. This catheter was also used for sampling arterial blood.

- Right arterial pressure was measured with a polyethylene catheter connected 
to an external pressure transducer. The catheter was inserted into the right atriun via the left feroral vein.

- A polyethylene catheter was inserted into the left brachial artery for sampling arterial blood as a reference for the calculation of regional myocardial blood flow, when using the ricrosphere technique (see section 3.2.10).

- After heparinization and sternotomy, a Swann-Ganz balloon guided themistor catheter (7F, KMA) was inserted through the left jugular wein for cardiac output measurements, wing the themadilution technique.

- A stainless steel cannula "used for the arterial return from the oxygenator, was inserted into the right femoral artery.

- A themistor (EIlab, type A-R7) was placed for the recording of rectal temperature. At the same time a urinary catheter was inserted if possible.

- The pericardium was opened and the aorta and the left anterior interventricular coronary artery (LAICA) were dissected. Electromagnetic flowprobes were mounted on the ascending aarta and the LAICA to measure volume blaod flow. The flow probes (skalar) were connected to an electromagnetic flow meter (Transflow 600).

- A $5 F$ or $7 F$ catheter was inserted into the left jugular vein and moved inta the right atrium. Approximately $2 \mathrm{~cm}$ of the catheter ending was carefully placed in the coronary sinus for collection of blood.

- In all dogs of the cardiopliegia group one thernistor (type A-K3, Ellab) was placed deep in the septum. In a few experiments, themistors were placed in the anterior and posterior left ventricular free wall (themistor, type A-KCl, El lab).

- A silastic catheter was placed in the left atrium, allowing the injection of radioactive microspheres for the measurement of regional and total myocardial blood flow.

- Left ventricular pressure was measured with a catheter-tip micrometer (MI11)ar, TF micromanometer), inserted through the left atmium. The left ventricular end-diastolic pressure was separately recorded (amplification a-3 $\mathrm{kPa}$ ) and the first derivative was determined as described by schaper and coworkers (1965).

- Epicardial deformation of the left ventricular free wall was measured using three coils situated on the epicardium as described in section 3.2.11. The field generating coil was attached by suction (underpressure not exceeding $-25 \mathrm{kPa})$ and the two sensor coils were attached to the epicardium with a 
siuture string.

- Just prior to instalment of CPB, a tube was inserted in the right atrium for wenous drainage by grawity. Immediately after the start of cPB the left ventricular vent was inserted through the apex.

- In the animals of the cardioplegia group a double lumen metal needle was inserted into the aortic root through the ascending aorta, for the infusion of the cardioplegic solution as well as for measurement of aoric perfusion pressure.

A11 hemodynamic wariables and the epicardial deformation paraneters were recorded continuously on a 10-channel Schwarzer recorder at a speed of 1.25 mm. $\mathrm{s}^{-1}$ and intermittently at speeds of 50 and $200 \mathrm{~mm} . \mathrm{s}^{-1}$. All thermistors were connected to an Ellab temperature display (Type Du-3).

\subsubsection{Design of the experiments}

- Introduction

Eighty four animals were included in this study and allotted to ten groups as shown in table 3.2. In this section all groups will be described in detail.

In the control group (CON), the amimals were not subjected to CPB, and the influence of anesthesia and compiete instrumentation on the hemodynamic wariables, mechanical perfomance, myocardial substrate uptake and plasma enzyme activity was examined. These data served as reference values. Twa groups were designed to ewaluate the influence of extracorporeal circulation on the above mentioned parameters. For this purpose dogs were subjected to CPB without periads of ischemia. In one group systenic termperature during CPB was main. tained at $34^{\circ} \mathrm{C}$ (Normothermic control; $\mathrm{MC}$ ) and in the other group this temperature was kept at $25^{\circ} \mathrm{C}$ (Hypothermic control; HC). In the latter group the heart fibrillated continuously and in the NC group the heart was fibrillated four times during $10 \mathrm{~min}$.

Three other groups were designed to simulate the patient situation. In two of them the animals were subjected to CPB and internittent aortic crossclamping, either nomothermic (N) or hypothermic (H). In the third group the animais were subjected to $C P B$ and the aorta was cross-clamped continuousliy. In this group (C) cardioplegic solution was infused into the aorta during 
Table 3.2 Survey of the antimal groups. + = present, - = absent, 0 = not relevant, $C P B=$ cardioputmonary bypass, $A C=$ aortic cross-cllamping.

\begin{tabular}{|c|c|c|c|c|c|c|}
\hline $\begin{array}{l}\text { Group } \\
\text { nr }\end{array}$ & $\begin{array}{l}\text { Group } \\
\text { name }\end{array}$ & $\begin{array}{l}\text { Abbre- } \\
\text { viation }\end{array}$ & $\begin{array}{l}\text { Number of } \\
\text { animals }\end{array}$ & $\mathrm{CPB}$ & $A C$ & $\begin{array}{l}\text { post } \mathrm{CPB} \\
\text { recovery }\end{array}$ \\
\hline 1 & No nmothermia & N & 14 & + & + & + \\
\hline 2 & Hypothermia & H & 10 & $t$ & $\pi$ & + \\
\hline 3 & Cardioplegía & C & 8 & + & + & * \\
\hline 4 & Nomothermia/Biopsies & NB & 6 & + & + & - \\
\hline 5 & Hypothemia/Biopsies & $M B$ & 6 & + & + & - \\
\hline 6 & Normothermi a/Control & $\mathrm{MC}$ & 11 & + & - & + \\
\hline 7 & Hypothemia/Control & $\mathrm{HC}$ & 11 & + & - & + \\
\hline 8 & Enzyme release/Control & $\mathrm{EC}$ & 5 & - & - & 0 \\
\hline 9 & Hypothermia/Plasma vol une & HPLW & 5 & + & + & + \\
\hline 10 & Control & CON & 8 & - & - & 0 \\
\hline
\end{tabular}

Table 3.3. Variables and parameters measured in the groups $N, H, C, N C$, HC and CON.

hemodymanics

plasma enzyme activity

biochemicall variabiles in blood

biochemical variables in tissue

mechanical function

regional coronary artery flow
Heart rate, Pao,syst, Pao,dia, Plv, Plv,ed, dplv/dtmax,pos, cardiac output, coronary flow.

AST, ALT, creatine kinase, MDH, HBDH. $\mathrm{PO}_{2}, \mathrm{PCO}_{2}, \mathrm{PH}, \mathrm{Hb}, \mathrm{O}_{2}$ SAT, lactate, inorganic phosphate, potassium and glucose.

ATP, creatine phosphate, inarganic phosphate, glycogen and lactate.

Epicardial deformation.

Left ventricular wall (subenda and subepricardium). 
cross-clamping. In the groups $\mathrm{N}$ and $\mathrm{H}$ ischemia was induced four times during 10 min by aortic cross-clamping. Intermittent reperfusion lasted 15 min, analogous to the clinical situation. In group $C$ the aortic cross-clamp period lasted for $60 \mathrm{~min}$. In these three groups protection was evaluated by assessing hemodynamic and mechianical recovery, myocardial substrate uptake, plasma enzyme activity and myocardial temperature. In addition myocardial biopsles were taken in group $C$.

Two other groups were designed to study more extensively nyocardial tissue metabolism during the CPB periad. In one group nomothermia $\left(34^{\circ} \mathrm{C}\right)$ was applied (NB) and in the other one hypothermia $\left(25^{\circ} \mathrm{C} ; \mathrm{HB}\right)$. Multiple transmural myocardial biopsies were collected at 12 sample points, mainly at the end of the ischemic and reperfusion periods, as shown in fig 3.4. Tissue samples were analyzed for glycogen, ATP, creatine phosphate, inorganic phosphate and lactate, and these data were related to the release and uptake of lactate and inorganic phosphate during reperfusion as measured in coronary sinus blood. The groups $N B$ and $H B$ were similar to the groups $N$ and $H$, respectively, except for the multiple biopsies taken. Because the multiple biopsy holes can be expected to influence post CPB myacardial function, the experiments were terminated at the end of $C P B$.

Finally two groups were designed to analyse more precisely the enzme release (EC) as a result of tissue damage and plasma volume changes (HPLV) after CPB. In group EC the animals were anesthetized and the thorax was opened through sternotomy. No other interventions were performed. Hemodynamic measurements such as heart rate and arterial pressure were recarded at regular intervals, and blood samples were taken to analyze plasma enzyme activities. Using this procedure enzyme release resulting from anesthesia and sternotomy, could be determined. These values were used to estimate enzyme release as the result of tissue damage for all other groups mentioned. The group HPLV (hypothermia with six plasma volume determinations) was designed to analyse plasma volume changes under circumstances similar to those in group H. CPB and intermittent aortic cross-clamping were included in the protocol, but the number of variables measured was kept to a minimum. only hemodynamic variables, mechamical performance and plasma enzyme activity were determined during a post $C P B$ recovery periad of 2 hours instead of the routine 1 hour recovery period following $\mathrm{CPB}$. 
- Protocol of subgroups

Group $\mathbb{N}$. Nomothermia with intermittent aortic cross-clamping $(n=14)$.

After complete instrumentation of the aninals control measurements were performed (table 3.3). Subsequently CPB was started and the rectal temperature was maintained at $34^{\circ} \mathrm{C}$. Within five minutes after the start of $C P B$, when the hearts were empty beating, a second set of measurements was performed. Thereafter ventricular fibrillation was induced and the next set of measurements was taken. The time course of CPB is shown in fig 3.4. The aorta mas cros5-clamped four times during $10 \mathrm{~min}$ and reperfused in between for $15 \mathrm{~min}$. During cross-clamping the hearts were fibrillating and imnediately after release of each clamp the hearts were defibrillated. During the first $10 \mathrm{~min}$ of reperfusion arterial and coronary sinus blood was sampled for biochemical analysis. This data $w 11$ be presented as wash-out curves. Myocardial release and uptake of the substrates, mentioned in table 3.3, were calculated by multiplying arterial-coronary sinus differences and coronary artery blood flow. After the last cross-clamping the dogs were rewarmed and a reperfusion period of $45 \mathrm{~min}$ allowed the hearts to recover before cessation of CPB. After weaning from $\mathrm{CPB}$ the recovery of the dogs was studied during 60 min. Measurements were performed at two time intervals, one within $15 \mathrm{~min}$ and one at the end of the 60 min recovery period. Finally the dogs were.killed with an averdose of thiopental. In some dogs biopsies of myocardial tissue were taken at the end of the experiment for biochemical determinations.

Group H. Hypothermia with intermittent aortic cross-clamping ( $n=10)$

After the start of CPB the rectal temperature was lowered to $25^{\circ} \mathrm{C}$ using the heat exchanger in the oxygenator. Throughout the hypothermic period the hearts fibrillated. Cross-clamping was performed as described for group $\mathbb{N}$. After the last clamp the dogs were rewarmed and defibrillated when rectal temperature exceeded $34^{\circ} \mathrm{C}$. The protocal of the experiments is shown in fig 3.4 and the variables measured are summarized in table 3.3 .

Group C. Mypothermic potassium cardioplegid with continuous aortic crosselamping $(n=8)$.

The protocol of the experiments is shown in fig 3.4. In addition ta the variables assessed in the groups $N$ and $H$, myocardial biopsies were taken 
GROUP
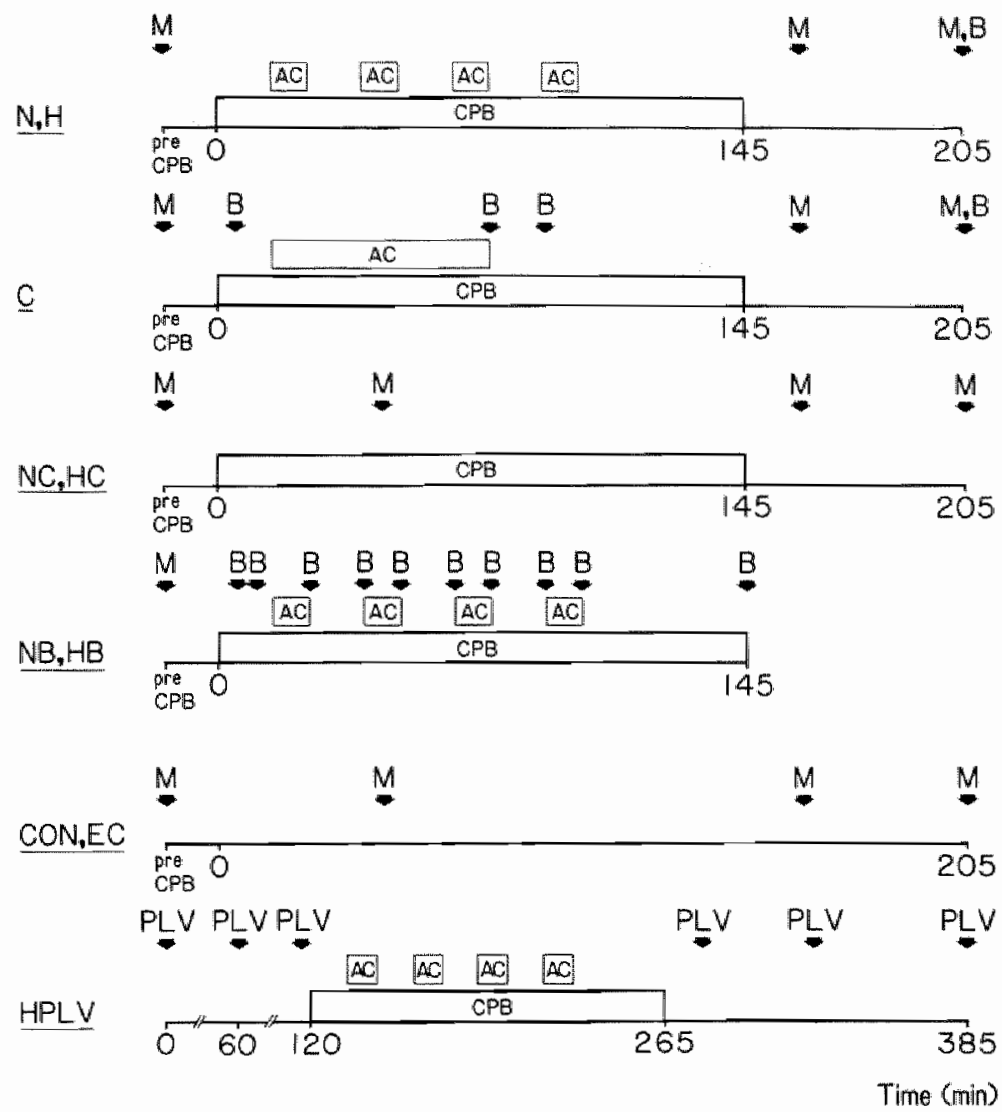

Fig 3.4 Protocols of the animal groups. $A C=$ Aortic cross-clamping. $C P B=$ Cardiopulmonary bypass. $M=$ measurement of plasma enzyme activity, biochenical variables, regional coronary flow and mechanical activity. $B=$ biopsies. (note that both hemodynamics and enzymes were measured at more sample times; see for details sections 3.2 .5 and 3.2 .7 ). 
before and at the end of the period of global ischemia, at the end of CPB and after a $60 \mathrm{~min}$ recovery period. Rectal temperature was decreased to $25^{\circ} \mathrm{C}$ after the start of CPB. Untike group and group $H$ the aorta remaned crassclamped during perfod of 60 min. After cross-clamping the aorta an ice-cold st. Thomas hospital cardioplegia solution for composition see technical note section 3.3) was infused into the aortic root, with a roller pump. Infusion pressure as measured within the aortic root, did not exceed $5.3 \mathrm{kPa}$. Initial$1 y^{*} 300 \mathrm{ml}$ of the cardioplegic solution was infused, sufficient to decrease septal temperature below $15^{\circ} \mathrm{C}$. Infusion of the $5 t$. Thomas cardioplegic solution was repeated every $20 \mathrm{~min}$ (with approximately $250 \mathrm{ml}$ ) to maintain septal temperature at a lewel below $18^{\circ} \mathrm{C}$. Data on septal temperature is shown in appendix 3. The dogs were rewarmed after release of the aortic clamp and defibrillated when rectal temperature reached $34^{\circ} \mathrm{C}$.

Group NB. Nomothermia with intemittent aortic cross-clamping and multiple left ventricular biopsies $(n=6)$

The protacol followed in these experiments was similar to that followed in group $N$, with the exception that during CPB multiple left wentricular biopsies for biochenical analysils were taken just before and at the end of each aortic cross-clamping (fig 3.4). The experiments were teminated at the end of the CPB period. The variables measured are listed in table 3.4 .

Group HB. Hypothemia with intermittent aortic cross-clamping and multiple left ventricular biopsies $(n=6)$

The protocol of these experiments is shown in fig 3.4. The only difference between this group and group $A B$ is the level of rectal temperature during $\mathrm{CPB}$, which was matintaned at $25^{\circ} \mathrm{C}$ in group HB. The wariabies and paraneters measured are shown in table 3.4 .

Group NC. Nomothemia without intemittent aortic cross-clamping (n=11)

The protocol followed in this group is similar to that of group $N$, but during CPB aortic cross-clanping was delleted. The hearts remained enpty beating during the CPB period, except far four periods of 10 min each, when they were fibrillating. The protocol of these experinents is shown in fig 3.4 . During the $C P B$ period rectal temperature was kept at $34^{\circ} \mathrm{C}$. The variables and parameters measured for routine evaluation are listed in table 3.3 . 
Table 3.4. List of variables measured in group NB and group HB.

hemodynamics

biochemicall variables in blood

biochemical wariables in tissue

regional coronary artery flow
Heart rate, Pao,sys, Pao,dia, coronary flow.

$\mathrm{PO}_{2}, \mathrm{PCO}_{2}, \mathrm{pH}, \mathrm{Hb}, 0_{2}$ SAT, lactate. inorganic phosphate, potassium.

ATP, creatine phosphate inorganic phosphate, glycogen and lactate.

Left ventricular wall (subendo and subepicand ium) .

Table 3.5. Variables measured in group HPLV.

hemodynamics

mechanical function

plasma enzyme activity
Heart rate, Pao,sys, Pao,dia.

Epicardial deformation.

AST, ALT, MDH, HBDH, creatine kinase. 
Group HC. Hypothemia without intermittent aortic crass-clamping ( $n=9$ )

The protocol of these experiments was analogous to the protocal of group NC, except that the rectal temperature was decreased to $25^{\circ} \mathrm{C}$ (fig 3.4 ). The hearts remathed fibmillating during the hypothermic period and were defibrillated after rewaming to $34^{\circ} \mathrm{C}$ as described for group $H$. The variables and parameters measured during the experiments are shown in table 3.3.

Group CoN. Control group with compilete instrumentation but without CPB $(n=8)$

The dogs were instrunented as in the groups $A, H$ and $C$. Subsequently the dags were studied during a period of 205 min without further interwention (fig 3.4). The variables and parameters measured during the experiments are shown in table 3.3.

Group EC. Enzyme release during control conditions ( $n=5)$

After induction of ariesthesia and sternotony, enzyme release was studied for a period, comparable to the duration of the experiments in the groups $\mathbb{N}$, $H$ and $C$. All cardiac interventions were avoided (fig 3.4).

Group HPLV. Hypothermia with intermittent aortic cross-clamping and multiple plasma volume determinations $(n=5)$

The protocol of these exferiments was similar to that in group $H$, but before and after $\mathrm{CPB}$ in total six plasma volume determinations were performed in controlled fluid infusion conditions. The total post CPB period lasted for 120 min. The protacol is shown in fig 3.4. and the variables and parameters measured during these experiments are summarized in table 3.5 .

\subsubsection{Cardiopuimonary bypass}

In the extracorporeal circuit blood was drained by grawity from the aninal to the axygenator through a tube in the right atrium. The blood was returned from the oxygenator via a canula in the femoral artery. The cardiopulmonary bypass set-up is shown schematically in fig 3.5 .

The blood was oxygenated with a Harvey (H200) or \& Polystan (VT 5000) 


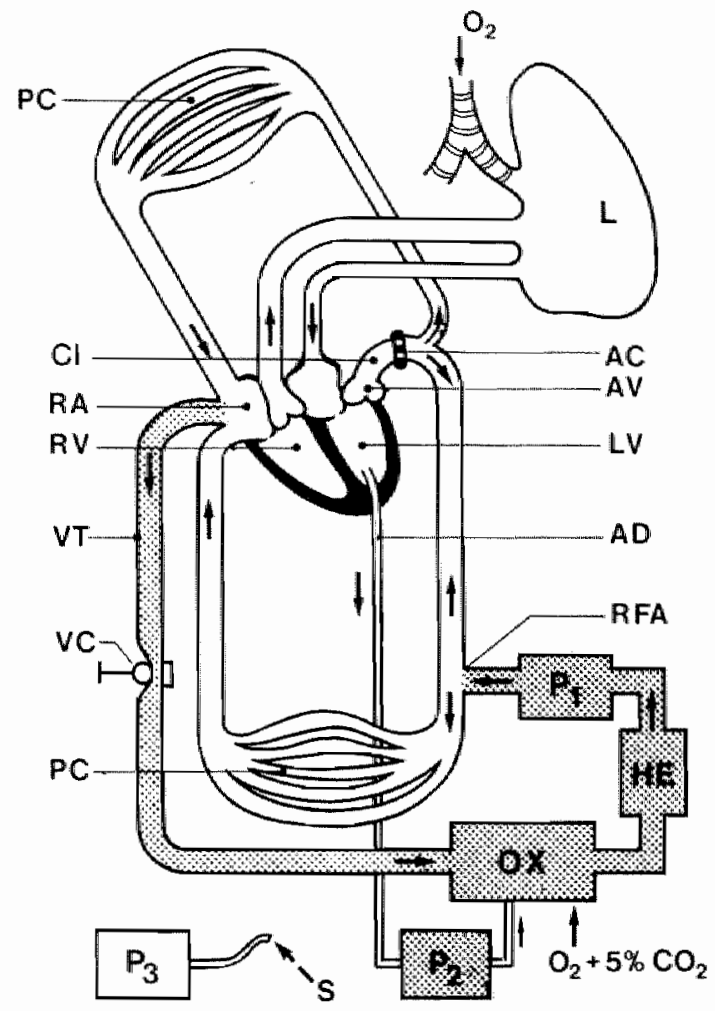

Fig 3.5 schema:ic representation of cardiopulmonary bypass. $A C=$ aortic clamp, $A D=$ apex drain; $A V=$ aortic valve; $H E$ = heat exchanger; $L=$ lung; $L V=$ left ventricle; $O X=$ oxygenator; $P 1, P 2, P 3=$ roller pumps; $P C=$ peripheral circulation; $R A=$ right atrium; $R F A=$ right femaral artery; $R V=$ right ventricle; $S=$ suction; $V C=$ venous clamp; $V T=$ venous tube. $C I=$ site of infusion of cardfoplegic soiution. The dotted area represents the extracorporeal circulation (After Van Renterghen, 1983). 
bubble oxygenator, including heat exchanger. A blood leval detector (light sensitive photo cell) and themistor (Ellab, type A-F6) were installed. Polystar tubing was used in this circuit except for the roller pumps in which sfllicone tubing was emplayed. Arterial inflow was controlled with a Polystan pump supplied with a precalibrated flow scale. A Bentley and a Sarns roller pump were used to drailin the left ventricular cavity and to collect intrathoracal blood, respectively. Intrathoracal blood and donor blood were stored in a Harwey Cardiotony Reservoir (H-70aF) and filtered ( 5 micron filter) before return to the extracorporeal circuit.

The oxygenator was primed with 11 of fresh heparinized donor blood, 1000 IU of heparin, 21 of Normosol and $80 \mathrm{ml}$ of sodium bicarbonate $(4.2 \%)$. Since plasma measurements showed an initiall drop in ionized calcium content in the first phase of CPB of $0.29 \pm 0.03$ mono $.7^{-1}, 1 \mathrm{~g}$ of caiciumgluconate (in solution) was added to the pribuing solution (Van der Veen et al, 1983). Heparinized donor blood was collected on the day of the experiments, or ult timately 2 days before and stored at $5^{\circ} \mathrm{C}$ if necessary. The prining solution was equilibrated with 31 oxygen and 21 carbogen $\left(95 \% \mathrm{O}_{2}, 5 \% \mathrm{CO}_{2}\right)$ per minute at $37^{\circ} \mathrm{C}$. During the $\mathrm{CPB}$ period the $\mathrm{CO}_{2}$ percentage in the sweep gas of the oxygenator was measured using a Mijnhardt infrared gas analyzer. Routinely this $\mathrm{CO}_{2}$ percentage was kept at 4-5\%, corresponding to an arterial $\mathrm{PCO}_{2}$ of 4.7-6.0 $\mathrm{kPa}$. At the same time arterial $\mathrm{PO}_{2}$ was kept above $21 \mathrm{kPa}$. Only during hypothermic perfusions $\left(25^{\circ} \mathrm{C}\right)$ the $\mathrm{PCO}_{2}$ of arterial blood was lowered to 1.3-2.7 $\mathrm{kPa}$, resulting in an increase of $\mathrm{pH}$ to $7.6-7.8$, according to Becker and coworkers (1981). Changing blood temperature resulted in different blood gas and $\mathrm{pH}$ values which could be corrected in the ABL-3 after introducing the actual value of the blood temperature. Heparinization was started at the time of stemotomy with a bolus of 250 IU heparin. $\mathrm{kg}^{-1}$ bady weight intravenously, resulting im an increase of the actual clotting time (ACT), as measured on a Henochron 400 (Bull et al, 1975). In the nomothemia, hypothemia amd cardioplegia groups the ACT increased from 108 to 257,100 to 333 and 101 to 202 seconds prior to CPB, respectively. No further heparin was administered unless ACT became less than 400 seconds during CPB.

When all connections were made, the arterial pump was started at a rate of 0.3-0.5 1 per min. The wenous retwrn was partially opened to malintain the initial oxygenator content. After at least five minutes, this exchange phase was teminated and bypass was started. Initially the arterial inflow was 
adjusted acconding to the pre CPB cardiac output walues and the vehous outfllow tract was opened completely. Mearwhile blood within the extracorporeal circuit was cooled to $25^{\circ} \mathrm{C}$ in the groups $H, H C, H B$ and $C$, and to $34^{\circ} \mathrm{C}$ in the groups $\mathbb{N}$, NC and $\mathbb{N B}$ as is shown im appendix 2 .

During the CPB period additional fluid for the oxygenator was selected on the basis of the hematocrit value. Donorblood was given when the hematacrit had decreased below 25\%. In all other instances Nomosol or Haemaccel was added to the oxygenator. Mean arterial blood pressure did not exceed $10.7 \mathrm{kPa}$ by adjusting the pump flow rate. The data on perfusion pressure and pump flow during $C P B$ is shown in appendix 5, and indicates that under homothermic circumstances adequate perfusion was generally associated with lower perfusion pressures. Systemic venous pressure was generally within the physiological range $(0.4-0.8 \mathrm{kPa})$. In groups with nomothemic perfusion conditions, induction of fibrillation was performed by touching the heart with battery electrodes. In all experiments the hearts were defibrillated with a $D C$ defibrillatar (B-D Electrodyne) delivering 40 joule totally.

\subsubsection{Hemodynamic measurements}

- Blood pressure

Systolic and diastalic arterial blood pressure were assessed from the instantaneous tracings and mean pressure was calculated by adding systolic and twice the diastolic value, and dividing this sum by three. The venous catheter, inserted into the right atrium, through the left femoral vein, was used for the registration of central venous blood pressure. All catheters were connected to external pressure transducers (Alltech). Prior to each experiment the pressure transducers were calibrated, using a mercury column. The Millar catheter-tip micromanometer was callibrated before the experinents. Quring the experiment, the zero $\mathrm{drift}$, if any, was checked by connecting the catheter Tumen to an extermal pressure transducer (Ailtech).

- Blood flow

From aortic blood flow tracings the start and the end of the ejection phase was estimated. This information is required for the assessment of left ventmicular mechanical function (see section 3.2.11). 
Changes in coronary blood flow were continuously recorded with the electromagnetic flow probe, mounted on the LAICA, just distal to the site of branching from the main left coronary artery. These flow probes were callbrated in vivo on a dog hind leg artery with the use of a Harvard withdrawal pump.

- Cardíac output

Cardfiac output was measured by themodilution, using a Swann-Ganz balloon guided thermistor catheter (KMA). This triple lumen catheter ( $7 F$ ) was connected to a KMA Cardlac Output Computer (Podel 3500 E) combined with a KMA Mini-Corder (Model 3501). Befare each experinent, the cardiac output computer was checked by internal callibration simultaneously shown on the reconder. During the experiment cardiac output measurements were perfomed in triplicate. Just prior to the injection of $5 \mathrm{ml}$ ice cold saline and after the saline was injected manually, the content of the catheter was withdrawn to prevent cold dissipation from the catheter according to snoeckx and coworkers (1976).

\subsubsection{Sampling of tissue}

Transmural myocardial bjopsies were taken fran the left ventricular free wall in the perfusion area of the LAICA as described in section 3.1.4. Biochemical evaluation of the tissue included the determination of ATP, creatine phosphate, glycogen, lactate and inorganic phosphate.

Myacardial biopsies were routinely collected at the end of each experiment (the groups $N, H, C, M C, H C$, CON). An additional series of biopsies was taken during the experiments in the groups $C$, $M B$ and HB. Biopsies in these three groups were taken within 5 min after the start of CPB (preischeanic biopses, similar to the clinical study) and at the end of each ischemic and reperfusion phase. All biopsies were immediately (within 3 s) frozen in 1 iquid nitrogen and stored at $-80^{\circ} \mathrm{C}$ unt il further analysis. The biopsies were subsequently freeze-dried and adherent blood was carefully removed. 


\subsubsection{Sampling of blood}

Chemical substances were detemined in either coronary sinus blood, or arterial blood. During the period of CPB arterial blaod was collected from the oxygenator.

For the determination of lactate, inorganic phosphate, potassium and oxygen $5 \mathrm{ml}$ of blood were used at the following sample times: 1) before CPB, during a period of stable hemodynamic function, 2) after onset of CPB when the heart was empty beating and the left ventricle was vented, 3) just before cross-clamping of the aorta when the heart was fibrillating in cases of hypothermic perfusions, 4) in the immediate reperfusion phase after each period of aortic cross-clamping within 30 seconds and at $1,2,3,4,5,6$, 7.5 and $10 \mathrm{~min}$ and 5 ) during the post $C P B$ period at $5,10,15$ and 60 min after cessation of $C P B$. During $C P B$ experiments without aortic cross-clamping, the sample times were reduced during the period of CPB and blood samples were collected at 15, 45,75 and 105 min after the start of CPB. A11 blood samples were immediately centrifuged and plasma was kept at $-80^{\circ} \mathrm{C}$ until analysis. The arterial glucose concentration was measured before $C P B, 60$ and $135 \mathrm{~min}$ after the start of $C P B$, and 15 min after weaning from $C P B$.

Plasma enzyme activity (AST, ALT, creatine kinase, $M D H, H B D H$ ), free hemoglobin content and hematocrit were determined routinely using arterial blood samples of $8 \mathrm{ml}$. These samples were collected prior to CPB, at 10,45 , 75 and 105 min after the start of CPB as well as 15 and 60 min after cessation of CPB. Blood samples were centrifuged at $1000 \mathrm{~g}$ during $15 \mathrm{~min}$ and subsequently stored at $-80^{\circ} \mathrm{C}$. The hematocrit was measured immediately.

Arterial blood gases were measured routinely as an findication of adequate anesthesia and ventilation. Arterial and coronary sinus blaod $(40$ w1) were separately analyzed for oxygen saturation and hemoglobin content at all sample times mentioned for blood analysis.

During the instrunentation of the dog, the actual clotting time was neasured prior to and after heparin administration as well as 5, 35 and 105 min after the start of CPB. At 15 and $60 \mathrm{~min}$ after CPB Dlood samples were analyzed as well!. 


\subsubsection{Biochemical analysis of tissue and blood}

- Blood

The analysis of chemical substances in blood samples was similar to that reported in the patient study (section 3.1.8). Glucose was determined in arterfal blood samiples by spectrophotometry on a Technicon AAII autoanalyzer with hexokinase and g1ucose-6-phosphate dehydrogenase, as reported by Bergmeyer and coworkers (1974).

\section{- Chemical substrates in myocardial tissue}

The tissue specimens were prepared as described for ATP, creatine phosphate and glycogen analysis (section 3.1.7). Shortly, the dried biopsy was crushed in a 3 mol. $7^{-1}$ perchloric acid solution at $-15^{\circ} \mathrm{C}$. This mixture was neutralized with $\mathrm{KHCO}_{3}$ and after centrifugation allquots were obtained from the supernatant for the determination of ATP, creatine phosphate, inorganic phosphate and lactate. The residue was used for glycogen anallysis. The biochemical analyses for ATP, creatine phosphate and glycogen were reported in section 3.1 .7 .

Inorganic phosphate was analyzed by spectrophotometry. The reaction mixture for inorganic phosphate contaimed malachite green-HCl $(0.06 \%$ solutian) and sodium molybdate (0.3\% solution). Measurements were performed at $625 \mathrm{~nm}$ (according to Van Belle, 1970). The reaction mixture for lactate (analyzed by filuorometry at $25^{\circ} \mathrm{C}$ ) contained per $100 \mathrm{ml}$ tridest water: $4 \mathrm{ml}$ Hydrazine solution ( $1 \mathrm{M}), 0.8 \mathrm{ml}$ LDH suspension $\left(3400 \mathrm{U}_{\mathrm{m}} \mathrm{m}^{-1}\right), 0.5 \mathrm{ml} \mathrm{NAD}^{+}$ solution (0.1 M), and was adjusted to pH 9.8 according to Passonneau (1974).

\section{- Pllasma enzymes}

In the animal experiments plasma samples were analyzed for creatine kinase, AST, ALT, HBDH and MDH. The analysis techniques for AST, creatine kinase, HBDH and free hemoglobin have been described in section 3.1.8. ALT (EC 2.6.1.2) was measured using a-ketoglutarate as a substrate according to Bergmeyer and Bernt (1974a). MDH (EC 1.1.1.37) was determined using a-ketoglutarate as a substrate according to Bergineyer and Bernt (1974b) using a testkit (Boehringer 124940). Hematocrit values were determined immediately after collection of the blood samples by the micracapillary method of McGovern and coworkers (1955). Values are expressed as the percentage of 
total blood volume.

- Bllood gases and blood pH

Detemination of blood gases and blood pH was performed at $37^{\circ} \mathrm{C}$ using a blood gas analyzer (Radioneter ABL 3). Blood pH was measured potentionetrically using a $\mathrm{pH}$ glass-electrode and a calomel reference electrode. The $\mathrm{CO}_{2}$ partial pressure $\left(\mathrm{PCO}_{2}\right)$ was determined using a $\mathrm{PCO}_{2}$ electrode, and $\mathrm{O}_{2}$ partial pressure $\left(\mathrm{PO}_{2}\right)$ was determined with an amperometrical method. When during $\mathrm{CPB}$ body temperature had decreased, temperature corrections were made.

\subsubsection{Plasma volume determination and cumulative enzyme release}

Plasma volume was measured in a selected number of experiments before and after CPB. The technique of plasma volume determination has been described in detail by Visser and coworkers (1982) and involves the intravascular injection of a known activity of enzyme. The subsequent increase in plasma enzyme activity quantitates the contribution of plasma to the intravascular volume.

Prior to injection of the enzyme bolus one reference blood sample was callected. Then a concentrated amount of AST (Sigma; purified from porcine heart) or ALT (dog liver extract) was introduced quantitatively into the left atrium. Approximately $250 \mathrm{U}$ of AST or $500 \mathrm{U}$ of ALT were administered during each plasma volume determination. Exactly 5 min after injection of the enzyme bolus one biood sample was withdrawn for measurement of enzyme activity.

Cumulative release of enzymes was calculated during the last $45 \mathrm{~min}$ of the experiments starting at 15 min after weaning from CPB and 60 min after CPB. Both creatine kinase and AST were appropriate for this purpose since the characteristics of the rate of enzyme breakdown in dogs were avallable for these enzymes. In the groups without extracorporeal circulation (group CON and group EC) the data on plasma volume, transport of enzyme from the plasma to the extravascular pool (TER) and the intravascular degradation of enzyme (FCR) was assumed to follow the normal values and rates. In the remaining groups ( $N, H, C, N C$ and $H C$ ) changes in plasma volume and TER, as observed in group HPLV, were employed. Because known values of the plasma volume could be employed in the animal experiments, the cumulative release is expressed in units of enzyme activity. In the patient study plasma wol ume was not measured 
and therefore cumulative release was calculated as units per liter of plasma (see section 3.1 .9 ).

Calculation of the curnulative release from two values of plasma activity was performed using the formula:

$\Delta A=P 1-P 2+k_{d} \times T \frac{P 1+P 2}{2}($ eq. 1$)$

where: $\Delta A=$ cumulative enzyme release (U)

$P 1$ = plasma enzyme content at $t 1$ (U)

P2 = plasma enzyme content at $t 2(U)$

$k_{d}=$ apparent enzyme disappearance constant

$T=$ total time interval between $t 1$ and $t 2$ (hr)

and $\quad P 1=V 1 \times C 1$

$P_{2}=V_{2} \times C 2$

where $V_{1}=$ plasma volume at $t \mathbb{1}(1)$

$v_{2}=$ plasma volume at $\mathrm{t} 2$ (1)

$\mathrm{Cl}=$ plasma enzyme activity at $\mathrm{t} 1\left(\mathrm{u} . \mathrm{1}^{-1}\right)$

$\mathrm{C} 2=$ plasma enzyne activity at $t 2\left(u .1^{-1}\right)$

Therefore eq. 1 transforms to:

$\Delta A=V 1 \times C 1-V 2 \times C 2+k_{d} \times T \frac{V_{2} \times C 2+V_{1} \times C 1}{2} \quad$ (eq. 2)

The apparent enzyme disappearance constant $\left(k_{d}\right)$, as introduced in a two compartment model for enzymes, is detemined by both TER and FCR ( $k_{d}=$ TER + FCR) (Hemens et al, 1982). These authors measured the transcapillary escape rate (TER=0.031) and the fractional catabolic rate for $A S T$ ( $F C R=0.21$ ) and for creatine kinase ( $F C R=0.36)$ in dogs. The control values of plasma volume as measured in the present study were $1.19 \pm 0.361$ (mean $\pm S D ; N=17$ ).

Subsequently calculations were performed in the groups without cardiopulmonary bypass with the use of normal circulatory parameters, whereas in the groups with cardiopulmonary bypass the data as obtained in group HPLV 
were employed.

Group coN and group $E C$ :

In these two groups without CPB the curnulative release of CK and AST was calculated using equation 2 and known values of plasma volume $(1.21), k_{d}$ of AST $(0.24), k_{d}$ of creatine kinase $(0.39)$ and $T(0.75$ hrs). Using these values, equation 2 can be written as follows:

AST: $\Delta A=1.26 \mathrm{C2}-1.13 \mathrm{Cl}$

$C K: \Delta A=1.31 \mathrm{C} 2-1.09 \mathrm{C} 1$.

Groups with CPB:

From the observations in group HPLV we can conclude that PLV and TER changed after the period of CPB. Plasma walume was $140 \%$ at 15 min after CPB (t1) as compared to 60 min $(100 \%)$ after CPB (t2). The transport of enzyme from plasma to the exteravascular pool (TER) was increased from 0.031 to 0.48 throughout the period after CPB. These data changes equation 2 into:
AST: $\triangle A=1.38 \mathrm{C} 2-1.38 \mathrm{Cl}$
$C K: \Delta A=1.42 \mathrm{C} 2-1.01 \mathrm{Cl}$. 


\subsubsection{Microsphere technique}

\section{- Introduction}

The microsphere method was used to measure regional blood flow (Rudolph and Heymann, 1967). In several studies (Domenech et al, 1969; Buckberg et al, 1971; Yipintsoi et al, 1973; Uttey et al, 1974) it was shown that the fraction of injected radio-activity retrieved in various organs is similar to the fraction of cardiac output, reaching these argans during the transit of the microspheres. If the flow to one organ (for example a reference organ) and its microsphere content is known, the flow to any other organ with a known micrasphere content can be calculated.

Since both Heymann and coworkers (1977) and Schamhardt (1980) reviewed the microsphere technique extensively, and Prinzen (1982) has reported on the accuracy of the method used in our laboratory, the microsphere method will be describied only briefly.

\section{- Choice of the type of microspheres}

In the present study microspheres with a diameter of 15 yn were used because they seem to be the best compromise between the particle size induced deviation from nomal transmural blood flow and the entrapment of microspheres in the microvessels (Andersen et al, 1983; Meesmann et al, 1983). Moreaver, microspheres of $15, \mathrm{wh}$ are less expensive as compared to the smaller sized ones. The specific activity of the microspheres used in this study was lower than that normally used. The reduced specificity was applicable because at a specific activity of $3 \mathrm{mci} \cdot \mathrm{g}^{-1}$ the number of nicrospheres per sample rather than the gamma counting determines the accuracy of the method. Additional advantages are the lower radiation load for the investigator and the more favourable price per number of microspheres.

\section{- Checks before experimental use}

The micraspheres were purchased from New England Nuclear (Boston, USA). Microspheres were delivered in injection vials, suspended in $10 \%$ Dextran with $0.05 \%$ Tween 80 as surfactant to reduce aggregation of the microspheres. Before use, each batch was checked for: a) purity of the nuclide, b) specific activity of the micraspheres, c) integrity of the spheres, d) leakage of the nuclides from the spheres and e) diameter distribution of the beads. 
And a):

Purity of the nuclide is required for accurate gama-spectrometry. The purity was checked by amalysis of the spectrum of a small sample of each batch on the monitor of the Multi-Channel Analyzer. In each batch the right nuclide was delivered and no contamination with other nuclides was found. Ad b):

In each batch of micmospheres the specific activity was measured to check whether the materials delivered were according to the mamufacturen"s specifications. Furthemore, for accurate deterinination of the number of microspheres in each blood or tissue sample, the specific activity of the beads has to be known precisely. A droplet of a diluted suspension of microspheres was spread on a piece of graph paper and the number of microspheres cusually 2000-4000) was counted microscopicalliy. After this procedure the radioactivity of this piece of paper was counted in a gama counter. subsequently. it served as an isotope reference sample during counting of each series of samples from an experiment (see Experimental use of microspheres). Ad C):

Damaged nitcrospheres may have a different flow behavior, may fail to be entrapped and may cause leakage of the nuclide form the spheres. These factors negatively influence the accuracy of the method. Therefore, microsphere integrity was checked microscopically in a small sample at an enlargement of $100 x$. A few hundred beads were checked per sample. Routinely, less than $1 \%$ damaged spheres was observed.

Ad $d$ ):

Substantial leakage of nuclides from the spheres will invalidate the method because in this case injected radioactivity is not only trapped in the micracirculation, but will also circullate as soluble radioactivity. This leakage was checked as follows. A sample of microspheres was taken from the batch, sedimentated and once washed to mimic the treatment of microspheres under experimental conditions. After one $10 \%$ dextram and $0.05 \%$ Tween 80 was added, and the tube was thoroughly shaken on a vortex agitator during 1 min and sonificated in an ultrasound bath during 5 inin, the content of the tube was counted. Thereafter, the suspension was mixed again on the Wortex and subsequently filtered through a 0.22 um millipore filter (Cathivex). The supernatant was counted and the percentage leakage was calculated. This acute leakage was maximal ly $0.15 \%$. 
The leakage at $37^{\circ} \mathrm{C}$ over langer periods of time was determined in a11 batches of microspheres. Samples of these batches were suspended in $10 \%$ Dextran solution after vigorous shaking and were stored in a $37^{\circ} \mathrm{C}$ water bath for 1 week. Intermittently the suspensions were shaken and after this period leakage was determined in the same way as in the acute leakage experiments. The walues of leakage were found to be about twice as high as the acute leakage values, which is in agreement with the manufacturer's specifications. Ad e):

Dilameter distribution of the microspheres. The importance of a narrow diameter distribution of each batch of microspheres has been emphasized by Reneman and coworkers (1975). Because beads of different size have different rheological properties, a large variation in microsphere size will also introduce larger coefficients of variation. For this reason and also to check whether the right size of spheres was delivered, in each batch the diameter distribution was determined in a sample of 50 microspheres. The diameter of the spheres was measured using an image splitting eye piece (Vickers A.E.I.) mounted on a light microscope. The observed diameters and their distributions were comparable with the data provided by the manufacturer.

\section{- Experimental use of microspheres}

The number of spheres in each batch was calculated using the data on total activity (mCi) and specific activity $\left(\mathrm{mCi} \cdot \mathrm{g}^{-1}\right)$ as well as the number of spheres per gram as provided by the manufacturer. From each batch a stock suspension in fresh $10 \%$ Dextran and $0.05 \%$ Tween 80 was made containing about. $5 \times 10^{6}$ microspheres per $\mathrm{ml}$. Prior to each experiment, the required number of microspheres was taken fram this stock solution and diluted twice in $10 \%$ Dextran in 5 ml syringe. The syringe was closed by a stopcock and thoroughly shaken on a Vortex agitator to suspend all microspheres priar to injection. Then the syringe was put in a beaker in an ultrasonic bath. The beads were somificated for 5-10 min to break up clumps of beads, occasionally present (Reneman and Verheyen, 1977). Shortly before injection, the syringe was taken out of the bath and again shaken on the Vortex mixer for 1 min. Within $1 \mathrm{~min}$ after the last procedure, the microspheres were injected into the left atrium wia a silastic catheter (inner diameter $2 \mathrm{~mm}$, length about 25 $\mathrm{cm})$. The syringe was washed once with about $3 \mathrm{ml}$ physiological saline and subsequently the catheter was flushed with another $7 \mathrm{ml}$ of physiological 
saline to remove residual microspheres. In case of microsphere injection during ces, the left atmium could not be used as the site of imjection. Considering the retrograde aortic perfusion during CPE, the microspheres were injected into the arterial lime, in between the oxygenator and the main pump.

An arterial reference sample was taken from the brachial artery at a rate of about $20.7 \mathrm{ml} m \mathrm{~min}^{-1}$, using a Harvard witharawal pump. Suction of blood started $5 \mathrm{~s}$ before the injection of the microspheres and was continued for at least 1 min. The arterial blood was put into test tubes and the sample syringe was flushed once with a few ml of water. After the experiment the heart was excised, rinsed and stored in fommaldehyde $5 \%$. The free wall of the left ventricle was cut into 5 slices (parallel to the base of the heart). Each slice was cut into 5 pieces of approximately 3 gram, and each piece was dewided into a subendocardial, a molde and a subepicardial layer. only the subendocardial and subepicardial data is presemted (see fig 3.6). Total flow and transinural differences were calculated from a selected number of tissue pieces. These five pieces correspond to $\mathrm{B} 2, \mathrm{D}, \mathrm{C3}, \mathrm{B} 4$ and $\mathrm{D4}$ in $\mathrm{fig} 3.6$. overall myocardial blood flow was calculated from these pieces assuming that the flow was uniformily distributed. All tissue samples were put into 10 mi PVC test tubes. These tubes were weighed empty and with the sample. The weighing results were typed in on a data-entry system with a portable memory (3.84 kbytes). In the Packard Multi-Channel Analyzer the following samples were counted according to the MIC II program input (schosser et al, 1979): background samples, isotope reference samples, substract samples (meant for empty syringes), arterial and venous reference samples, and tissue samples. To be able to distinguish between the radioactivity of different nuclides within one sample as many counting windows were programmed as isotopes were present. Each window was located around the photopeak(s) of an isotope in such a way that the overlap of ather nuclides in that window was as small as possible. The spectruit of each isotope could be wisualized on a display. facilitating the positioning of the windows.

\section{- Calculation of regional myocardial blood fliow}

Data obtained from the gammacounter, e.g. counting time and the gross counts in each window, were printed on paper and on papertape. The papertape data were fed into the MINC II computer, using a Facit papertipe reader, and stored on file on a floppy disc. The weighing data in the portable memory 


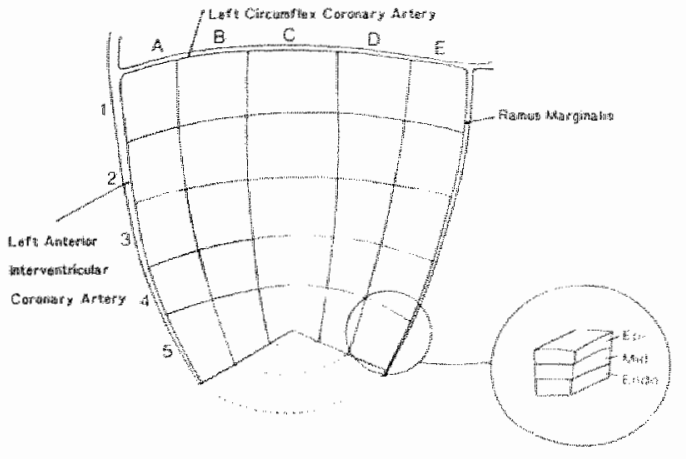

Fig 3.6 Sectioning of left ventricular free wall for transmural blood flow measurements. (Reproduced with permission of Prinzen et al, 1981). 
were read into the computer by a data entry system manufactured at the university of Limburg) in octal code and subsequently converted into alpha numeric figures. By using a screening program these data were checked on errors in the input and the data were ranked in negative numbers (for the empty tubes) and positive numbers (for tubes with samples) for direct use in the MICRO program.

The MICRO program is based on the MIC II program of Schosser and coworker's (1979). Shortly, the analysis of the energy spectra is performed according to the matrix method. Isotope reference samples (containing a certain amount of one pure isotope each) are measured to obtain the overlap matrix. The unkinown amounts of the nuclides in the samples are calculated by solving a set of lineair equations. The original MIC I I program has beem changed for conwenience with respect to calculation of the ratio count per min (cpm) per microsphere. This ratio was originally determined by dividing activity of the whole injectate by the estimated number of injected microspheres. Direct gama counting of the injectate, however, is not feasible, because a high dose of radioactivity is required when a large experimental animal is used. Therefore, from each nuclide 2000-4000 inicrospheres were counted micrascopically on a piece of graph paper. This piece of paper was carefully browght into a counting tube to serve as a reference. Manual input into the MICRO program of this number of microspheres, together with the paper tape input of the counting data, results in the cpm per ificrosphere. Subsequently the counts per gran of tissue for each isotope in the tissue were calcullated, and then the local myocardial flow (expressed in ml min ${ }^{-1} \cdot g^{-1}$ ) was obtained from the equation:

rinyocardial blood flow $=\frac{\text { CPM (tissue) } \times \text { reference flow }}{\text { CPM (reference sample of arterial blood) }}$

\subsubsection{Myocardial mechanical function}

\section{- Introduction}

Beside the routine determination of global myocardial mechanical function by means of the measurement of left ventricular pressure and its maximal positive first derivative (dPlv/dtmax, pos), local mechanical performance was 
Fing 3.7 Rectangle OABC deforms to paralellogram $O A^{\prime} B^{\prime} C$ '. Deformation is defined by natural strain $e_{c}$ along $A O$, natural strain $e_{z}$ along $O C$ and shear angle $\mathrm{e}_{z \mathrm{C}}$.

Fig 3.8 Measurement of the deformation parameters. A magnetic field ratates around the magnetic field generating coil (MFGC) and induces voltages $V_{C}$ and $V_{Z}$ in sensor coils $\mathrm{SC}_{\mathrm{C}}$ and $\mathrm{SC}_{2}$, respectively. The deformation parameters are determined from the amplitudes of and the phase difference between $W_{c}$ and $v_{z}$
THEORETICAL MODEL

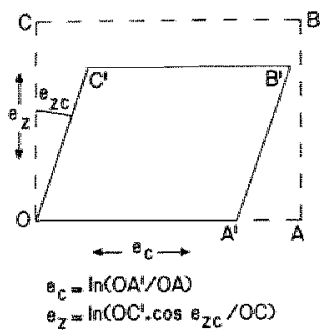

PRAGTICAL APPROACH

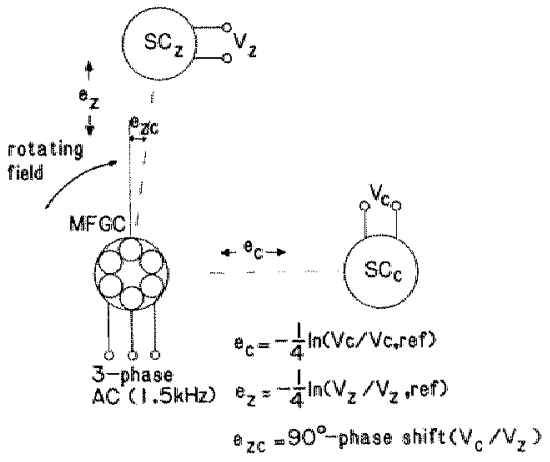


assessed, using an electromagnetic induction technique (Arts and Reneman, 1980). This technique enables the measurement of epicardial deformation du ring the ejection phase, and allows the estimation of fiber shortenimg in subepi and subendocardial layers as weil as the assessment of torsion of the left ventricular free wall (Prinzen 1982, Prinzen et al, 1984).

\section{- Epicardial deformation}

The principle of measuring epicardial deformation is based on assessing the distance between three coils attached to the epicardial surface in a predetemined position. Theoretically the three coils are part of the rectangle $O A B C$ as shown in fig 3.7 . During contraction this rectangle defomis to a parallelogram $O A^{\prime} B^{\prime} C^{\prime}$. O is assumed to be the origin, OA and $O A^{\prime}$ the direction along the c-axis (circumferential direction) and oc and $O C^{\prime}$ the direction along the z-axis (base to apex direction, perpendicular to the c-axis). The deformation of the rectangle can be described by the natural tangential stratin $\left(e_{c}\right)$, the natural axial strain $\left(e_{2}\right)$, and the shear angle $e_{2 c}$ as defined in fig 3.7. The wariables $e_{c}$, $e_{z}$ and $e_{z c}$ determine the dymatic change in the position of the three coils with the addition of torsion.

In the practical situation, one magnetic field generating coil (MFGC) and two sensor coils (SC) are situated within the perfusion area of the LAICA at the outer surface of the left ventricular free wall. The MFGC is attached at the origin 0 and the two sensor coils at the position $A$ and $C$ as indicated in fig 3.7. The MFGC is supplied by a three-phase alternating-current system, thus generating a rotating magnetic field (fig 3.8 ). This magnetic field induces a voltage in each sensor coil, proportional to the time derivative of the magnetic field strength. Changes in the induced voltages are subsequentlly used to calculate strains between the MFGC and sensor cails. The angle $90^{\circ}-e_{z c}$ equals the phase difference between the voltages induced in the sensor coils $(f i g 3.8)$.

The changes in the induced voltages and the phase difference were registered with a recorder (Schwarzer). The actual changes of the strains were recorded as $0.2,0.4$ or $0.8 \%$ per man and the phase differences as 0.005 or 0.01 rad per min.

- Subepi and subendocardial fiber shortening

Fron the epicardial deformation parameters $e_{c}, e_{z}$ and $e_{z c}$, the direction 
and ragnitude of minimal and maximal shortening can be calculated. The direction of maximal shortening approximately coincides with the fiber direction in the outer layers (Arts et al, 1982; Prinzen et al, 1984). Consequently, the magnitude of maximal shortening at the epicardium $\left(e_{\max }\right)$ is almost equal to shortening along the fibers in the outer layers. The direction of minimal shortening at the epicardium is approximately along the fiber direction in the inner layers (Prinzen et al, 1984). A mathematical model of left ventricular mechanics predicted that the magnitude of fiber shortening in the inner layers can be estimated (e endo, est) using:

$$
e_{\text {endo,est }}=1.42 \mathrm{e}_{\min }+0.78 \mathrm{e}_{\max }
$$

where:

$$
\begin{aligned}
& e_{\text {min }}=0.5\left(e_{c}+e_{z}\right)-0.5 \sqrt{\left(e_{c}-e_{z}\right)^{2}+e_{z c}^{2}} \\
& e_{\text {max }}=0.5\left(e_{c}+e_{z}\right)+0.5 \sqrt{\left(e_{c}-e_{z}\right)^{2}+e_{z c}^{2}}
\end{aligned}
$$

The calculated values of e endo,est were found to correlate well with shortening in the inner layers, as measured approximately along the fiber direction (Prinzen et al, 1984). Therefore, in the present study e endo,est was used as estimate of fiber shortening in the inner layers. This approach to assess fiber shortening across the myocardial wall is advantageous because the magnitude of $e_{\text {max }}$ and $e_{\text {min }}$ is essentially independent of the orientation of the inductive colls with espect to the fiber direction. 


\subsection{Technical notes}

Chemical composition of solutions and dog food:

Normosol $(R)$

$\begin{array}{lcc}\mathrm{NaCl} & 90 & \text { mmol.1 } \\ \text { Na-acetate } & 43 & \text { mmol.1 } \\ \text { Na-gl utamate } & 23 & \text { mmol. } \\ \mathrm{KCl} & 5 & \text { mmol.1 } \\ \mathrm{MgCl}_{2} & 0.7 & \mathrm{mmol} .1^{-1}\end{array}$

St Thomas hospital cardioplegia

$\begin{array}{lcl}\mathrm{NaCl} & 92 & \text { mmol. } 1^{-1} \\ \mathrm{NaHCO}_{3} & 25 & \text { mmol. } 1^{-1} \\ \mathrm{KCl} & 15 & \text { mmol } .7^{-1} \\ \mathrm{MgSO}_{4} \cdot 7 \mathrm{H}_{2} \mathrm{O} & 1.2 & \text { mmol. } 1^{-1} \\ \mathrm{MgCl}_{2} \cdot 6 \mathrm{H}_{2} \mathrm{O} & 15 & \text { mmol. } 7^{-1} \\ \mathrm{KH}_{2} \mathrm{PO}_{4} & 1.1 & \text { mmol. } 7^{-1} \\ \mathrm{CaCl}_{2} \cdot 2 \mathrm{H}_{2} \mathrm{O} & 1.2 & \text { mmol. } 7^{-1}\end{array}$

Haemaccel (R)

$$
\begin{array}{lcl}
\mathrm{NaCl} & 145 & \text { mmol. } 1^{-1} \\
\mathrm{~K}^{+} & 5.1 & \mathrm{mmol}^{-1} \mathrm{1}^{-1} \\
\mathrm{Ca}^{2+} & 6.25 \mathrm{mmol} . \mathrm{1}^{-1} \\
\text { polypeptides } & 3.5 \%
\end{array}
$$

Doko Food

$\begin{array}{lc}\text { Protein } & 28 \% \\ \text { Fat } & 9 \% \\ \text { Linoleic acid } & 1.7 \% \\ \text { Water } & 10 \% \\ \text { Carbohydrates } & 48 \% \\ \text { Minerals and vitamins trace amounts }\end{array}$




\section{3,4 Statistical amalysis}

The data from the patient study are presented as median walues and $95 \%$ confidence limits or as mean values and standard deviations. Oifferences in the values of the various variables were evaluated for statistical significance in two manners. Intraindividual differences (within one group) were analyzed by applying Hilcoxon's matched pairs signed-rank test (two-tailed probability) using the program BMDP 35. Intergroup differences were evalluated for statistical significance with Kruskal-wallis non-parantetric one-way analysis of variance with the BMDP 35 program. The changes in arterial-coronary sinus differences of biachemical substances in blood, as determined immediately after the periods of aortic cross-clamping, were evaluated for statistical significance with the randonization analysis of univariate responses according to Zerbe (1979).

The data from the animal experiments are presented as mean values and standard deviation, or as mean values and standard error of the mearl. Intraindividual differences within one group were analyzed using Wilcoxon's matched paires signed-rank test (two-tailed probability) with the BMDP 35 program, or with the use of the two sample t-test (BMDP 3D program) when the number of observations was less than five. Intergroup differences were evaluated for statistical significance by applying the one sample t-test with the BMDP $3 D$ program. 
$-78-$ 


\section{RESULTS}

\subsection{Patient study}

\subsubsection{Climical outcome}

Patients in the clinical study were treated according to a routine anesthetic policy before, during and imfediately after the surgical procedure. only when mean arterial blood pressure had decreased to $70 \%$ or less of the control value, postoperative inotropic support was applied. For this purpose dopanine was administered to two patients in each group within one hour after cessation of C.PB.

One patient in each group died within 3 weeks after the operation. One patient died because of bacterial sepsis in combination with respiratory complications (hypothermia group), one because of bacterial sepsis alone (cardioplegia group), and one because of heart failure (nomothermia group) due to an occluded graft on the right descending coronary artery, as was abserved at autopsy.

The intraoperative data of the patients of group $N, H$ and $C$ are shown in table 4.1. The number of distal grafts was not significantly different between the three groups. In groups $\mathrm{N}$ and $\mathrm{H}$ the mean duration of aortic crossclamping varied from 9 to $10 \mathrm{~min}$ for the first through fourth cross-clamping and the intermediate reperfusion periods lasted between 12 and $14 \mathrm{~min}$. The differences between groups $\mathrm{N}$ and $H$ were not statistically significant. The total duration of aortic cross-clamping was significantly longer in group $C$ $(63 \pm 13 \mathrm{~min})$ than in group $N(42 \pm 11 \mathrm{~min})$ and group $H(45 \pm 11 \mathrm{~min})$. The total CPB time was significantly shorter in group $\mathrm{N}$. 
Table 4.1 Intraoperative data of group $N$ (normothermia), group $H$ (hypothermia) and group $C$ (cardiaplegia). $A C=$ aortic cross-cllamping, $C P B=$ cardiopulmonary bypass. Mean values and S.D. are presented.

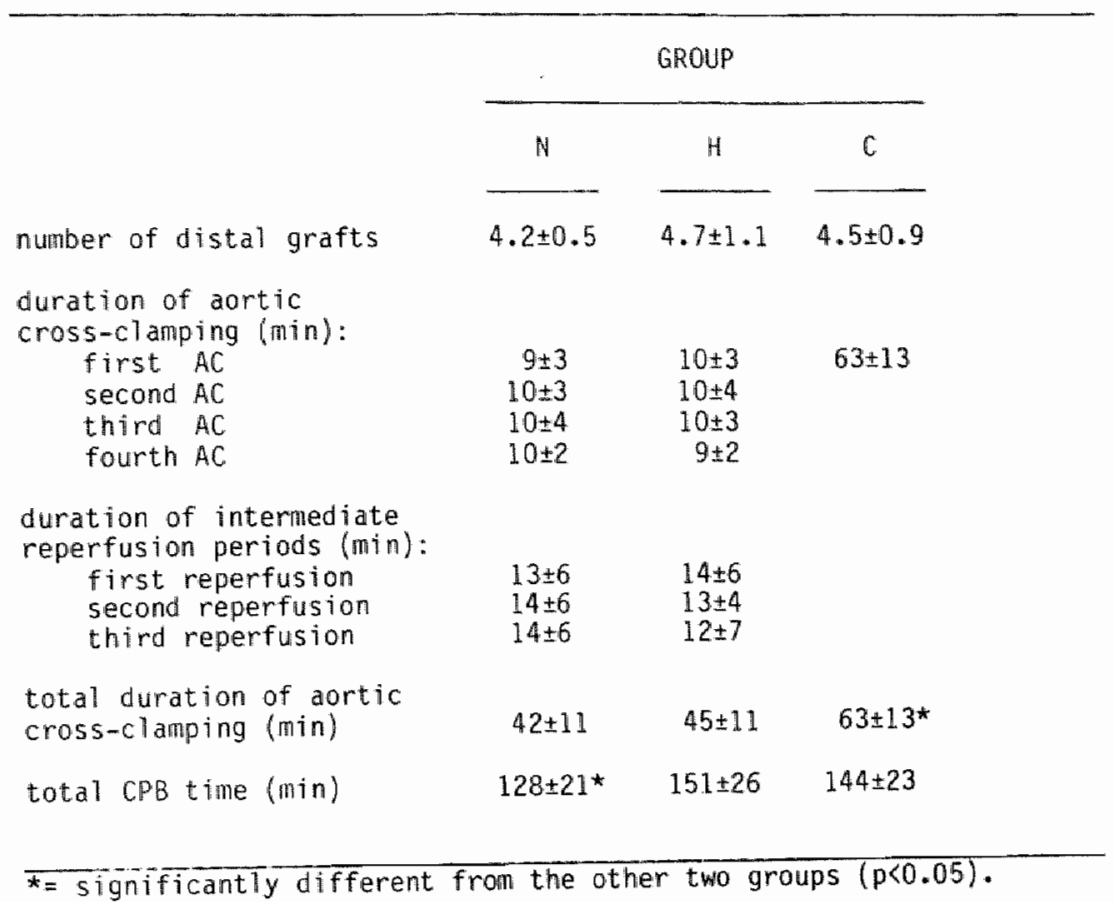




\subsubsection{Hemodynamics}

The values of the hemodymamic variables as measured before and after CPB are sumarized in table 4.2 . Heart rate significantly uncreased in al three groups, whereas both systolic (Pao,sys) and diastolic (Pao,dia) arterial blood pressures significantly decreased as compared to their corresponding pre CPB values.

PWP was significantly increased in group $H$ and group $C$, but was unchanged in group $N$. After CPB the maximum positive first derivative of left ventricular pressure (dPlv/dtmax, pos) was significantly decreased, whereas cardiac index (CI) was significantly increased in group $N$ and group $C$. A rellatively small but significant decrease in left ventricular stroke wark index (LVSWI) was noticed in all three groups $15 \mathrm{~min}$ after weaning from CPB.

Perfusion pressure (mean arterial blood pressure) and arterial pump flow during the period of CPB is shown in $\mathrm{fig} 4.1$ and figl 4.2 , respectively. Both during the first 15 min and the final period of CPB perfusion pressure was considerably depressed in all groups, as compared to the mean arterial blood pressure prior to CPB. In comparison with groups $H$ and $C$, patients in group $N$ had higher perfusion pressures immediately after the start of CPB, preceding the first aortic cross-clamping, while pump flow was similar in all three groups. This indicates a higher systemic vascular reșistance in group $N$. Around 45 to 75 min after the start of CPB pump flow in group $N$ exceeded pump flow in the groups $H$ and $C$.

Data on rectal and systemic blood temperatures, which were registrated continuously during the surgical procedure, are shown in fig 4.3 and fig 4.4 , respectively. The rectal temparture was set at $25^{\circ} \mathrm{C}$ in the groups $\mathrm{C}$ and $\mathrm{H}$, and at $34^{\circ} \mathrm{C}$ in group $\mathrm{N}$ by means of the heat exchanger in the oxygerator. A small delay in the decrease of rectal temperature was noticed in comparison to systemic blood in both hypothemically perfused groups. A similar phenomenon was observed duming rewaming after the last aortic cross-clamp.

Septal temperature in group $C$ was kept below $18^{\circ} \mathrm{C}$ throughout the period of cardioplegic infusion. The latter temperature was registrated internittently with a needle probe pierced into the septum after performance of each distal graft. 
Table 4.2. Hemodynamic variables in the three groups before and $15 \mathrm{~min}$ after CPB. Median values and $95 \%$ confidence limits are presented.

\section{GROUP'}

\begin{tabular}{|c|c|c|c|c|c|}
\hline \multicolumn{2}{|c|}{$\begin{array}{l}\text { Normothermi a } \\
\qquad(n=24)\end{array}$} & \multicolumn{2}{|c|}{$\begin{array}{l}\text { Hypothermia } \\
(n=23)\end{array}$} & \multicolumn{2}{|c|}{$\begin{array}{l}\text { Cardioplegia } \\
\qquad(n=25)\end{array}$} \\
\hline $\begin{array}{c}\text { before } \\
\text { CPB }\end{array}$ & $\begin{array}{c}\text { after } \\
C P B\end{array}$ & $\begin{array}{c}\text { before } \\
\text { CPB }\end{array}$ & $\begin{array}{c}\text { after } \\
\text { CPB }\end{array}$ & $\begin{array}{c}\text { Defore } \\
C P B\end{array}$ & $\begin{array}{c}\text { after } \\
\text { CPB }\end{array}$ \\
\hline 79 & $97^{*}$ & 74 & $94 *$ & 72 & $89 *$ \\
\hline $65-90$ & $90-101$ & $64-80$ & $83-98$ & $63-84$ & $79-93$ \\
\hline
\end{tabular}

\begin{tabular}{|c|c|c|c|c|c|c|}
\hline Pao, sys & 15.9 & $13.7^{*}$ & 15.2 & $12.1 *$ & 14.8 & $1.2 .5^{\star}$ \\
\hline$(\mathrm{kPa})$ & $14.3-16.8$ & $12.3-14.8$ & $13.6-16.4$ & $10.8-13.1$ & $14.0-16.1$ & $11.1-13.7$ \\
\hline Pao,dia & 9.6 & $7.5^{*}$ & 8.1 & $6.5^{*}$ & 8.0 & $6.3^{*}$ \\
\hline$(\mathrm{kPa})$ & $8.3-10.4$ & $6.9-8.1$ & $7.7-9.2$ & $6.0-7.6$ & $7.5-9.2$ & $6.1-7.5$ \\
\hline PWP & 1.1 & 1.1 & 0.9 & $1.4^{*}$ & 0.9 & $1.1^{*}$ \\
\hline$(k P a)$ & $0.9-1.2$ & $1.1-1.2$ & $0.8-1.1$ & $1.1-1.5$ & $0.8-1.1$ & $0.9-1.5$ \\
\hline $\mathrm{dP} 1 \mathrm{v} / \mathrm{d}$ tmax, pos & 140 & $115 *$ & 108 & 97 & 112 & $107^{*}$ \\
\hline$\left(\mathrm{kPa}, \mathrm{s}^{-1}\right)$ & $120-170$ & $100-140$ & $97-125$ & $90-127$ & $103-140$ & $87-143$ \\
\hline $\mathrm{CI}$ & 2.21 & $2.60^{\star}$ & 2.25 & 2.56 & 2.17 & $2.66^{\star}$ \\
\hline$\left(1 . \mathrm{min}^{-1} \cdot \mathrm{m}^{-2}\right)$ & $1.84-2.47$ & $2.46-3.08$ & $1.88-2.53$ & $2.29-2.85$ & $1.91-2.78$ & $2.20-3.16$ \\
\hline LWSWI & 0.32 & $0.28^{*}$ & 0.34 & $0.24^{*}$ & 0.32 & $0.28^{\star}$ \\
\hline$\left(\mathrm{d} \cdot \mathrm{m}^{-2}\right.$. beat $\left.{ }^{-1}\right)$ & $0.28-0.38$ & $0.24-0.32$ & $0.27-0.41$ & $0.22-0.26$ & $0.26=0.37$ & $0.22-0.34$ \\
\hline
\end{tabular}

* significantly different from pre CPB values $(0<0.05)$. 


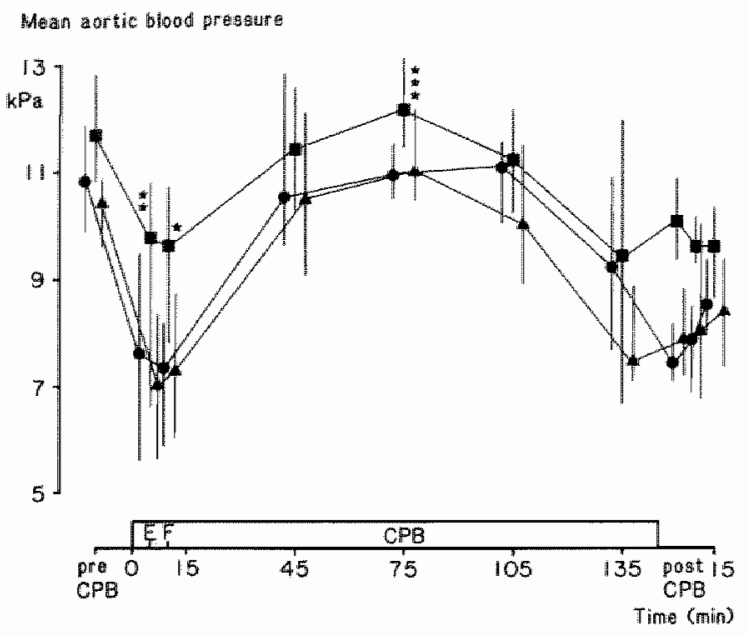

Fig 4.1 Mean aortic blood pressure before, during and 5, 10 and 15 min after cardiopulmonary bypass. Median values and $95 \%$ confidence limits are presented. $\mathbf{E}$ = normothemia, $\bullet=$ hypothermia, $\boldsymbol{\Delta}$ = cardioplegia, $\mathbf{E}=$ empty beating, $F=$ fibrillating. *= significantly different from the value in the groups $H$ and $C, * *=$ significantly different from the value in the group $C$, $w^{*}=$ significantly different from the value in the group $H$. 


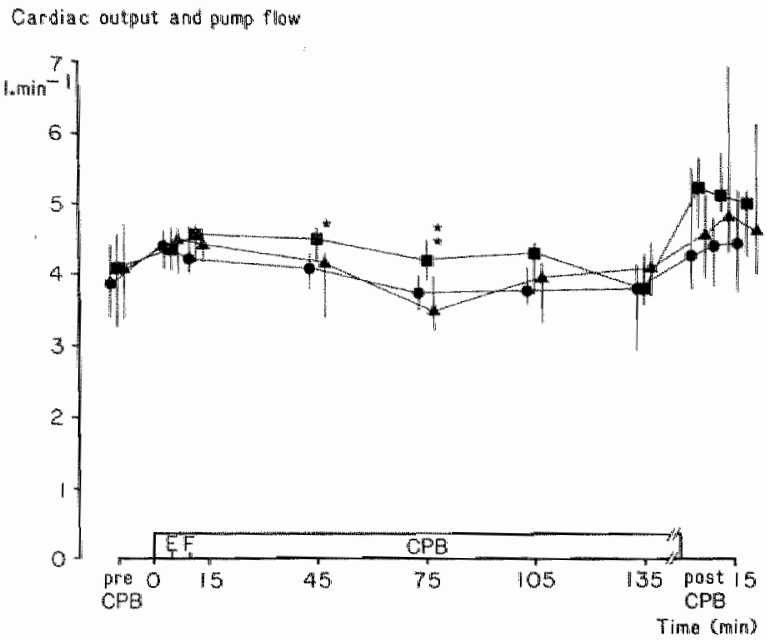

Fig 4.2 Cardiac output prior to and after CPB, and arterial pump flow during cardiopulmonary bypass. Fedian values and 95\% confidence limits are presented. $\mathbf{E}$ = nomothermid, $\boldsymbol{\bullet}$ = hypothemia, $\boldsymbol{\Delta}$ = cardioplegia, $\mathbf{E}=$ empty beating, $F=$ fibrillating. For further explanation see legend to fig 4.1 . 


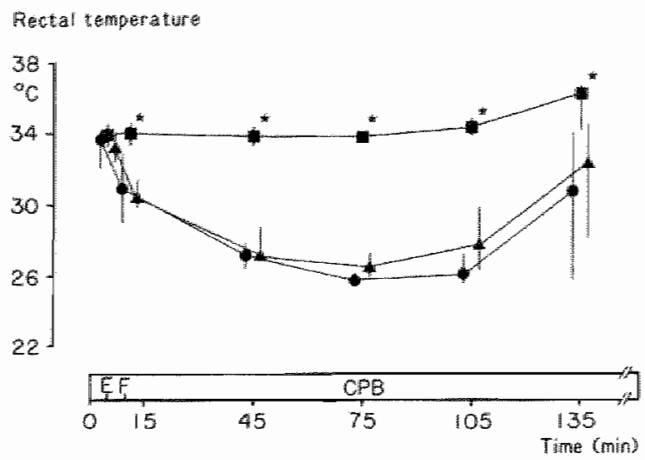

Fig 4.3 Rectal temperature of patients on CPB. Median values and $95 \%$ conf ${ }^{-}$ dence limits are presented. $\mathbf{v}=$ normathermia, $\mathbf{a}=$ hypothemia, $\mathbf{\Delta}=$ cardioplegia, $E=$ empty beating, $F=$ fibrillating. For further explanation see legend to fig 4.1 .

Arterial blood tomperature

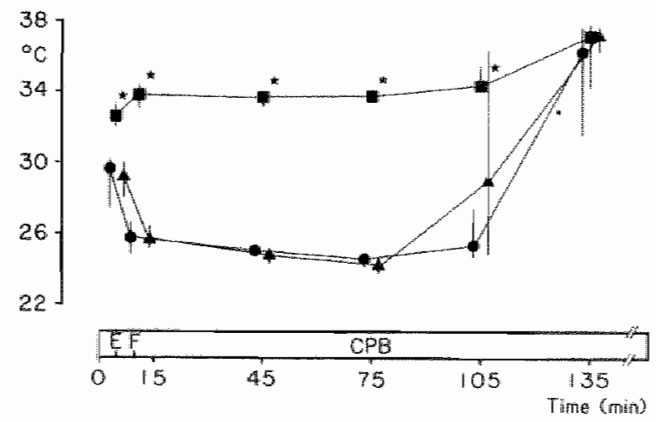

$\mathbb{F i g} 4.4$ Arterial systemic blood temperature during CPB. Median walues and $95 \%$ confidence limits are presented. $\mathbf{0}=$ normothermí, - = hypothermia, $\Delta=$ cardioplegia, $\mathbb{E}=$ empty beating, $F=$ fibrillating. For further explanation see legend to fig 4.1 . 


\subsubsection{Biochemical analysis}

\subsubsection{Plasma catechol amine concentration}

Norepinephrine, epinephrine and dopamine, were selected to evaluate the effect of anesthetic or surgical interventions on the sympathetic nervous system during the surgical procedure.

The plasma concentration of norepinephrine measured prior to intubation was about $0.7 \mathrm{ng} . \mathrm{mi} \mathrm{7}^{-1}$ in ali patients, and decreased after intubation and sternotomy (fig 4.5). Before the start of CPB morepinephrine had increased to preinduction values. In all groups plasma levels of norepinephrine further increased during $C P B$ and remained elevated in group $N\left(1.85 \mathrm{ng} . \mathrm{ml}^{-1}\right)$, group $H$ (1.23 $\left.\mathrm{ng}_{\mathrm{mml}}{ }^{-1}\right)$ and group $\mathrm{C}\left(1.49 \mathrm{ng}^{\mathrm{m}} \mathrm{ml}^{-1}\right)$ until $15 \mathrm{~min}$ after weaning from $C P B$. During the first $15 \mathrm{~min}$ postoperatively the norepinephrime concentrations were significantly higher in group $N$ than in groups $H$ and $C$.

Before the start of $C P B$ the epinephrine concentration decreased significantly in all three groups ( $f$ ig 4.5). At the end of $C P B$ the plasma level had increased significantly as compared to the immeditate pre CPB vaiues and remained elevated during the first 15 min after CPB. There were no significant differences between the groups throughout the period of investigation.

In contrast to norepinephrine and epinephrine, no change in the dopamine plasma concentration was abserved during the pre CPB phase. The patients of group $H$ had significantly higher plasma levels as compared to the other two groups immediately before the onset of CPB (fig 4.5). During the first 15 min and at the end of $C P B$, anly the patients in group $N$ and group $C$ had elevated plasma dopanine concentrations as compared with the pre CPB walues. The differences between the three groups did not reach the level of significance. 


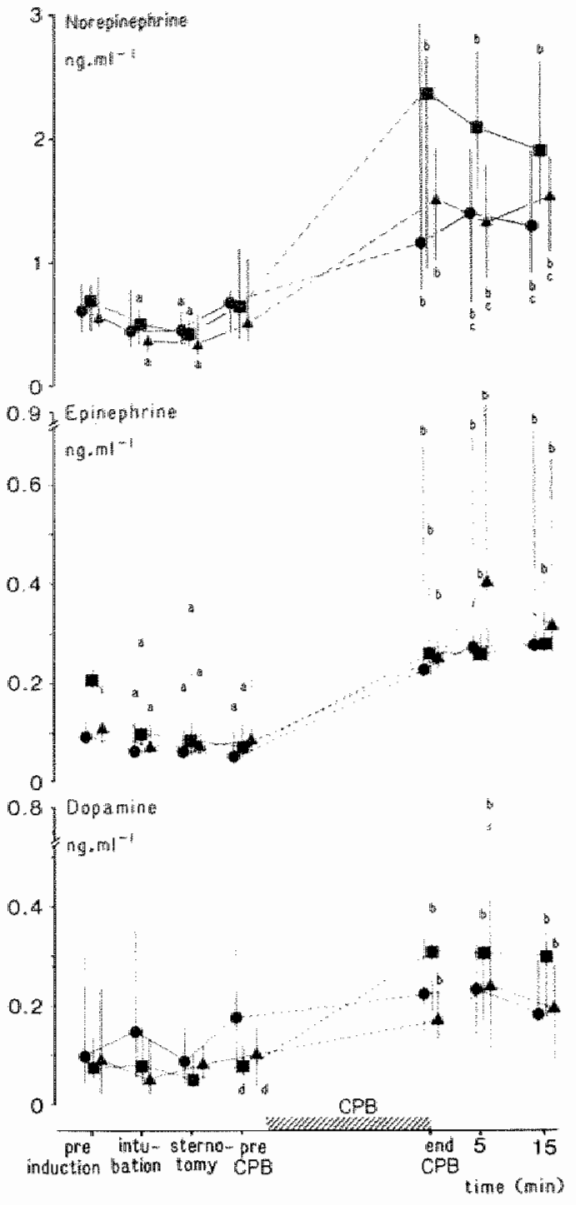

Fig 4.5 Plasma concentration of norepinephrine, epinephrine and dopamine. Median values and $95 \%$ confidence ilmits are presented. $\mathbf{a}=$ nomom themia $(n=16) ; \quad=$ hypothermia $(n=15) ; \Delta=$ cardiopiegia $(n=18)$. p<0.05 was considered as statistically significant.

a, different from preinduction values by paired andlysis

$b$, different from pre CPB walues by paired analysis

c. different from corresponding values in the group $M$ by non-paired analysis

d, different from the corresponding value in group $H$ by non-paired malysis. 


\subsubsection{Postoperative enzyme release}

The plasma activity of AST, creatine kinase, CK-MB and HBDH was not significantly different in the three groups before the period of CPB. The fallowing median values and $95 \%$ confidence limits were found: AST $=11(10-12)$ U. $1^{-1} ;$ creatine kinase $=30(28-33) U .7^{-1} ; C K-M B=4.4(3.6-6.6) U .1^{-1} ;$ HEDH= $117(92-212) \cup \cdot 1^{-1}(n=72)$. These values were comparable to the control values as found in healthy subjects, except for an increased value of $H B D H$, which might be due to hemolysis (Hermens et al, 1982). The plasma enzyme activity in the postoperative period is presented after correction for control plasma values (see section 3.1.9) in fig 4.6. Creatine kinase levels significantly increased after the operation and reached a maximum value at 24 hrs after weaning from CPB. In contrast, CK-MB reached a maximum value between 4 and 8 hrs and levelled thereafter. The activity of AST reached a maximum 24 hrs after weaning from $C P B$. $H B D H$ plasma activity was already increased immediateiy after cessation of CPB and remained elevated thereafter. No differences between the three groups could be observed with respect to the plasma activity of these four enzymes during the investigated postoperative period.

A11 plasma enzyme activities were subsequently used to calculate the cumulative enzyme reilease, in order to estimate the amount of tissue damaged, if any, during the surgical procedure (see section 3.1.9). The 24 and 36 hour vallues for cumulative release of creatine kinase, AST, HBDH and CK-MB (expressed as gram-equivalents of tissue per liter plasma) are summarized in table 4.3. In each group the values measured at 36 hrs after CPB are generalIy higher than those measured at $24 \mathrm{hrs}$. The plasma values observed during the iast 12 hrs of plasma enzyme analyses were not significantly different between the three groups. 

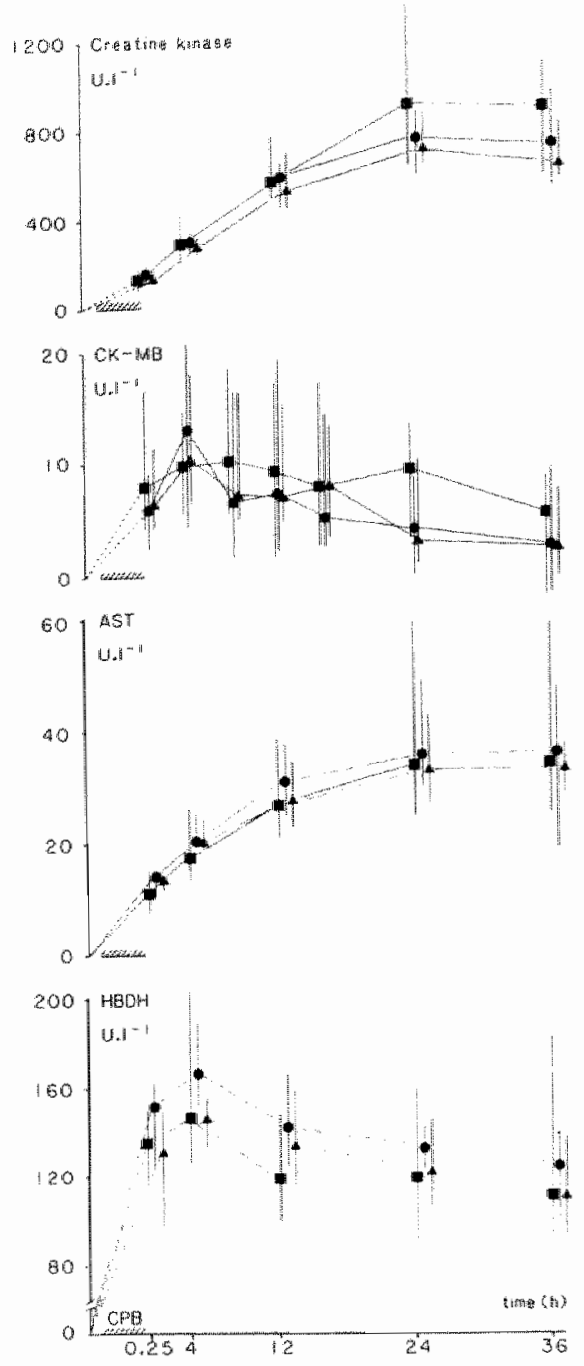

Fig 4.6 Plasma activities of creatine kinase, its isoenzyme CK-MB, AST and HBDH during 36 hours after cessation of CPB. Values given in this figure were corrected for normal pre CPB vallues (Cs, see section 3.1.9). Median values and $95 \%$ confidence limits are presented. $\mathbf{E}=$ nomothemia, $\quad$ = hypothemia, $\quad \boldsymbol{\Delta}=$ cardioplegia. 
Table 4.3 Cumulative release of enzymes during the first 24 and 36 hours after CPB. Data refer to median values and 95 confidence limits,

a, cumulative release expressed as gram-equivalents of myocardial tissue per liter plasma. In this case, the heart was considered as the sole source of postoperative enzyme release inta the blood.

b, cumulative release of $\mathrm{HBDH}$ after substraction of the amount of enzyne released from erythrocytes danaged during CPB (see section 3.1 .9 ).

c. cumulative release of enzymes from heart and skeletal muscle, respective1y. Calculations were based on the release of creatine kimase and AST after weaning from CPB (see section 3.1 .9 ).

Enzyme Tine Group

Nomathemia Hypothemia Cardioplegia

\begin{tabular}{|c|c|c|c|c|}
\hline & & & & \\
\hline \multirow[t]{2}{*}{$\begin{array}{l}\text { creatine }{ }_{1}^{\text {kinase }} \\
\left(g-e q .1^{a}\right.\end{array}$} & $24 \mathrm{~h}$ & $\begin{array}{c}6.1 \\
5.3 .8 .8\end{array}$ & $\begin{array}{c}6.0 \\
5.0-6.7\end{array}$ & $\begin{array}{l}5.2 \\
4.8-6.2\end{array}$ \\
\hline & $36 \mathrm{~m}$ & $\begin{array}{l}10.3 \\
7.9-13 \cdot 4\end{array}$ & $\begin{array}{l}9.2 \\
7.1-11.0\end{array}$ & $\begin{array}{l}8.1 \\
7.4-11.1\end{array}$ \\
\hline \multirow[t]{2}{*}{$\begin{array}{l}A S T^{a} \\
\left.(g-e q \cdot)^{-1}\right)\end{array}$} & $24 \mathrm{~h}$ & $\begin{array}{c}1.8 \\
1.4-2.9\end{array}$ & $\begin{array}{l}2.1 \\
1.8-2.4\end{array}$ & $1.7-2.3$ \\
\hline & $36 \mathrm{~h}$ & $\begin{array}{l}2.5 \\
2.1-4.1\end{array}$ & $\begin{array}{l}2.8 \\
1.9-3.5\end{array}$ & $2 \cdot \frac{2.5}{3-3.0}$ \\
\hline \multirow[t]{2}{*}{$\begin{array}{l}\text { HEDH } \\
\left(9-\mathrm{eq}^{\mathrm{b}} 1^{-1}\right)\end{array}$} & $24 h$ & $\begin{array}{c}0.6 \\
0.4-0.9\end{array}$ & $\begin{array}{c}0.6 \\
0.6-1.0\end{array}$ & $\begin{array}{c}0.7 \\
0.4-0.9\end{array}$ \\
\hline & $36 \mathrm{~h}$ & $\begin{array}{c}0.8 \\
0.5-1.3\end{array}$ & $\begin{array}{c}0.9 \\
0.5-1.4\end{array}$ & $\begin{array}{l}0.9 \\
0.7-1.3\end{array}$ \\
\hline \multirow[t]{2}{*}{$\begin{array}{l}C K-M B^{a} \\
\left(g-e q \cdot 1^{-1}\right)\end{array}$} & $24 \mathrm{ln}$ & $\begin{array}{c}1.2 \\
0.7-1.8\end{array}$ & $\begin{array}{c}0.7 \\
0.3-1.7\end{array}$ & $\begin{array}{c}0.8 \\
0.5-1.4\end{array}$ \\
\hline & $36 \mathrm{~h}$ & $\begin{array}{c}1.6 \\
1.0-2.4\end{array}$ & $\begin{array}{c}1.2 \\
0.4 \cdot 2.3\end{array}$ & $\begin{array}{c}0.9 \\
0.5-2.0\end{array}$ \\
\hline \multirow{2}{*}{$\begin{array}{l}\text { QHeart } \\
\left(9-\operatorname{eq} \cdot 1^{-1}\right)\end{array}$} & $24 \mathrm{~h}$ & $\begin{array}{c}0.7 \\
0.4-1.2\end{array}$ & 0.7 .2 & $\frac{1.1}{0.6-1.5}$ \\
\hline & $36 \mathrm{~h}$ & $\begin{array}{l}0.8 \\
0.5-1.2\end{array}$ & $\begin{array}{c}1.2 \\
0.6-2.0\end{array}$ & $\begin{array}{l}1.5 \\
0.7-2.0\end{array}$ \\
\hline \multirow{2}{*}{$\begin{array}{l}Q_{\text {skelletal muscle }} \\
\left(9-e q .1^{-1}\right)\end{array}$} & $24 h$ & $\begin{array}{c}1.7 \\
1.4-2.3\end{array}$ & $\begin{array}{c}1.4 \\
1.1-1.7\end{array}$ & $1.1-1.6$ \\
\hline & $36 h$ & $\begin{array}{c}2.9 \\
1.5-3.9\end{array}$ & $\begin{array}{c}2.4 \\
1.5-2.9\end{array}$ & $\begin{array}{l}2.2 \\
1.7-3.0\end{array}$ \\
\hline
\end{tabular}


Calculation of the amount of injured tissue revealed an equivalent for heart tissue in the order of 1 gram and for skeletal muscle of about 2.5 gram per liter plasma during $36 \mathrm{hrs}$. The amount of heart enzyme $\left(Q_{H}\right)$ released is in good agreement with the direct measured and calculated cumulative values based on $\mathrm{HBOH}$ and $\mathrm{CK}-\mathrm{MB}$.

Assuming a mean heart weight of about $400 \mathrm{~g}$ and a cinculating plasma volume of 31 in these patients, an equivalent for myocardial tissue of 1 to $1.5 \mathrm{~g}$ per $11 t$ er plasma suggests that about $1 \%$ of the myocardial cells became injured due to the surgical procedure. The equivalents of 2.5 gran per liter plasma for skeletal muscle indicates that $0.02 \%$ of all skeletal muscle cells were dalmaged, when assuming that skeletal muscle represents about 50 \% of total body weight.

\subsubsection{Tissue content of ATP, creatine phosphate and glycogen}

Changes in the tissue content of ATP, creatime phosphate and glycogen during the period of CPB were investigated in pre and postischemic transmural myocardial biopsies (figs $4.7,4.8$ and 4.9 ).

After the reperfusion period of about $20 \mathrm{~min}$, following the release of the (last) aortic cross-clamp, the content of ATP was found to be 83,74 and $100 \%$ of the control values in group $N$, group $H$ and group $C$, respectively. In both the groups $N$ and $H$ the decrease was significant.

No significant difference in the content of creatine phosphate could be observed between the pre and postischemic samples in all three groups (fig $4.8)$.

In the groups $N$ and $H$ the glycogen content was significantly reduced to 54\% and $57 \%$ of the preischenic values, respectively. No significant change in the carbohydrate store could be observed in the group $c$. 


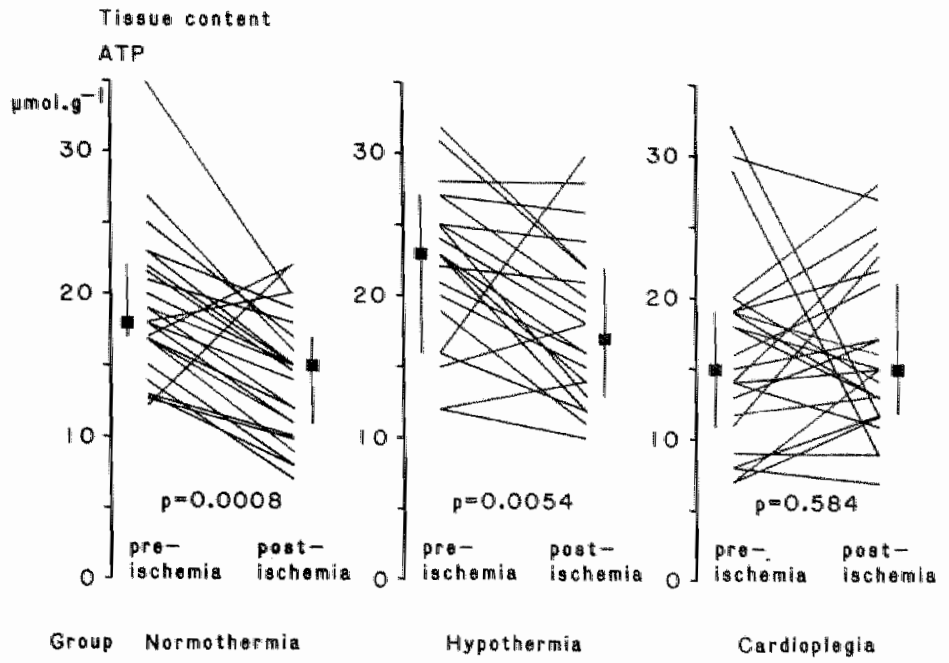

Fig 4.7 Content of ATP in pre and postischemic myocardial biopsies of all individual patients. - refer to median values and $95 \%$ confidence limits. Values are expressed as $\mu m_{0} 7 . g^{-1}$ dry weight of tissue. $p$ indicates the level of significance of the difference between the pre and postischemic values. 


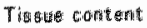

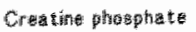
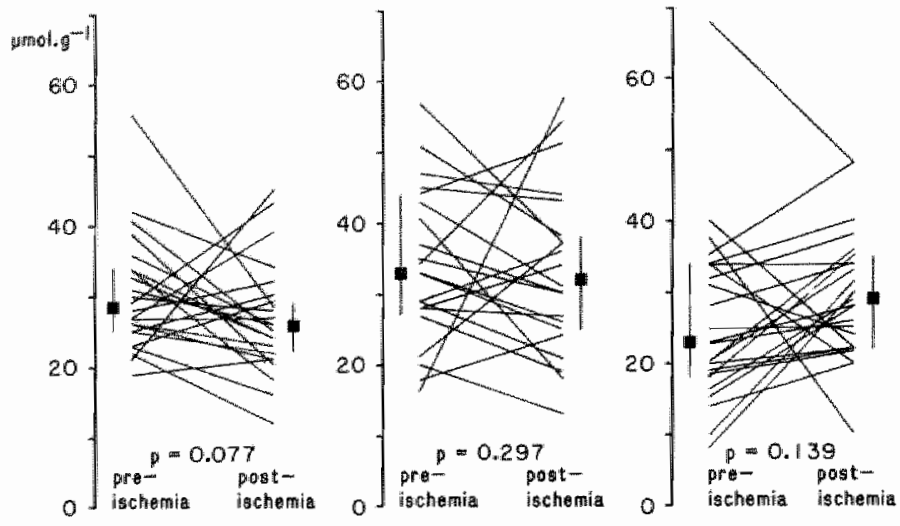

Group Hormothermia

Hypothermis

Cardioplegia

F49 4.8 Content of creatine phosphate in pre and postischemic myocardial biopsies of all patients (for explanation see legend to fig 4.7 ).

Tisusue cant ent

Glycagen
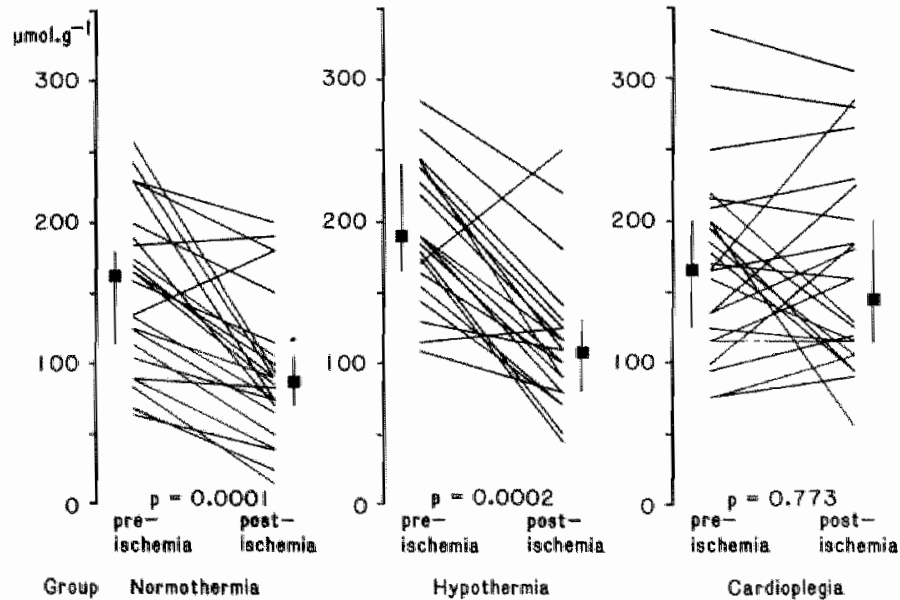

Hy otherimin

Carnioplegita.

Fig 4.9 Content of glycogen (expressed as umol glucose moleties per gram dry weight of tissue) in pre and postischenic myocandial biopsies of all patients (for explanation see legend to fig 4.7). 

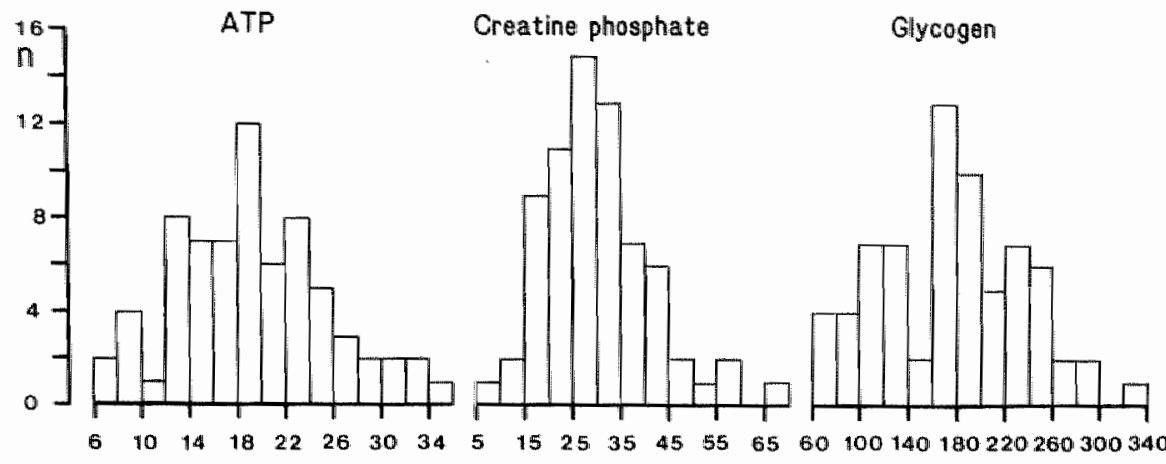

Wmolug- Idry weight

Fig 4.10 Histograms representing the interindividual variation of the tissue contents of ATP, creatine phosphate and glycogen in preischemic myocardial biopsies, taken during cardiopulmonary bypass ( $n=70$ patients). Tissue values were growped in cohorts of 2,5 and 20 umol. $g^{-1}$ dry weight in case of ATP, creatine phosphate and glycogen, respectively. $n=$ the number of values belonging to one specific cohort. (reproduced by permission of Van der Vusse et a1, 1982) 

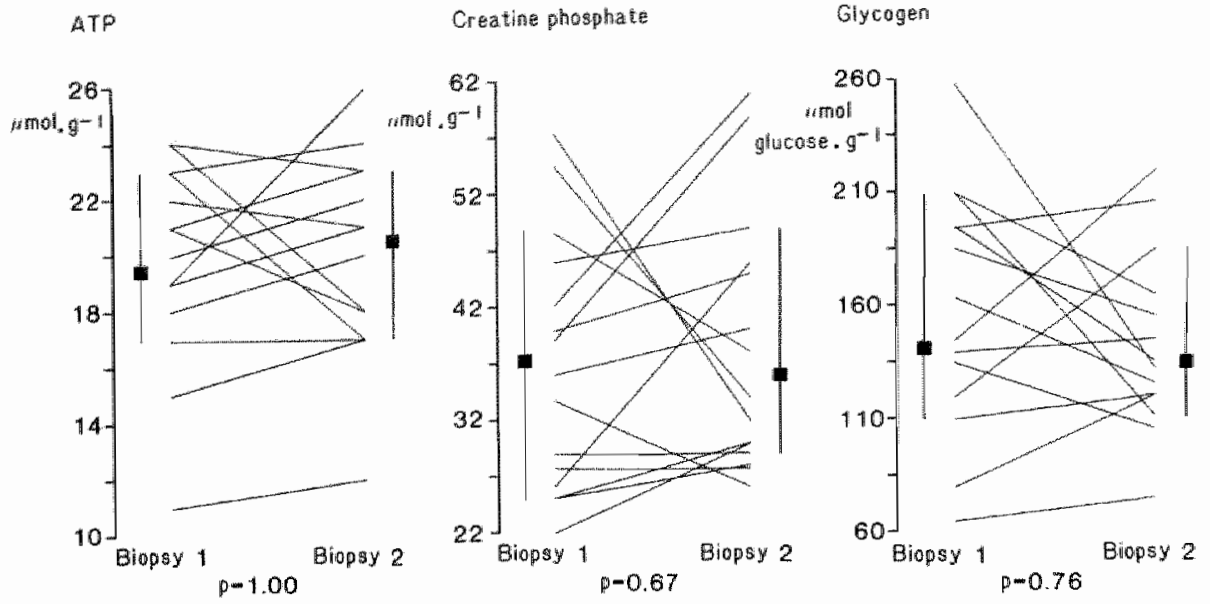

Fig 4.11 Intraindividual varilation of the contents of ATP, creatine phosphate and glycogen in the human left wentricle. Biopsy 1 and 2 were taken from adjacent areas withim 2 min, in the preischenic period during cardiopulmonary bypass $(n=14) . \longrightarrow=$ refers to median values and 95\% confidence limits. (reproduced by permission of Wan der Wusse et at, 1982) 
The content of ATP, creatine phosphate and glycogen varied substantially in the preischemic myocardial biopsies of the individual hearts as is shown in the figs $4.7,4.8$ and 4.9 . The preischemic data, when transformed to histograms (fig 4.10), depicts a near normal distribution, but does not eliminate the possibility of spatial inhonogenieties within the heart. Interindividual variation amounted to. $35 \%$ for ATP, $37 \%$ for creatine phosphate and $34 \%$ for glycogen. Whether inhomogenieties rather than interindividual variation prevail, was analyzed in a subset of the three patient groups. To this purpose two preischemic biopsies of adjacent left ventricular free wall areas were collected in a limited number of patients $(n=14)$. There was no significant difference in the mean ATP, creatine phosphate or glycogen content between these two biopsies (fig 4.11). Howewer, in some hearts pronounced differences exist between the two sampling sites, which resulted in a mean intraindividual variation of $11 \%$ for ATP, $11 \%$ for creatine phosphate and $20 \%$ for glycogen. Since these patients had 3-vessel disease these differences may be explained by spatial inhomogeneities due to partly underperfused areas of the left ventricular free wall (Jones et al, 1981).

4.1.3.4. Plasma levels of lactate, inorganic phosphate, potassium, and oxygen content

Insight into the metabolic functioning of the myacardium during the surgical procedure was abtained by determining the plasma concentrations of lactate, inorganic phosphate and potassium and the blood oxygen content in coronary sinus and arterial blood samples and assessing the arterial-coromary sinus (A-CS) differences. Besides, the arterial concentrations of these substances do give some information about systemic metabolism.

- Arterial plasma concentrations of lactate, inorganic phosphate,

potassium and oxygen.

The arterial concentrations of lactate are shown in fig 4.12 for the three groups of patients. In all groups arterial lactate tended to increase during the surgical procedure, and about 10 min after the start of CPB all values were significantly higher as compared to the pre CPB lactate levels. These levels randinad increased after CPB. Statistically significant diffe- 

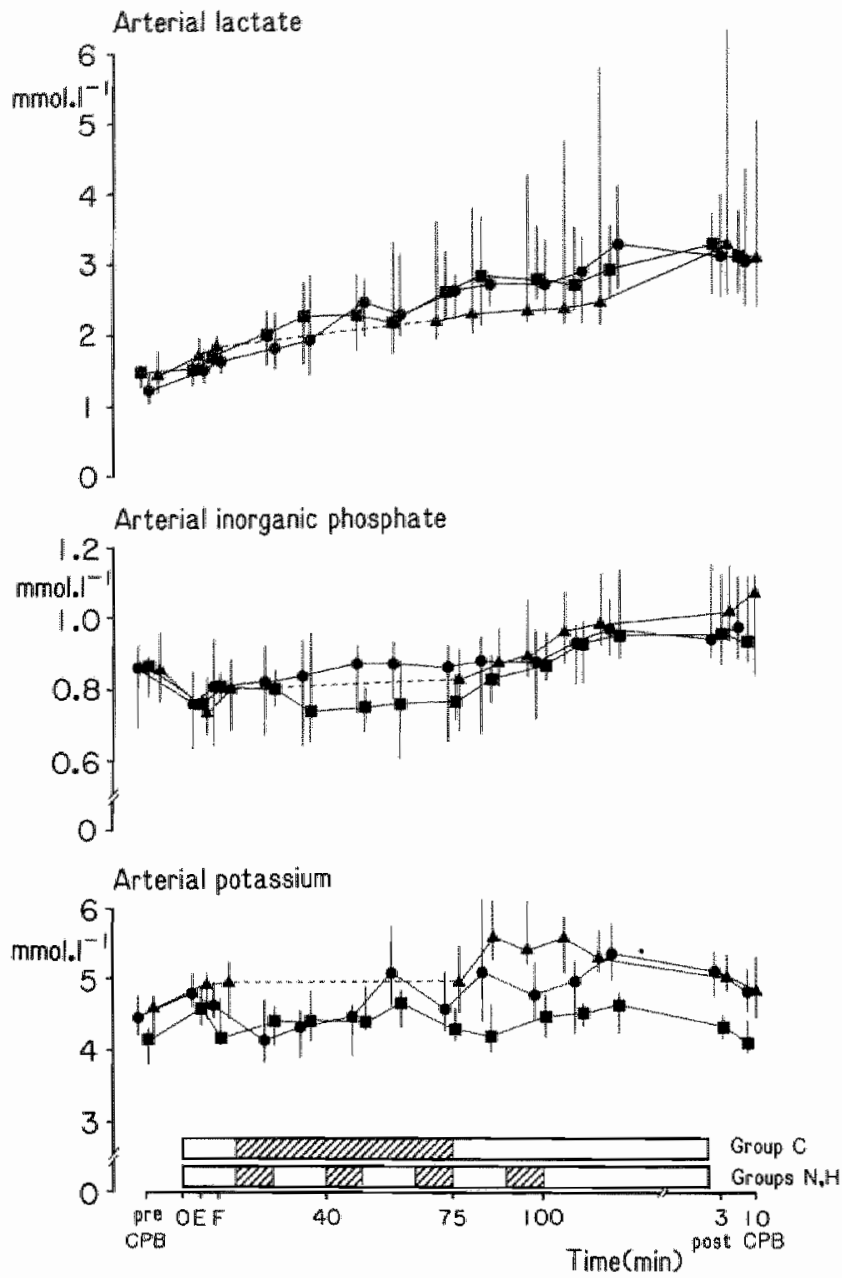

Fig 4.12 Arterial plasma concentrations of lactate, inorganic phosphate and potassium in the three patient groups. Horizontal bars refer to the period of $C P B$, and the inserted dashed areas represents the duration of aortic cross-clamping. Median values and $95 \%$ confidence linitis are shown for group $N(\mathbf{M})$, group $H(\bullet)$ and group $C(\bullet) . E=$ empty beating heart, $F=$ fibrillating heart. Post CPB samples were collected 3 and 10 min after weaning from CPB. 
rences between the groups were not observed.

The arterial concentration of inorganic phosphate fell significantiy after the start of CPB in all three groups (fig 4.12). The arterial inorganic phosphate levels in group $N$ tended to renain low during the periods of aortic cross-clamping, but in group $H$ the arterial concentration increased in this period, reaching values not significantly different amymore from the pre CPB concentration. After aortic cross-clamping arterial inorganic phosphate levels increased gradually in the three groups, resulting in significantly higher levels after CPB, as compared to the pre CPB vallues.

In the early phase of CPB the arterial concentration of potassium increased significantly in all groups (fig 4.12). In the groups $N$ and $H$ the arterial potassium concentration initialiy remained at pre CPB levels, but increased significantly during the second half of the CPB period. In group $C$ the arterial potassium concentration increased immediately during the reperfusion phase, probably as a result of the contribution of the cardioplegic solution to the circulating blood volume. Within the first 10 min after cessation of CPB the arterial potassium concentration tended to decrease to pre CPB walues in all groups.

The arterial oxygen saturation remained within a narrow range, close to 100\% (data not shown) throughout the operation.

- Arterial-coronary sinus differences of substances

The A-CS differences of lactate, inorganic phosphate, potassium and $0_{2}$ are presented in the figs $4.13,4.14,4.15$ and 4.16 , respectively.

The A-CS differences of lactate show that in mast hearts hardly no lactate was extracted before CPE. During empty beating (E) and especially ventricular fibrillation $(F)$, the A-CS differences of lactate were significantly changed into release as compared to their corresponding pre CPB values in all groups. The negative values indicate melease of lactate during the Initial period of CPB.

The A-CS differences of inorganic phosphate (fig 4.14) were hardly different from zero in all groups during the periods before and after aortic cross-clamping.

Priom to CPB the $R-C S$ differences of potassium (fig 4.15 ) were 51 ightiy negative in most patients, indicating some release of this ion. During empty beating and fibrillation of the hearts the negative wilues appeared to de- 


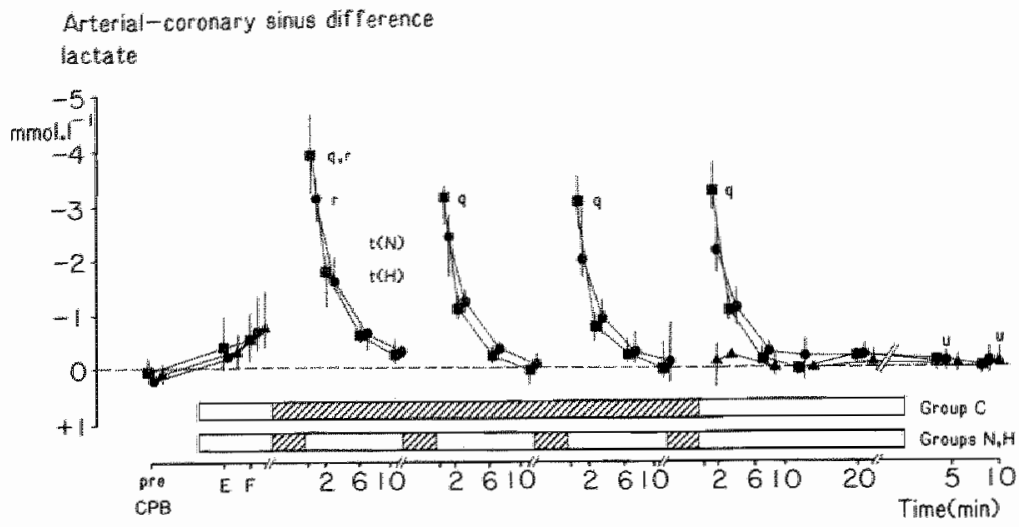

Fig 4.13 Arterial-coronary sinus difference of lactate in group $N$ (normothermia, - ), group $H$ (hypothemia, $\bullet$ ) and group $C$ (cardioplegia, -1$)$. Median walues and $95 \%$ confidence limits are presented in mol. $1^{-1}$. E = empty beating heart; $F=$ fibrillating heart (in groups $H$ and $C$ ) . Horizontal bars refer to the period of CPB, and inserted diashed areas represent duration of aortic cross-clanining. Negative values of A-CS differences correspond to washout of lactate into coronary sinus blood.

q - initial peak value $(0-30 \mathrm{~s})$ of group N differs significantly from the corresponding walue measured in growp $H$.

$r$ - initial peak value $(0-30 \mathrm{~s})$ of the reperfusion perfod following the first aortic cross-clamping differs significantly from corresponding values of the subsequent reperfusion periods within the same group of patients.

$s$ - release curve of group $N$ differs significantiy from the corresponding curve in group $H$ during a given reperfusion period.

t - release curve of the first reperfusion period differs significantly fram the curves of subsequent reperfusion periods within the same group of patients.

- value obtained after cardiopulmonary bypass differs significantly from the value prior to CPB.

Statistical analysis of differences between group $C$ and the other two groups during the reperfusion periods was not performed. 


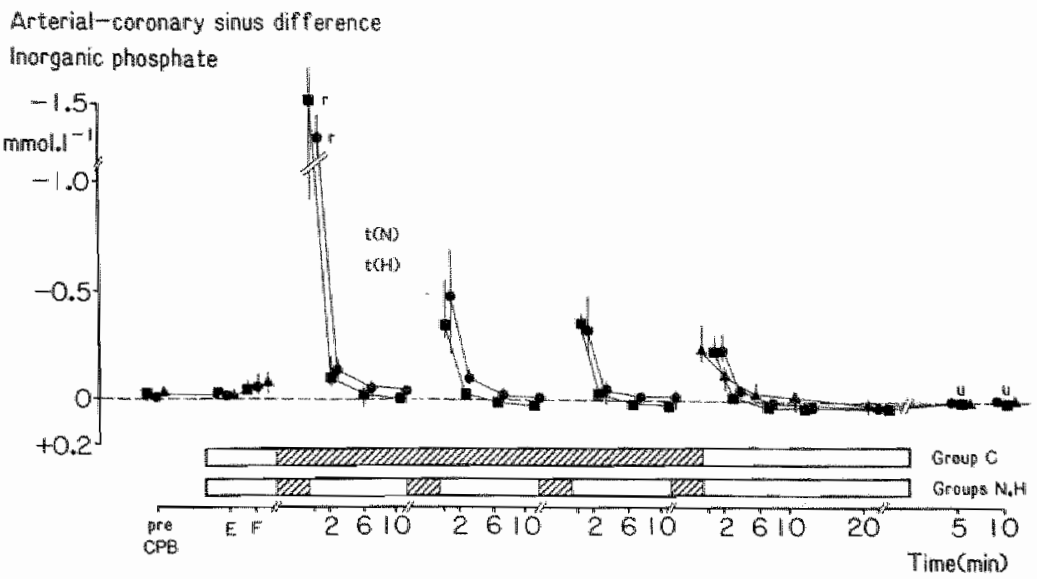

Fig 4.14 A-CS difference of inomganic phosphate in the three patient groups. For explanation see iegend ta fig 4.13.

Arterial-caronary sinus difference

Potassium

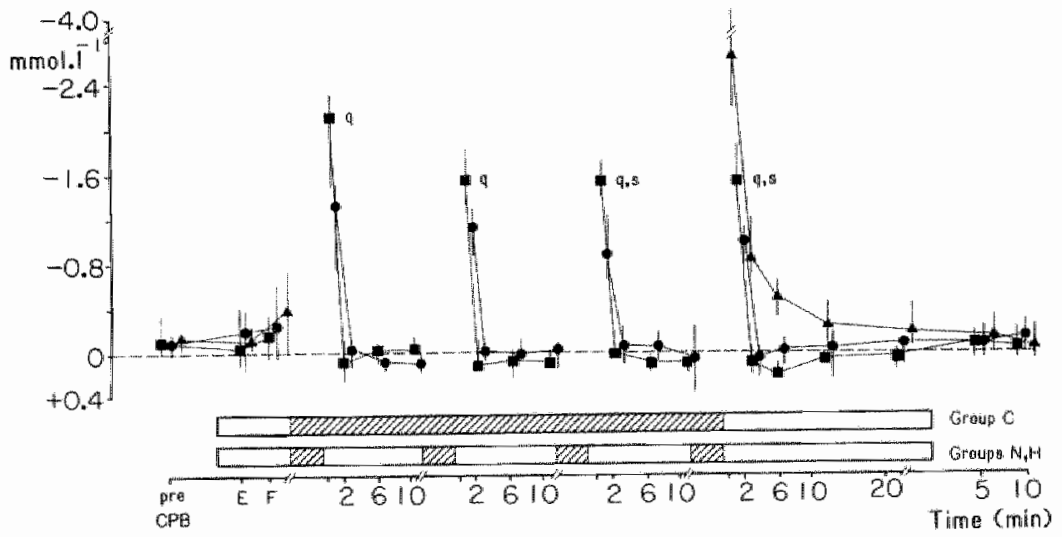

Fig 4.15 A-CS difference of potassium in the three patient groups. For expla nation see legend to fig 4.13 . 


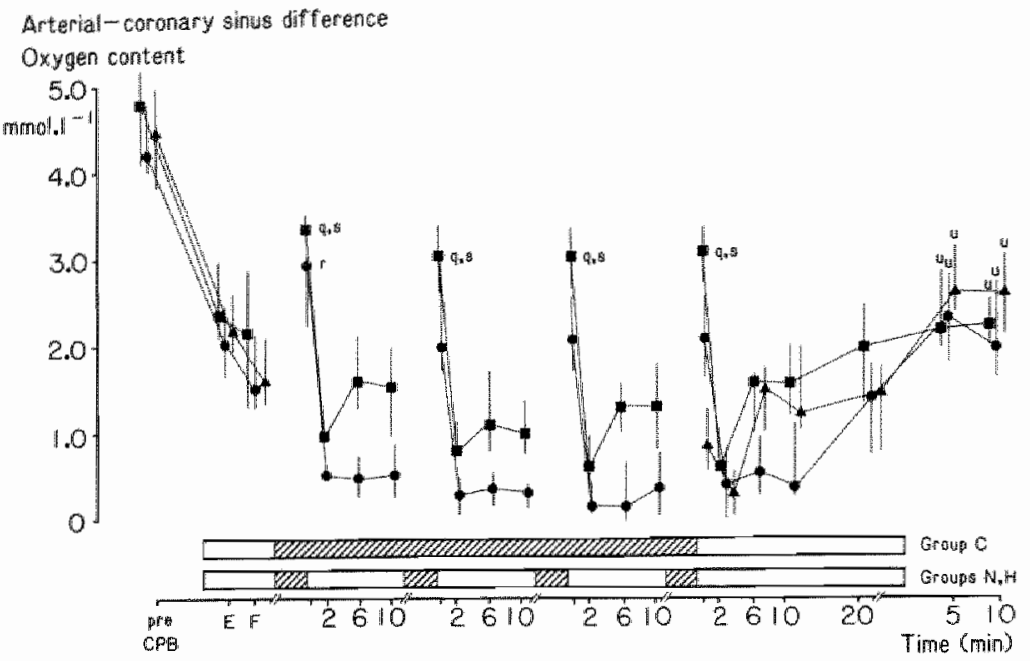

Fig 4.16 A-CS difference of oxygen content in the three patient groups. For explanation see legend to fig 4.13 . 
crease further in both group 4 and group $C$, as campared to group N. The pre and post bypass A-CS differences were not significantily different from each other in all three groups.

The A-cS differences of oxygen were expressed as oxygen content. The venous axygen saturation was substracted from $100 \%$ (artenial oxygem saturation) and subsequently multiplied by the venous hemogiobin content. The data as presented in fig 4.16 , indicates that there are no differences between the three groups before CPB. Within a few min after the start of CPB, venous oxygen content increased significantly in all groups and a further increase was observed in group $C$ and group $H$ at the time of fibrillation, possibly due to cooling of the heart. After cessation of CPB, A-CS differences of oxygen remained significantly decreased in all groups, as compared to the pre CPB wal tues.

- Arterial-coronary sinus differences of substances during the immediate reperfusion period following aortic cross-clanping.

Release of the aortic clamp resulted in instantaneous reperfusion of the global ischenic myocardium. During this reperfusion phase release of substances, accumulated during the preceding period of ischemia, readily occurred. Examples of these substances are lactate, potassfum and inorganic phosphate known as reliable markers of metabolic changes induced by ischemia. (Owen et al, 1970; 0pie et a1, 1972; Van der Vusse et a1, 1979, 1980).

The presentation of the values of A-CS differences is restricted to 0.5. 2, 6 and $10 \mathrm{~min}$ after release of the aortic clamp for the sake of clarity, whereas the intermediate values were also used for statistical analysis.

The release of lactate (fig 4.13) during the first 10 min following each aoricic cross-clamp periad was highest in the samples collected immediately after release of the clamp in both group $\mathbb{N}$ and group $H$ (sample period from 0 to 3051 . During 10 min of reperfusion the A-CS differences gradually decreased.

In both group $N$ and group H the A-CS differences during the very first reperfustion period were higher than the corresponding differences during the following reperfusion periods at each sample time. In the four reperfustion periods at all first sample tines $(0-30 \mathrm{~s})$ the A-CS differences of lactate were significantly higher in group than in group $H$. The A-CS differences of lactate in the cardioplegia group were hardly different from zero, indicating 
that virtually no lactate was released.

In group and group the rellease of inorganic phosphate at the first sample time $(0-30$ s) was significantly higher in the first reperfusion period than in the three following reperfusion periods (fig 4.14 ). The A-CS differences of inorganic phosphate rapidy fell to zero. In the group $N$ even a measurable amount of inorganic phosphate was taken up by the heart during the second, third and fourth reperfusion period at sample times 6 and 10 min. This phenomenon was also observed in the group 15 after release of the fourth cross-clamping. The A-CS differences of inorganic phosphate in the cardioplegia group were highest at the first sample time $(0-30 \mathrm{~s})$ and gradually decreased during the succeeding 6 min of reperfusion.

In both group $\mathbb{N}$ and group $H$, the $H_{-}$CS differences of potassium ( $\mathbb{H i g} 4.15$ ) during reperfusion were initially high, but fell rapidly to low levels. The A-CS differences as measured in the first samples $(0-30 \mathrm{~s})$, were significantly higher in group $N$ than in group $H$ during each reperfusion period. In group $N$ potassium was extracted by the heart at sample time 2 min during the first reperfusiom period, and at sample times 2 through 10 min during the second, third and fourth reperfusion periods. In contrast, sustained negative A-CS differences af this ion were measured during the first 10 min of reperfusion in group $C$.

The patterns of the A-CS differences of oxygen (fig 4.16) show that during reperfusion the initially high values raplidy fell to low levels in group $\mathbb{N}$ and group $H$. The rimitial A-CS differences of oxygen were significantIy higher in group $N$ than in group H. During reperfusion A-CS differences of axygen mapidly fell to very low values in both groups. In group w these

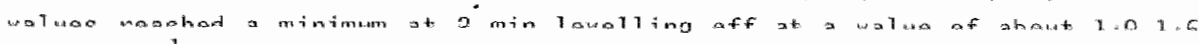
mol $0_{2} \cdot 1^{-1}$. In contrast the A-CS differences remained significantly decreased (median value ranging from $0.2-0.6 \mathrm{~mol} 0.2^{-1}$ ) in group 4 . In the cardioplegia group the A-CS differences of oxygen during reperfusion were initially small, but gradually increased to values of $1.2-1.5$ mol $0_{2} .1^{-1}$, which was not significantly different from the values as measured in group 


\subsubsection{Mitochondrial ultrastructumal findings}

Mitochondrial ultrastructure was evaluated before and after the periods of ischemia using seniquantitative parameters (table 4.7). This scoring systern has been discussed in detail in section 3.1.6.

In the three groups the preischemic tissue specimens were well preserved and over 95\% of the mitochondria belong to the grading score 0 or 1 , which indicates an excellent membrane ultrastructure with or without typical small intramitochondria? particles. Hardly no heawily danaged mitochondria were abserved.

After ischemia (and reperfusion) no significant changes in the value of score $\mathbb{D}$ and 1 were found in all myocardial layers of the three groups, except for the endocardial layers of group $C$, where significantiy more mitochondria with scare 0 were found in the postischemic biopsy. Simultaneously, a decrease of the percentage of mitochondria with scare 1 was observed $(p<0.05)$. In both internittently cross-clamping groups the mitochondria showed an increased tendency to clarification of the matrix (score 2) in the postischemic specimens as compared to preischemic specimens. This increase was noticed in both the subendo and the subepicardial layer, but did not reach the level of significance most likely due to a substantial patient to patient variation. 
Table 4.7 Mitochondrial utrastructural appearance. Deta refer to mean values and standard deviations. Meaning of score (see also section 3.1 .6 ): 0 = nomal ultrastructure of the mitochondrion, 1 =nomal appearance of the crests and matrix, but absence of granular deposits (small electron dense granules), $2=$ loss of matrix granules and clarification of the matrix without breaking of crests. $3=10 s$ of matrix granules, uniform clarification of the matrix and disruption of crests (facal condensation maly be seen: inclusions having at least twice the dianeter of normal mitochondrial granules). $4=$ loss of matrix granules, uniform disruption of crests and lass of integrity of mitochondrial inner and outer membranes.

Group

Score

$\begin{array}{lllll}0 & 1 & 3 & 4\end{array}$

Nomathermia

\begin{tabular}{|c|c|c|c|c|c|c|}
\hline Epicard: & $\begin{array}{l}\text { preischentc } \\
\text { postischemic }\end{array}$ & $\begin{array}{l}61 \pm 29 \\
53 \pm 28\end{array}$ & $\begin{array}{l}36 \pm 26 \\
40 \pm 22\end{array}$ & $\begin{array}{l}3.3 \pm 7.3 \\
6.2 \pm 11\end{array}$ & $\begin{array}{l}0.1 .40 .4 \\
0.5 \pm 1.4\end{array}$ & $\begin{array}{l}0 \pm 0 \\
0.1 \pm 0.4\end{array}$ \\
\hline or & $\begin{array}{l}\text { preischemic } \\
\text { postischemic }\end{array}$ & $\begin{array}{l}50 \pm 23 \\
50+28\end{array}$ & $\begin{array}{l}43+21 \\
39 \pm 23\end{array}$ & $\begin{array}{r}5.4 \pm 13 \\
10 \quad \pm 18\end{array}$ & $\begin{array}{l}1.0 \pm 2.8 \\
0.6 \pm 1.3\end{array}$ & $\begin{array}{c}0.4 \pm 1.6 \\
0 \pm 0\end{array}$ \\
\hline
\end{tabular}

Hypotherrita

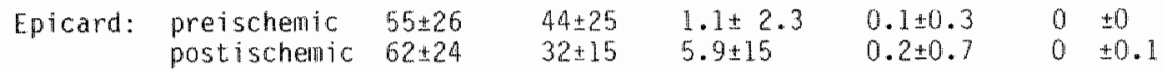

$\begin{array}{rllllll}\text { Endocard: preischemic } & 62 \pm 25 & 38 \pm 25 & 0.7 \pm 1.8 & 0 & \pm 0 & 0.1 \pm 0.4 \\ \text { postischemic } & 66 \pm 19 & 32 \pm 17 & 1.5 \pm 4.4 & 0.2 \pm 0.5 & 0 \pm 0.1\end{array}$

\section{Cardioplegia}

\begin{tabular}{|c|c|c|c|c|c|c|}
\hline Epicard: & $\begin{array}{l}\text { preischentic } \\
\text { postischenic }\end{array}$ & $\begin{array}{l}49+29 \\
58+30\end{array}$ & $\begin{array}{l}48+22 \\
39 \pm 27\end{array}$ & $\begin{array}{l}2.3 \pm 4.3 \\
2.8 \pm 5.8\end{array}$ & $\begin{array}{l}0.6 \pm 2.5 \\
0.1 \pm 5.8\end{array}$ & $\begin{array}{l}0.1 \pm 0.5 \\
0.3 \pm 0.5\end{array}$ \\
\hline Endocard: & $\begin{array}{l}\text { preischem ic } \\
\text { post ischemic }\end{array}$ & $\begin{array}{l}44 \pm 29 \\
64 \pm 27\end{array}$ & $\begin{array}{l}53+29 \\
33 \pm 24\end{array}$ & $\begin{array}{l}2.7 \pm 4.7 \\
2.4 \pm 8.1\end{array}$ & $\begin{array}{l}0.2 \pm 0.4 \\
0.3 \pm 0.8\end{array}$ & $\begin{array}{l}0.2 \pm 0.5 \\
0.1 \pm 0.3\end{array}$ \\
\hline
\end{tabular}

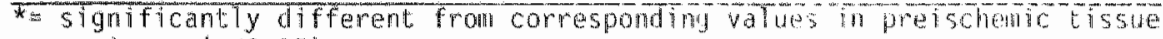
spechners $(p<0.05)$.
} 


\subsection{Animal experiments}

\subsubsection{Introduction}

The procedures followed in the animal experiments were aimed at being comparable to those in the clinical study, with respect to duration of CPB, ischemia, and reperfusion, and to the techniques of myocardial protection. The experiments were teminated one hour after cessation of $\mathrm{CPB}$, when myocardial biopsies were taken. Within this post CPB period the hemodynamic and metabolic variables could be determined for a longer period than in the clinical study, in which the last measurement was performed at 15 min after termination of $C P B$.

In this section the results of the animal experiments are presented as far as used for further evaluation and comparison to clinical measurements. Additionally, data already briefly discussed in the method section, are summarized in the appendix. Amimal data (body weight and left ventricular weight) is presented in appendix 1. Data on cardiopulmonary bypass (rectal and septal temperature, perfusion pressure, pump flow) are shown in appendix 2,3 and 5 , respectively and indicates adequate perfusion circunstances.

\subsubsection{Hemodynamics}

In fig 4.17 the hemodynamic variables as measured before and 15 and 60 min after $C P B$ in the groups $\mathbb{N}, H$ and $C$ are shown. In all groups heart rate was relatively high before $C P B$ and did not change significantly during the postoperative period. After CPB cardiac output was increased in the groups $H$ and $C$, but not in group $N$. As compared to the pre LPB values, Pao, sys and Pao,dia were significantly decreased in group $H$, and $P$ ao, dia in the groups $\mathbb{N}$ and $C$ after $C P B$. Although $P l y$ did not change significantly in either group a tendency to decrease was observed in groups $N$ and $H$. The mean values of Plv, ed tended to be increased after $C P B$, but only reached the level of significance in group $C$. In group $H$ mean $d P l y / d$ tmax, pos showed a translent decrease from 220 to $160 \mathrm{kPa} \cdot \mathrm{s}^{-1} 15 \mathrm{~min}$ after $C P B$. The henodynamic variables as neasured before CPB in the groups NB, HB, NC, HC and HPLV, were comparable 

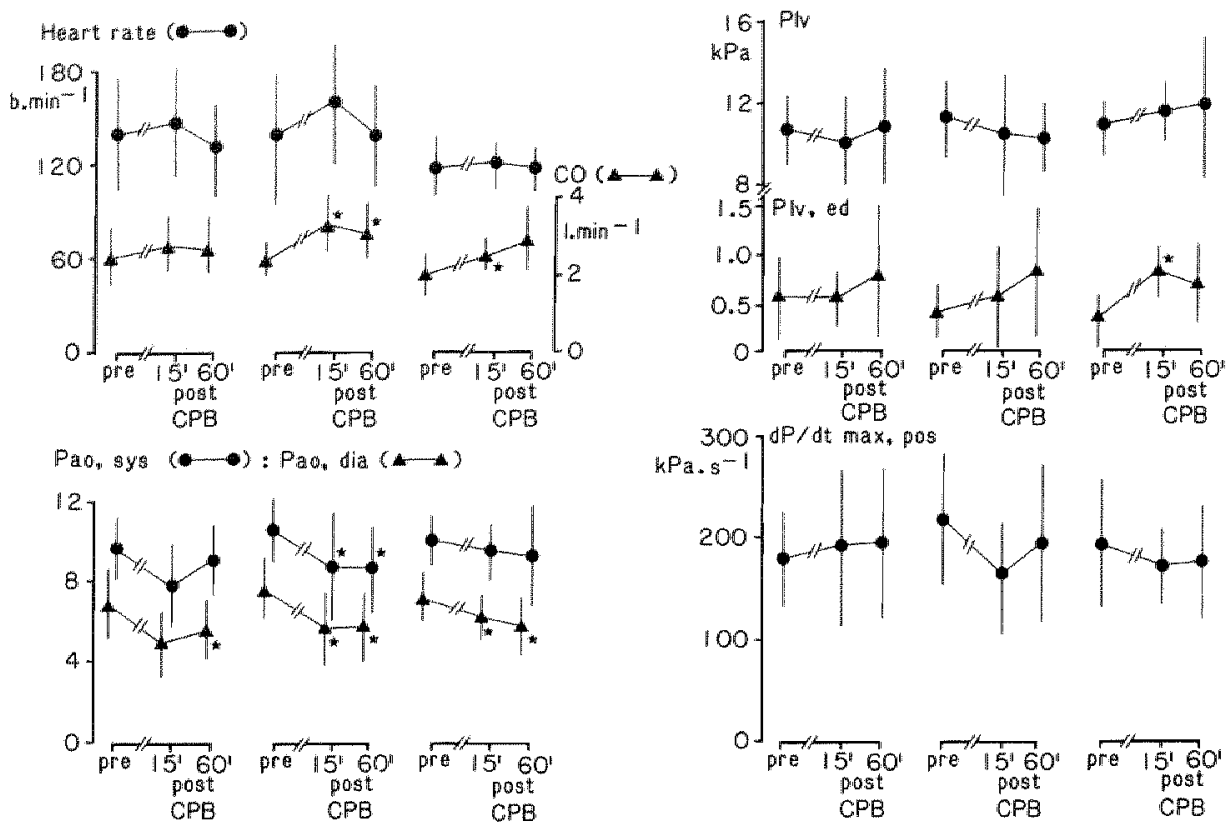

group $N$

group $\mathrm{H} \quad$ group $\mathrm{C}$

group $N$

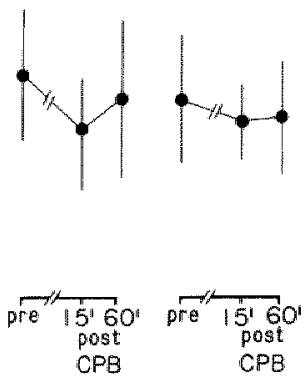

Fig 4.17 Time course of hemodynamic variables before and 15 and 60 min after cardiopulmonary bypass in the groups $\mathrm{N}, \mathrm{H}$ and $\mathrm{C}$. The variables presented are heart rate, cardiac output (CO), systolic (Pao,sys) and diastalic aortic pressure (Pao,dia), left ventricular pressure (PIv), left ventricular end-diastolic pressure $(P T w, e d)$ and the positive first derivative of $P I W$ (dPlw/dtmax,pos). Mean values and SD are presented. * = significantly different from the pre CPB values $(p<0.05)$. 
to those as measured in the groups mentioned abowe (appendix 4). The significant decrease in Pao, sys in group HPLV (mean Paosys decreased fron $10.8 \mathrm{kPa}$ before $C P B$ to $7.1 \mathrm{kPa} 120 \mathrm{~min}$ after CPB) was mainly caused by the different policy in fluid administration after cessation of CPB, necessary to determine the apparent disappearence constant rate and the plasma volume. In group CoN, in which all instrumentation was employed but CPB was excluded, PIv significantly decreased which may indicate the influence of instrumentation and experimental procedure on the hemodynamic stability of the preparation, although the other variables did not change significantly.

\subsubsection{Myacardial blood flow}

Coronary artery blood flow was measured continuously during the experiments, using an electromagnetic flow probe placed around the LAICA. Infomation about transmural distribution of blood flow was obtained from radioactive microspheres.

The myocardial blood flow values were similar in the groups $N$, $H$ and $C$ during the pre CPB period (fig 4.18). After weaning from CPB significantly higher flows were measured in the groups $N, H$ and $C$ as compared to the pre $C P B$ values for a substantial period of time.

In all groups coronary artery blood flow increased to the same extent after the start of CPB, both under empty beating and fibrillating conditions. Release of the aortic cross-clamp resulted in a reactive hyperemia response in all three groups. In the groups $N$ and $H$ this response tended to be less pronounced after the release of succeeding aortic cross-clampings as compared to the first release. This was indicated by the diminished peak reactive hyperemia (group $\mathrm{N}$ ), and the more rapid fall to the control values (oroups $\mathrm{N}$ and $H$ ). A pronounced reactive hyperemia response was observed after release of the cross-clamping in group $C$, reaching higher peak values $(1.90 \pm 0.40$ ml.min ${ }^{-1} \cdot g^{-1}$, and lasting longer than in the groups $M$ and $H$.

The subendo to subepicardial blood flow ratios in the left ventricle are sumenarized in table 4.8 . This ratio did not change in group $\mathbb{N}$ and group $C$, but decreased significantly in group $H$ after reperfusion, indicating relative underperfusion of the subendocardial layers at that moment. The subenda to subepicardial blood flow ratios in the groups NC, HC and CON did not change 
Coronary artery bhood flow
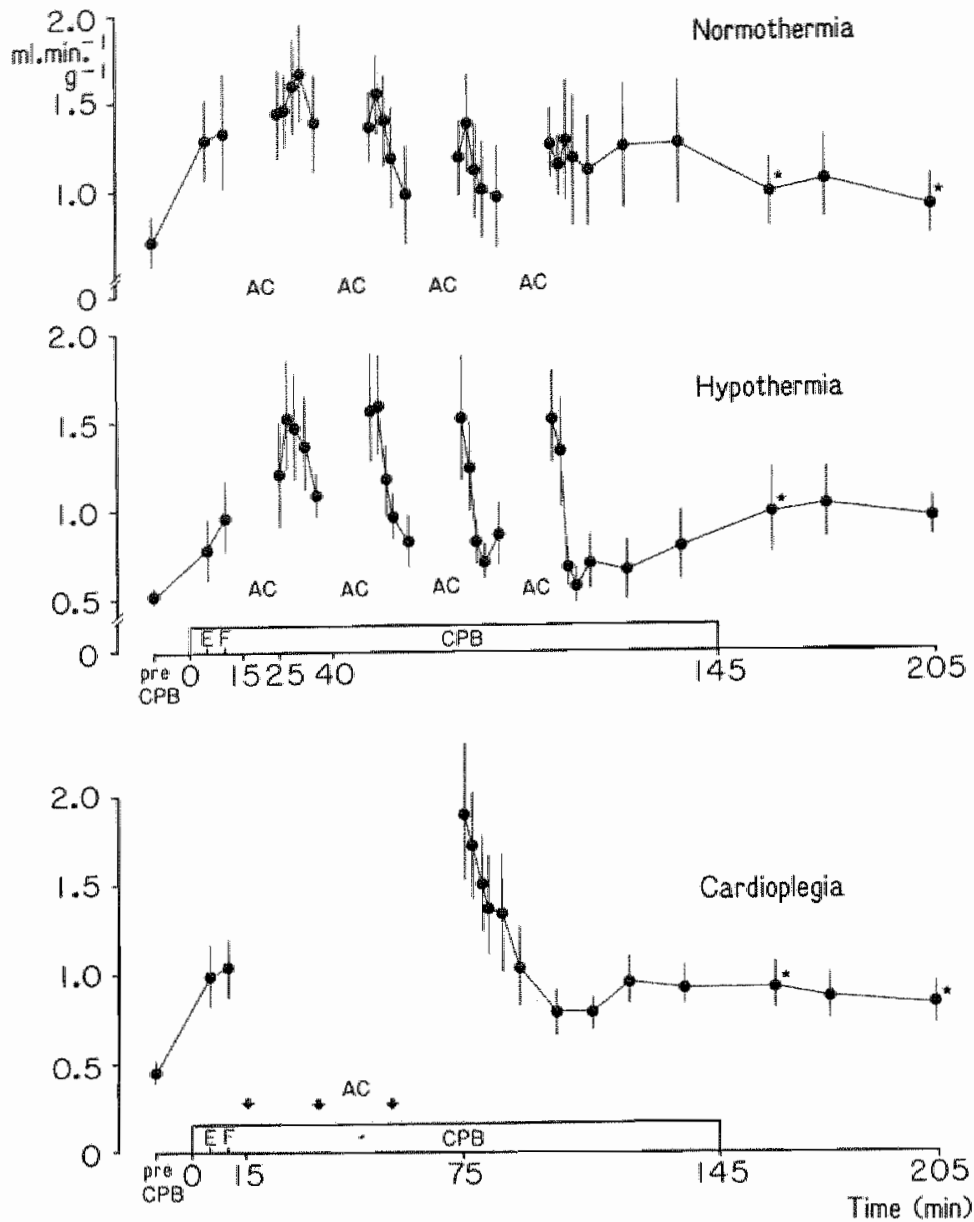

Fig 4.18 Coronary artery blood flow of the groups $N, H$ and $C$. Mean values and SEM (m). mit $\left.n^{-1} \cdot \mathrm{g}^{-1}\right)$ are presented. $A C=$ aortic cross-clamping, CPB = cardiopulnonary bypass, $E=$ empty beating, $F=$ fibrillating. * = significantiy different from pre CpB values $(p<0.05)$. 
Table 4.8 Subendo to subepicardial coronary blood flow ratios in the left ventricular free wall in the groups $\mathrm{N}, \mathrm{H}, \mathrm{C}, \mathrm{NC}, \mathrm{HC}$ and CON. Mean values and SD are presented.

\section{Group}

\begin{tabular}{|c|c|c|c|c|c|c|}
\hline Time & $N$ & $H$ & $\mathrm{C}$ & NC & $\mathrm{HC}$ & $\mathrm{CON}$ \\
\hline pre $C P B$ & $1.13 \pm 0.18$ & $1.11 \pm 0.17$ & $1.05 \pm 0.15$ & $1.27 \pm 0.63$ & $1.10 \pm 0.21$ & $1.04 \pm 0.23$ \\
\hline $\begin{array}{l}15 \mathrm{~min} \\
\text { post } \mathrm{CPB}\end{array}$ & $1.03 \pm 0.25$ & $0.82 \pm 0.26^{*}$ & $1.04 \pm 0.37$ & $1.09 \pm 0.25$ & $0.98 \pm 0.45$ & $0.95 \pm 0.12$ \\
\hline $\begin{array}{l}60 \text { min } \\
\text { post CPB }\end{array}$ & $1.12 \pm 0.25$ & $0.89 \pm 0.29$ & $0.98 \pm 0.16^{\star}$ & $1.06 \pm 0.35$ & $0.98 \pm 0.24$ & $0.88 \pm 0.28$ \\
\hline
\end{tabular}

* = significantly different from pre CPB values $(p<0.05)$.

Table 4.9 Epicardial ( $e_{\text {max }}$ ) and endacardial (e endo,est) fiber shortening before and 15 and 60 min after CPB. Mean values and SD are presented.

\begin{tabular}{|c|c|c|c|}
\hline Group & Time & $e_{\max }(\%)$ & endo, est $(\phi)$ \\
\hline \multirow{2}{*}{$\begin{array}{l}n=7) \\
(n=7)\end{array}$} & pre $C P B$ & $8.8 \pm 4.2$ & $9.3 \pm 4.9$ \\
\hline & $\begin{array}{l}\text { post cpis } \\
15 \text { min } \\
60 \mathrm{~min}\end{array}$ & $\begin{array}{r}9.4 \pm 6.5 \\
10.5 \pm 7.0\end{array}$ & $\begin{array}{l}6.2 \pm 6.4 \\
9.6 \pm 12.4\end{array}$ \\
\hline \multirow{2}{*}{$\begin{array}{l}H \\
(n=4)\end{array}$} & pre $\mathrm{CPB}$ & $7.3 \pm 10.6$ & $5.5 \pm 19.8$ \\
\hline & $\begin{array}{l}\text { post CPB } \\
15 \mathrm{~min} \\
60 \mathrm{~min}\end{array}$ & $\begin{array}{l}7.2 \pm 3.8 \\
7.8 \pm 2.8\end{array}$ & $\begin{array}{l}4.6 \pm 7.7 \\
7.0 \pm 4.7\end{array}$ \\
\hline \multirow{2}{*}{$\begin{array}{l}c \\
(n=0)\end{array}$} & pre $C P B$ & $8.9 \pm 3.2$ & $5.2 \pm 4.5$ \\
\hline & $\begin{array}{l}\text { post CPB } \\
15 \text { min } \\
60 \text { min }\end{array}$ & $\begin{array}{l}10.3 \pm 3.6 \\
11.8 \pm 3.9\end{array}$ & $\begin{array}{l}7.5 \pm 5.7 \\
9.5 \pm 5.9\end{array}$ \\
\hline
\end{tabular}


significantly during the experimental procedure.

More detalls about the myocandial blood flow measurements in all groups are presented in appendix 6 .

\subsubsection{Myocardial mechanical performance}

The measured values of subepicardial fiber shortening $\left(e_{\text {max }}\right)$ and the estimated values of subendocardial fiber shortening (e endo,est) for the groups $H, H$ and $C$ are presented in table 4.9 .

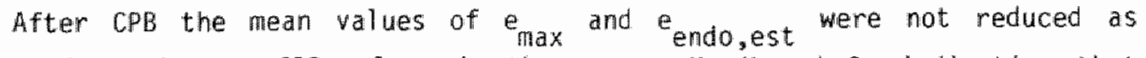
campared to the pre CPB walues in the groups $\mathbb{N}_{\text {, } H}$ and $C$, indicating that regional fiber shortening was not impaired in these groups. In group $C$, $e_{\text {max }}$ was even significantly increased 60 min after CPB.

However, the large variation within each group might implicate regionally impaired fiber shortening, both before and after CPB. Depressed values were noticed in some dogs in all three groups, especially with respect to endo,est. The abnomal positioning of the dog on his back, may have affected the technique of measurement and certaimly limits the area of the coils attached at the epicardium to a small part of the left ventricular free wall just above one of the papillary musciles.

\subsubsection{Biochemical analysis}

4.2.5.1. Release and uptake of lactate, inorganic phosphate and potassium, and uptake of oxygen

\section{- Lactate}

Fig 4.19 shows the A-CS differences of lactate for the groups $N, H$ and $C$. Before and after CPB, no major differences could be detected between the three groups. Before CPE lactate was taken up by the heart in all groups, but after the start of CPB lactate was released in the groups $\mathbb{N}$ and $C$, and to a llesser extent in group $H$. In the groups $N$ and $H$ during the reperfusion periods following the release of aortic cross-clamping lactate was initially 
released, but lactate was taken up again within 10 min. The peak release values at 0.5 min after the start of the first reperfusion period were comparable in group $N$ and group $H$, but this peak value significantly decreased in group $H$ during the succeeding reperfusion periods. In group $C$ only minor A-CS differences of lactate were found immediately after reperfusion. The calculated walues of lactate uptake or release (fig 4.20 ) show that changes in coronary artery bilood flow did not substantially affect the qualitative patterns of A-CS differences before and after CPB. However, during CPB the quantity of lactate released was more prominent in group N. Yet during the initial phase of reperfusion the peak values in group $H$ remained constant during the four reperfusion periods, which is at variance with the A-CS differences.

\section{- Imorganic phosphate}

The A-CS differences of inorganic phosphate are shown in fig 4.21 . At the sample times before and 60 min after $C P B$ these differences were not significantly different from zero, but immediately after the start of CPB the venous concentration tended to increase. Five min later the values were nomialized. Release of inorganic phosphate was observed within the first min after release of the aortic cross-clamp in all groups. In group the mean peak value was about -1.00 mmol. $1^{-1}$, whereas the mean peak value in group $H$ and group $c$ was on the average -0.40 and -0.06 mmo $1.1^{-1}$, respectively. Only in group $H$ the peck walue during the first reperfusion period was significantly higher than the peak values in the subsequent reperfusion periods. Positive A-CS differences were measured within 4 min after the start of reperfusion in all instances, indicating extraction of inorganic phosphate from the blood.

Calculated values of net inorganic phosphate uptake and release ifig 4.22) show that during the initial phase of reperfusion the differences between group $N$ and group $H$ were comparable to the differences observed on the basis of the A-CS differences alone. The average peak value within 0.5 min after release of aortic cross-clarmping was -1.30 unol. $\mathrm{g}^{-1}$. min $^{-1}$ in group $H,-0.50$ unol. $g^{-1}$. min $n^{-1}$ in group $H$, but anly -0.12 umol. $\mathrm{g}^{-1} \cdot \mathrm{min}^{-1}$ in group $c$. After 5 to $10 \mathrm{~min}$ of reperfusion the uptake of inorganic phosphate was quantitatively higher in group $N$. In all groups considerable amounts of inorganic phosphate were taken up by the heart during the prolonged reperfusion phase 
Arterial-coronary simus dif prence
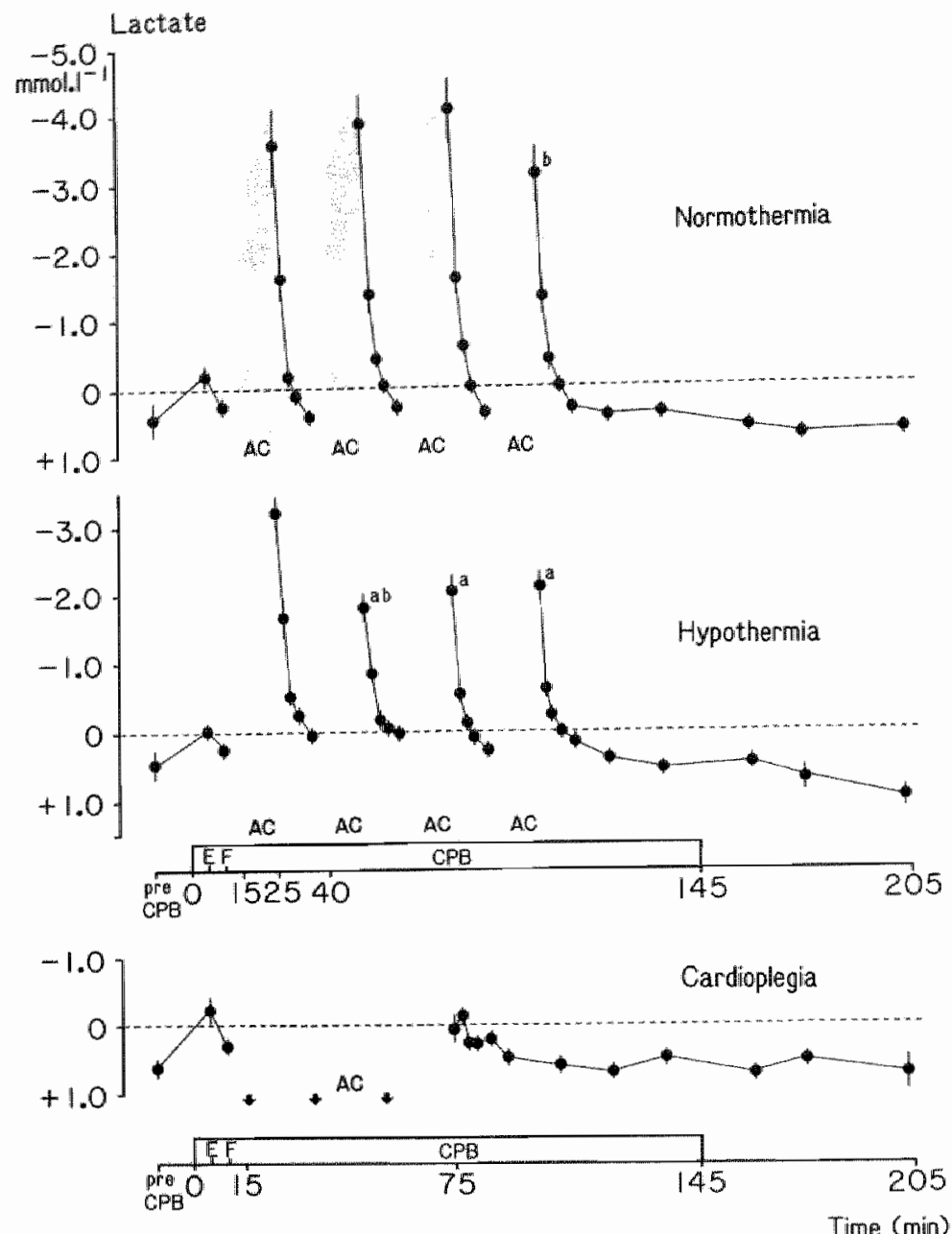

Fig 4.19 Arterlal-coronary sinus difference of lactate in the three dog groups with aortic cross-glamping (N, $H$ and $C H$. Mean wal ves and $S D$ are presented in mol. $1^{-1}$. Negative values of $A-C S$ differences correspond to washout of lactate into coronary sinus blood. CPB = cardiopulmonary bypass, $A C=$ aortic cross-clamping, $E=$ empty beating. $F=$ fibrillating heart. $a=$ peak value different from the first peak value $(p<0.05)$, $b=$ peak value different from the preceding peak value $(p<0.05), c=$ peak value diffierent from the second peak value $(p<0.05), d=$ wallue different from the pre CPB value $(p<0.05)$. 

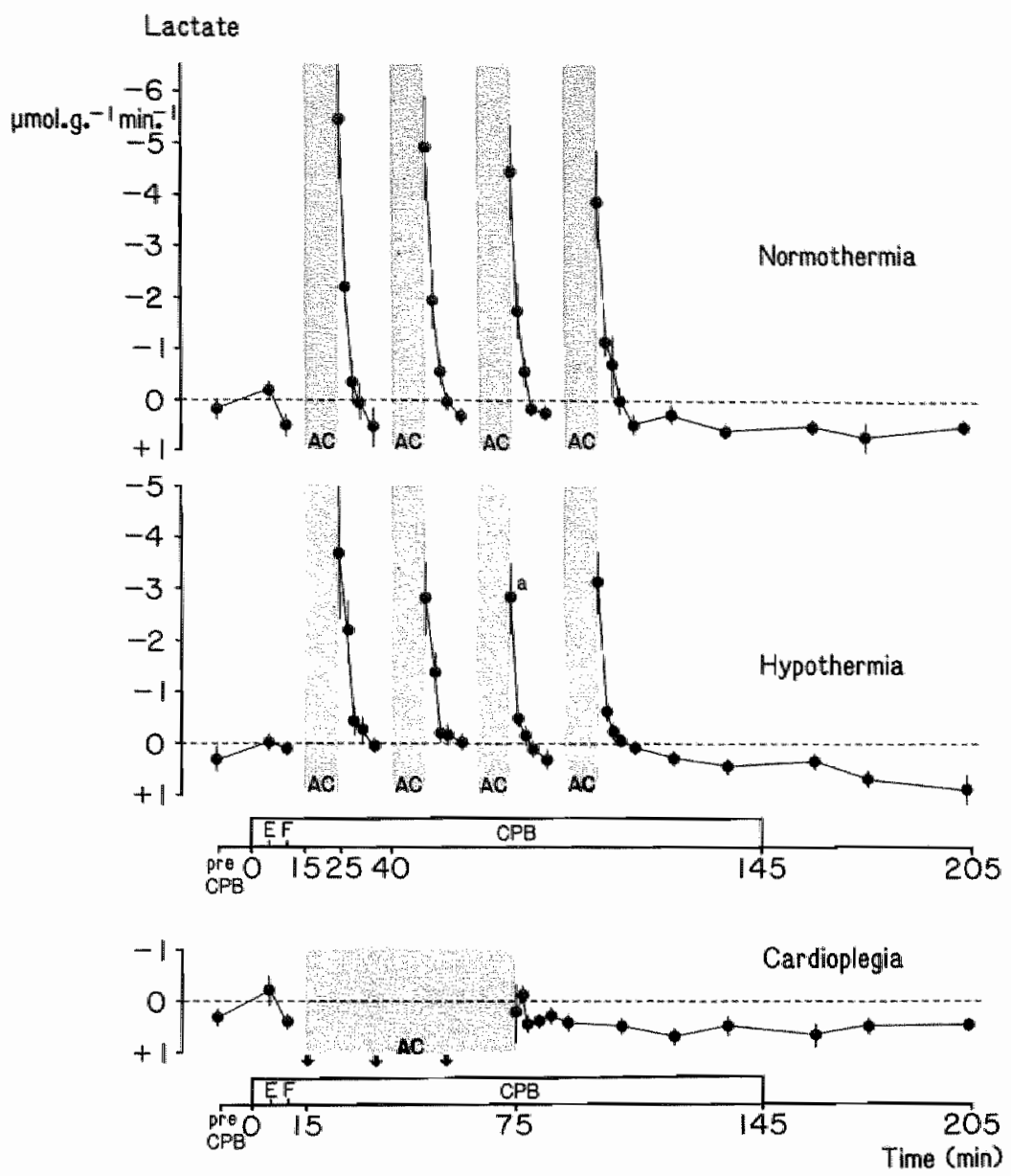

Fig 4.20 Uptake/release values of Tactate $\left(\mu \mathrm{mol} \cdot \mathrm{g}^{-1} \cdot \mathrm{min}^{-1}\right)$. For explanation see legend to fig 4.19 . 
Arterial-coronary sinus difference Inorganic phosphate

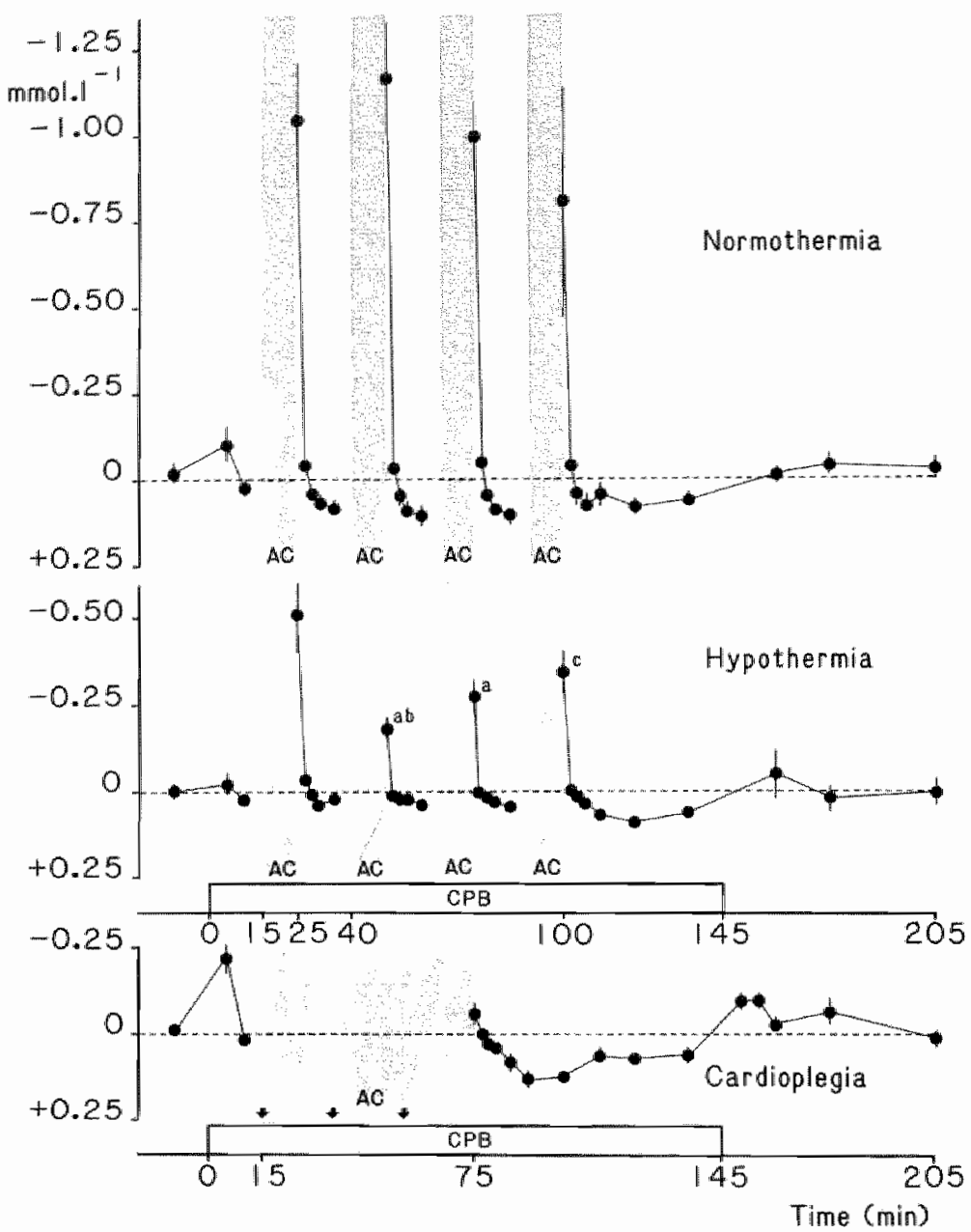

Fig 4.21 Arterial-coronary sinus difference of inorganic phosphate $\left(\right.$ monol. $\left.1^{-1}\right)$. For explanation see legend to fig 4.19 . 
inorganic phosphate

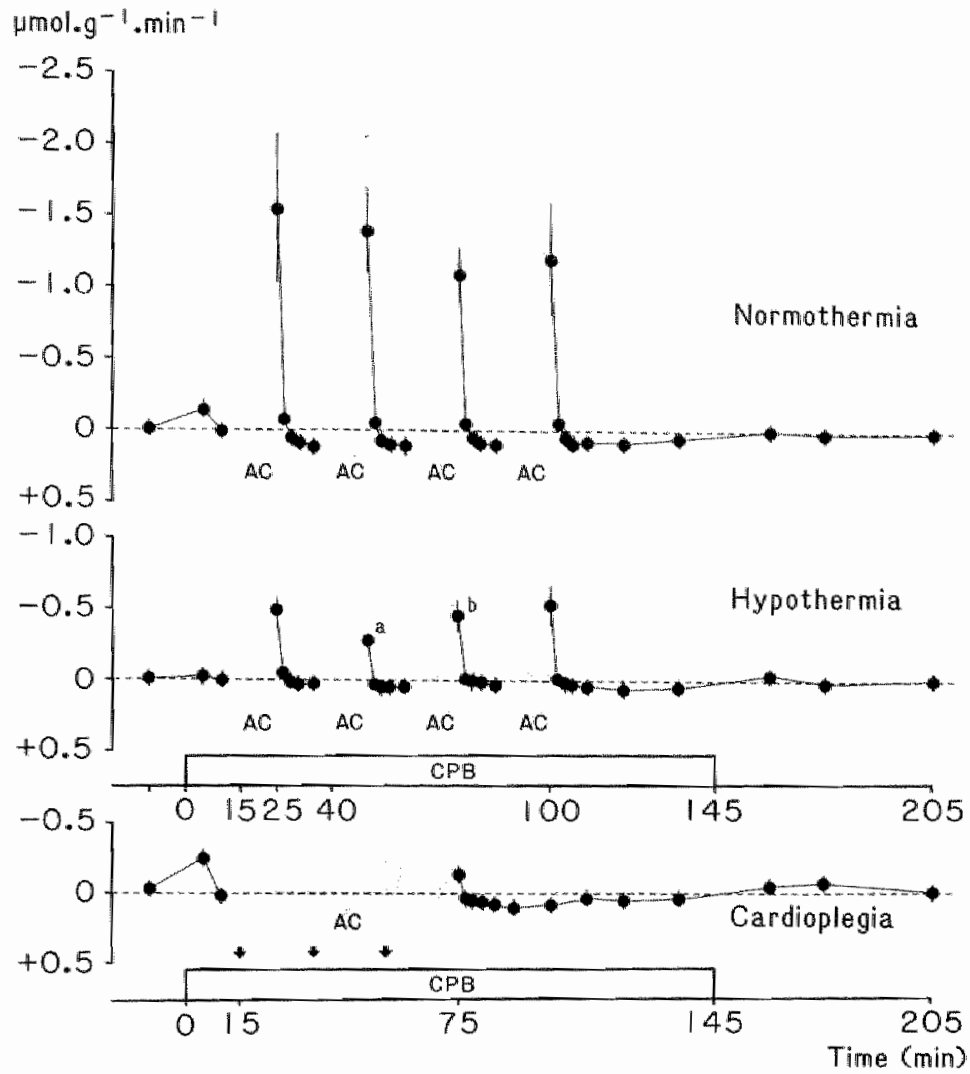

Fig 4.22 Uptake/release values of inorgantic phosphate (umol. $9^{-1}$. min $^{-1}$ ). For explanation see legend to fig 4.19. 


\section{Arterial-coronery sinus difference}

\section{Potassium}
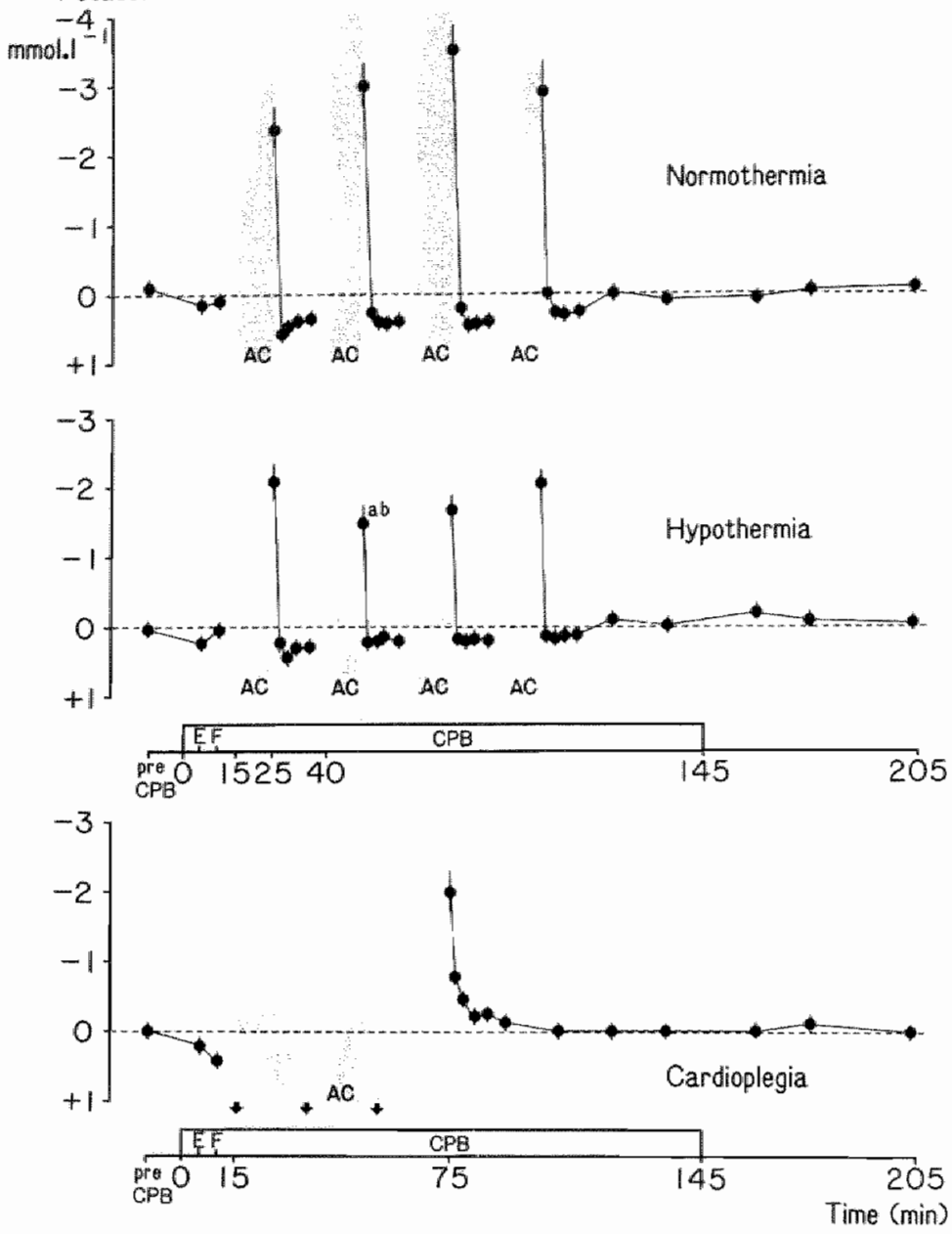

Fig 4.23 Arterial-coronary sinus difference of potassium (monol. $1^{-1}$ ). For explanation see legend to fig 4.19. 


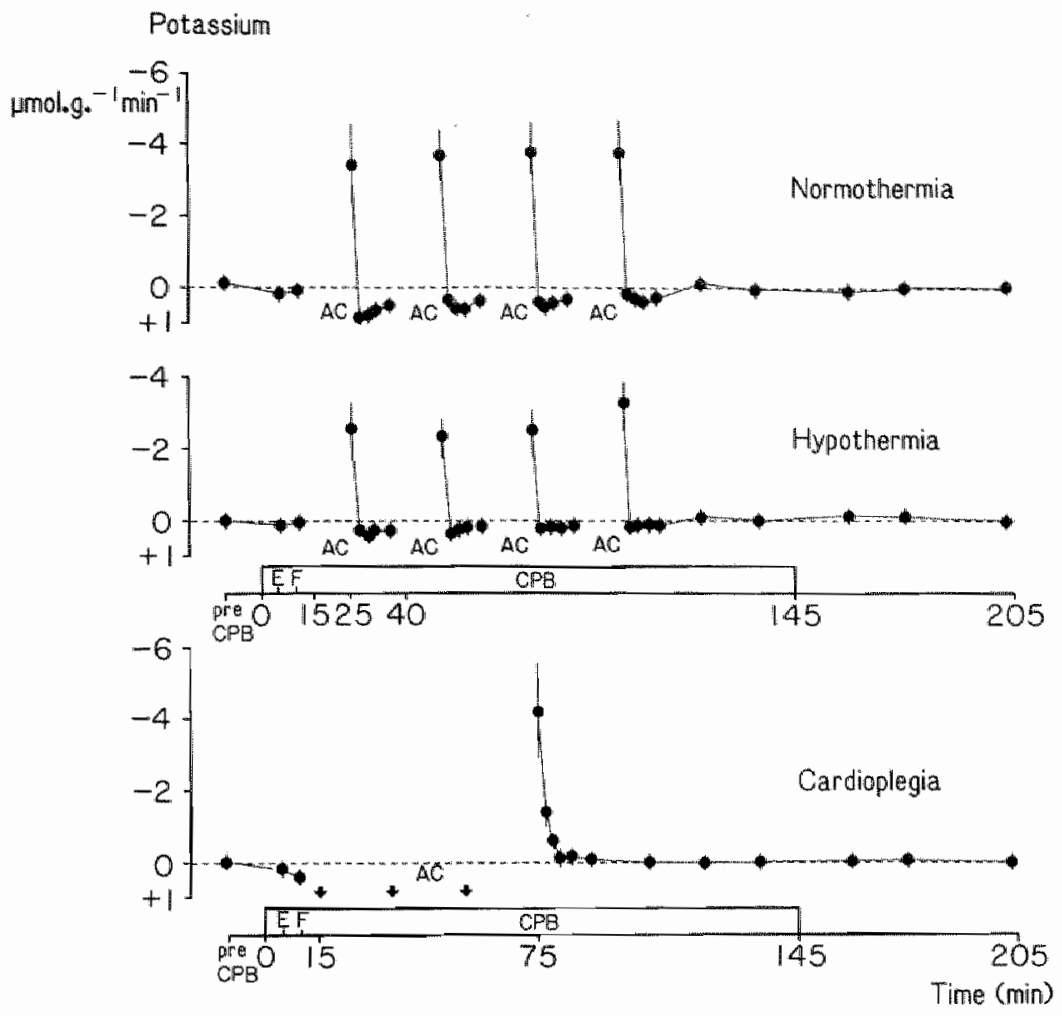

Fig 4.24 Uptake/release values of potassium (umol. $\left.g^{-1} . m i n^{-1}\right)$. For explanation see legend to fig 4.19 . 
Arterial-coronary sinus difference

Oxygen coment
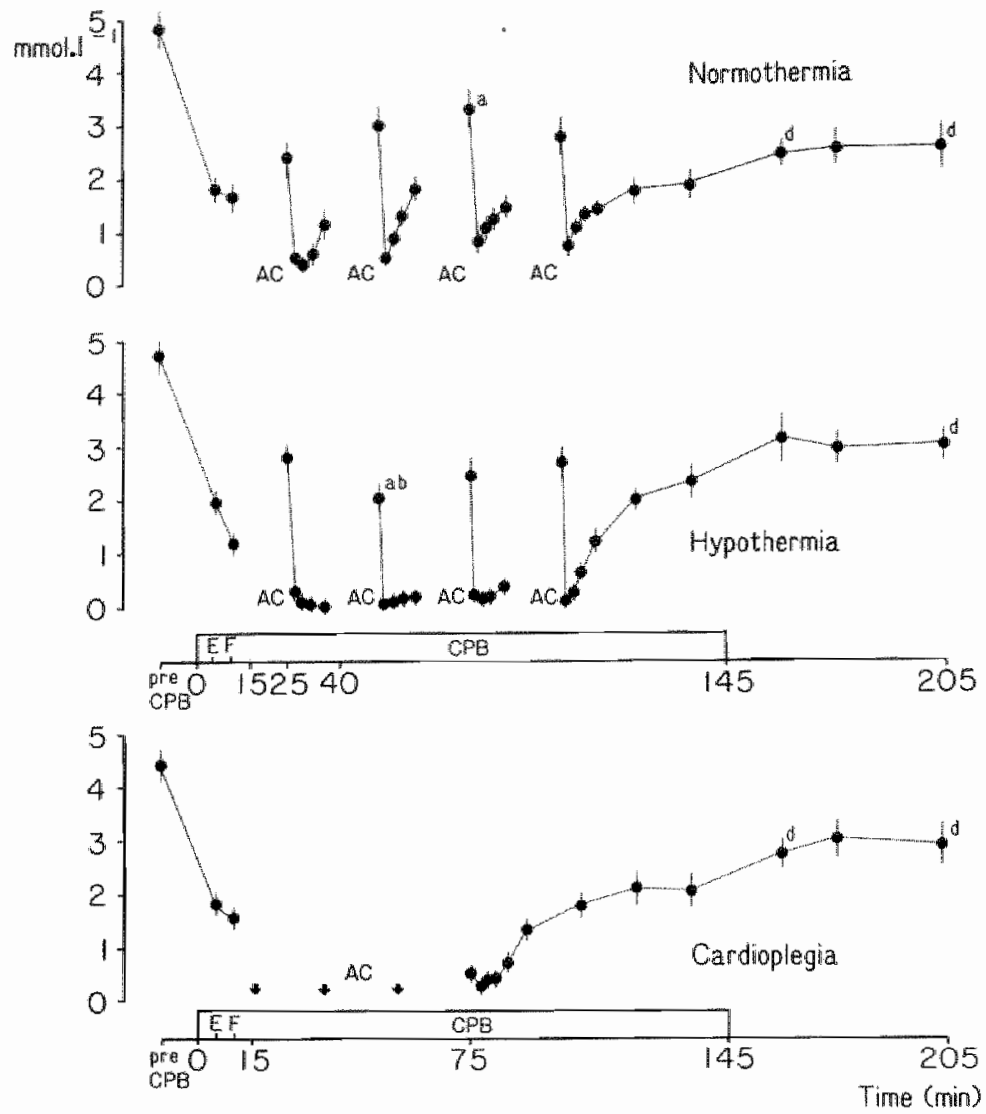

Fig 4.25 Arterial-coronary sinus difference of the oxygen content (mmol. $1^{-1}$ ). For explanation see legend to fig 4.19 . 


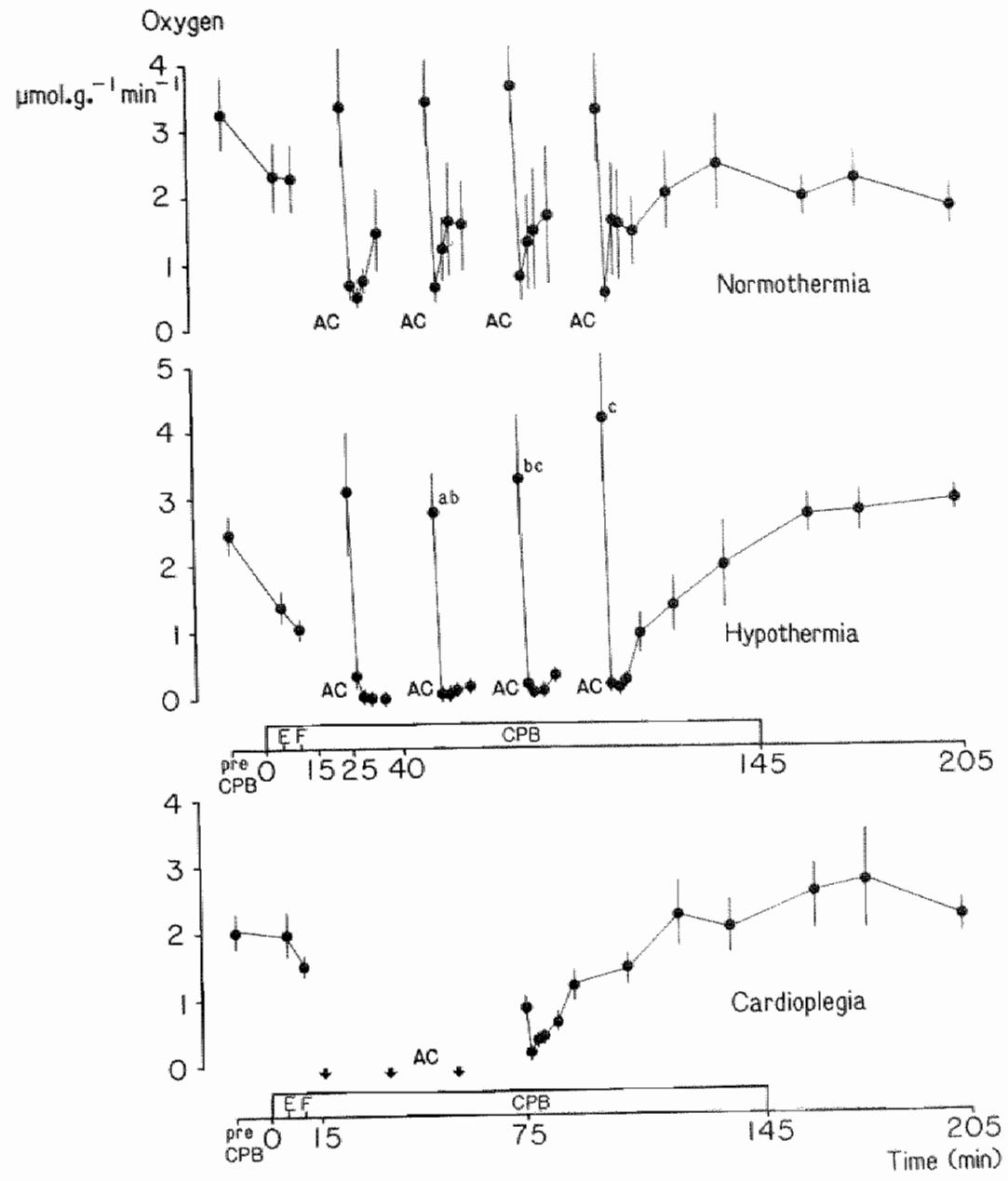

Fig 4.26 Uptake values of oxygen (uno $1 . g^{-1}$.min $\left.{ }^{-1}\right)$. For explanation see legend to fig 4.19 . 
arter the last aortic cross-clamp $\left(2.2\right.$ to 5.0 wmol. $9^{-1}$ wet weight). Values at 60 min after CPB were not dfferent from zero, as was the case in the pre CPB period.

\section{- Potassium}

At most instances before and after CPB only minor A-CS differences were found for potassium, but after the start of CPB at all instances potassum was axtracted from the blood (fig 4.23). During reperfusion after release of aortic cross-clamping considerable A-Cs differences were observed in all three groups. In group N the mean peak A-CS difference of potassium varied from -2.35 to -3.51 mol. $1^{-1}$, indicating release of this ion. Within 2 min this release was followed by uptake of potassium. In group $H$ potassium was also released initialiy as indicated by the mean peak value A-CS difference, ranging from -1.52 to -2.12 mmol. $1^{-1}$. This release was rapidly followed by uptake during the reperfusion period. In contrast, in group C negative $A-C S$ differences of potassium, with a mean peak value of -2.01 mol.1 ${ }^{-1}$, was continued for a longer period of time, indicating sustained washout of this 1on. Calculation of the quantitative release and uptake of potassium confirmed the observations on A-CS differences (fig 4.24). The peak release walues during the repetitive reperfuston periods were higher in group $N$ than in growp H. The intial values during each reperfusion period were similar in group $N$ and in group $H$, respectively. The uptake of potassium from 2 to 10

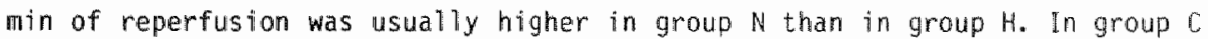
the sustained release of potassiun most likely results from the preceding infusion with the potassium containing cardioplegic solution i.e. 16 momo $\left.1.1^{-1}\right)$.

\section{- oxygen content}

The mean A-CS differences of oxygen content varied between 4 and 5 mol $.1^{-1}$ before CPB and were found to wary around 3 mol. $1^{-1}$ after CPB in the groups $N$, $H$ and $C$ (fig 4.25). Immediately after the start of CPB, the A-CS differences of oxygen were about 2 nno $1.1^{-1}$ with a tendency to further decrease during ventricular fibrillation in group II and group $C$. During the immediate reperfusion phase, the peak values of A-CS differences increased significantly in the groups $N$ and $H$. In contrast, this initial high value of 
A-CS difference of oxygen was not observed in the cardioplegila group (fig 4.25 lawer panel). In group $N$ the initial peak in AuCS difference was followed by transient low A-CS differences, which increased again later during reperfusion, reaching values between 1 and 2 malnol. $1^{-1}$ after 10 min. In contrast, in group $H$ the A-CS differences of oxygen content remained low following the initial peak (below 0.5 mol. $1^{-1}$ ). However, following rewarming after the last aortic cross-clamping, a rapid increase in the A-CS difference was observed in this group. This increase was found to be delayed in group $C$ (fig 4.25 lower pannel).

Calculated values of oxygen uptake are presented in fig 4.26. Although the pre CPB values were higher in group $N$ than in group $C$, the mean values of axygen uptake after $C P B$ were not significantly different in all three groups (ranging from 2 to $3 \mu \mathrm{mo} \cdot \mathrm{g}^{-1} \cdot \mathrm{min}^{-1}$ ). After the start of extracorporeal circulation the mean values of oxygen uptake decreased in group $N$ and group H, but only during fibrillation in group $C$. Within the first 30 seconds of a11 meperfusion periods high values of oxygem uptake were measured in group $N$ and group $\mathrm{H}$. Thereafter oxygen uptake remained at a low level in group $\mathrm{H}$, but after a transient fall increased again in group $N$. Upon rewarming in group $H$ (after 100 min of $\mathrm{CPB}$ ) and in group $C$ (after 75 min of $C P B$ ) comparable patterns were observed as far as increase in oxygen uptake is concerned.

\subsubsection{Tissue content of retabolic substances}

Myocardial transmural tissue biopsies were routinely abtained in groups $N$, $H$ and $C$ at 60 min after $C P B$ and in group $C$ also at three intervals during CPB. In two different groups of animals (NB and $H B$ ), comparable with the nomothermic and hypothermic intermittent cross-clanip groups $\mathrm{N}$ and $\mathrm{H}$, respectively, multiple biopsies before the first cross-clamping, and at the end of each cross-clanping and each reperfusion period were obtained. For statistical analysis the results as obtained in comparable groups (groups $N$ and NB as mormothermia group, and groups $H$ and $H B$ as hypotherinia group) were combined. The data on ATP, creatine phosphate, inorganic phosphate, glycogen and lactate is shown in the figs $4.27,4.28,4.29,4.30$ and 4.31 , respectively. The first biopsy, taken when the heart was enpty beating, was considered as the control or preischemic value. 
Tissue content

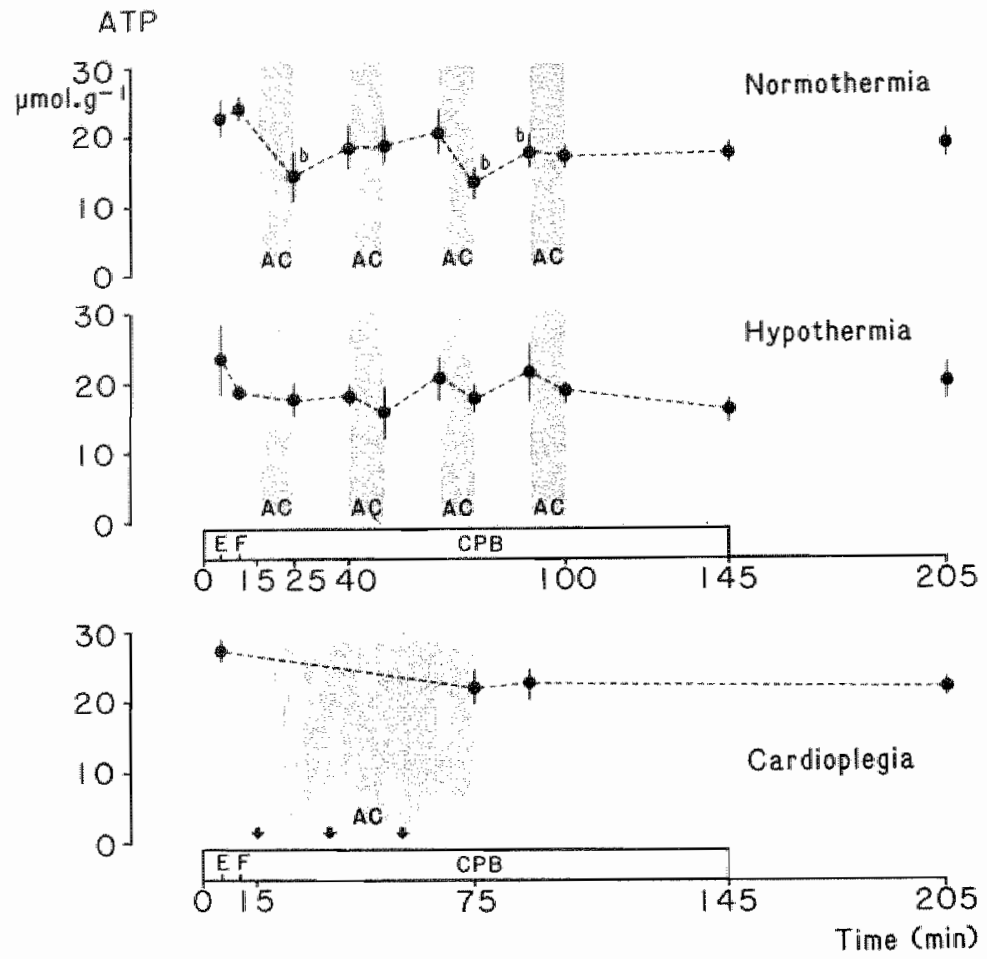

Fig 4.27 Content of ATP in myocardial biopsies obtatned during and 60 min after $C P B$. Mean values and SD are presented (umol.g $g^{-1}$ dry weight). The single observations in the Nomothemia and Hypothermia groups after CPB refer to the groups $N$ and $H$.

$A C=$ aort $1 C$ cros $5-C$ lamping, $C P B=$ cardiopulmanary bypass, $E=$ empty beating, $F=$ fibrillating. $a=$ significantiy different from the corresponding vallue in the other two graups $(p<0.05), b=$ significantly different fron the preceding value within the same group $(p<0.05), c=$ significantly different from the control value obtained during empty beating (E) $(p<0.05)$. 
Tissue content

Creatine phosphate
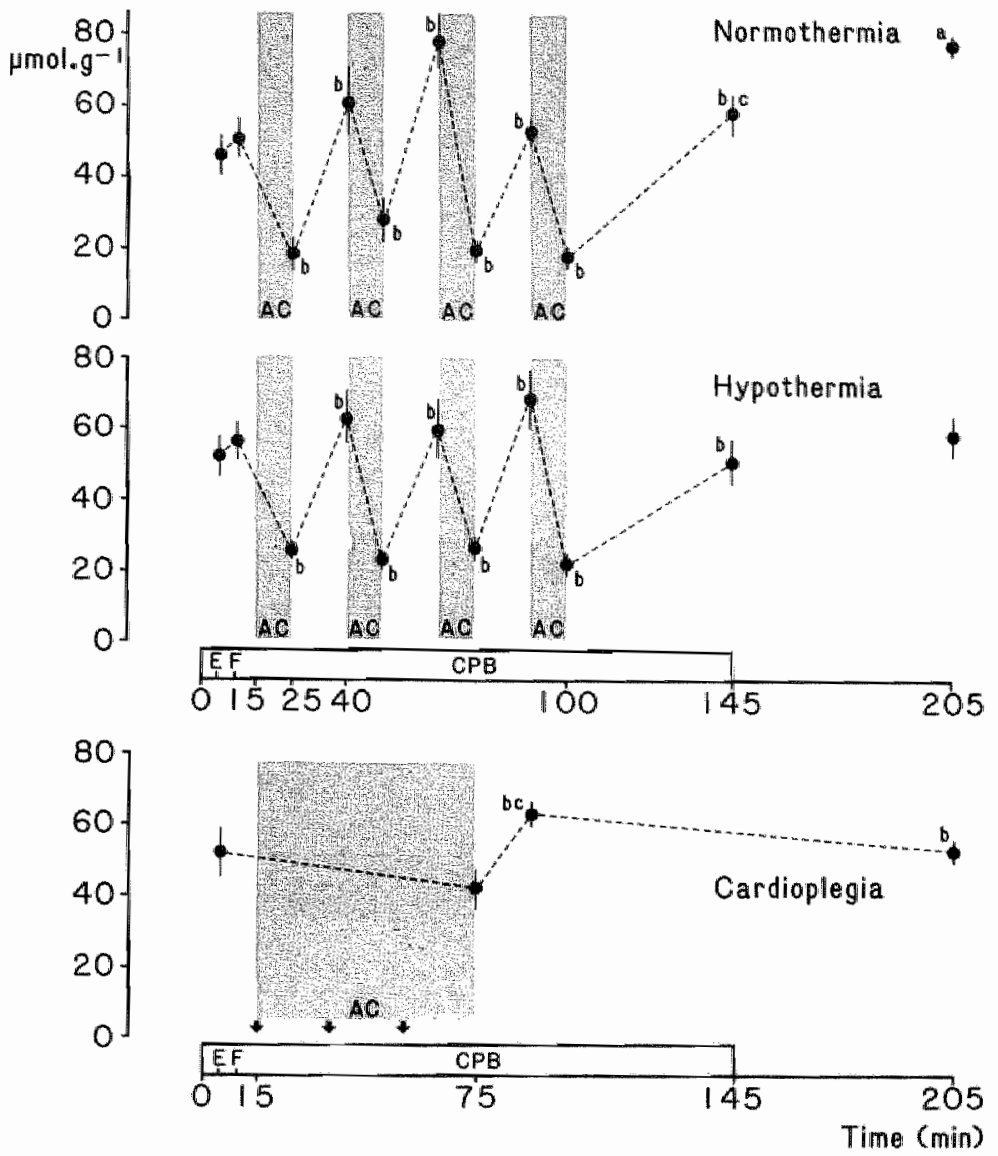

Fig 4.28 Content of creatine phosphate in myocardial biopsies. Mean values and SD are presented ( $\mu$ mol. $g^{-1}$ dry weight). For explanation see legend to fig 4.27 . 
Tissue content

Inorganic phosphate
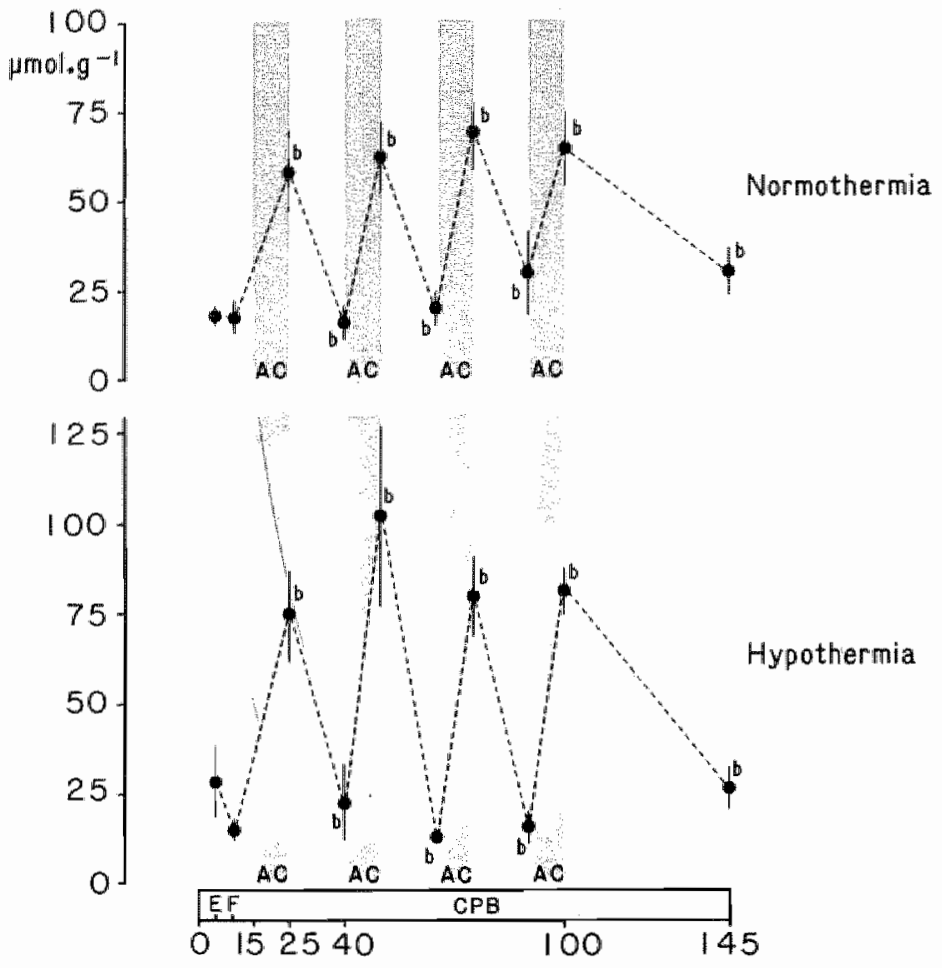

$\left.\begin{array}{c}50 \\ 25 \\ 0\end{array}\right]$

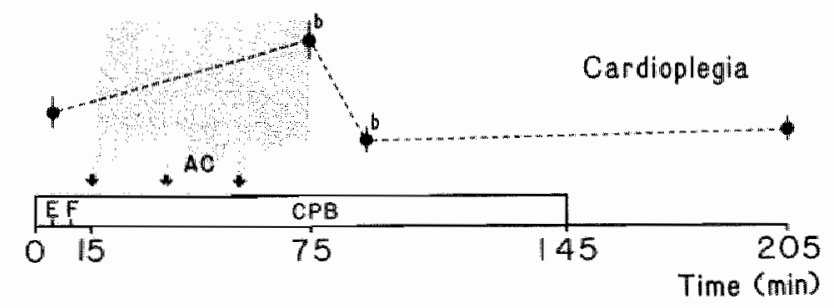

Fig 4.29 Content of inorganic phosphate in myocardial biopsies. Mean values and SD are presented. ( $\mu$ mol $\mathrm{gg}^{-1}$ dry weight). For explanation see legend to fig 4.27 . 
Tissue content

Glycogen
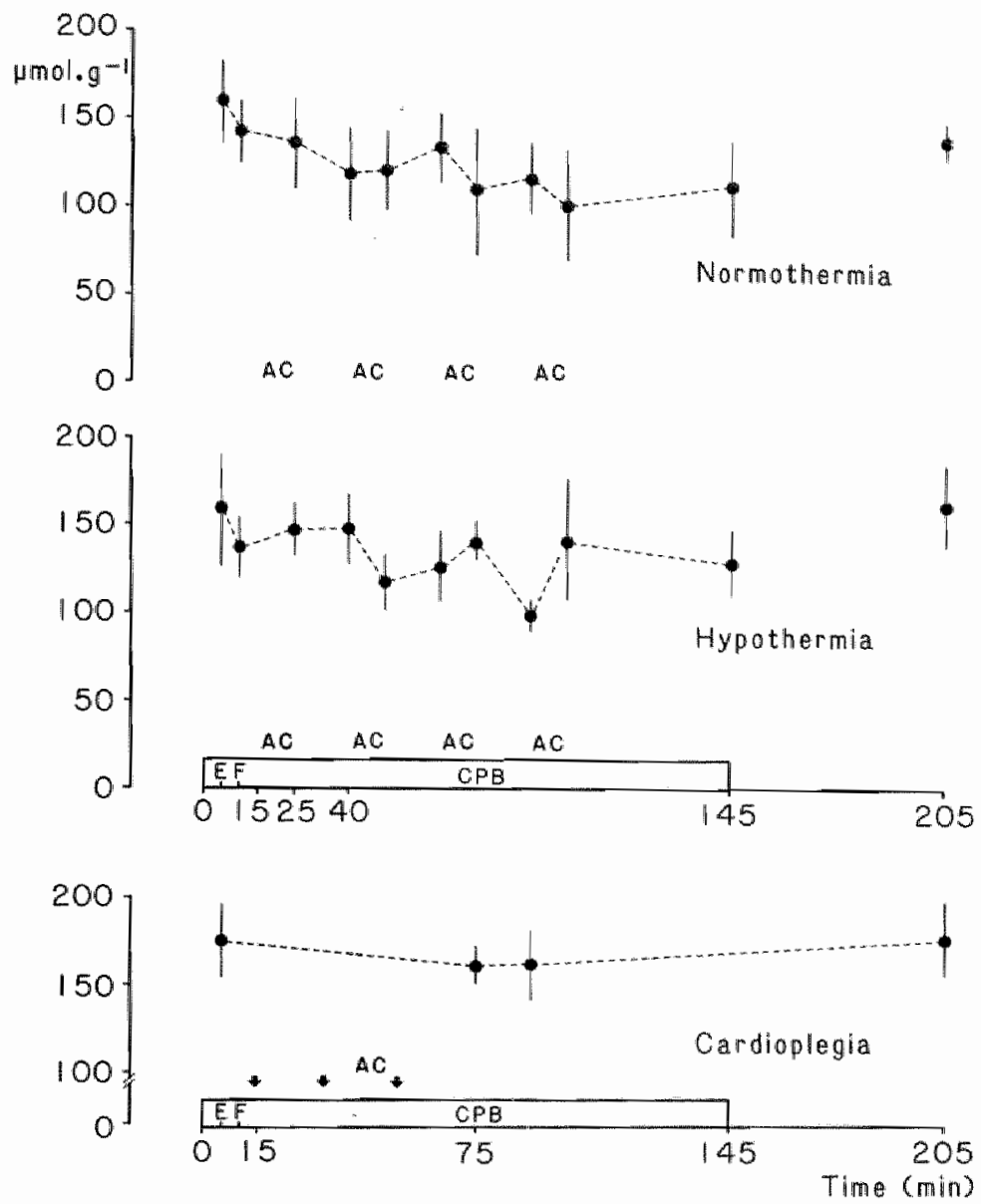

Fig 4.30 Content of glycogen in myocardial biopsies. Mean values and SD are presented ( $\mu$ mol glucose moieties. $g^{-1}$ dry weight). For explaniation see legend to fig 4.27 . 
Tissue content
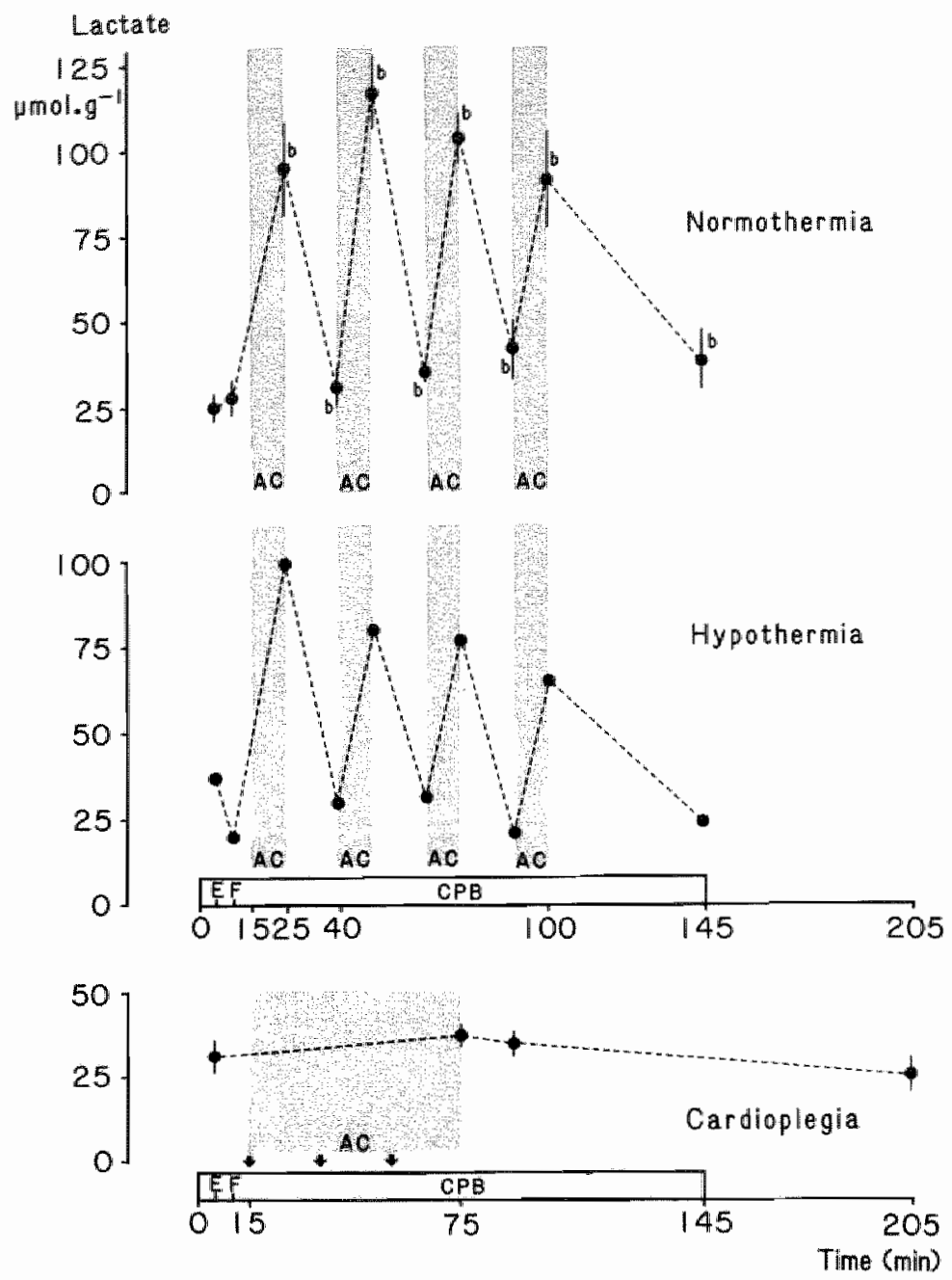

Fig 4.31 Content of lactate in myocardial biopsies. Mean values and 50 are presented (umol. $g^{-1}$ dry wellght). For explanation see legend to fig 4.27. Each value in the hypothermia group refers to two measurements. 
- ATP

In group NB, the ATP content at the end of the first and third ischemic period was significantly lower than the value measured at the end of the preceding nomoxic periad, but the changes observed in the groupis $A B$ and $C$ were not significant (fig 4.27). The ATP content of the biopsies obtained at the end of the experiment, following a 60 min recovery period, was not significantiy different between the three groups.

\section{- Creatine phosphate}

The creatine phosphate content of biopsies decreased significantly in the normothermia group and the hypothermia group after each period of ischemia, and returned to or exceeded the control values after $15 \mathrm{~min}$ of reperfusion (fig 4.28). The pattern of changes in creatine phosphate content was uniform during the succeeding periods of reperfusion. In group $C$ lower values were observed at the end of ischemia, but this decrease did not reach the levell of significance. In this group significantly increased levels of creatine phosphate were found within 15 min of reperfusion.

The creatine phosphate content in the final biopsies, taken 60 min after $C P B$, were comparable to the control values in the hypothermila groups and cardioplegia group, but higher values were found in the normothermia groups amounting to $170 \%$ of the control value. Differences in creatine phosphate content between preischemic (before aortic cross-clamping) and postischemic (just prior to the end of cardiopulmonary bypass) biopsies were found in the groups $N B$ and $C$, but no significant differences were observed in group $H B$.

\section{-. Inorganic phosphate}

The inorganic phosphate content of myocardial biopsies is shown in fig 4.29 for the groups $N, H, C, N B$ and $H B$. The content of inorganic phosphate was significantly increased after each ischemic period of 10 min in group NB and $H B$, and after 60 min of ischemia in group $C$. The increase was most outspoken in the group HB (ranging from 61 to 81 umol. $\mathrm{g}^{-1}$ d.w. after the various cross-clamp periods) and group NB (ranging from 37 to 51 umol.g ${ }^{-1} \mathrm{~d}$. W*) but much less in group $C$ (maximal increase 20 umol. $\mathrm{g}^{-1} \mathrm{~d}$.w.). Restoration to the preischemic (control) levels of inorganic phosphate readily accured in a11 three groups within 15 min of reperfusion. 


\section{- Glycogen}

The glycogen content in the myocardial biopsies was detemined as glucose moletfes and the results are shown in fig 4.30 . The data shows that the maximuli decrease was observed after the fourth aortic cross-clamping in the group $M B$, where the glycogen content had decreased to $74 \%$ of the initial preischemic values. In group $H B$ the maximum decrease to $63 \%$ was observed after the third reperfusion period. Otherwitse inconsistent changes were seen during the periods of ischemia and reperfusion. The analysis of the values at the end of CPB as compared to the preischemic glycogen content did not show a significant decrease.

\section{- Lactate}

Data on myocardial lactate content in the normothermia, hypothermia and cardioplegia groups is shown in fig 4.31 . This substance was measured in a 1 imited number of biopsies of the group $H B$ for technical reasons, and as a result no statistical analysis were performed. Before ischemia the myocardial lactate content was low (mean values varying from 25 to 37 unol.g $\mathrm{g}^{-1} \mathrm{~d} . \mathrm{w}$.) in all groups, but remarkably increased after each period of aortic cross-clamping in group $N B$ and group $H B$ (mean increase ranging from 65 to $117 \mu$ mol. $\mathrm{g}^{-1}$ d.w.). After 15 min of reperfusion the lactate content decreased to low values in both groups with intermittent aortic cross-clamping. The myocardial lactate content at the end of CPB was not different from the preischemic levels in both the group $A B$ and group HB. In the group $C$ no significant differences from the control values were observed throughout the experiment.

\subsubsection{Hemodynamic and biochemical changes during the initial period of cardioputmonary bypass}

Since several investigators (Hottenrott et al, 1974; Vinas et al, 1979) have suggested that the heart is very succeptible to damage during the in:tial extracorporeal perfusion phase, especially during ventricular fibrillation, we have investigated this particular phase in more detail. During this period, lasting in the average $15 \mathrm{~min}$, CPB had completely replaced the normal circulation. 
About 5 min after the start of CPB, when the heart was vented through the apex, the first set of measurements was performed, referred to as "during the efipty beating state" ("El"). Approximately 5 min later, when systemic cooling in the hypothermia and cardioplegia groups had caused the heart to fibrillate, a second set of measurements during this "fibrillating state" ("F") was performed. In the nomothemia group the heart was still empty beating after CPB had lasted approximately 10 min and the sample interval was designated as "E2"

Table 4.10 sumarizes the functional and biochemical parameters of the heart during the empty beating and fibrillating conditions. For the sake of comparison the wallues abtained before CPB are shown as well. The nomothermia group refers to the combination of the animal groups $N$, NC and NB, and the hypotherilia group refers to the animal groups $H_{3} H C, H B$ and $C$.

The rectal temperature was slightly decreased in both groups at the time of "El', Which confirms that cooling has started only recently. The rectal temperature at the time of " $F$ " indicates progression of cooling im the hypothermia group.

Mean aortic pressure decreased considerably during 'El' and "F" in both groups as compared to the values before CPB. However, differences between the values during ' $E 1$ ', 'E2' and 'FIB' could not be detected. Similar falls in aortic pressures were observed in the patients of groups $H$ and $C$ (section $4.1 .2)$, but no differences between the values obtained during the intial phase of CPB could be detected.

coronary artery blood flow increased considerably in all antmal groups after the start of CPB. Whether this increase in totali blood flow was directed preferentially to the subendo or subepicardial layers of the left ventriculiar free all was investigated in group 4 with the use of radioactively labelled microspheres. The subendo to subeplcandial ratio decreased from $1.11 \pm 0.17$ to $0.48 \pm 0.16$ during 'El', Indicating redistribution of flow towards the epicardial layers under these cimcumstances (mean $\pm 50 ; n=5$ ). During fibrillation this ratio increased to $1.21+0.69$, suggesting that in this condition blood flow is shifted towards the endocardial layers.

The influence of empty beating and fibrillating conditions on myocardial flow resistance appeared to be marked in all groups (table 4.10). In group H myocardial resistance fel from $0.17 \pm 0.06 \mathrm{kpamin.g.m7^{-1 }}$ before cpo to $0.10 \pm$

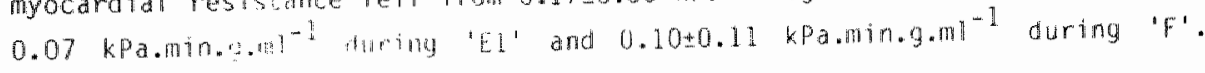


Table 4.10 Functional and biochemical variables in dogs during the initial period of cardiopulmonary bypass in dogs. Mean values and 50 are

\begin{tabular}{|c|c|c|c|}
\hline \multirow{3}{*}{$\begin{array}{l}\text { Group } \\
\text { Time interval } \\
\text { Parameter }\end{array}$} & \multicolumn{3}{|c|}{ Noming thernia } \\
\hline & pre $\mathrm{CPE}$ & 'EI' & ${ }^{\prime} E_{2}$ \\
\hline & & 5 min on $C P B$ & 10 min on CPB \\
\hline $\begin{array}{l}\text { Rectall temperature } \\
\left({ }^{\circ} \mathrm{C}\right)\end{array}$ & $36 \pm 2$ & $36 \pm 1$ & $35 \pm 1$ \\
\hline $\begin{array}{l}\text { Perfusion pressure, } \\
\text { mean aortic pressure ( } \mathrm{kP}\end{array}$ & a) $8.7 \pm 1.7$ & $6.3 \pm 2.0^{9}$ & $6.7 \pm 2.0^{9}$ \\
\hline $\begin{array}{l}\text { Coronary flow } \\
\left.\text { (ml.min }{ }^{-1} \cdot g^{-1}\right)\end{array}$ & $0.66 \pm 0.40$ & $1.12 \pm 0.77^{9}$ & $1.07 \pm 0.87^{9}$ \\
\hline $\begin{array}{l}\text { Myocardial flow } \\
\text { resistance(kPa.min.min }\end{array}$ & $0.17 \pm 0.07$ & $0.08 \pm 0.05^{9}$ & $0.09 \pm 0.049$ \\
\hline \multicolumn{4}{|l|}{ Uptake/Release: } \\
\hline $\begin{array}{l}\left.\text { (umol } \cdot 9^{-1} \cdot \mathrm{min}^{-1}\right) \\
\text { Lactate }\end{array}$ & $0.16 \pm 0.76$ & $-0.18 \pm 0.43$ & $0.49+0.86^{r}$ \\
\hline Inorganic phosphate & $-0.01 \pm 0.06$ & $-0.14 \pm 0.21$ & $0.02 \pm 0.05^{r}$ \\
\hline Potassium & $-0.13 \pm 0.38$ & $0.17 \pm 0.34$ & $0.12 \pm 0.33$ \\
\hline oxygen & $3.26 \pm 2.09$ & $2.31 \pm 1.97^{9}$ & $2.28 \pm 1.92^{9}$ \\
\hline
\end{tabular}

Myocardial content:

(umol. $\mathrm{g}^{-1} \mathrm{dry}$ welight)

ATP

$22 \pm 6$

$24 \pm 5$

Creatine phosphate

$46 \div 12$

$52+11$

Inorgamic phosphate

$19 \pm 5$

$18 \pm 7$

alycogem

$160+56$

$143+40$

Lactate

$25+9$

$28 \pm 12$

$q$ significantly different from the pre CPB value $(0<0.05), r=$ significantly different from the value obtained after $5 \mathrm{~min}$ on $C P B(p<0,05)$ * $5=5$ ignificantly different from the corresponding value in the hypothermia groups $(p<0.05)$. 
presented. * = the mean value of two dogs is presented. "E1" and "E2" = empty beating, "F" = fibrillating.

\begin{tabular}{|c|c|c|c|}
\hline \multirow{2}{*}{$\begin{array}{l}\text { Group } \\
\text { Time interval }\end{array}$} & \multicolumn{3}{|c|}{ Hypothermia } \\
\hline & pre CPB & 'EI' & 'F' \\
\hline Parameter & & 5 mim on CPB & 10 min on $C P B$ \\
\hline $\begin{array}{l}\text { Rectal temperature } \\
\left({ }^{\circ} \mathrm{C}\right)\end{array}$ & $37 \pm 1$ & $35 \pm 3$ & $31 \pm 3$ \\
\hline $\begin{array}{l}\text { Perfusion pressure, } \\
\text { mean aortic pressure }\end{array}$ & $8.5 \pm 1.5$ & $6.4 \pm 2.1^{9}$ & $6.1 \pm 1.6^{9}$ \\
\hline coronary flow & $0.52+0.18$ & $0.85 \pm 0.45^{9}$ & $0.92 \pm 0.53^{9}$ \\
\hline $\begin{array}{l}\text { Myocardial flow } \\
\text { resistance }\end{array}$ & $0.17 \pm 0.06$ & $0.10 \pm 0.07 \mathrm{q}$ & $0.10 \pm 0.11^{9}$ \\
\hline Uptake/Release: & & & \\
\hline Lactate & $0.29 \pm 0.62$ & $-0.01 \pm 0.36$ & $0.09 \pm 0.20$ \\
\hline Imorganic phosphate & $0.00 \pm 0.03$ & $-0.02 \pm 0.05$ & $0.01 \pm 0.04$ \\
\hline potassium & $0.02 \pm 0.13$ & $0.11 \pm 0.18$ & $0.05 \pm 0.26$ \\
\hline oxygen & $2.43 \pm 1.07$ & $1.38 \pm 0.78^{9}$ & $1.04 \pm 0.59^{9}$ \\
\hline Myocardial comtent: & & & \\
\hline ATP & - & $23 \pm 11$ & $19 \pm 2$ \\
\hline Creatine phosphate & - & $52 \pm 13$ & $57 \pm 12$ \\
\hline Inorganic phosphate & - & $29+22$ & $14 \pm 4$ \\
\hline Glycogen & - & $158 \pm 78$ & $136 \pm 38$ \\
\hline Laclates & - & $37 *$ & $19^{*}$ \\
\hline
\end{tabular}


These values were not different from those measured in the group $\mathbb{N}$.

The uptake of lactate as abserved before CPB decreased considerably in both groups, resulting in an average net release of lactate in group $\mathbb{H}_{\text {. Five }}$ min later this release was reversed again significantly in uptake of lactate. The uptake/release of inorganic phosphate did not alter significantly after Instalment of $\mathrm{CPB}$, but in the normothemia group an initial release was restored to control vallues within 5 min ("E2").

potassium was not significantly extracted from or released by the heart, neither before CPB nor during the initial period of CPB.

As a consequence of reduced work load and decreased temperature "the axygen uptake was significantly reduced in group H. Evaluation of differences in oxygen consumption, if any, due to the shift from empty beating to fibrilllation cowld not be performed because blood temperature of the heart changed as well. In group $N$, prolonged empty beating did not sigmificantly affect axygen uptake.

Biochemical analysis of myocardial biopsies revealed only minor differences between ' $E 1$ ', 'E2' and ' $F$ '.

\subsubsection{Enzyme release}

In the dog experiments plasma samples for enzyme activity were routimely obtained before, during, upto and including one hour after cessation of CPB. To illustrate the course of changes during the experiments in the groups $N, H$ and $C$ the results of AST measurements are shown in fig 4.32. Immediately after the start of CPB the meam values were decreased in all groups as a result of dilution of the blood with the priming solution. During CPB the AST activity gradually increased in all groups. This trend was accentuated after CPB. It should be noted, however, that after CPB the total circulating plasma volunte was considerably increased, so that enzyme release may be underestimated.

The slope of the curves indicate that even 60 min after CPB sustained release of AST into the plasma can be observed and the maximum values have not been reached. At the last sample point no significant differenices in total AST plasma actiwity could be detected between the three groups.

The data of AST, creatine kinase, MDH, ALT, $H B D H$, free hemoglobin and 


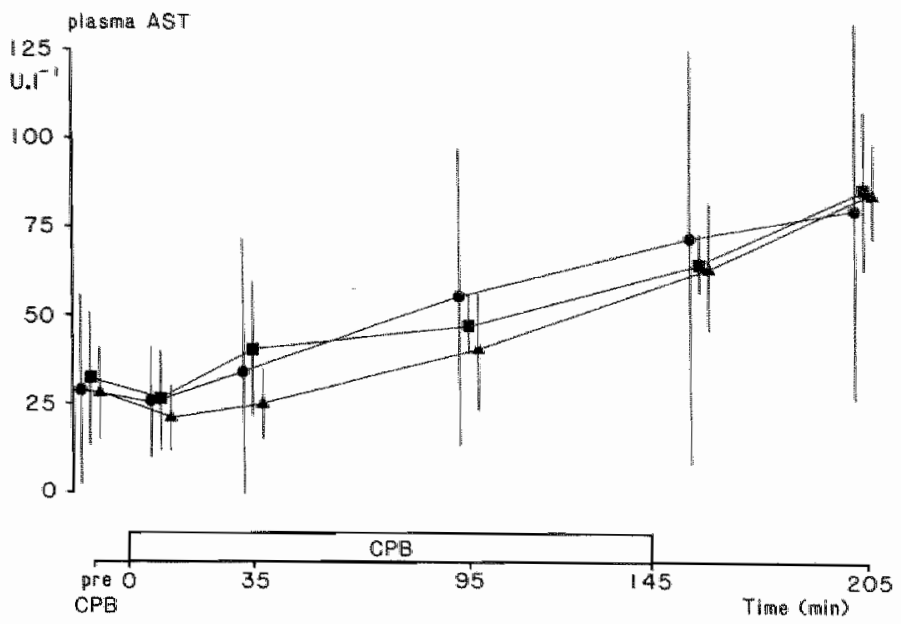

FHg 4.32 Plasma enzyme activity of AST as measured in group $N(\mathbf{0})$, group $H$ (-) and group C ( $\Delta$ ). Mean values and SD $\left(U .1^{-1}\right)$ are presented. CPB = cardioputmonary bypass.

Table 4.11 Calculated enzyme release from 15 to $60 \mathrm{~min}$ after weaning from CPB. Mean values and SEM are presented, and expressed as units released per hour.

Enzyme

Group

\begin{tabular}{|c|c|c|c|c|c|c|c|}
\hline & $\begin{array}{c}n=8) \\
(n=8)\end{array}$ & $(n=9)$ & $\begin{array}{c}C \\
(n=8)\end{array}$ & $\begin{array}{c}N C \\
(n=9)\end{array}$ & $\begin{array}{c}\text { HC } \\
(n=8)\end{array}$ & $\begin{array}{c}\text { CON } \\
(n=8)\end{array}$ & $\begin{array}{c}E C \\
(n=5)\end{array}$ \\
\hline AST & $30 \pm 11$ & $12 \pm 2$ & $31 \pm 5^{1}$ & $24 \pm 8$ & $22 \pm 7$ & $11 \pm 7$ & $20 \pm 15$ \\
\hline$C K$ & $503 \pm 119^{2}$ & $541+110^{2,3}$ & $476 \pm 95^{2} \cdot 3$ & $682 \pm 239^{3}$ & $722 \pm 116^{2,3}$ & $184 \pm 86$ & $80 \pm 7$ \\
\hline
\end{tabular}

$1=$ diffeçent from group $H$ and $\operatorname{CON}(p<0.05), 2=$ different from group CON $(p<0.05), 3=$ different from group EC $(p<0.05)$. 
hematocrit are shown in appendix 13 for all groups of animals. Comparison of the groups $N$, H and $C$ shows that the free hemoglobin content was higher in group $c$ than in the other two groups. Beside the initial decrease in plasma AST activity (see above), no marked changes were observed during the first 35 min of CPB. Therefore plasma emzyme activity increased at the end of CP: except for RLT. During that period the total volume of blood within the intravascular space and the oxygenator should be considered when plasma activity is used for quantitative calculations. The gradual increase of enzyme activity is also observed for creatine kinase and MoH at 15 and 60 min after GPB. The pasma enzyme activity for HBDH and the free hemoglobin content increase to a lesser extent after CPB, which is in favor of the idea that the release mainly results from pump-induced danage of red blood celis during $C P B$.

The data as presented in appendix 13 indicates that the enzyme release in group $A C$ and group $H C$ was not different from the groups with aortic crossclanping (1.e. the groups $N, H$ and $C$ ). In contrast, in group CON (without CPB) the release of creatine kinase, $M D H$. HBDH and the formation of free hemoglobin was reduced which indicates the detrimental influence of CPB. In group EC (without cardiac manipulation) reduced release of AST, ALT and creatine kinase was observed, as compared to the groups with CPB (MDH and HBOH activity and free henoglobin content were not measured in group EC). Comparison of the results of group $E C$ and group CON indicates that the increased plasma activity of AST and ALT in group CoN is most likely caused by cardiac manipulation and instrumentation.

From fig 4.32 , it is evident that quantification of enzyme release in the present series of dog experiments can only be perfarmed on a small intercept of the total enzyne release curve, $i$.e. during 60 min after temination of CPB. From the data obtained at the last two tume intervals 115 and 60 min after CPB) the cumulative release can be assessed after correction for enzyme degradation and plasma volume changes (see section 3.2 .9 for full details). This calculation was applied to AST and creatine kimase with the use of formerly obtained specific circulatory paraneters. The cumulative release of these enzymes was also caiculated in the groups $N C, H C$, CON and EC, to analyse the influences, if any, of aortic cross-clamping, CPB and cardiac instrumentation (table 4.11). The data on plasma enzme activity of these groups are summarized in appendix 12 . The releasa of AST was significantly 
higher in the groups $\mathbb{N}$ and $C$, as compared to group $H$. The differences between the groups $\mathrm{N}, \mathrm{H}$ and $\mathrm{C}$ were not statistically significant for creatine kimase. The effect of aortic cross-clamping on enzyne release was evaluated in groups NC and HC. The cumulative release of AST in both groups was not significantly different from that in the corresponding groups with aortic cross-clampling, N and $H$, respectively. However, the creatine kinase release was less in group $H$ than in group $H C$.

For group CON and group EC, in which the animals were not subjected to CPB, the cumulative release of creatine kinase was decreased as compared to the groups with CPB, but this difference was not significant when comparison was made between group CON and group NC.

\subsubsection{Plasma volume}

In group HPLW serial plasma volume measurenents were performed before and after CPB. The experimental protocol in this group was comparable to that in group $H$, including hypothermic $C P B$ and four periods of aortic cross-clamping. In group HPLV the total post CPB recovery period was extended to 120 min. Data on plasma volume was obtained 5 min after the administration of a bolus of AST into the circulation (fig 4.33). The plasma walues calculated are shown in fig 4.34 and indicate that changes in plasma volume after anesthesia and sternotomy were insignificant. Fifteen min after CPB, however, significantly increased plasma volumes, amounting to $150 \%$ of the walues before induction of anesthesia, were measured. During the recovery period piasma volume rapidly nomalized within $90 \mathrm{~min}$ to $110 \%$ of the plasma volumes before anesthesia.

Beside plasiua volume the disappearance rate constant $\left(k_{d}\right)$ of ALT was determined in the same group of animals (HPLV) after CPB, Using an ALT bolus injection (fig 4.35). Analysis of the $k_{d}$ walue for ALT as a measure of the enzyme leakage fron the intravascular space, revealed that $k_{\text {d }}$ had increased to $50 \pm 19 \%$ per hour (mean walue $\pm 5 D ; n=5$ ). This indicates a markedly increased value of $T E R$, from 0.03 to 0.46 , assuming a constant value of FCR equal to 0.04 for ALT. Both the plasma volume changes and the kd value after CPB were used to calculate cumulative release of AST and creatine kinase as reported in section 4.2 .7 . 


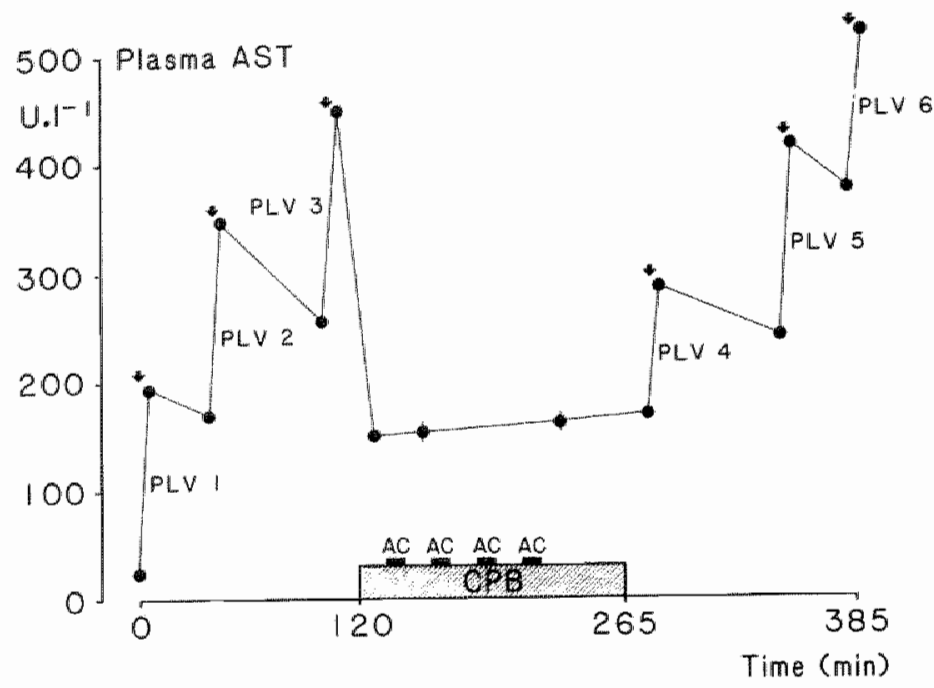

Fig 4.33 Plasma levels of AST used for plasma volume calculation with the use of an AST bolus injection (indicated by an arrow). Mean values are presented $\left.(U .)^{-1}\right)$. The value of PLVI was abtained after induction, PLV2 after sternotomy and PLV3 just prior to CPB. PLV4, PLV5 and PLVG was determined 15,90 and 120 min after weaning from CPB, respectively, $A C=$ aortic cross-clamping, $C P B=$ cardiopulmonary bypass. 


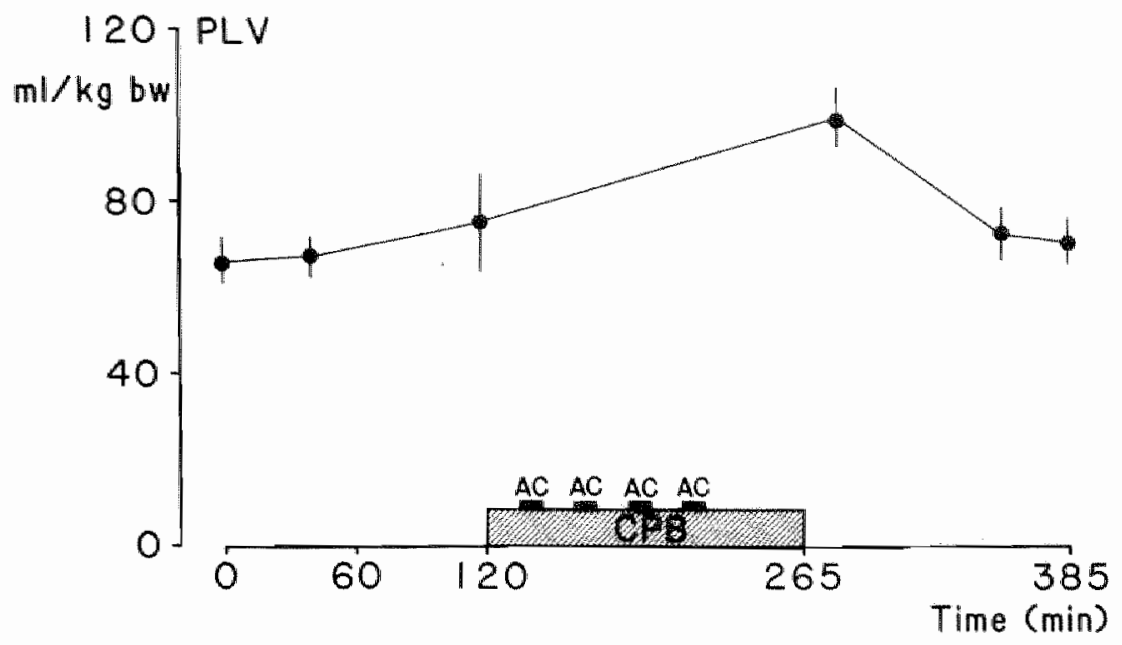

Fig 4.34 Plasma volume (PLV) in dogs before and after cardiopulmonary bypass (CPB) as calculated from the data shown in fig 4.33. Mean values and SEM (m) $1 . \mathrm{kg}^{-1}$ body weight) are presented $(n=5)$.

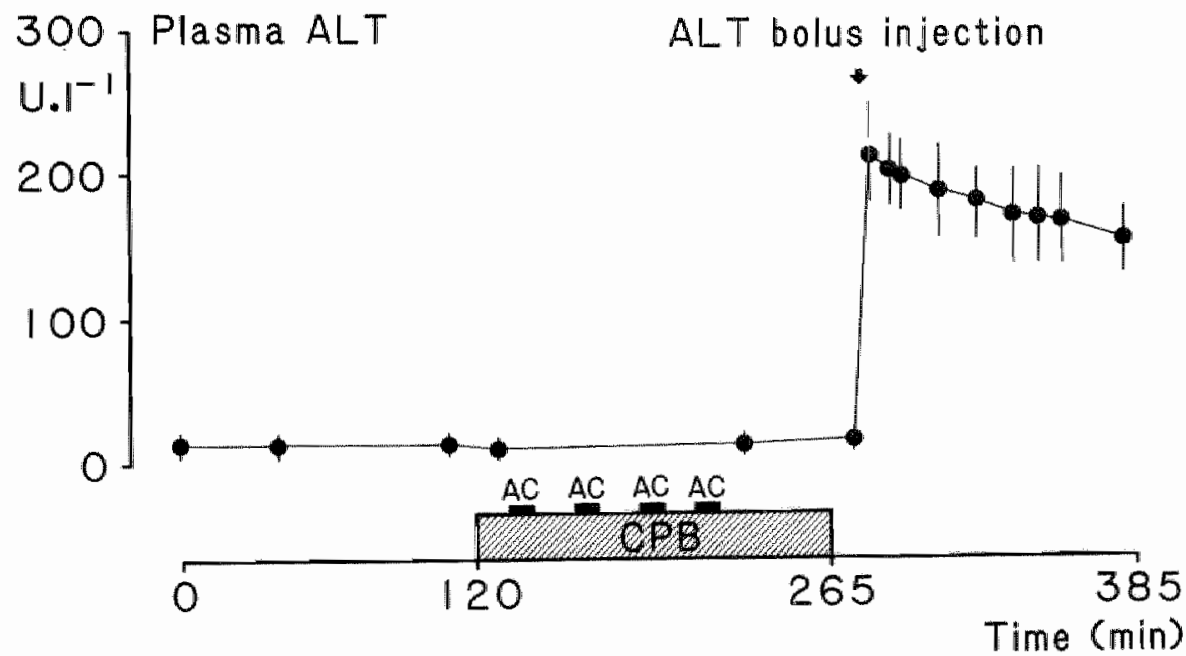

Fig 4.35 Plasma levels of ALT used for $k_{d}$ calculation after an ALT bolus injection. Mean values and $S D\left(U .1^{-1}\right)$ are presented. $A C=$ aortic cross-clamping, $C P B=$ cardiopulmonary bypass. See legend of fig 4.33 . 


\section{5. aIscussion}

In this chapter the results of the clinical and experimental studies will be discussed. In the clinical study the efficacy of the protective measures against ischemia during three different operation techniques, i.e. intermittent aortic cross-clamping at $34^{\circ} \mathrm{C}$ and at $25^{\circ} \mathrm{C}$, and continuous aortic crossclamping in combination with st Thomas hospital cardioplegia, were evaluated.

From the experimental study mome detiled infomation about the significance of some of the variables measured could be obtained. These findings will be discussed in relation to the observations in the clinical study* Besides, topics such as the hemodynamic and biochemical function of the heart during the initial phase of cardiapulmomary bypass (CPB), and the effect of CPB on coronary artery blood flow will be discussed separatelly.

\subsection{General topics}

\section{1 .1 clinical outcome and hemodynamic recovery}

The myocardial pratection affered by the three techniques under investigation resulted in adequate postoperative recovery, a low incidence of inotropic support and an hospital mortality of about $4 \%$ (one patient in each group).

The hemodynamic function as assessed during the 15 minute time interval after cessation of CPB, showed that both left ventricular $d P / d t$ max, pos and stroke work index were depressed in all three groups. The postoperative increase th pulmonary artery wedge pressure observed in the hypothermia and cardioplegia groups should be interpreted with care, because the pulmonary artery wedge pressure was deliberately set at a value between 1.1 and $1.4 \mathrm{kPa}$ by the anesthesiologist at the end of the CPB phase. This level of pulnonary artery wedge pressure was achieved by infusing the content of the heart-lung machine and donor blood into the patient. The increase of cardiac index in all three groups after the operation most likely results from a decreased systemic vascular resistance.

It should be emphazised that the changes in hemodynamic function do not 
solely reflect the influences of the periods of ischemia during aortic crossclamping, but are also caused by the anesthetic policy and the CPB procedure. This is illustrated by the results of the animal study, because henodynamic recovery was not different in the groups with and without aortic cross-clamping (Appendix 4), indicating that the application of global ischenia did not adversely influence systemic hemodymamics after CPB. Yet no significant difference could be detected in subendo and subepicandial fiber shortening in these two experimental groups.

In addition, hemodynamic function during and after CPB can also be imfluenced by humoral factors, such as circulating and locally released catecholamines. The higher perfusion pressure during CPB abserved in the normothermia group may be related to an increase in the plasha level of norepinephrine (Kim et a), 1981), as measured immediately after CPB in this group, as suggested by kim and coworkers (1981). Whether the significantily higher norepinephrine levels in the normothermia group exert a positive effect on left ventricular hemodynamics and thereby masking a more pronounced deletertous effect of the intermittent aortic cross-clamp technique at $34^{\circ} \mathrm{C}$ on post CPB hemodynamic function, remains to be elucidated.

The origin of the postoperative increase in plasma catecholanine levels is not exactly known. The adrenal glands might be involwed, although the involvement of other organs can not be excluced. Mori and coworkers (1983), for instance, propased that myocardial ischemia itself caused an increase in plasma norepinephrine content, whille Reves and colleagues (1984) conctuded that increased catecholamine levels resulted from reperfusion of the heart following ischemia. In our clinical study the highest correlation between the maximum plasma norepinephrine level and the tatal duration of aortic crossclamping was found in the nomothermila group $(r=0.77)$. No such correlation was abserved in the other two groups. The latter observation is in agreement with Engelman and coworkers (1983), who did mot find a correlation between duration of aortic cross-clamping on the one hand and plasma levels of catecholamines on the other in patients submitted to aortocoronary bypass surgery or valve replacement in hypothermic conditioms.

In the clinical study hemodynamic function was deternined during a relatively short postoperative period of 15 minutes after CPB. The rationale was to assess early hemodynamic recovery and to exclude the influence of various interventions routinely epplied postoperatively at the intensive care unit. 
because in principal no medication was given during the initial period after CPB. This does not imply that the condition immediately after the surgical intervention is representative of the situation after one or two days. Several studies report a changed hemodynamic function imnediately after the operation, and a return to preoperative conditions within two days (Levinsky et 1 1, 1979; Roberts et a1, 1981; Jalonen et a1, 1981c).

In conclusion, hemodynamic function immediately after CPB was changed in all patient groups, but no major differences between the groups could be observed. It is likely that myocardial ischemia as induced during the surgical pracedure, is mot the sole cause of the reduced values of parameters related to cardiac contractility lleft ventricular $\mathrm{dP} / \mathrm{dt}$ max, pas and stroke work index), but that the anesthetic policy, CPB procedures and humoral factors should be considered as well.

\subsubsection{Biochemical variables in arterial blood}

\section{- Lactate}

The gradual increase of serum lactate concentration in the three patient groups under investigation indicates that the patients were not stable from a metabolic point of view. This confirms the findings of 01 in and coworkers (1981). Since no differences were observed between the nomothermia group and the two other groups, we might conclude that the metabolic instability is not directly related to body temperature during CPB. Theoretically, an increased production of this metabolite, most. likely in skeletal muscle, or a reduced degradation, for instance, in the 1 iver and the heart, might occur.

A similar phenomenon was observed in dogs subjected to CPB. Since the increase of serum lactate was less prominent in the dogs not subjected to $C P B$, the imbalance between lactate production and degradation is partly induced by extracorporeal circulation.

- Inarganic phosphate

With respect to inorganic phosphate the arterial serum concentration did not substantially change, neither in patients nor in dogs, although a small but significant tramsient decrease was observed after the start of CPB in all three patient groups and in the animal groups. This is most likely due to 
henodilution by the priming solution of the oxygenator.

\section{- Potassium}

The concentration of potassium showed a rapid, but transient increase in the last period of $C P B$ in the cardioplegia group. Part of these ions originates from the cardioplegic solution. Since the arterial potassium concentration also increased in the patients of the hypothermia group, an endogenous source of potassium should be considered as well. In both groups mentioned before, the enhanced mean potassium levels did not exceed a value of 5.5 mono $1.1^{-1}$, so that serious disturbances caused by high circulating levels of this ian should not readily be anticipated (Weber and Yarnoz, $1982)$.

\subsubsection{Arterial-coronary sinus differences of biochemical variables in blood}

\section{- Lactate}

In the clinical study the arterial-coronary sinus (A-CS) difference of lactate during the hemodynamically stable phase prior to CPB; did not differ from zero. This indicates no net uptake of this substrate by the heart. In contrast, a substantial amount of lactate was extracted from the blood in the pre CPB phase by the dog heart. Net lactate uptake by animal hearts has been considered as a sign of an adequate aerobic condition (Opie et al, 1973; Apstein et al, 1979; Drake et al, 1980a; Van der Vusse et a1, 1982). The discrepancy between human and dog hearts most likely results from spatial inhomogeneities in the former hearts. Lactate release from diseased parts of the patient hearts, might mask the ability to extract net amounts of lactate (Apstein et a1, 1979). In this respect it is noteworthy that healthy human hearts are able to extract significant amounts of lactate (Kaijser et al, 1979). A similar discrepancy was observed in the post CPB phase. In both the human and experimental study the $A-C S$ differences returned to their pre CPB levels. No net uptake of lactate was found in the human situation despite an assumed adequate $\mathrm{O}_{2}$ supply of the fomerily potentially underperfused areas through the aortocoronary bypass grafts. The significance of this observation is open to speculation. 
The release of lactate during the reperfuston phase, following artic cross-clamping in the nomothemia and the nypothermia groups indicates that anaerobic glycolysis was activated during the periods of global ischemia. In contrast, the finding that hardly no release of lactate was observed after unclanping of the arta in the cardioplegia group most likely reflects the absence of glycolytic activity in the cardioplegia treated hearts, although washout of lactate by the intermittently adninistered cardioplegic solution cannot be excluded. The abservation that the myocardial glycogen content was not significantly altered in this group (see section 4.1 .3 .3 ) makes the latter explanation less feasible.

The higher peak values of the A-CS differences of lactate in the nomothemia group than in the hypothermia group suggest that the glycolytic activity during the preceding period of ischemia is more enthanced at nomothemia. This conclusion is supported by the calculation of the net release of lactate in the dog experiments. The loss of lactate during reperfusion in the nomothemia and hypothermia patient graups gradually decreased, reaching zero values 10 minutes after unclamping of the aorta. In contrast, in the dog experiments within 5 minutes of reperfusion release generally changed into net uptake of lactate. Thils difference between dogs and humans may also result from the partially diseased state of the human hearts under investigation.

This data shows that washout of lactate accumulated during ischemia, generally occurs in the first two minutes of reperfusion. In other studies a delayed washout of lactate was observed (Gray et al, 1976; 01 in et a1, 1981; Jalonen, 1981d; Edlund et al, 1982). These investigators, however, only took blood samples 3 to 10 minutes after release of the aortic clamp. At the present state of the art it is impossible to decide whether this is a different pattern of lactate washout, because in these studies the man lactate release during the first two minutes of reperfusian might have been missed. For proper judgement of the occurrence of ischemic episodes during aortic crossclamping, early sampling is required.

\section{- Inorganic phosphate}

With respect to the $A-C S$ differences af inorganic phosphate, basically no disturbances in the cardiac homeostasis of this jon could be observed during the pre and post CPB phase, in both the humar and dog study. 
In the patient groups washout of inorganic phosphate was prominent in the first minutes after release of the aortic cross-clamping, and the duration of this imbalance was shorter than observed for lactate. A significantly higher A-CS difference after the first aortic cross-ciamping as compared to the succeeding peak values of A-CS differences, was prominent in the nomathermia and hypothermia patient groups. This phenomenon was not observed in the dags of the normothermia group, and only to a minor degree in the dogs of the hypothermia group. No explanation is at hand for the differences in release pattern between man and dog. The peak values of the A-CS differences of inorganic phosphate after unclamping the aorta were less pronounced in the patient cardioplegia group, as compared to the other two groups. A similar observation was made in the dog study.

In contrast to the patient study, in the animal experiments hypothermic conditions during aortic cross-clamping resulted in reduced inorganic phosphate washout at reperfusion, as compared to the normothemic situation. The significance of this finding will be discussed in section 5.1.4.

In dogs uptake of inorganic phosphate from the blood occurred after approximately 4 minutes of reperfusion in all groups, but in patients a positive A-CS difference of inorganic phosphate in the normothermia and hypothermia graups was only abserved during reperfusion after the fourth aortic cross-clamping. Similar to the findings of lactate, this observation most likely reflects differences in the state of healthiness between human and dag hearts.

Since the findings in the experiments with dogs on $C P B$ without aartic cross-Clamping revealed that A-CS differences were not different from zero under both normothermic and hypothermic circumstances (Appendix 11), we may conclude that the extraction of inorganic phosphate from the blood does reflect replenishment of intraceliular inorganic phosphate stores, which are reduced during the preceding reperfusion phase. This abservation suggests the reversible nature of the repetitive ischemic insults.

\section{- Potassium}

Since the A-CS differences of potassium did not substantially differ from zero in the pre and post CPB period in both patients and dogs, disturbances in the potassiyn tomeostasis of the heart can be excluded. The rapid release of potassian aftor unclanping of the aorta in the normothermia and hypother- 
mia groups reflects accumulation of this ion in the extracellular space during ischemia. A variety of authors has shown that washout of potasstum from myocardial tissue occurs within the first minutes of ischenta, when only reverstble ischemic changes are involved (Opie et al, 1973; Van der Vusse et al, 1980; Kleber et a1, 1984). This phenomenon may be caused by disturbances at the level of the membrane $\mathrm{Ma}^{+}-\mathrm{K}^{+} \mathrm{ATPase}$ or by a nigher potassium conductance induced by ischemia (section 2.2.4). The observation that the initial high washout of this ion is followed by a significant uptake indicates the abllity of the heart to replenish the reduced intracellular potassium stores. This supports the notion that the insult of the preceding ischemic period is reversible in nature. It is noteworthy that the time interwal of potassium release, following unclamping of the aorta, is much shorter in dogs than in patients which might reflect a less healthier state of the myocardial tissue in the latter.

The higher peak values and more sustained releasie of potassium in the cardioplegia group in comparison with the other two groups, in both patients and dogs, reflects the washout of potassium ions. These ioms are most likely derived from the vascular space filled with cardioplegia solution containing a relatively high concentration of potassium (16 mol. $\left.1^{-1}\right)$. From the dog experiments we were able to estimate the quantitative contribution of the potassium derived from the cardioplegic solution, trapped in the vascular space during ischemia, to the anount of potassiun released during reperfusion. On the average 8.6 umol potassium. $g^{-1}$ wet weight of heart tissue were released. This amount corresponds with about 1.3 mol per dog heart. Assuming a left ventricular weight of $150 \mathrm{~g}$ and a vascular volume of $15 \mathrm{ml}$ filled with the cardioplegic solution, about 0.24 mnol can be expected to ariginate from this solution. This difference can only be explained when potassium ions originating from the intracellular space are released as well. It is not likely that potassium release due to the period of ischemia will contribute to the release callculated above, since only minor metabolic disturbances on the base of the tissue lactate and high-energy phosphate contents were observed.

\section{- Oxygen}

The A-CS differences in the axygen content were significantly decreased during the post CPB period as compared to the A-CS differences before CPB, in 
both the aninal and the patient groups. This observation was also reported in patients by 0lin and coworkers (1981) and by Jalonen (1981d). This change in A-CS differences most likely results from a simultaneously increased myocardial bllood flow as was observed after CPB in the animal groups. The latter observation is in agreement with the finding of Gray and coworkers (1976).

After the release of aortic cross-clamping initially high values of A-CS differences in the axygen content were observed in patients of the nomothernia and hypothermia groups, which suggests that the blood sampled from the coronary sinus during the first 30 seconds is low in oxygen due to repayment of axygen debt.

The animal experiments show that oxygen consumption was lower during CPB under hypothemic than under nomothemic conditions. This clearly indicates a reduction of energy demand of the heart due to a lower temperature of the heart (Appendix 11).

In general, the findings in the patient and animal studies were comparabie and indicate that the effect of aortic cross-clanping on oxygen consumption was reversible; a stable condition was reached again within 5 min of reperfusion.

\subsubsection{Biochemical variables in tissue}

\subsubsection{Tissue high-energy phosphates and glycogen in patients}

The reduction in the ATP content and the instantaneous release of inorgamic phosphate during the periods of reperfusion in the normothermia and hypothemia patient groups, cleamly indicate that the myacardial energy requirements exceeded the oxygen and substrate supply during ischemia. Although the tissue content of creatine phosphate was not changed after ischemia, a decrease during ischemia might have been restored to comtrol values during the short reperfusion period prior to taking biopsies. In the cardioplegia group, the energy demand has obviously been reduced to low levels since no change in myocardial AP was observed. Besides, only minor differences in the content of inorganic phasphate between arterial and coronary sinus blood coutd be detected upon reperfusion. The apparent abolishiment of energy consuming processes such as basal metabolism and electro-mechamical 
activity, likely results from the low temperature of the heart $\left(618^{\circ} \mathrm{C}\right.$ during the ischemic perfod) and the high levels of potassium and magnesium present in the infusate.

This conclusion is supported by the observations on tissue glycogen. The reduced content of myocardial tissue glycogen and the release of lactate after restoration of coronary artery blood fllow in the normothermia and hypothemia patient groups indicates that anaerobic glycolysis is activated during the periods of global ischemia in these groups. In contrast, hardly any sign of accelerated glycolytic breakdown of glycogen stores could be detected in the cardioplegia group.

Reports on the determination of high-energy phosphates in myocardial tissue are limited. During valve replacements 0lin and coworkers (1981) obserwed that ATP and creatine phosphate levels were diminished at the end of one hour of aortic cross-cliamping, using one single dose of blood cardioplegia. In contrast, these levels did not change when continuous blood cardioplegia was employed. In patients operated upon for aorto-coronary bypass surgery, protection with the use of multidose blood cardioplegia plus topical cooling of the heart during an ischemic insult of less than 80 minutes was evaluated by Cunningham and coworkers (1979). They could differentiate between "adequate" and "inadequate" myocardial protection on the basis of high-energy phosphate levels.

Lowering the temperature of the heart in the patient groups from $34^{\circ} \mathrm{C}$ to $25^{\circ} \mathrm{C}$ did apparentiy not result in a decrease of the energy needs of the heart, since the content of glycogen and ATP was lowered to a comparable extent in both groups. One should conclude on the basis of these findings that the difference between energy demand and supply was equal in both groups. This conclusion is not supported by the finding, that the A-CS differences in oxygen content was reduced at $25^{\circ} \mathrm{C}$ as compared to $34^{\circ} \mathrm{C}$, which was confirmed quantitatively in the dog study. It is likeliy that the metabollic activity during ischemia, and the subsequent restoration during reperfusion, is more prominent under nomothemic than under hypothermic circumstances and that these two processes will ultimately result in a similar reduction of energy stores at the moment of measurement.

The consequences of the reduced ATP and glycogen contents in human myocardial tissue is open to speculation. In dogs a relationship between low ATP levels and lethal injury in myocardial ischemia was found by Jennings and 
colleagues (1978). Loss of $65 \%$ of the tissue ATP was associated with minimal ultrastructural changes. Depletion of more than $90 \%$ of the ATP was associated with significant morphological disturbances and markedly altered cell volume regulation. The decrease in tissue ATP content in patients of the normothermia and hypothermia groups was found to be 28 and $29 \%$, respectively. Although extrapolations from animal data have to be done with care, it may be concluded that the levels of ATP as observed in the human hearts after global ischemia and reperfusion are not likely to be associated with severe myocardial damage.

It should be realized that the tissue content of high-energy phosphates and glycogen were measured in biopsies obtained at least 20 minutes after unclamping of the aorta. Therefore, a combined effect of ischemia and reperfusion on the tissue content of these substances should be considered. In the dog experiments we have investigated the separate effects of ischemia and reperfusion in more detail.

5.1.4.2 Tissue content of ATP and glycogen in dag hearts. Comparison with the hurnan situation

In the course of the experimental study we became aware of an interesting observation. The significantly decreased levels of ATP and glycogen as observed in the postischemic biopsies of the patients of the nomothermia and hypothermia groups, was not seen in the comparable dog groups. To understand this discrepancy between the clinical and experimental results two factors should be considered. Firstiy, the last postischemic biopsy in dogs was obtained 45 minutes after the last aortic cross-clamping, while in patients these biopsies were taken about 20 minutes after release of the last crossclamp. This difference in recovery time might allow the resynthesis of tissue ATP. Secondiy, differences in the functional state of the heart (i.e. healthy dog hearts versus regionally diseased human hearts) or species differences might play a role. With respect to ATP it is moteworthy that in the dog study after each individual reperfusion interval of 15 minutes the ATP levels were not different from the control values. In contrast, the values as measured at the end of the ischemic periad, were significantly decreased after the first and third aortic cross-clamping in the nomotherala group. This clearly 
indicates that dog hearts car easily restore their ATP content, as reduced during a period of 10 minutes of ischemia.

With respect to glycogen in dog hearts, no significant change in the content of this carbohydrate store could be observed neither at the end of the ischemic, nor after the reperfusion period. These findings most likely reflect that the enzynatic system involved in the glycogen degradation is less sensitive to ischemin in dog than in human hearts.

\subsubsection{Tissue content of creatine phosphate in dog hearts}

Similar to the observations in the three patient groups, no significant decrease in the tissue content of creatine phosphate could be observed in the last reperfusion biopsy as compared to preischemic values. Since Janes and colleagues (1976) in regional ischemic hearts, and kao and coworkers (1982) in global ischemic dog hearts have clearly demonstrated that the myocardial creatine phosphate content rapidly decreased during ischemia, a process of alternating dephosphorylation during ischenia and rephosphorylation during reperfusion is most likely mesponsible for the virtually unchanged levels in the postischenic biopsies. The findings in the normothernia and hypothemia dog groups demomstrate the feasibility of this notion, and clearly indicate the reversibility of the degradation of creatine phosphate in creatine and inorganic phosphate during the ischemic insult. The conclusion of Engelman and coworkers (1977) that multiple short periods of ischemia are deleterious to the heart is therefore only justified in case of short periods of intermediate reperfusion $(5 \mathrm{~m} n)$.

Despite the decrease in myocardial temperature from approximately $34^{\circ} \mathrm{C}$ (nomothemia) to $25^{\circ} \mathrm{C}$ (hypothemia) in the animal groups, the decrease in tissue content of creatine phosphate during ischemia was not different between these two animal groups (table 5.1). This finding does not necessarily imply that the energy demands during hypothermic and nomothemic ischemia are similar. The reduction in tissue creatine phosphate content has shown to be a very rapid process at $37^{\circ} \mathrm{C}$ (Hearse, 1979; Dunn, 1984; Prinzen et al, submitted for publication), ultimately levelling of in the dog heart at about 10-20 whol. $9^{-1}$ wet weight of tissue after 5 minutes of oxygen deprivation. Reduction of temperature may delay the rapidity of the degradation of creati- 
Table 5.1 Relation between the content of ATP, creatine phosphate and inorganic phosphate in myocardial biopsies at the end of ischemia, and inorganic phosphate release during reperfusion in dogs. Mean values and SEM are presented (umol.g $g^{-1}$ d.w.). Each period of aortic cross-clamping was separately used in the normothermia and hypothermia groups.

Group

Duration of ischemia (min)

10

10

60

Decrease in tissue content:

ATP

creatine phosphate

Increase in tissue content:

inorganic phosphate

Washout of inorganic

phosphate into venous blood

bloo
$4 \pm 2$

$41 \pm 4$

$44 \pm 3$

$70 \quad \pm 7$

$20 \pm 3$

$2 \pm 2$

$5 \pm 3$

$38 \pm 4$

$10 \pm 4$

$(n=8)$

$(n=24)$

hypothermia

cardioplegia

$(n=24)$ 
ne phosphate but not prevent it.

5.1.4.4 Tissue inorganic phosphate content in relation to high-emergy phosphate content and inorganic phosphate release.

The findings in the animai study show that the content of inorganic phosphate increased rapidly during ischemia and decreased to the same extent upon reperfusion. An important difference was found between the two dog groups with interittent aortic cross-clamping, with respect to the quantitative rise in tissue inorganic phosphate content at the end of the ischemic period. In the nomothemia group the increase of inorganic phosphate at the end of ischemia could be explained by the tissue ATP and creatine phosphate reduction, but in the hypothemia group, this increase exceeded the simultameous reduction in high-energy phosphates (table 5.1). From these findings: it might be comcluded that another intracellular source of inorganic phosphate, for instance phosphorylated proteins, is responsible for the rise in tissue content of this ion.

Despite the higher tissue levels of inorganic phosphate at the end of ischemia in the hypothemia group, the total amoumt released was less than in the normothemia group (table 5.1). This implicates that the release during reperfusion was not quantitatively related to the high tissue levels as the result of ischenia. A possible explanation for this finding is that the rate of passage through cell membranes at lower temperatures is reduced (pine et. al, 1981). The significance of this finding might be that the simultaneously higher total tissue level of imorganic phosphate may represent a potential danger for the ischenic tissue, since a positive correlation between the height of the inorganic phosphate content and disturbances in the calcium homeostasis has been described (Ponce-Hornos and Langer, 1982; Ponce-Homos et al, 1982).

5.1.4.5. Tissue lactate in relation to glycogen and release of lactate in the coronary sinus blood 
Table 5.2 Relation between the content of glycogen and lactate in myocardial tissue at the end of ischemia, and the lactate release duming reperfusion in dogs. Meam values and SEM are presented (umol.g ${ }^{-1}$ d.w.). Each period of aortic cross-clamping was separately used in the normothermia and hypothermia groups. * = tissue lactate was detemined in 2 dogs of the hypothermia group.

Group

normothermia hypothemia cardioplegia

$(n=24)$

$(n=24)$

$(n=8)$

Change in tissue glycogen content

$-15 \pm 8$

$13 \pm 14$

$16 \pm 15$

Lactate increase in tissue ${ }^{*}$

$68 \pm 6$

55

$6 \pm 4$

Washout of lactate into venous blood $48 \pm 11$

$16 \pm 2$

$7 \pm 4$ 
fusion in the animal groups with intermittent aortic cross-clamping. The increase of the lactate content during ischenia to two to four times the initial preischentic walue and the return to the initial low levels during the subsequent reperfuston phase confims the findings of Levitsky and Feinberg (1975). Imai and colleagues (1979) and Guilbeau and coworkers (1984).

The quantitative relation between the tissue content of glycogen and of lactate at the end of ischernia, and the release of lactate during the following reperfusion period is presented in table 5.2. This data shows that the increase in tissue lactate as measured at the end of ischemia, could not be explained by a simultaneous decrease in the glycogen content. An alternative source of tissue lactate may be the glucose, present in the cells at the start of ischemia. To calculate the possible contribution of tissue glucose to the lactate increase during ischemia, we assumed that the tissue glucose content was in equilibrium with the arterial glucose concentration. The latter concentration was found to be about $5 \mathrm{mmol}^{-1} \mathrm{l}^{-1}$ in the dogs on CPB (Appendix 9). This amounit of glucose can be converted to 50 w mol lactate per gram dry weight, which is in the range of the total increase in tissue lactate as observed in the dog groups. The assumption that during the initial phase of ischemia lactate is most probably originating from glucose breakdown, is supported by the findings of Prinzen and colleagues (subritted for publication). In a model of regional myocardial ischemia they observed that a significant venous washout of lactate was associated with an increased glucose uptake during the first mimutes of ischenia. Within this time interval net glycogen degradation was not measurable.

5.1.4.6 Variations in the high-energy phosphate and glycogen contents in preischemic myocardial biopsies

In the myocardial blopsies obtained from the patient study in the preischemic period, relatively large variations in ATP, creatime phosphate and glycogen content were measured. To evaluate whether these variations were the result of intracardial inhomogenieties in the patients with three vessel disease or of interindividual differences, the concomitant coefficients of variation were calculated (table 5.3). Besides, the coefficient of variation calculated for the preischemic biopsies obtained in the dog groups is shown, 
Table 5.3 Coefficients of variation ( $M S D / m e a n$ value) of the ATP, creatine phosphate and glycogen contents in human and dog myociardial biopsies obtained shortly after instalment of CPB, but before induction of ischentia. Interindividual values refer to the biopsies as obtained from different hearts, while intraindividual values refer to two biopsies obtained in the same heart.

interindividual

$(n=70)$

ATP

Creatine phosphate

37
intraindividual
$(n=14)$

interindividual

$(n=20)$

11

29

11

29

Glycogen

34

20

36 
to elucidate whether differences between species may be involved. It is evident from table 5.3 that the large variation as observed in preischenic biopsies, occurs in both animals and man and that the occurrence of myocardial inhomogenieties does not contribute considerably to the total variation. From this finding it nay be concluded that evaluation of the glycogen and high-energy phosphate contents in small postischemic myocardial biopsies implites the occurrence of large interindividual variations. These findings indicate that the use of changes in tissue content of these biochemical substances as markers for myocardial ischemia, is onlly allowed when using the patient or the animal as its own control. Therefore pre and postischemic biopsies are requilred.

\subsubsection{Summary of biochemical findings in tissue}

The reduction in ATP and glycogen content, and the release of inorganic phosphate and Vactate during reperfusion in the normothermia and hypothermia. patient groups, indicate sustained metabolic requirements during ischenia in these patient groups. The rapid process of alternating dephosphorylation and rephosphorylation of creatime phosphate as observed in the dog study, is most. likely responsible for the unchanged levels of creatine phosphate in the postischemic biopsies as was observed in patients. The animal study demonstrates that the temperature difference between the normothermia and hypothermila groups is not reflected in the changes in the high-energy phosphate tissue levels at the end of ischemia. However, the washout of imorganic phosphate was more prominent in the normothermia than in the hypothermia group. Similarly, the decrease in carbohydrate content does not differentiate between the latter two groups, except for the lactate washout during reperfuston. In general, the metabolic activity in the cardioplegia group was reduced to low levels as can be concluded from the absence of changes in tissue content of high-energy phosphates and glycogen, and the smill release of metabolic markers of ischenta during reperfusion.

\section{1 .5 Changes in mitochondrial ultrastructure}

Preservation of mitochondrial ultrastructure has been accepted as a 
reliable parameter to detemine the efficacy of myocardial protection during cardiac surgery (Cunningham et al, 1979; Flameng et al, 1980; Balderman et al, 1981 ).

Deterioration of mitochondrial ultrastructure during the operation was absent in the three patient groups under investigation. Both before and after aortic cross-clamping less than one percent of all mitochondria examined, exhibited signs of irreversible injury. Since five photographs were examined for mitochondrial evaluation, maximally 15 cells were included for evaluation. Therefore, a low incidence of cell damage could not accurately be detected.

It should be noted that the postischemic biopsy was obtained after ischewia and reperfusion for approximately $20 \mathrm{~min}$. Therefore, possible changes at the end of ischemia may have been restored during the following reperfusion phase. Because this recovery of reversible changes is known to occur, our findings allow the conclusion that changes at the end of ischemia, if any, were not irreversible.

The observations in the present study show that the majority of the mitochondria in preischemic tissue specimens from subepi and subendocardial layers had normal cristae. Within approximately half of the mitochondria specific small granules were observed and in some cases irreversibly injured mitochondria were present. This observation is in agreement with the findings reported by Levinsky and coworkers (1979) and most likely reflects the morphologically inhomogeneous state of cardiac tissue of patients with three vessel disease (Laquens et al, 1979).

Ultrastructural evaluation was not employed in the animal study because the findings in patients had shown that no changes could be expected in the three techniques of myocardial protection.

In sumary, ultrastructural evaluation of mitochondria reveal ed adequate protection in the three patient groups.

\subsubsection{Enzyme release}

In the patient study the amount of irreversibly damaged myocardial tissue due to the surgical procedure was estimated from serial deteminations of plasma enzymes after CPB. 
The curves of the plasma enzyme activity reveal a comparable pattern in the three patient groups. The plasma peak values occurred within 24 hours postoperatively for the enzymes under investigation, and these values were not significantly different in the three groups.

Athough plasma enzyme actiwity can be applied to quantitate myocardial injury, this is more difficult in patients after cardiac surgery due to additional interventions which may cause enzyme release from non-cardiac sources (Hermens et al, 1982). Similar to quantification of enzyme release after acute myocardial infarction (Shell et al, 1973; Willems et al, 1979), we calculated the cumulative release of heart specific enzymes. Corrections were made for the occcurrence of hemolysis, changes in circulatory parameters and the release of enzymes from non-cardiac sources (see section 2.2.6). The cumullative enzyme release was transformed into the equivalence of myocardial tissue injured and revealed comparable values of irreversibly damaged cardiac tissue in the three patient groups.

Assuming that the elevated levels of CK-MB are specifically originating from myocardial tissue, we nay conclude that release of cardiac enzymes mainily occurs within the first 12 hours after CPB. Calculation of the cumulative release of $C K-M B$ indicates that the amount of irreversibly damaged tissue is in the order of. $1 \%$ of the total heart of the patients of the three groups. Comparable findings were reparted by sylven and cowarkers (1982). They calculated that enzyme release equivalent to $5 \mathrm{~g}$ of myocardial tissue was present after uncomplicated aorto-coronary bypass surgery. In contrast, Roe and coworkers (1979) found that upto $16 \mathrm{~g}$ of heart tissue was irreversibly injured in patients operated under comparable circumstances.

Cunulative release of $\mathrm{HBDH}$, corrected for $\mathrm{HBDH}$ released from red biood cells due to hemolysis, was in keeping with the findings on the basis of the CK-MB release. However, when the heart was considered as the sole source of creatine kinase released into the circulation, erroneously high values of damaged myocardial tissue were estimated. This was also obserwed for AST, although to a lesser extent. Beside the heart, prominent sources of these two enzymes will be the intercostal, pectoral and diaphragmatic muscles which are appamently at risk during open-heart surgery (Hermens et al, 1982). It should be realized that cardiac enzyme release can be caused by other interventions than global ischemia of the heart due to aortic cross-clamping. Such procedures as application of themporobes and biops: needles, and insertion of 
tubes for venous return to the heart-lung machine and for venting of the left ventricle should be considered. In addition, defibrillation may cause tissue injury (Dahl et al, 1974). Finally, reperfusion of chronically ischemic tissue through the installed aorto-coronary bypasses might provoke the release of enzynes as well. The quantitative contribution of these factors to cardiac enzyme release is difficult to estimate, but we assumed these factors contributed similarly in the three patient groups.

The findings in the animal experiments support the above mentioned assumptions. The increase of plasma $\mathrm{HBDH}$ was observed in the groups with CPB, independent of aortic crass-clamping, and occurred parallel to the increase of plasma free hemoglobin (Appendix tables $12 \mathrm{e}$ and $12 f$ ). This indicates that hemolysis is induced by the arterial pump in combination with extracorporeal oxygenation, which is supported by the finding that hemolysis did not occur when the employement of CPB was ontitted.

The cumulative release of creatine kinase was calculated in the dogs during the first hour after cessation of $C P B$, and revealed that release of this enzyme did not allow to discriminate between the three techniques of myocardial protection. In groups without $C P B$ reduced release was abserved, even when thoracotomy and insertion of cardiac cannulas was perfomed (table 4.11). This indicates that the CPB procedure of 145 minutes in itself caused a significant release of creatine kinase. The cumulative release of AST in the dogs did not discriminate between groups because of the small release during this phase of the operation.

Decreased hematocrit values were commonly observed during and after CPB as a consequence of both hemodilution and increased plasma volume during the immediate postoperative phase. It should be noted that in the patient groups the hematocrit returned to nomal values within 4 hours (Willems et al, accepted for publication). Cumulative enzyne release is basically determined by the release between 0 and 36 hours postoperatiwely. Because during the first four hours a significant contribution to the totally measured release can be expected (creatime kinase 10\%; AST 20\%; CK-MB 30\%; HBDH 40\%), changes in hematocrit will have some effect. It was assumed that this effect was rather small as compared with the total anount of enzymes released.

In one specific dog group we also measured a considerable increase of $k_{c}$ after CPB, which was used as a measure of enzymes disappearing from the intravascular space. It is not known, whether the transcapillary exchange 
rate (responsible for the change in $k_{d}$ value) remains increased thereafter. Most likely the changes in colloid osmotic capacitance of the circulating blood plasma are impartant determimants of the transcapillary exchange rate of proteins. Since the colloid osmotic properties have been reported to return to nomal values within 2 hours postoperatively (Ghadiali and Cox, 1981), we assume that changes in $k_{d}$ will be less pronounced during the time interval of enzyme release.

In sumnary, the enzyme release during the first 36 hours after the operation was similar in the three patient groups under investigation. With the use of multi-enzyme analysis, we were abie to calculate the contribution of non-cardiac sources of enzyme release (i.e. hemolysis, skeletal muscle). After correction for changes in circulatory parameters like plasma volume and transcapillary exchange rate, we calculated that in the three patient groups less than one percent of the heart was irreversibly damaged. From the animal study we can conclude that the cardiac enzyme release due to the periods of ischenia could not be separated from other causes of enzyme release. Thoracotomy, anesthesia and extracorporeal circulation should be considered as inportant causes of increased enzyme activity in postoperative plasma.

\subsection{Selected topics}

\subsubsection{Hemodynamic and biochemical changes in the initial period of cardio- pulmonary bypass}

The Initial extracorporeal perfusion phase was examined in more detail, because several investigators have suggested that this particular period may be harmful to the heart (Hottenrot et al, 1974; Vinas et a , 1979). Hemodillution, hypotension (Gray et a?, 1976) and fibriilation (Hottenrot et al, 1974), or a combination of these conditions have been suggested to cause a shortage of myocardial oxygen leading to a considerable ischemic insult.

In the animal study we did observe hemodilution and hypotension, but. were umable to demonstrate impaired coronary artery blood flaw (section 4.2.3). The oxygen consumption reduced significantly after instalment of CPB in normothermic (from 3.26 to $2.31 \mu \mathrm{mol} . \mathrm{g}^{-1} \cdot \mathrm{min}^{-1}$ ) and hypothermic conditions 
(from 2.43 to 1.38 mol. $\mathrm{g}^{-1} \cdot \mathrm{min}^{-1}$ ). This can be ascribed to the lower metabolic activity of the empty beating heart especially because the delivery of oxygen was not diminished. Despite these findings net lactate uptake stimultaneously disappeared in the dags and turned into lactate release in the patients, indicating that amaerobic glycolysis was activated despite adequate oxygen delivery.

In contrast to the patients, in dog hearts lactate uptake had returned to pre CPB walues within 10 min after the start of CPB. In all three patient groups release of lactate remained. This difference in metabolic response between dogs and patients probably results from regional ischenic areas in the patient hearts. From these findings we may conclude, that the instalment of CPB, hemodilution and hypotension caused a metabolic change in both dogs and patients. This emphazises that the early phase of CPB may affect the heart, although this insult was shown to be reversible in the dog hearts.

From the hemodynanic and biochemical variables as measured in the hypothermic animal group, we could not confirm the hamful influences of fibrillation. Because these influences were reported to occur during fibrillation under continuous electrical stimulation (Hottenrott et al, 1974; Vinas et al, 1979), we conclude that spontaneous fibrillation or fibrillation without. continuous stimulation, does not exert harmful effects on the heart.

\section{2 .2 Coronary artery blood flow}

In the nomothemia, hypothermia and cardioplegia amimal groups an increase in coronary artery blood flow in combination with a decrease in A-CS difference of the oxygen content was observed after the period of CPB. The net axygen consumption was calculated to be comparable during the pre and post CPB phase. Most likely the reduced hematocrit walue after CPB, resulting in a lower oxygen carrying capacity, was compensated by an increased myocardial blood flow.

An increase in coronary artery blood flow was also reported in patients after aorto-coronary bypass surgery (Albert et al, 1970; Gray et al, 1976), although these reports do not reveal whether the enhanced blood flow is caused by hemodilution or improved distal run-off through the grafts (Reneman and Spencer, $1972 ; 1975$ ).

Marked changes in coronary artery flow were observed during CPB, follow- 
ing unclamping of the aorta. This hyperentic response appeared to be delayed in the nomothemia group. In contrast, this respomse occurred inmediately in the other two groups and was followed by a rapid (within 5 minutes) reduction of coronary artery blood flow. The difference in hyperemic myocardial flow pattern between the nomothermia and hypothermia groups might be explained by a combined effect of Ischemia, reduced temperature and different state of the myocardium (i.e. Fibrillating in the hypothemia group versus empty beating in the nomothemia group). Although it was not the aim of the present study, some attention has been payed to the differences in reactive hyperemila between the two groups with intemittent aortic cross-clamping. It should be noted, that such differences might influence the interpretation of the release of substances front the heart observed during reperfusion. In the animal study, however, the patterns of A-CS differences were basically comparable with the curves related to net uptake or release, (i.e. A-CS differences multiplied by coronary flow). Although extrapolation of animal data on the reactive hyperemic response to the human situation should be done with care, we may assume that the A-CS differences as assessed in the human study, globally reflect the changes in metabolic comdition of the heart. 
5.3 General considerations on normothermic, hypothermic and cardiaplegic techniques in open-heart surgery

Continuous aortic cross-clamping to perform the distal anastomosis in combination with multidose cardioplegic solutions is commonly employed in aorto-coronary bypass surgery. The technique of nyocardial protection through several short lasting periods of aortic cross-clamping, in both hypothermic $\left(25^{\circ} \mathrm{C}\right)$ and nomothermic $\left(34^{\circ} \mathrm{C}\right)$ conditions is less commonly used, although good clinical results have been reported (Flameng et al, 1981b; Pepper et al, 1982). In the present study these three techniques were compared in a randomized clinical trial, and ewaluated by hemodynamic, biochemical and ultrastructural variables.

The hemodynamic recovery of the patients after weaning from CPB was adequate. No major differences between the three groups could be observed. The reduced left ventricular stroke work index and left ventricular $\mathrm{dP} / \mathrm{dt}$ max, pas and the increase in cardiac index are generally observed as a transient response to anesthetics used and to the CPB procedure per se (this study, Roberts et al, 1981; Jalonen et al, 1981c).

The increase of plasma catecholamine levels during $C P B$, which was also reported by other investigators, most likely result from the non-pulsatile flaw, as generated by the heart-lung machine, and hemodilution (Sebel et al, 1981; Estaphanous et a1, 1984). The higher plasma levels of norepinephrine mmediatly after CPB in the normothemia patient group suggests a more prominent release as the resuit of nomothermic perfusion. As a consequence cardiac function can be stimulated in this group as was suggested by Regan and coworkers (1970).

The amolint of irreversibly damaged myocardial tissue was very small as assessed with the use of postoperative enzyne release. Besides, no significant differences between the three operative techniques could be observed. These findings confirm the results of earlier reports in which cardioplegia was compared with intermittent aortic cross-clamping combined with moderate $\left(32^{\circ} \mathrm{C}\right.$; Roberts et al, 1981 ; Pepper et a1, 1982), ar more profound hypothermta (Conti et al, 1978, Lolley et al, 1980). In contrast, other investigators found significantly higher CK-MB plasma levels in patients after intermittent aortic cross-clauping at 28 to $32^{\circ} \mathrm{C}$ as compared to cardioplegia (Adappa et 
a1, 1978; Weisel et a1, 1978; Follette et al, 1978; Brower et a1, 1982). The conclusion from the data on enzyme release, that less than one percent of myocardial tissue was irreversibiy damaged, is in agreement with the finding that postischenic ultrastructure was very well preserved.

The decrease of glycogen content in postischemic biopsies and the instantaneous release of lactate during the intemittent reperfusion periods revealed that glycolysis was accelerated in the normothermia and hypothemia groups. Although this process is stimulated by the imbalance in energy demand and supply, this metabolic change fajled to maintain the ATP cantents at their preischemic values. Obviously, the decreased ATP levelis remained within safety limits. In the cardioplegia group the ATP and glycogen tissue contents. did not decrease, and the washout of metabolites was clearly reduced. In canclusion cardioplegia is superfor to the other techniques as far as the biochemical data is concerned. 
$-164-$ 
6. Appendix: animal data

Appendix 1. Body weight and left ventricular weight (including the free wall and septum) of the 10 animal groups. Mean values and $\mathrm{SD}$ are presented.

Bady Weight

(kg)

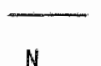

N

H

C

NC

HC

NB

HB

EC

HPLV

CON

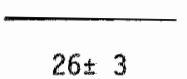

$26 \pm 6$

$23 \pm 3$

$28 \pm 5$

$27 \pm 5$

$24 \pm 2$

$28 \pm 6$

$34 \pm 10$

$22 \pm 2$

$28 \pm 6$
Left ventricular weight (g)

$152 \pm 31$

$147 \pm 60$

$129 \pm 21$

$150 \pm 45$

$150 \pm 27$

$129+27$

$155 \pm 29$

$-$

$141 \pm 28$ 
Appendix 2. Rectal temperature of the animals in group $\mathbb{N}(\mathbf{D})$, group $H(\mathbf{0})$ and group $C(4)$. Mean values and $S D$ are presented. $E=$ empty beating, $\mathbb{F}=$ fibrillating.

Rectal temperature

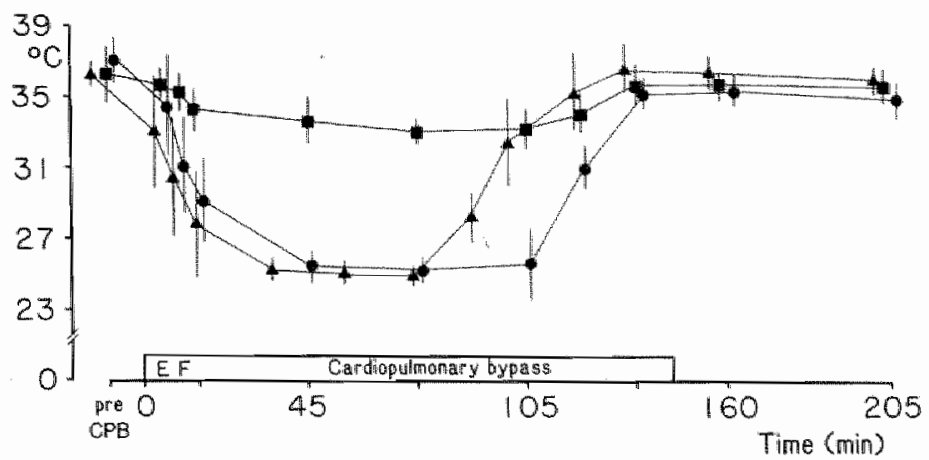

Appendix 3. Septal temperature during cardioplegic infusions in group C. Mean values and SEM are presented $(n=8)$. The cardioplegic solution was infused each $20 \mathrm{~min}$ as indicated by the arrows. Mean volume of 450,475 and $325 \mathrm{ml}$ was infused, respectively.

\section{Septal temperature}

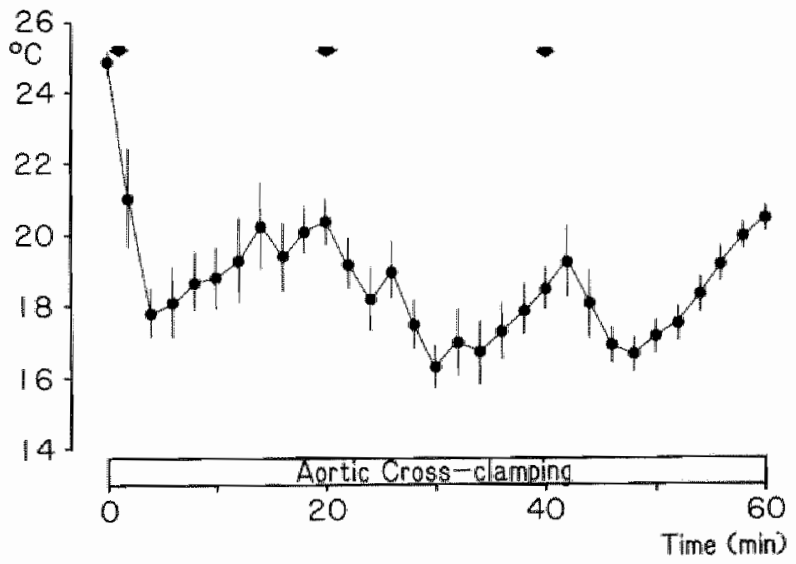


Appendix 4. Hemodymamic variables determined immediately before (time 0 min) and 15 and 60 min after cardiopulmonary bypass. Mean values and SO are presented.

\begin{tabular}{|c|c|c|c|c|c|c|c|}
\hline \multirow{2}{*}{ Variable } & \multirow{2}{*}{$\begin{array}{l}\text { Tüne. } \\
\text { (nin) }\end{array}$} & \multicolumn{5}{|c|}{ Group } & \multirow[b]{2}{*}{ CON } \\
\hline & & $\mathbb{N}$ & $H$ & C & $\mathrm{NC}$ & $\mathrm{HC}$ & \\
\hline $\begin{array}{l}\text { Heart rate } \\
\text { (beats. } \\
\text { minn }^{-1} \text { ) }\end{array}$ & $\begin{array}{r}0 \\
15 \\
60\end{array}$ & $\begin{array}{l}142+38 \\
149 \pm 30 \\
132 \pm 31\end{array}$ & $\begin{array}{l}143 \pm 46 \\
161 \pm 24 \\
138+29\end{array}$ & $\begin{array}{l}117 \pm 16 \\
122 \pm 10 \\
119 \pm 15\end{array}$ & $\begin{array}{l}112 \pm 38 \\
133 \pm 26 \\
125 \pm 25\end{array}$ & $\begin{array}{l}138 \pm 35 \\
132+25 \\
130 \pm 25\end{array}$ & $\begin{array}{l}124 \pm 44 \\
122 \pm 25 \\
128 \pm 35\end{array}$ \\
\hline $\begin{array}{l}\text { Pao, sys } \\
(k P a)\end{array}$ & $\begin{array}{r}0 \\
15 \\
60\end{array}$ & $\begin{array}{l}9.6 \pm 1.7 \\
7.7 \pm 2.0^{*} \\
8.8 \pm 1.5\end{array}$ & $\begin{array}{l}10.5 \pm 1.5 \\
8.5 \pm 2.7 * \\
8.5 \pm 2.1\end{array}$ & $\begin{array}{r}10.0 \pm 1.2 \\
9.5 \pm 1.5 \\
9.3 \pm 2.7\end{array}$ & $\begin{array}{r}10.0 \pm 1.9 \\
10.1 \pm 2.9 \\
9.1 \pm 2.1\end{array}$ & $\begin{array}{r}10.7 \pm 2.5 \\
10.1 \pm 2.5 \\
9.5 \pm 2.1\end{array}$ & $\begin{array}{r}10.9 \pm 2.4 \\
10.8 \pm 3.1 \\
9.9 \pm 2.8\end{array}$ \\
\hline $\begin{array}{l}\text { Pao, dia } \\
\text { (kPa) }\end{array}$ & $\begin{array}{r}0 \\
15 \\
60\end{array}$ & $\begin{array}{l}6.8 \pm 1.7 \\
4.8 \pm 1.5 * \\
5.6 \pm 1.6\end{array}$ & $\begin{array}{l}7.6 \pm 1.5 \\
5.6 \pm 1.6 \\
5.7 \pm 1.6\end{array}$ & $\begin{array}{r}7.2 \pm 1.2 \\
6.1 \pm 0.9 \\
5.7 \pm 1.3\end{array}$ & $\begin{array}{l}7.3 \pm 1.9 \\
6.9 \pm 2.4 \\
6.5 \pm 2.1\end{array}$ & $\begin{array}{l}7.2 \pm 1.3 \\
6.0 \pm 1.7 \\
6.4 \pm 2.0\end{array}$ & $\begin{array}{l}7.3 \pm 2.0 \\
7.6 \pm 2.7 \\
6.5 \pm 2.3\end{array}$ \\
\hline$\left(1 . \operatorname{lin}^{-1}\right)$ & $\begin{array}{r}0 \\
15 \\
60\end{array}$ & $\begin{array}{l}2.5 \pm 0.7 \\
2.8 \pm 0.7 * \\
2.7 \pm 0.7^{*}\end{array}$ & $\begin{array}{l}2.4 \pm 0.4 \\
3.3 \pm 0.7^{*} \\
3.1 \pm 0.7^{*}\end{array}$ & $\begin{array}{l}2.0 \pm 0.5 \\
2.5 \pm 0.4^{*} \\
2.9 \pm 0.8^{*}\end{array}$ & $\begin{array}{l}2.1 \pm 0.6 \\
3.1 \pm 1.4^{*} \\
2.8 \pm 1.1\end{array}$ & $\begin{array}{l}2.3 \pm 0.9 \\
* 3.8 \pm 1.3^{*} \\
* 2.9 \pm 1.2^{*}\end{array}$ & $\begin{array}{r}2.4 \pm 0.7 \\
+2.0 \pm 0.4 \\
+1.8 \pm 0.3\end{array}$ \\
\hline $\begin{array}{l}P 1 v \\
(k P a)\end{array}$ & $\begin{array}{r}0 \\
15 \\
60\end{array}$ & $\begin{array}{l}10.7 \pm 1.6 \\
10.0 \pm 1.9 \\
10.9 \pm 2.9\end{array}$ & $\begin{array}{l}11.3 \pm 1.7 \\
10.4 \pm 3.2 \\
10.1 \pm 1.6\end{array}$ & $\begin{array}{l}11.1 \pm 1.5 \\
11.5 \pm 1.5 \\
11.7 \pm 3.5\end{array}$ & $\begin{array}{l}10.7 \pm 2.1 \\
10.7 \pm 3.3 \\
10.4 \pm 1.6\end{array}$ & $\begin{array}{l}11.6 \pm 3.5 \\
11.7 \pm 3.6 \\
10.1 \pm 1.7\end{array}$ & $\begin{array}{l}12.1 \pm 2.4 \\
9.9 \pm 3.6^{*} \\
9.2 \pm 2.9^{*}\end{array}$ \\
\hline $\begin{array}{l}P: y, e d \\
(k P d)\end{array}$ & $\begin{array}{r}0 \\
15 \\
60\end{array}$ & $\begin{array}{l}0.5 \pm 0.4 \\
0.5 \pm 0.3 \\
0.8 \pm 0.7\end{array}$ & $\begin{array}{l}0.4 \pm 0.3 \\
0.5 \pm 0.5 \\
0.8 \pm 0.7\end{array}$ & $\begin{array}{l}0.3 \pm 0.3 \\
0.8 \pm 0.3 \\
0.7 \pm 0.4\end{array}$ & $\begin{array}{l}0.5 \pm 0.5 \\
0.9 \pm 0.7 \\
0.8 \pm 0.7\end{array}$ & $\begin{array}{l}0.5 \pm 0.5 \\
0.9 \pm 0.4 \\
0.7 \pm 0.4\end{array}$ & $\begin{array}{l}0.5 \pm 0.5 \\
0.7 \pm 0.1 \\
0.7 \pm 0.3\end{array}$ \\
\hline $\begin{array}{l}\text { dP/dt max } \\
\left(\mathrm{KP}_{\mathrm{i}} \mathrm{s}^{-1}\right)\end{array}$ & $\begin{array}{r}0 \\
15 \\
60\end{array}$ & $\begin{array}{l}180 \pm 40 \\
193 \pm 80 \\
193 \pm 73\end{array}$ & $\begin{array}{l}220 \pm 57 \\
160 \pm 53^{*} \\
193 \pm 80\end{array}$ & $\begin{array}{l}193 \pm 60 \\
173 \pm 40 \\
180 \pm 60\end{array}$ & $\begin{array}{l}173 \pm 40 \\
187 \pm 47 \\
160+47\end{array}$ & $\begin{array}{l}173 \pm 53 \\
187 \pm 107 \\
173 \pm 56\end{array}$ & $\begin{array}{l}167 \pm 60 \\
140 \pm 27 \\
147 \pm 47\end{array}$ \\
\hline
\end{tabular}

* - different from the value before cardiopulmonary bypass $(p<0.05)$. 
Appendix 5. Mean aortic pressure and pump flow during cardiopulmonary bypass.

The data of the mean aortic pressure are supplemented with the mean aortic blood pressure measured prior to and after cardiopulmonary bypass. Values of the pump flow and the results of cardiac output measurements obtained prior to and $15 \mathrm{~min}$ after cardiopulmonary bypass are presented. The results of the groups $N$ and NB, and of the groups $H$ and $H B$ were combined. Mean values and $S D$ are presented. $C P B=$ cardiopulmonary bypass, $E B=$ empty beating heart, $F=$ fibrillating heart. Time indication in min refers to the duration of cardiopulmonary bypass.

Mean aortic pressure $(\mathrm{kPa})$.

Time

Groula

\begin{tabular}{|c|c|c|c|c|c|}
\hline & $N+N B$ & $\mathrm{H}+\mathrm{HB}$ & C & NC & $H C$ \\
\hline $\begin{array}{l}\text { pre } C P B \\
\text { during } C P B\end{array}$ & $8.7 \pm 1.9$ & $8.5 \pm 1.3$ & $8.1 \pm 1.2$ & $8.8 \pm 1.7$ & $8.8 \pm 1.7$ \\
\hline $\begin{array}{l}5 \min (E B) \\
10 \min (F) \\
45 \min \\
75 \min \\
105 \mathrm{~min} \\
135 \mathrm{~min} \\
\text { post CPB }\end{array}$ & $\begin{array}{l}5.9 \pm 1.6 \\
6.1 \pm 1.5 \\
7.7 \pm 2.3 \\
6.4 \pm 1.5 \\
6.1 \pm 1.7 \\
6.0 \pm 2.1 \\
6.7 \pm 1.5\end{array}$ & $\begin{array}{l}5.9 \pm 2.0 \\
5.6 \pm 1.3 \\
9.3 \pm 2.0 \\
9.3 \pm 2.3 \\
9.5 \pm 1.7 \\
8.4 \pm 2.4 \\
6.7 \pm 1.7\end{array}$ & $\begin{array}{r}5.9 \pm 2.7 \\
5.9 \pm 1.3 \\
9.5 \pm 1.2 \\
10.9 \pm 2.3 \\
7.2 \pm 1.2 \\
7.7 \pm 1.6 \\
7.1 \pm 1.9\end{array}$ & $\begin{array}{l}6.5 \pm 2.3 \\
7.3 \pm 2.3 \\
7.9 \pm 1.5 \\
7.9 \pm 1.6 \\
8.4 \pm 2.4 \\
8.0 \pm 1.6 \\
7.5 \pm 2.0\end{array}$ & $\begin{array}{l}7.3 \pm 2.0 \\
6.8 \pm 1.9 \\
8.8 \pm 2.3 \\
9.3 \pm 3.5 \\
8.5 \pm 2.1 \\
6.4 \pm 1.1 \\
8.6 \pm 2.5\end{array}$ \\
\hline
\end{tabular}


pumpi flow and cardiac output $\left(1, \mathrm{~min}^{-1}\right)$.

Time

\begin{tabular}{|c|c|c|c|c|c|}
\hline & $N+N B$ & $H+H B$ & $c$ & $N C$ & $\mathrm{HC}$ \\
\hline $\begin{array}{l}\text { pre } C P B \\
\text { during } C P B\end{array}$ & $2.5 \pm 0.7$ & $2.4 \pm 0.4$ & $2.0 \pm 0.5$ & $2.1 \pm 0.6$ & $2.3 \pm 0.9$ \\
\hline 5 min $n(E B)$ & $2.3 \pm 0.7$ & $2.6 \pm 0.5$ & $1.7 \pm 0.3$ & $1.8 \pm 0.7$ & $2.3 \pm 0.8$ \\
\hline 10 min $(F)$ & $2.2 \pm 0.7$ & $2.5 \div 0.5$ & $1.6 \pm 0.3$ & $1.8 \pm 0.7$ & $2.2 \pm 1.0$ \\
\hline 45 min & $2 \pm 1 \pm 0.7$ & $2.4 \pm 0.6$ & $1.4 \pm 0.3$ & $1.8 \pm 0.7$ & $1.8 \pm 1.0$ \\
\hline 75 min & $2.1 \pm 0.7$ & $2.3 \pm 0.5$ & $1.3 \pm 0.2$ & $1.5 \pm 0.4$ & $1.5 \pm 0.8$ \\
\hline $105 \mathrm{mth}$ & $2.1 \pm 0.8$ & $2.1 \pm 0.5$ & $1.4 \pm 0.3$ & $1.7 \pm 0.6$ & $1.5 \pm 0.9$ \\
\hline $135 \mathrm{~min}$ & $2.1 \pm 0.8$ & $2.1 \pm 0.6$ & $1.5 \pm 0.2$ & $1.5 \pm 0.4$ & $1.6 \pm 0.8$ \\
\hline post CPB & $2.8 \pm 0.7$ & $3.3 \pm 0.7$ & $2.5 \pm 0.4$ & $3.1 \pm 1.4$ & $3.8 \pm 1.3$ \\
\hline
\end{tabular}

Group 
Appendix 6. Coronary artery blood flow. The overall left ventricular blood flow data are obtained from the combined measurements with radioactive microspheres and magnetic flow probes situated around the LAICA. Mean values and SD are presented $(\mathrm{m}) \cdot \mathrm{min}^{-1} \cdot \mathrm{g}^{-1}$ of heart tissue).

Törne

\begin{tabular}{c}
\hline \\
\\
pre CPB \\
during $C P B$ \\
5 min \\
10 min \\
45 min \\
75 min \\
105 min \\
135 min \\
post $C P B$ \\
15 min \\
30 min \\
60 min
\end{tabular}

Group

\begin{tabular}{|c|c|c|}
\hline $\mathrm{NC}$ & $\mathrm{HC}$ & $\mathrm{CON}$ \\
\hline $0.57 \pm 0.21$ & $0.57 \pm 0.15$ & $0.54 \pm 0.16$ \\
\hline $\begin{array}{l}0.88 \pm 0.80 \\
0.56 \pm 0.18 \\
0.68 \pm 0.19 \\
0.54 \pm 0.20 \\
0.71 \pm 0.42 \\
0.58 \pm 0.17\end{array}$ & $\begin{array}{l}0.78 \pm 0.23 \\
0.63 \pm 0.19 \\
0.50 \pm 0.27 \\
0.43 \pm 0.21 \\
0.68 \pm 0.45 \\
0.72 \pm 0.24\end{array}$ & $\begin{array}{c}- \\
- \\
0.57 \pm 0.23 \\
- \\
-\end{array}$ \\
\hline $\begin{array}{l}0.64 \pm 0.28 \\
0.91 \pm 0.71 \\
0.68 \pm 0.22\end{array}$ & $\begin{array}{l}1.38 \pm 0.76 \\
1.31 \pm 0.55 \\
0.81 \pm 0.20\end{array}$ & $\begin{array}{c}0.65 \pm 0.30 \\
- \\
0.57 \pm 0.25\end{array}$ \\
\hline
\end{tabular}


Appendix 7. Epicardial defomation parameters and derived parameters before (time 0 min) and 15 and 60 min after cardiopulmonary bypass. Mean values and $S D$ are presented. $e_{C}=$ natural tangential strain, $e_{z}=$ natural axial strain, $e_{z c}=$ shear angle, $e_{\text {max }}=$ maximum shortening on the epicardium, e endo,est = estimated subendocardial fiber shortening.

\begin{tabular}{|c|c|c|c|c|c|c|c|}
\hline \multirow[t]{2}{*}{ Varíable } & \multirow{2}{*}{$\begin{array}{l}\text { Timle } \\
\text { (min) }\end{array}$} & \multicolumn{6}{|c|}{ Group } \\
\hline & & $\begin{array}{c}N \\
(n=7)\end{array}$ & $\begin{array}{c}H \\
(n=4)\end{array}$ & $\begin{array}{c}c \\
(n=8)\end{array}$ & $\begin{array}{c}M C \\
(n=5)\end{array}$ & $\begin{array}{c}H C \\
(n=6)\end{array}$ & $\begin{array}{c}C O N \\
(n=5)\end{array}$ \\
\hline $\mathrm{e}_{\mathrm{c}}(\mathrm{w})$ & $\begin{array}{r}0 \\
15 \\
60\end{array}$ & $\begin{array}{l}5.2 \pm 3.7 \\
2.8 \pm 4.0 \\
5.9 \pm 5.4\end{array}$ & $\begin{array}{l}2.7 \pm 6.6 \\
2.6 \pm 1.9 \\
3.3 \pm 3.1\end{array}$ & $\begin{array}{l}3.6 \pm 2.8 \\
5.9 \pm 3.7 \\
6.9 \pm 3.0\end{array}$ & $\begin{array}{r}2.7 \pm 1.9 \\
10.3 \pm 6.5 \\
5.8 \pm 6.0\end{array}$ & $\begin{array}{l}2.6 \pm 4.1 \\
6.2 \pm 5.6 \\
4.1 \pm 6.0\end{array}$ & $\begin{array}{l}6.8 \pm 4.2 \\
5.6 \pm 2.5 \\
4.4 \pm 1.3\end{array}$ \\
\hline$e_{Z}(w)$ & $\begin{array}{r}0 \\
15 \\
60\end{array}$ & $\begin{array}{l}4.8 \pm 4.5 \\
5.8 \pm 5.6 \\
5.7 \pm 6.9\end{array}$ & $\begin{array}{l}4.9 \pm 10.2 \\
4.0 \pm 5.9 \\
2.8 \pm 3.2\end{array}$ & $\begin{array}{l}4.0 \pm 3.8 \\
4.0 \pm 5.9 \\
5.0 \pm 5.9\end{array}$ & $\begin{array}{l}2.0 \pm 1.1 \\
3.1 \pm 1.7 \\
4.2 \pm 5.5\end{array}$ & $\begin{array}{l}1.8 \pm 3.4 \\
3.9 \pm 5.1 \\
1.2 \pm 3.3\end{array}$ & $\begin{array}{r}0.2 \pm 5.6 \\
-1.3 \pm 3.6 \\
1.6 \pm 4.2\end{array}$ \\
\hline $\mathrm{e}_{2 c}(\mathrm{rad})$ & $\begin{array}{r}0 \\
15 \\
60\end{array}$ & $\begin{array}{r}-0.01 \pm 0.06 \\
0.03 \pm 0.10 \\
0.04 \pm 0.11\end{array}$ & $\begin{array}{l}0.01 \pm 0.07 \\
0.02 \pm 0.07 \\
0.03 \pm 0.08\end{array}$ & $\begin{array}{l}0.09 \pm 0.06 \\
0.04 \pm 0.07 \\
0.06 \pm 0.10\end{array}$ & $\begin{array}{l}0.07 \pm 0.06 \\
0.08 \pm 0.01 \\
0.05 \pm 0.07\end{array}$ & $\begin{array}{l}0.00 \pm 0.07 \\
0.04 \pm 0.08 \\
0.04 \pm 0.07\end{array}$ & $\begin{array}{l}0.04 \pm 0.09 \\
0.00 \pm 0.04 \\
0.01 \pm 0.06\end{array}$ \\
\hline $\mathrm{e}_{\max }\left(\begin{array}{l}y^{\prime} \\
)\end{array}\right.$ & $\begin{array}{r}0 \\
15 \\
60\end{array}$ & $\begin{array}{r}8.8 \pm 4.2 \\
9.4 \pm 6.5 \\
10.5 \pm 7.0\end{array}$ & $\begin{array}{l}7.3 \pm 10.6 \\
7.2 \pm 3.8 \\
7.8 \pm 2.8\end{array}$ & $\begin{array}{r}8.9 \pm 3.2 \\
10.3 \pm 3.6 \\
11.8 \pm 3.9\end{array}$ & $\begin{array}{r}5.8 \pm 3.4 \\
12.4 \pm 5.3 \\
10.4 \pm 6.3\end{array}$ & $\begin{array}{r}6.1 \pm 3.0 \\
20.7 \pm 4.1 \\
6.9 \pm 6.1\end{array}$ & $\begin{array}{r}10.0 \pm 3.0 \\
6.4 \pm 2.3 \\
6.5 \pm 1.6\end{array}$ \\
\hline Eendi, est & $\begin{array}{r}(*) \quad 0 \\
15 \\
60\end{array}$ & $\begin{array}{l}9.314 .9 \\
6.2 \pm 6.4 \\
9.6 .12 .4\end{array}$ & $\begin{array}{l}5.5 \pm 19.8 \\
4.6 \pm 7.6 \\
7.0 \pm 4.7\end{array}$ & $\begin{array}{l}5.2 \pm 4.5 \\
7.5 \pm 5.7 \\
9.5 \pm 5.9\end{array}$ & $\begin{array}{l}3.0 \pm 3.3 \\
9.4 \pm 9.5 \\
8.9 \pm 4.8\end{array}$ & $\begin{array}{l}2.5 \pm 4.6 \\
7.5 \pm 5.5 \\
3.1 \pm 5.6\end{array}$ & $\begin{array}{l}3.6 \pm 3.1 \\
2.7 \pm 3.8 \\
4.3 \pm 5.5\end{array}$ \\
\hline
\end{tabular}


Appendix 8 . Blaod gas values. Mean values and 50 are presented. pH values of arterial blood.

Time

N

pre $C P B$

during $C P B$

5 min

$10 \mathrm{~min}$

$45 \mathrm{~min}$

75 min

$105 \mathrm{~min}$

post $\mathrm{CPB}$

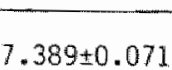

$7.483 \pm 0.134$

$7.488 \pm 0.154$

$7.485 \pm 0.089$

$7.449 \pm 0.075$

$7.437 \pm 0.084$

$7.407 \pm 0.080$
H

$7.392 \pm 0.080$

$7.450 \pm 0.104$

$7.444 \pm 0.102$

$7.528 \pm 0.169$

$7.549 \pm 0.144$

$7.550 \pm 0.121$

$7.469 \pm 0.067$

$7.353 \pm 0.087$

$7.363 \pm 0.087$

$7.357 \pm 0.120$
C

$7.393 * 0.054$

$7.498 \pm 0.127$

$7.594 \pm 0.102$

$7.658 \pm 0.101$

$7.676 \pm 0.095$

$7.436 \pm 0.049$

$7.415 \pm 0.033$

$7.341 \pm 0.062$

$7.340 \pm 0.078$

$7.350 \pm 0.085$

Time

$7.351 \pm 0.104$

$7.387 \pm 0.074$

Group

\begin{tabular}{ccccc}
\hline NC & HC & CON & EC \\
\cline { 5 - 6 } \cline { 5 - 6 } $7.387 \pm 0.034$ & $7.407 \pm 0.051$ & $7.418 \pm 0.087$ & $7.410 \pm 0.089$ \\
$7.407 \pm 0.075$ & $7.488 \pm 0.114$ & - & - \\
$7.380 \pm 0.086$ & $7.583 \pm 0.147$ & $7.415 \pm 0.075$ & - \\
$7.441 \pm 0.072$ & $7.558 \pm 0.138$ & $7.393 \pm 0.081$ & $7.422 \pm 0.064$ \\
$7.398 \pm 0.090$ & $7.573 \pm 0.141$ & $7.402 \pm 0.062$ & - \\
$7.409 \pm 0.066$ & $7.597 \pm 0.165$ & $7.384 \pm 0.058$ & $7.407 \pm 0.036$ \\
$7.426 \pm 0.062$ & $7.509 \pm 0.057$ & $7.394 \pm 0.079$ & -
\end{tabular}

post $C P B$

pre CPB

during $C P B$

$5 \mathrm{~min}$

$10 \mathrm{~min}$

$45 \mathrm{~min}$

75 min

105 min

$135 \mathrm{~min}$

15 min

30 min

$60 \mathrm{~min}$
$7.336 \pm 0.095 \quad 7.346 \pm 0.100$

$7.328 \pm 0.131 \quad 7.348 \pm 0.093$

$7.415 \pm 0.048 \quad 7.402 \pm 0.065$
$7.416 \pm 0.049$

$7.425 \pm 0.073$
$7.434 \pm 0.027$

$7.412 \pm 0.028$ 
$\mathrm{pCO}_{2}$ values of arterial blaod $(\mathrm{kPa})$.

Trme

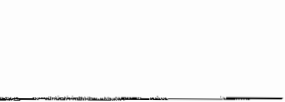

pre CPD

during $C P B$

5 min

10 min

45 min

75 min

105 min

135 min

post CPB

15 min

30 min

60 min

N

$5.4 \pm 1.2$

4. $7 \pm 1.1$

$4.2 \pm 1.1$

$4.3 \pm 0.5$

$4.5 \pm 0.5$

$4.6 \pm 0.6$

$4.9 \pm 0.8$

$5.8 \pm 0.8$

$5.8 \pm 1.2$

$5.5 \pm 1.2$
Group

th

c

$5.4 \pm 1.3$

$5.2+0.5$

$5.1+1.6$

$4.5 \pm 1.0$

$5.1 \pm 1.9$

$4.0 \pm 2.5$

$3.6 \pm 2.0$

$3.4 \pm 1.5$

$3.9+1.1$

3. $3 \pm 0.8$

$2.5 \pm 0.5$

2. $3 \pm 0.4$

$4.4 \pm 0.7$

$4.6 \pm 0.5$

$6.5 \pm 1.5$

$6.3+1.5$

$6.1 \pm 1.2$

$5.8 \pm 1.5$

$6.1 \pm 1.9$

$6.1 \pm 1.3$
Time

post CPB

pre CPB

during $\mathrm{CPB}$

5 min

10 min

$45 \mathrm{~min}$

75 min

$105 \mathrm{~min}$

$135 \mathrm{~min}$

15 min

30 min

60 min

NC

$5.5 \pm 0.6$

$5.5 \pm 1.2$

$5.4 \pm 1.1$

$4.5 \pm 0.6$

$4.7 \pm 0.9$

$4.9 \pm 0.8$

$4.7 \pm 1.0$

$5.7 \pm 1.3$

$5.9 \pm 1.6$

$5.3 \pm 0.5$
Group

CON

EC

$5.1+1.1$

$5.0 \pm 0.8$

$5.3 \pm 0.7$

$4.8 \pm 1.6$

$4.0 \pm 1.6$

$3.6 \pm 1.8$

$3.3 \pm 1.8$

$3.2 \pm 1.8$

$3.9 \pm 0.8$

$5.1 \pm 1.4$

$4.5 \pm 0.8$

$5.0 \pm 1.1$

4. $9+1.2$

$4.8 \pm 1.1$

$6.1 \pm 1.7$

$5.9 \pm 1.3$

$5.5 \pm 0.8$

$4.7 \pm 1.0$

$5.2 \pm 0.8$

4. $7 \pm 1.4$

$5.2 \pm 0.4$ 
$\mathrm{PO}_{2}$ values of arterial blood (kPa).

Time

+2.

pre $C P B$

during $C P B$

$5 \mathrm{~min}$

$10 \min$

45 min

75 min

$105 \mathrm{~min}$

post $C P B$

Time

$15 \mathrm{mim}$
$30 \mathrm{~min}$
$60 \mathrm{mitm}$

\begin{tabular}{ccc}
\multicolumn{3}{c}{ Group } \\
\hline $\mathrm{N}$ & $\mathrm{C}$ & $\mathrm{C}$ \\
\hline $24.8 \pm 6.7$ & $28.4 \pm 7.1$ & $29.2 \pm 5.5$ \\
$48.3 \pm 20.7$ & $41.9 \pm 27.1$ & $50.1 \pm 20.8$ \\
$56.3 \pm 18.4$ & $41.1 \pm 22.8$ & $52.4 \pm 22.8$ \\
$58.8 \pm 16.3$ & $58.3 \pm 26.4$ & $65.6 \pm 16.0$ \\
$60.0 \pm 18.1$ & $61.7 \pm 25.6$ & $51.7 \pm 17.1$ \\
$64.8 \pm 17.5$ & $52.9 \pm 28.8$ & $50.9 \pm 19.2$ \\
$58.1 \pm 20.4$ & $50.0 \pm 24.3$ & $54.0 \pm 15.7$ \\
$40.1 \pm 21.3$ & $21.9 \pm 19.9$ & $24.8 \pm 16.3$ \\
$37.7 \pm 24.3$ & $24.7 \pm 17.7$ & $22.8 \pm 15.3$ \\
$45.3 \pm 24.4$ & $17.5 \pm 7.9$ & $21.9 \pm 16.4$
\end{tabular}

Group 
Appendix 9. Arterial concentration of lactate, inorganic phosphate, potassium and glucose. Mean values and SD are presented (mol. $1^{-1}$ ). Arterial lactate concentration (mol. $1^{-1}$ ).

Tirme

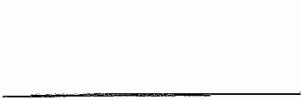

pre $C P B$

during $C P B$

post CPB

$\begin{array}{rr}5 \mathrm{~min} & 3.92 \pm 2.28 \\ 10 \mathrm{~min} & 4.37 \pm 1.98 \\ 45 \mathrm{~min} & 6.77 \pm 2.94 \\ 75 \mathrm{~min} & 7.83 \pm 2.54 \\ 105 \mathrm{~min} & 7.54 \pm 1.92 \\ 135 \mathrm{~min} & 8.13 \pm 2.64\end{array}$

$15 \mathrm{~min}$

30 min

$60 \mathrm{~min}$
$7.17 \pm 1.46$
$6.99 \pm 1.97$
$6.85 \pm 2.61$

Group

H

N

$2.37 \pm 1.30$

\begin{tabular}{|c|c|}
\hline$H$ & C \\
\hline $3.02 \pm 2.20$ & $2.24 \pm 1.32$ \\
\hline $\begin{array}{l}4.86 \pm 2.43 \\
6.34 \pm 3.45 \\
8.14 \pm 2.48 \\
8.19 \pm 2.65 \\
8.24 \pm 2.55 \\
8.62 \pm 2.54\end{array}$ & $\begin{array}{c}3.31 \pm 1.95 \\
4.75 \pm 2.16 \\
- \\
6.27 \pm 2.16 \\
6.31 \pm 2.51 \\
6.25 \pm 1.89\end{array}$ \\
\hline $\begin{array}{l}8.87 \pm 2.42 \\
8.31 \pm 2.70 \\
8.11 \pm 3.53\end{array}$ & $\begin{array}{l}6.26 \pm 2.61 \\
5.83 \pm 2.35 \\
6.02 \pm 2.84\end{array}$ \\
\hline
\end{tabular}

Time

pre $C P B$

during $C P B$

$5 \mathrm{~min}$

$10 \min$

$45 \mathrm{~min}$

$75 \min$

$105 \mathrm{~min}$

post CPB

$135 \mathrm{~min}$

$15 \mathrm{~min}$

30 min

$60 \mathrm{~min}$
NC

$2.33 \pm 1.20$

$4.10 \pm 2.69$

$4.87 \pm 2.63$

$6.10 \pm 1.93$

$6.20 \pm 1.96$

$6.58 \pm 1.68$

$6.36 \pm 2.26$

$5.39 \pm 2.40$

$5.49 \pm 2.52$

$5.15 \pm 2.63$
Group

$H C$

CON

$2.46 \pm 1.92$

$2.68 \pm 1.15$

$4.22 \pm 2.32$

$2.61 \pm 1.07$

$4.02 \pm 1.64$

$6.26 \pm 2.01$

$2.70 \pm 1.11$

$6.40+2.06$

$2.44 \pm 0.97$

$6.27 \pm 1.99$

$3.02 \pm 1.41$

$6.50 \pm 2.09$

$3.34 \pm 1.77$

$7.04 \pm 2.66$

$3.74 \pm 2.44$

$6.37 \pm 2.45$

$5.72 \pm 2.47$ 
Arterial concentration of inorganic phosphate (rnuol.1-1).

Time

pre CPB

during $C P B$

$\begin{array}{rl}5 \min & 1.39 \pm 0.47 \\ 10 \mathrm{~min} & 1.44 \pm 0.43 \\ 45 \mathrm{~min} & 1.36 \pm 0.42 \\ 75 \mathrm{~min} & 1.27 \pm 0.48 \\ 105 \mathrm{~min} & 1.17 \pm 0.32 \\ 135 \mathrm{~min} & 1.16 \pm 0.34\end{array}$

post CPB

$15 \mathrm{~min}$

$30 \mathrm{~min}$

$60 \mathrm{~min}$
$1.20 \pm 0.14$

$1.25 \pm 0.03$

$1.52 \pm 0.15$
Group

H

c

$1.58 \pm 0.72$

$1.97 \pm 0.33$

$1.20 \pm 0.53$

$1.08 \pm 0.59$

$1.07 \pm 0.50$

$0.93 \pm 0.54$

$0.75 \pm 0.43$

$0.78 \pm 0.41$

$0.99 \pm 0.47$

$1.16 \pm 0.48$

$1.47 \pm 0.53$
$1.40 \pm 0.13$

$1.59 \pm 0.27$

$1.15 \pm 0.22$

$1.19 \pm 0.24$

$1.27 \pm 0.25$

$1.48 \pm 0.24$

$1.60 \pm 0.25$

$1.83 \pm 0.31$

Time

Group

\begin{tabular}{|c|c|c|}
\hline NC & $\mathrm{HC}$ & CON \\
\hline $1.84 \pm 0.49$ & $1.66 \pm 0.55$ & $1.76 \pm 0.33$ \\
\hline $\begin{array}{l}1.35 \pm 0.30 \\
1.52 \pm 0.19 \\
1.13 \pm 0.32 \\
1.15 \pm 0.32 \\
1.10 \pm 0.32 \\
1.18 \pm 0.35\end{array}$ & $\begin{array}{l}1.28 \pm 0.32 \\
1.39 \pm 0.24 \\
1.13 \pm 0.30 \\
1.00 \pm 0.28 \\
0.98 \pm 0.24 \\
0.89 \pm 0.26\end{array}$ & $\begin{array}{c}1.77 \pm 0.33 \\
- \\
1.67 \pm 0.22 \\
1.82 \pm 0.28 \\
1.86 \pm 0.43 \\
1.86 \pm 0.35\end{array}$ \\
\hline $\begin{array}{l}1.46 \pm 0.30 \\
1.54 \pm 0.28 \\
1.75 \pm 0.28\end{array}$ & $\begin{array}{l}1.08 \pm 0.31 \\
1.20 \pm 0.36 \\
1.50 \pm 0.49\end{array}$ & $\begin{array}{c}1.92 \pm 0.35 \\
- \\
2.07 \pm 0.41\end{array}$ \\
\hline
\end{tabular}

pre $C P B$

during $C P B$

5 min

10 min

45 min

75 min

$105 \mathrm{~min}$

post $\mathrm{CPB}$

$15 \mathrm{mim}$

$30 \mathrm{mim}$

60 min

$1.54 \pm 0.28$

$1.75 \pm 0.28$

$1.28 \pm 0.32$

$1.39 \pm 0.24$

$1.13 \pm 0.30$

$1.00 \pm 0.28$

$0.88 \pm 0.24$

0.35

$1.20 \pm 0.36$

$.50 \pm 0.49$

$1.77 \pm 0.33$

$1.67 \pm 0.22$

$1.82-0.28$

$1.86 \pm 0.43$

$1.86 \pm 0.35$

$2.07 \pm 0.41$ 
Arterial potassium concentration (mal.1-1).

Time

N

\section{pre CPB}

during $C P B$

5 min

10 min

$45 \mathrm{~min}$

75 min

$105 \mathrm{~min}$

post $\mathrm{CPB}$

$135 \mathrm{~min}$

15 min

30 min

60 min

\begin{tabular}{ccc}
\hline$N$ & $H$ & $C$ \\
$3.49 \pm 0.26$ & $3.54 \pm 0.70$ & $3.45 \pm 0.57$ \\
$3.78 \pm 0.46$ & $3.78 \pm 0.61$ & $3.90 \pm 0.44$ \\
$3.63 \pm 0.43$ & $3.08 \pm 0.44$ & $3.83 \pm 0.74$ \\
$3.22 \pm 0.62$ & $2.94 \pm 0.84$ & \\
$3.08 \pm 0.51$ & $2.80 \pm 1.11$ & $3.76 \pm 0.61$ \\
$2.89 \pm 0.23$ & $2.93 \pm 0.88$ & $3.49 \pm 0.31$ \\
$3.11 \pm 0.55$ & $2.96 \pm 0.69$ & $3.47 \pm 0.26$ \\
$2.94 \pm 0.20$ & $2.60 \pm 0.43$ & $3.23 \pm 0.18$ \\
$2.90 \pm 0.19$ & $2.49 \pm 0.31$ & $3.23 \pm 0.30$ \\
$2.95 \pm 0.24$ & $2.76 \pm 0.38$ & $3.29 \pm 0.31$ \\
& &
\end{tabular}

Time

Group

NC

HC

CON

pre $C P B$

during $C P B$

5 min

10 min

$45 \mathrm{~min}$

$75 \mathrm{~min}$

$105 \mathrm{~min}$

post CPB

$135 \mathrm{~min}$

$15 \mathrm{~min}$

$30 \mathrm{~min}$

$60 \mathrm{~min}$

Group

$3.49 \pm 0.31$

$\pm 0.26$

$3.23 \pm 0.18$

$3.29 \pm 0.31$

\begin{tabular}{|c|c|c|}
\hline NC & $H C$ & $\mathrm{CON}$ \\
\hline $3.75 \pm 0.37$ & $3.60 \pm 0.69$ & $3.48 \pm 0.68$ \\
\hline $\begin{array}{l}4.15 \pm 0.38 \\
4.01 \pm 0.19 \\
3.52 \pm 0.39 \\
3.45 \pm 0.38 \\
3.25 \pm 0.30 \\
3.48 \pm 0.52\end{array}$ & $\begin{array}{l}3.87 \pm 0.69 \\
3.97 \pm 0.81 \\
3.08 \pm 0.76 \\
3.14 \pm 0.73 \\
3.19 \pm 0.65 \\
3.44 \pm 0.68\end{array}$ & $\begin{array}{c}3.53 \pm 0.67 \\
- \\
3.25 \pm 0.47 \\
3.64 \pm 0.46 \\
3.71 \pm 0.63 \\
3.74 \pm 0.52\end{array}$ \\
\hline $\begin{array}{l}3.40 \pm 0.68 \\
3.15 \pm 0.40 \\
3.55 \pm 0.75\end{array}$ & $\begin{array}{l}2.78 \pm 0.45 \\
2.71 \pm 0.44 \\
2.86 \pm 0.42\end{array}$ & $\begin{array}{c}- \\
3.69 \pm 0.52 \\
4.06 \pm 0.81\end{array}$ \\
\hline
\end{tabular}


Arterial glucose concentration (mimol. $7^{-1}$ ).

\begin{tabular}{|c|c|c|c|}
\hline \multirow[t]{2}{*}{ Time } & \multicolumn{3}{|c|}{ Group } \\
\hline & $N$ & H & c \\
\hline \multirow{3}{*}{$\begin{array}{l}\text { pre CPB } \\
\text { during CPB } \\
60 \text { min } \\
135 \text { min } \\
\text { post CPB } \\
15 \text { min }\end{array}$} & $6.3 \pm 0.9$ & $7.2 \pm 0.9$ & $7.9 \pm 2.3$ \\
\hline & $\begin{array}{l}3.6 \pm 1.4 \\
2.4 \pm 1.7\end{array}$ & $\begin{array}{l}4.9 \pm 1.2 \\
5.0 \pm 1.5\end{array}$ & $5.0 \pm 2.1$ \\
\hline & $2.2 \pm 1.9$ & $4.7 \pm 2.1$ & $4.6 \pm 2.4$ \\
\hline \multirow[t]{2}{*}{ Time } & \multicolumn{3}{|c|}{ Group } \\
\hline & NC & $\mathrm{HC}$ & $\mathrm{CON}$ \\
\hline pre $C P B$ & $7.1 \pm 0.8$ & $7.5 \pm 1.8$ & $6.6 \pm 1.7$ \\
\hline $\begin{array}{r}60 \mathrm{~min} \\
135 \mathrm{~min}\end{array}$ & $\begin{array}{l}5.3 \pm 1.6 \\
4.3 \pm 2.3\end{array}$ & $\begin{array}{l}4.8 \pm 1.6 \\
4.8 \pm 1.6\end{array}$ & $6.1 \pm 1.5$ \\
\hline $\begin{array}{l}\text { post } \mathrm{CPB} \\
15 \text { min }\end{array}$ & $3.8 \pm 2.3$ & $4.8 \pm 2.2$ & $5.8 \pm 1.4$ \\
\hline
\end{tabular}


Appendix 10. Arterial-coronary sinus differences of lactate, inorganic phosphate, potassium and oxygen content. Mean values and SD are presented $\left(\operatorname{mmol} .1^{-1}\right)$.

Lactate $\left(\right.$ mino $\left.1.1^{-1}\right)$.

Time

Imorganic phosphate (monol. $1^{-1}$ ).

Time

Group

pre CPB

during $C P B$

5 min

$45 \mathrm{~min}$

75 min

$105 \mathrm{~min}$

$135 \mathrm{~min}$

past CPB

15. min

30 min

Group

\begin{tabular}{|c|c|c|}
\hline NC & $H C$ & CON \\
\hline $0.40 \pm 0.41$ & $-0.07 \pm 0.84$ & $0.29 \pm 0.56$ \\
\hline $\begin{array}{l}0.07 \pm 0.73 \\
0.40 \pm 0.33 \\
0.58 \pm 0.31 \\
0.57 \pm 0.46 \\
0.72 \pm 0.37\end{array}$ & $\begin{array}{r}-0.02 \pm 0.93 \\
0.33 \pm 0.58 \\
0.33 \pm 0.59 \\
0.27 \pm 0.42 \\
0.05 \pm 0.64\end{array}$ & $\begin{array}{r}0.30 \pm 0.25 \\
0.04 \pm 0.61 \\
0.22 \pm 0.52 \\
0.19 \pm 0.60 \\
-0.06 \pm 0.81\end{array}$ \\
\hline $\begin{array}{l}0.66 \pm 0.46 \\
0.86 \pm 0.23 \\
0.81 \pm 0.20\end{array}$ & $\begin{array}{l}0.38 \pm 0.24 \\
0.44 \pm 0.33 \\
0.24 \pm 0.24\end{array}$ & $\begin{array}{c}0.09 \pm 0.71 \\
- \\
0.20 \pm 0.61\end{array}$ \\
\hline
\end{tabular}

$0.24 \pm 0.24$

$0.20 \pm 0.61$
Time

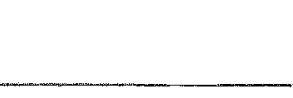

pre CPB

during CPB

5 mî̀

45 กับ

75 min

105 mกิำ

post CPB
NC

$-0.02+0.09$

$-0.11 \pm 0.19$

$0.02+0.04$

$0.05 \pm 0.05$

$0.05 \pm 0.04$.

$0.03 \pm 0.06$

$-0.04 \pm 0.07$

$-0.04 \pm 0.09$

$0.02 \pm 0.08$

$H C$
$-0.05 \pm 0.12$
$0.00 \pm 0.11$
$0.04 \pm 0.05$
$0.05 \pm 0.05$
$0.04 \pm 0.05$
$-0.02 \pm 0.07$
$-0.01 \pm 0.04$
$0.03 \pm 0.04$
$0.02 \pm 0.05$

CON

$-0.03 \pm 0.05$

$-0.08 \pm 0.09$

$-0.13 \pm 0.25$

$-0.07 \pm 0.13$

$-0.04 \pm 0.12$

$-0.11 \pm 0.25$

$-0.08 \pm 0.20$

$-0.01 \pm 0.11$ 
Potassium (mnol.1 $1^{-1}$ ).

Tine

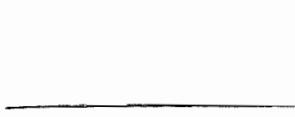

\section{pre CPB}

during $C P B$

$\begin{array}{rl}5 \mathrm{~min} & 0.03 \pm 0.27 \\ 45 \mathrm{~min} & 0.18 \pm 0.08 \\ 75 \mathrm{~min} & 0.16 \pm 0.15 \\ 105 \mathrm{~min} & 0.10 \pm 0.15 \\ 135 \mathrm{~min} & 0.08 \pm 0.16\end{array}$

post CPB

\begin{tabular}{ccc}
\hline NC & HC & CoN \\
\cline { 2 - 3 }$-0.04 \pm 0.20$ & $-0.14 \pm 0.33$ & $-0.04 \pm 0.06$ \\
$0.03 \pm 0.27$ & $0.24 \pm 0.36$ & $-0.16 \pm 0.18$ \\
$0.18 \pm 0.08$ & $0.14 \pm 0.14$ & $-0.30 \pm 0.49$ \\
$0.16 \pm 0.15$ & $0.17 \pm 0.17$ & $-0.21 \pm 0.29$ \\
$0.10 \pm 0.15$ & $0.05 \pm 0.24$ & $-0.11 \pm 0.19$ \\
$0.08 \pm 0.16$ & $-0.04 \pm 0.19$ & $-0.31 \pm 0.57$ \\
$-0.01 \pm 0.11$ & $0.03 \pm 0.13$ & $-0.11 \pm 0.34$ \\
$-0.08 \pm 0.18$ & $-0.01 \pm 0.20$ & $-0.20 \pm 0.33$ \\
$0.09 \pm 0.28$ & $-0.02 \pm 0.08$ & -0.39 \\
\hline
\end{tabular}

oxygen (monol. $y^{-1}$ ).

Time

15 min

30 min

$60 \mathrm{~min}$

\begin{tabular}{ccc}
\hline$N C$ & HC & CON \\
\cline { 2 - 3 } $4.51 \pm 1.43$ & $3.73 \pm 1.56$ & - \\
$1.90 \pm 0.82$ & $2.08 \pm 0.85$ & $4.23 \pm 1.53$ \\
$2.11 \pm 0.60$ & $1.09 \pm 0.46$ & $4.43 \pm 1.08$ \\
$2.25 \pm 1.11$ & $1.02 \pm 0.63$ & $4.50 \pm 1.18$ \\
$1.88 \pm 1.00$ & $1.43 \pm 0.51$ & $3.99 \pm 0.73$ \\
$2.32 \pm 1.07$ & $2.12 \pm 0.61$ & $4.09 \pm 1.07$ \\
$3.06 \pm 0.79$ & & $4.18 \pm 0.70$ \\
$3.18 \pm 0.84$ & $2.36 \pm 0.53$ & \\
$3.92 \pm 0.50$ & $2.54 \pm 0.57$ & $4.08 \pm 0.77$ \\
& $2.86 \pm 0.69$ & $4.53 \pm 1.37$
\end{tabular}

pre CPB

during $C P B$

5 min

45 rilin

$75 \mathrm{~min}$

105 min

post $\mathrm{CPB}$
15 畔
$30 \mathrm{~min}$
$60 \mathrm{~min}$

Growp

$0.24 \pm 0.36$

$0.17 \pm 0.17$

$0.05 \pm 0.24$

$-0.11 \pm 0.19$

$-0.31 \pm 0.57$

$-0.11 \pm 0.34$

$-0.20+0.33$ 
Appendix 11. Uptake and release of lactate, inorganic phosphate and potassium, and oxygen consumption as calculated from the arterialcoronary sinus differences and coronary flow values. Mean values and SD are presented $\left(\right.$ mol. $g^{-1}$. min $\left.{ }^{-1}\right)$.

Lactate (umo $) \cdot g^{-1} \cdot \mathrm{min}^{-1}$ )

Time

-

pre $C P B$

during $C P B$

post CPB

$\begin{array}{rl}5 \mathrm{~min} & 0.26 \pm 1.02 \\ 45 \mathrm{~min} & 0.25 \pm 0.17 \\ 75 \mathrm{~min} & 0.22 \pm 0.15 \\ 105 \mathrm{~min} & 0.33 \pm 0.45 \\ 135 \mathrm{~min} & 0.41 \pm 0.24\end{array}$

15 min

$30 \mathrm{~min}$

$60 \min$
$0.49 \pm 0.27$

$0.82 \pm 0.85$

$0.53 \pm 0.23$
Group

$\mathrm{HC}$

CON

$0.27 \pm 0.40$

$-0.07 \pm 0.46$

$0.29 \pm 0.16$

$0.20 \pm 0.55$

$0.17 \pm 0.37$

$0.42 \pm 0.18$

$0.35 \pm 0.17$

$-0.07 \pm 0.36$

$0.18 \pm 0.53$

$0.57 \pm 0.48$

$0.60 \pm 0.47$

$0.19 \pm 0.21$

$0.13 \pm 0.28$

Inorganic phosphate $\left(\mu \mathrm{mol} \cdot \mathrm{g}^{-1} \cdot \mathrm{min}^{-1}\right)$

Time

post $\mathrm{CPB}$

pre $C P B$

during $C P B$

$5 \mathrm{~min}$

$45 \mathrm{~min}$

$75 \mathrm{~min}$

$105 \mathrm{~min}$

$135 \mathrm{~min}$

$15 \mathrm{~min}$

$30 \mathrm{~min}$

$60 \mathrm{~min}$
NC

$-0.01 \pm 0.04$

$-0.09 \pm 0.08$

$0.00 \pm 0.03$

$0.01 \pm 0.02$

$0.03 \pm 0.06$

$0.00 \pm 0.03$

$-0.03 \pm 0.03$

$-0.05 \pm 0.07$

$0.02 \pm 0.05$
Group

$\mathrm{HC}$

$\mathrm{CON}$

$-0.01 \pm 0.03$

$-0.03 \pm 0.07$

$-0.06 \pm 0.13$

$0.02 \pm 0.02$

$0.02 \pm 0.02$

$0.01 \pm 0.03$

$-0.03 \pm 0.05$

$-0.07 \pm 0.08$

$-0.17 \pm 0.30$

$-0.05 \pm 0.08$

$-0.01 \pm 0.10$

$-0.07 \pm 0.13$

$-0.02 \pm 0.10$

$0.01 \pm 0.13$

$0.02 \pm 0.05$

$0.02 \pm 0.05$ 
Patassium (umal. $\mathrm{g}^{-1} \cdot \mathrm{min}^{-1}$ )

Time

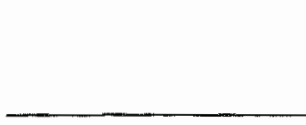

\section{pre $C P B$}

during $C P B$

5 min

$45 \mathrm{~min}$

75 min

105 min

post $C P B$

$135 \mathrm{~min}$

$15 \mathrm{~min}$

$30 \mathrm{~min}$

$60 \mathrm{~min}$
NC

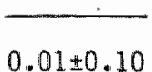

$0.07 \pm 0.30$

$0.12 \pm 0.06$

$0.08 \pm 0.08$

$0.10 \pm 0.19$

$0.01 \pm 0.08$

$-0.03 \pm 0.07$

$-0.10 \pm 0.15$

$0.04 \pm 0.18$
Group

$H C$

CON

$-0.02 \pm 0.04$

$-0.09 \pm 0.15$

$-0.39 \pm 0.53$

$-0.12 \pm 0.18$

$-0.06 \pm 0.20$

$-0.19 \pm 0.17$

$-0.03 \pm 0.31$

$0.07 \pm 0.18$

$0.01 \pm 0.11$

$-0.01 \pm 0.08$

$-0.10 \pm 0.15$

Oxygen $\left(\mu \mathrm{mol} \cdot \mathrm{g}^{-1} \cdot \mathrm{min}^{-1}\right)$

Tìne

NC

pre $C P B$

during $\mathrm{CPB}$

5 min
45 min
75 min
105 min
135 min

post CPB
Group

\begin{tabular}{ccc}
\hline NC & HC & CON \\
\cline { 2 - 3 } $2.97 \pm 1.58$ & $2.03 \pm 1.00$ & $2.43 \pm 1.24$ \\
$1.58 \pm 1.19$ & $1.89 \pm 0.91$ & $3.43 \pm 0.54$ \\
$1.48 \pm 0.86$ & $0.53 \pm 0.22$ & $4.01 \pm 0.49$ \\
$1.09 \pm 0.50$ & $0.44 \pm 0.28$ & $2.39 \pm 1.30$ \\
$1.20 \pm 0.85$ & $0.84 \pm 0.43$ & $3.29 \pm 1.25$ \\
$1.29 \pm 0.76$ & $1.45 \pm 0.41$ & $3.21 \pm 0.66$ \\
$1.79 \pm 0.84$ & $3.83 \pm 2.62$ & \\
$2.76 \pm 2.14$ & $3.03 \pm 1.13$ & $2.80 \pm 1.70$ \\
$2.30 \pm 0.87$ & $2.53 \pm 0.85$ & $2.54 \pm 1.11$
\end{tabular}


Appendix 12. Plasma enzyme activity, hematocrit and free hemoglobin. Mean walues and SD are presented. Enzyme activity is expressed in units per liter of plasma.

Table a. Plisma enzyne activity of AST (U. $\left.)^{1-}\right)$.

Time

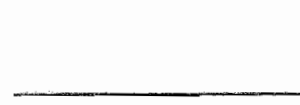

pre CPB

during $C P B$

10 min

35 min

110 min

post CPB

$15 \mathrm{~min}$

$60 \mathrm{~min}$

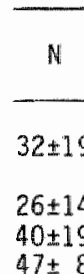

$47 \pm 8$

$65 \pm 8$

$86 \pm 23$
Group

\begin{tabular}{cc}
$H$ & $C$ \\
\hline $29 \pm 27$ & - \\
$25 \pm 16$ & $28 \pm 12$ \\
$34 \pm 37$ & $21 \pm 9$ \\
$55 \pm 42$ & $40 \pm 17$
\end{tabular}

$72 \pm 54$

$80 \pm 54$
$64 \pm 18$

$86 \pm 14$
Time

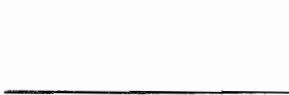

pre $C P B$

during $C P B$

10 min

$35 \mathrm{~min}$

post CPB

$110 \mathrm{~min}$

$15 \mathrm{~min}$

$60 \min$
Group

\begin{tabular}{|c|c|c|c|}
\hline $\mathrm{CON}$ & $N C$ & $H C$ & EC \\
\hline $36 \pm 18$ & $25 \pm 21$ & $33 \pm 15$ & $16 \pm 3$ \\
\hline $\begin{array}{c}- \\
44 \pm 15 \\
53 \pm 21\end{array}$ & $\begin{array}{l}18 \pm 10 \\
22 \pm 12 \\
48 \pm 31\end{array}$ & $\begin{array}{l}22 \pm 8 \\
31 \pm 13 \\
41 \pm 10\end{array}$ & $\begin{array}{l}21 \pm 3 \\
23 \pm 4 \\
25 \pm 3\end{array}$ \\
\hline- & $\begin{array}{l}60 \pm 41 \\
86 \pm 67\end{array}$ & $\begin{array}{l}59 \pm 13 \\
70 \pm 25\end{array}$ & $\begin{array}{l}26 \pm 4 \\
39 \pm 27\end{array}$ \\
\hline
\end{tabular}


Table b. Plasma enzyme activity of ALT (U.1 $\left.1^{1-}\right)$.

Time

post $\mathrm{CPB}$

CPB

during $C P B$

$$
\begin{aligned}
& 10 \mathrm{~min} \\
& 35 \mathrm{~min}
\end{aligned}
$$$$
110 \mathrm{~min}
$$

$15 \mathrm{~min}$

$60 \mathrm{~min}$

N

$13 \pm 7$

$14 \pm 8$

$19 \pm 10$

$21 \pm 9$

$20 \pm 3$
Group

\begin{tabular}{cc}
$H$ & $C$ \\
\hline $19 \pm 11$ & \\
$14 \pm 5$ & $21 \pm 9$ \\
$14 \pm 8$ & $14 \pm 2$ \\
$25 \pm 21$ & $15 \pm 3$ \\
$31 \pm 21$ & $22 \pm 15$ \\
$32 \pm 21$ & $35 \pm 26$ \\
& $53 \pm 34$
\end{tabular}

* - mo measurements due to the determination of plasma volume (injection of 1 iverenzymes).

\begin{tabular}{|c|c|c|c|c|}
\hline & \\
\hline & CON & NC & $\mathrm{HC}$ & $\mathbb{E C}$ \\
\hline pre CPB & $24 \pm 21$ & $26 \pm 22$ & $26 \pm 17$ & $19 \pm 6$ \\
\hline $\begin{array}{r}\text { during CPB } \\
10 \text { min } \\
35 \text { min } \\
110 \text { min }\end{array}$ & $\begin{array}{l}- \\
24 \pm 13 \\
26 \pm 15\end{array}$ & $\begin{array}{l}16 \pm 11 \\
16 \pm 10 \\
23 \pm 9\end{array}$ & $\begin{array}{l}30 \pm 45 \\
33 \pm 51 \\
33 \pm 43\end{array}$ & $\begin{array}{l}18 \pm 5 \\
19 \pm 7 \\
18 \pm 6\end{array}$ \\
\hline $\begin{array}{l}\text { post } C P B \\
15 \text { min } \\
60 \mathrm{~min}\end{array}$ & $\begin{array}{c}- \\
29 \pm 21\end{array}$ & $\begin{array}{l}28 \pm 8 \\
32 \pm 8\end{array}$ & $\begin{array}{l}35 \pm 39 \\
48 \pm 52\end{array}$ & $\begin{array}{l}19 \pm 6 \\
18 \pm 6\end{array}$ \\
\hline
\end{tabular}

Time

Group 
Tabie c. Plasma enzyme activity of creatine kinase $\left(u .1^{2-}\right)$.

Time

during CPB
$10 \mathrm{~min}$
$35 \mathrm{~min}$
$110 \mathrm{~min}$

post $C P B$

Time

n

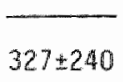

$231 \pm 115$

$333 \pm 222$

$405 \pm 166$

$636 \pm 247$

$797 \pm 380$

Group

\begin{tabular}{|c|c|}
\hline$H$ & $c$ \\
\hline $461 \pm 408$ & $421+492$ \\
\hline $\begin{array}{l}310 \pm 207 \\
452 \pm 464 \\
787 \pm 563\end{array}$ & $\begin{array}{l}240 \pm 161 \\
284 \pm 184 \\
490 \pm 313\end{array}$ \\
\hline $\begin{array}{r}975 \pm 661 \\
1080 \pm 697\end{array}$ & $\begin{array}{l}720 \pm 405 \\
851 \pm 465\end{array}$ \\
\hline
\end{tabular}

\section{rime}

\begin{tabular}{|c|c|c|c|c|}
\hline & \\
\hline & $\mathrm{CON}$ & MC & $\mathrm{HC}$ & $E C$ \\
\hline $\begin{array}{l}\text { pre } C P B \\
\text { during } C P B\end{array}$ & $335 \pm 146$ & $335 \pm 433$ & $470 \pm 327$ & $94 \pm 38$ \\
\hline$\$ 0$ min & - & $214 \pm 184$ & $254 \pm 131$ & $145 \pm 9.6$ \\
\hline $35 \mathrm{~min}$ & $444 \pm 201$ & $264 \pm 134$ & $362 \pm 192$ & $187 \pm 7$ \\
\hline 110 min & $535 \pm 223$ & $653 \pm 578$ & $543 \pm 224$ & $229 \pm 77$ \\
\hline post $C P B$ & & & & $237 \pm 67$ \\
\hline $\begin{array}{l}15 \mathrm{~min} \\
60 \mathrm{~min}\end{array}$ & $586 \pm 258$ & $\begin{array}{c}939 \pm 834 \\
1165 \pm 1213\end{array}$ & $\begin{array}{l}752 \pm 299 \\
988 \pm 450\end{array}$ & $\begin{array}{l}237 \pm 67 \\
259 \pm 52\end{array}$ \\
\hline
\end{tabular}


Table d. Plasma enzyme activity of $M D H\left(U .1^{1-}\right)$.

Time

-

pre $C P B$

during $\mathrm{CPB}$

$10 \mathrm{~min}$

35 min

$110 \mathrm{~min}$

post $\mathrm{CPB}$

$15 \min$

60 min
Group

\begin{tabular}{ccc}
\hline$N$ & $H$ & $C$ \\
$262 \pm 271$ & $-278 \pm 301$ & $191 \pm 109$ \\
$220 \pm 192$ & $219 \pm 103$ & $194 \pm 100$ \\
$287 \pm 193$ & $271 \pm 210$ & $260 \pm 141$ \\
$388 \pm 140$ & $463 \pm 218$ & $431 \pm 223$ \\
$540 \pm 207$ & $615 \pm 241$ & $653 \pm 337$ \\
$825 \pm 354$ & $727 \pm 294$ & $824 \pm 324$
\end{tabular}

Time

pre $\mathrm{CPB}$

during $C P B$

$10 \mathrm{~min}$

$35 \mathrm{~min}$

$110 \mathrm{~min}$

post CPB

15 min

60 min

Group

\begin{tabular}{ccc}
\hline $\operatorname{CON}$ & NC & HC \\
\cline { 2 - 3 } $206 \pm 78$ & $154 \pm 133$ & $227 \pm 90$ \\
- & $162 \pm 126$ & $172 \pm 61$ \\
$307 \pm 58$ & $212 \pm 150$ & $266 \pm 110$ \\
$384 \pm 61$ & $460 \pm 197$ & $391 \pm 117$ \\
- & $614 \pm 272$ & $586 \pm 184$ \\
$489 \pm 148$ & $709 \pm 380$ & $797 \pm 288$
\end{tabular}


Table e. Plasma enzyme activity of HBDH (U.1 ${ }^{1-}$ ).

Time

$$
\begin{array}{r}
\text { during } C P B \\
10 \mathrm{~min} \\
35 \mathrm{~min} \\
110 \mathrm{~min}
\end{array}
$$

pre $\mathrm{CPB}$

post CPB

15. min

$60 \min$
Group

\begin{tabular}{ccc}
\hline \multirow{2}{*}{$N$} & \multicolumn{1}{c}{} & \multicolumn{1}{c}{$C$} \\
& & \\
$65 \pm 82$ & $33 \pm 29$ & $33 \pm 5$ \\
$42 \pm 33$ & $51 \pm 37$ & \\
$78 \pm 56$ & $55 \pm 41$ & $44 \pm 31$ \\
$127 \pm 58$ & $108 \pm 38$ & $48 \pm 39$ \\
$166 \pm 78$ & & $118 \pm 74$ \\
$192 \pm 114$ & $158 \pm 13$ & $175 \pm 88$ \\
& $162 \pm 51$ & $203 \pm 99$
\end{tabular}

Time

pre CPB
during $C P B$
$10 \mathrm{~min}$
$35 \mathrm{~min}$

post $C P B$

$110 \mathrm{~min}$

$15 \mathrm{~min}$

$60 \mathrm{~min}$

Group

\begin{tabular}{crr}
\hline CON & \multicolumn{1}{c}{$N C$} & HC \\
\cline { 2 - 3 } $32 \pm 8$ & $21 \pm 7$ & $26 \pm 9$ \\
- & $26 \pm 25$ & $35 \pm 19$ \\
$52 \pm 7$ & $49 \pm 32$ & $62 \pm 33$ \\
$50 \pm 14$ & $122 \pm 40$ & $105 \pm 41$ \\
- & $149 \pm 35$ & $150 \pm 55$ \\
$51 \pm 23$ & $133 \pm 37$ & $168 \pm 71$
\end{tabular}


Table $f$. Plasma content of free henoglobin (nwhol. $1^{-1}$ ).

Time

$+$

pre $C P B$

during $C P B$

$10 \min$
$35 \min$
$110 \min$

post CPB
$15 \mathrm{~min}$

60 min
Time

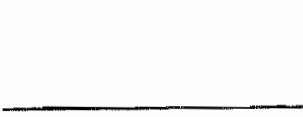

pre $C P B$

during $C P B$
$0.118 \pm 0.036$

$0.118 \pm 0.043$

Group

\begin{tabular}{|c|c|c|}
\hline$N$ & $H$ & c \\
\hline $0.044 \pm 0.007$ & $0.043 \pm 0.023$ & $0.043 \pm 0.017$ \\
\hline $\begin{array}{l}0.041 \pm 0.025 \\
0.061 \pm 0.031 \\
0.094 \pm 0.046\end{array}$ & $\begin{array}{l}0.050 \pm 0.051 \\
0.062 \pm 0.051 \\
0.094 \pm 0.052\end{array}$ & $\begin{array}{l}0.066 \pm 0.058 \\
0.087 \pm 0.076 \\
0.141 \pm 0.112\end{array}$ \\
\hline
\end{tabular}

$0.134 \pm 0.066$

$0.189 \pm 0.151$

$0.137 \pm 0.083$ post $C P B$

$$
\begin{array}{r}
10 \text { min } \\
35 \text { min } \\
110 \text { min }
\end{array}
$$

\begin{tabular}{|c|c|c|}
\hline CON & NC & $H C$ \\
\hline $0.028 \pm 0.010$ & $0.034 \pm 0.015$ & $0.038 \pm 0.029$ \\
\hline $\begin{array}{c}- \\
0.037 \pm 0.025 \\
0.036 \pm 0.023\end{array}$ & $\begin{array}{l}0.049 \pm 0.056 \\
0.047 \pm 0.050 \\
0.087 \pm 0.058\end{array}$ & $\begin{array}{l}0.040 \pm 0.023 \\
0.058 \pm 0.036 \\
0.098 \pm 0.056\end{array}$ \\
\hline$\frac{-}{0.036 \pm 0.029}$ & $\begin{array}{l}0.087 \pm 0.060 \\
0.082 \pm 0.049\end{array}$ & $\begin{array}{l}0.139 \pm 0.084 \\
0.140 \pm 0.102\end{array}$ \\
\hline
\end{tabular}

15 min

$60 \mathrm{~min}$ 
Table g. Hematocrit values $(\%)$.

Tine

Group

\begin{tabular}{|c|c|c|c|c|}
\hline & N & $H$ & c & NC \\
\hline $\begin{array}{l}\text { pre } C P B \\
\text { during } C P B\end{array}$ & $28 \pm 9$ & $30 \pm 8$ & $27 \pm 5$ & $31 \pm 9$ \\
\hline $\begin{array}{r}45 \mathrm{~min} \\
125 \mathrm{~min} \\
\text { post CPB }\end{array}$ & $\begin{array}{l}23 \pm 6 \\
21 \pm 5\end{array}$ & $\begin{array}{l}21 \pm 3 \\
23 \pm 3\end{array}$ & $\begin{array}{l}22 \pm 4 \\
21 \pm 3\end{array}$ & $\begin{array}{l}23 \pm 5 \\
26 \pm 7\end{array}$ \\
\hline 60 min & $24 \pm 3$ & $24 \pm 5$ & $24 \pm 7$ & $29 \pm 8$ \\
\hline
\end{tabular}

Time

Group

\begin{tabular}{|c|c|c|c|c|}
\hline & $\mathrm{HC}$ & $\mathrm{CON}$ & HPLV & EC \\
\hline pre $C P B$ & $29 \pm 7$ & $33 \pm 6$ & $26 \pm 7$ & $31 \pm 5$ \\
\hline $45 \mathrm{~min}$ & $21 \pm 3$ & $33 \pm 5$ & $23 \pm 2$ & $26 \pm 3$ \\
\hline post $\mathrm{CPB}^{125 \mathrm{~min}}$ & $22 \pm 5$ & $31 \pm 7$ & $25 \pm 2$ & $28 \pm 3$ \\
\hline 60 min & $25 \pm 7$ & $30 \pm 8$ & $32 \pm 3$ & $26 \pm 4$ \\
\hline
\end{tabular}




\section{LITERATURE}

Adappa, M.G., Jacobson, L.B., Hetzer, R., Hill, J.D., Kamm, B. and Kerth, W.J.: Cold hyperkalemic cardiac arrest versus intermittent aortic cross-clamping and topical hypothermia for coronary bypass surgery.

J. Thorac. Cardiovasc. Surg. 75: 171-178, 1978 .

Akins, C.W.: Non cardioplegic myocardial preservation for coronary rewascularization.

J. Thorac. Cardiovasc. Surg. 88: 174-181, 1984.

Albert, H., Moccetti, T., Senning A. and Lichtlen, P.: Zur Myocarddurchblutung nach rekonstruktiver Koronarchirurgie.

Schweiz. med. Wschr, 100: 17491759,1970 .

Andersen, K.S., Skjerven, R. and Lekven, J.: Stability of 8-, 15and 25-um microspheres entrapped in feline myocardium.

Am. J. Physial. 244: H121-H131, 1983.

Apstein, C.S., Gravino, F., Hood Jr., W.B., Frazer, J., Hagopian, L. and Bissel1, P.: Limitations of lactate production as an index of myocardial ischemia.

Circulation 60: 877-888, 1979.

Apstein, C.S., Gravino, F.N. and Haudenschild, C.C.: Determinants of a protective effect of glucose and insulin on the ischemic myocardium: Effects an contractile function, diastolic compliance, metabolism and ultrastructure during ischemia and reperfusion.

Circ. Res. 52: 515-527, 1983.

Arts, T. and Reneman, R.S.: Measurement of deformation of camine epicardium in vivo during cardiac cycle.

Am. J. Physiol. 239: H432-H437,
1980.

Arts, T., Veenstra, P.C. and Reneman, R.S.: Epicardial defomation and left ventricular wall mechanics during ejection in the dog.

An. J. Physiol.: H379-H390, 1982.

Badeer, H.: Effect of hypothermila on oxygen consumption and energy utilization of heart.

Circ. Res. 4: 523-526, 1956.

Baer, H. and Blount, S.G." The response of the serum glutamtc oxalacetic transaminase to openheart operation.

Am. Heart J. $60: 867-878,1960$.

Balderman, S.C., Bhayana, J.N., Binette, P., Chau, A. and Gage, A.A.: Perioperative preservation of myocardial ultrastructure and high-energy phosphates im man.

J. Thorac. Cardiovasc. Surg. 82: $860-869,1981$.

Balderman, S.C., Binette, J.P., Chau, A.W.K. and Gage, A.A... The optimal temperature for preservation of the myocardium during global ischemia.

Ann. Tharac. Surg. 35: 605-614, 1983 ,

Baur, H.R*, Stede, B.W.* Preiruesberger, K.F. and Gobel, F.L., Serum myocardial creatine kinase (CK-MB) after coronary arterial bypass surgery.

An. J. Candial. 44: 679-686, 1979.

Becker, H., Vintenjohanson, J., Buckberg, G.D., Robertson, J.M., Leaf, J.0., Lazar, H.L. and Manganaro, A.J.: Myocardial damage caused by keeping $\mathrm{pH} 7.40$ during systemic deep hypothermia.

J. Thorac. Cardiovasc. Surg. 82: $810-820,1981$.

Bedard, P., Marcinek, H., Morton, B., Sintth, F., Akyurek11, $F_{\text {. }}$ 
Brais, M. and Keon, W.J.: Mucardial infarction following coronary artery bypass: factors influencing its occurrence.

Can. J. Surg. 20: 135-139, 1977.

Berglund, E* Monroè, R.G. and Schreiner, G.L: Myocardial oxygen consumption and coronary blood flow during potassium-induced cardiac arrest and during ventricular fibrillation.

Actea Physiol. Scand. 41: 261-268, 1.957.

Bergmeyer, M.U. and Bernt, E.: Glutamate-oxaloacetate transaminase.

In: Bergneyer, H.U. ed.: Methods of enzymatic analysis. Mcademic Press, New York 727-733, 1974a.

Bergmeyer, H.U. and Bernt, E.: Mal ate dehydrogenase.

In: Bergneyer, H.U. ed.: Methods of enzymatic analysis. Academic Press, New York 613-617, 1974b.

Bergmeyer, H.U., Bernt, E., Schmidt, F. and Stork, H.: D-glucose determination with hexokinase and glucose-6-phosphate dehydrogenase.

In: Methods of enzymatic analysis. H. U. Bergmeyer ed., Academic Press, New York, N.Y., 1196 1201,1974 .

Berne, R.M.: Cardiodynamics and the coronary circulation in hypothermia.

Ann. New York Ac. Sci. 365-383, 1974.

Bernhard, W.F., Schwarz, H.F. and Mallich, N.P.: Intermittent cold coronary perfusion as an adjunct to open heart surgery.

Surgery, Gynecology and obstetrics 111: $744-748,1960$.

Bigelow, W.G., Lindsay, W.K. and Greenwood, W.F.: Hypothemia. Its possible role in cardiac surgery: an investigation of factors goverring survival in dogs at low body temperatures.

Ann. Surg. 132: 849-866, 1950.

Brazier, J., Cooper, H., McConnell, D.H. and Buckberg, G.D.: Studies on the effect of hypothermia on regional myocardial blood flow and metabolism during cardiopulmonary bypass. III. Effects of temperature, time, and perfusion pressure in fibrillating hearts.

d. Thorac. Cardiowasc. Surg. 73: $102-109,1977$.

Brazier, d., Hottenrott, C. and Buckberg, G.D.: Non coronary collateral myocardial blood flow.

Ann. Thorac. Surg. 19: 426-435. 1975.

Bretschneider, H.J., Huebner, G., Knall, D., Lohr, B., Nordbeck, $H$. and Spieckermann, P.G.: Myocardial resistance and tolerance to ischemia: Physiological and biochernical basis.

3. Cardiovasc. Surg. 16: 241-260, 1975.

Brower, R.W., Katen, ten, H.J. and Meester, G.T.: Direct Method for determining regional nyocardial shortening after bypass surgery from radiopaque markers in man.

Am. J. Cardiol. 41: 1222-1229, 1978.

Brower, R.W., De Jong, J.W., Haallebos, M., Simoons, M.L., Van de Bos, A., De Jong, D.S., Bos, E. and Hugenholtz, P.G.: Evaluation of cardioplegia in coronary artery bypass graft surgery.

In: Kalziumantagonisten zur Kardioplegie und Myokard protektion in der offemen Herzchirurgie. Just, H. ed., Tschirkov, A. und Schlosser, V. (1982) 69-B.3 Georg Thieme Verlag stuttgart.

Buckberg, G.D. and Hottenrott, C.E.: Ventricular fibrillation: its 
effect on myocardial flow, distribution and performance.

Ann. Thorac. Surg. 20: 76-85, 1975.

Buckberg, G.D., Luck, J.C., Payne, D.B. , Hoffiman, J.I.E., Archie, J.P. and Fixler, D.E.: Some sources of error in measuring regional blood flow with radioactive microspheres. J. Appl. Physiol. 31: 598-604, 1971.

Brown, A.D.,Braimbridge, M.V., Darracott, S., Chayen, J. and Kasap, H.: An experimental evaluation of continuous nornothermic, intermittent hypothermic, and intermittent normothermic coronary perfusion.

Thorax 29: 38-50, 1974.

Buja, L.M., Levitsky, S., Ferrans, V.J. , Souther, S.G., Roberts, W.C. and Morrow, A.G.: Acute and chronic effects of normothermic anoxia on canine hearts.

Cardiovasc. Surg. 43,44 (Supp1. I): 44-50, 1970.

Bull, B.S., Huse, W.M., Braver, F.S. and Korpman, R.A.: Heparin therapy during extracorporeal circulation.

J. Thorac. Cardiovasc. Surg. 69: 685-689, 1975.

Chitwood, W.R., Sink, J.D., Hill, R.C. and wechsler. A.S.: The comparative effects of pulsatile and nonpulsatile myocardial perfusion during cardiopulmonary bypass.

J. Surg. Res. 30: 553-562, 1981.

Chitwood, W.R., Sink, J.D., Hill, R.C., Wechsiler, A.S. and Sabiston, D.C.: The effects of hypothermia on myocardial oxygen consumption and transmural coronary blood fllow in the potassium-arrested heart. Ann. Surg. 190: 106-116, 1979.

Clark, L.C., Gollan, F. and Gupta, V.B.: The oxyyenation of bland by gas dispersion.
Science, $\mathbb{I I}: 85-87,1950$.

Clomes, G.H.A., Hopkins, A.L. and Neville, W.E.: An artificial lung dependent upon diffusion of oxygen and carbon dioxide through plastic membranes.

J. Thorac. Cardiovasc. Surg. 32: $630-637,1956$.

Conahan, T.J. III: Cardiac anesthesia.

Menlo Park, C.A., Addison-Wesley Publ. Co., 1982.

Conti, V.R., Bertranou, E.G., Blackstone, E.H., Kirklin, J.W. and Digerness, S.B.: Cold cardioplegla versus hypothernia for myocardial protection.

]. Thorac. Cardiovasc. Surg. 76: $577-589,1978$.

Cunningham, J.N., Adams, P.X. . Knopp, E.A., Bauman, F.G. . Snively, S.L.., Gross, R.I., Nathan, I.M. and Spencer, F.C.: Preservation of ATP, ultrastructure, and ventricular function after aortic cross-clamping and reperfusion.

d. Tharac. Cardiovasc. Surg. 78: $708-720,1979$.

Dah1, C.F., Ewig, G.A., Warner, E.D. and Thomas, E.D.: Myocardial necrosis from direct current countershock. Effect of paddle electrode size and time interval between dischages.

circulation 50: 956-961, 1974.

Davids, H.A.: Per-operatieve hartspierbeschadiging.

Ph.D.-thesis, University of Leiden, Leiden, The Netherlands.

1982 .

Debakey, M.

New Orleans Med. Surg. J. 87 : $380-389,1934$.

Delva, E., Maille, J.G., Solymoss, B.C., "Chabot, M., Grond in, C.M. and Bourassa, M.G." Exaluation of 
myocardial damage during coronary artery grafting with serial deterinfintions of serum CPK-MB is soenzyme.

3. Thorac. Cardiovasc. Surg. 75: $467-475,1978$.

Dennis, C., Spreng, 0.S., Nelson, $\langle$ G.E. et a 1: Development of pump axygenator to replace the heart and lungs: an apparatus applicable to human patients and application to one case.

Ann. Surg. 134:709-721, 1951.

De Vries, H.W.: Anesthesia and monttoring of the dog in cardiovascular research.

Ph. D. thesis, Utrecht, The Netherlands, 1976.

Dewal1, R.A., Warden, H.E., Gott, W.L. Read, R.C., Varca, R.L. and Lllehei, C.W.: Total body perfuston for open cardiotomy utilyzing the bubble oxygenator.

J. Thorac. Cardiovasc. Surg. 32: $591-603,1956$.

Dietrich, E.B., Liddicoat, J.E., Alessi, F.u., Kihard, S.A. and De Bakey, M.E.: Serum enzyme and electrocardiographic changes immediately following mocardial revascularization.

Ann. Thorac. Surg. 5: 195-203, 1968.

Dogliotti, A.M. and costantini, A. : Primo caso dif applicazione all womo apparecchio di circolazione sangutnea extra corporea.

Minerva Chir, 6: 657-659, 1951 .

Domenech, R.d., Hoffman, J.I.E., Noble, M.I.M., Saunders, K.B. Henson, J.R. and Subijanto, $S .:$ Total and regionel coronary blood flow measured by radioactiwe microspheres in conscious and anesthetized dogs.

circ. Res. 25: 581-596, 1969.

Drake, A.J., Haines, J.R. and
Nob7e, M.I.M.: Prefermential uptake of lactate by the nomal myocardium in dogs.

Cardiovasc. Res. 14:65-72, 1980a.

Drake, A.J. Papadoyannis D.E.,

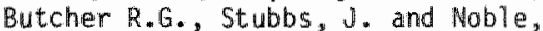
M. I. M.: Inhibition of glycolysis in the denervated dog heart.

Cifrc. Res. $47: 338-345,1980 \mathrm{~b}$.

Drake-Holliand, MobTe, M.I.M. (eds.): Cardiac metabolism. John wiley and Sons Ltd. 1983.

Dumn, R. B.: High energy phosphate depletion and lactate accumulation in the interventricular septum and left ventricular free wall of the dog after total coronary occlusion. Circ. Res. 5.4: 405-413, 1984.

Edlund, A., Bomfim, W., Kayser, L., 01 in, C., Patrona, C., Pinca, $E$. and Wennmalm, $A_{\text {. : }}$ Cardiac formation of prostacyclin during cardioplegia in man.

Prostaglandins 24: 5-19, 1982.

Ellis, R.J., Mangano, D.T., Van Dyke, D.C. and Ebert, P.A.: Protection of myocardial function not eninanced by high concentrations of patassium during cardioplegic arrest.

J. Thorac. Cardiovasc. Surg. 78: $698-707,1979$.

Engelman, R.M., Haag, B. Lenteshow, S., Angelio, A., Rousou, J.H.: Mechanism of plasma cathecholamine increases during coronary artery bypass and walke procedures.

J. Thorac. Cardiovasc. Surg. 86 : $606-616,1983$.

Engelman, R.M., Lewitsky, S. and Wyndham, C.R.C.: Optinal conditions for reperfusion during cardiopulmonary bypass.

Circulation (Suppl. II), 56: 148$156,1977$.

Engelman, R.M., Rousou, J.H., 
Lemeshow, S. and Dobbs, W.A.: The metabolic consequences of blood and crystalloid cardioplegia.

Circulation 64 (Suppl. II): 67-74, 1981.

Engelman, R.M., Rousou, J.H., Longo, F., Auvil, J. and Vertrees, R.A.: The time course of myocardial high-energy phosphate degradation during potassium cardioplegic arrest.

Surgery 86: $138-147,1979$.

Estafanous, F.G., Urzua, J., Yared, J.P., Zurich, A.M., Loop, F.D. and Tarazi, R.C.: Pattern of hemodynamic alterations during coronary artery operations.

3. Thorac. Cardiovasc. Surg. 87: $175-183,1984$.

Favaloro, R.G.: Saphonous vein graft in the surgical treatment of comanary artery disease - operation technique.

J. Thorac. Cardiovasc. Surg. 58: 178-185, 1967.

Favaloro, R.G.: Direct myocardial revascularization: A ten year journey (Myths and realities). Am. J. Cardio1. 43: 109-129, 1979.

Fennel, W.H., Chua, K.G., Cohen, L., Morgen, J., Karunaratne, H.B, Resnekow, L., Alsadir, J., Lin, C.Y., Lamberti, J.J, and Anagnostopoulos, C.E.: Detection, prediction and significance of perioperative myocardial infarction following aortocoronary bypass.

j. Thorac. Cardiovasc. Surg. 78: $244-253,1979$.

Fisk, R.L., Gelfand, E.T. and Callaghan, J.C.: Hypothermic coronary perfusion for intraoperative cardioplegia.

Ann. Thorac. Surg, 23: 58-61, 1977.

Flameng, W., Borgers, M., Daenen, W. and Stalpaert, G.: Ultrastructural and cytochemical correlates of myocardial protection by cardiac hypothernia in man.

J. Thorac. Cardiovasc. Surg. 79: $413-424,1980$.

Flameng, $W_{0}$, Daenen, $W_{.}$, Borgers, M., Thone, F., Xhonneux, R., Van der water, $A_{\text {. }}$ and Van Belle, $H_{*}$ : Cardioprotective effects of lidoflazine during 1 hour mornothermic global ischemic.

Circulation, 64: 796-807, 1981a.

Flameng, W. Van der Vusse, G.J., Borglers, M., De Meyere, R. and Suy, $R_{n}$ : Intermittent aortic crosscliamping at $32^{\circ} \mathrm{C}$, a safe technique for multiple aortocoronary bypass grafting.

Thorac. Cardiovasc. Surg. 29: 216-222, 19816 .

Flameng, W., Van der Vusse, G.J., De Meyere, R., Borgers, M., Sergeant, P., Vander Meersch, E., Geboers, $J$. and Suy, R.: Intermittent aortic cross-claming versus St. Thomas Hospital cardioplegia in extensive aorta-coronary bypass grafting.

J. Thorac. Cardiovasc. Surg. 88: 164-173, 1984 .

Follette, D., Fey, K., Mulder, D., Maloney, J.V. and Buckberg, G.D.: Prolonged safe aortic clamping by combining membrane stabilization, multidose cardioplegia, and appropriate pH perfusion.

J. Thorac. Cardiovasc. Surg. 74: $682-690,1977$.

Fallette, D.M., Mulder, D.G., Maloney, J.V., and Buckberg, G.D.: Advantages of blood cardioplegia over continuous coronary perfusion or intermittent ischemia. Experimental and citrical study.

J. Thorac. Cardiovasc. Surg. 76 : 604-619, 1978 .

Galletti, P.M. and Brecher, G.A.: Heart-lung Bypass.

Grune and Stratton, New York, 
Loridon, 1962.

Gay, W.A.: Hypothermic cardioplegia.

Ann. Thorac. Surg. 30:517-519, 1980.

Ghadioli, P.E. and Gox, N.P.: Prelliminary corminulcation on monitoring of collotd osmotic pressure during extracorporeal circulation.

In: Montitoring of vital parameters during extracoporeal curculation. Proc. Int. Comf. Hijmegen 1980, Karger, Basel, 166-168, 1981 .

Ghidoni, H.J., Liotta, D. and Thomas, H.: Massive subendocardial damage accompanying prolonged ventricular fibrillation.

An. J. Pathol. 56: 15-29, 1969.

Glock, J., Puel, J. Fauvel, J.M., Boccalon, H., Vaislic, C., Bounhouse, J.P. and Puel, P.: Surgical revascularization of infarcted myocardium. Effects on left ventricular function.

Arch. Ma1. Coeur Wais. 74: 399-408, 1981 .

Goldschlager, N., Gerbode, F., Osborn, J.J. and Cohn, K.E.: Patterns of myocardial oxygen and lactate extraction in patients undergoing cardiopulmonary bypass.

Am. Heart J. 83: 167-178, 1972.

Gray, R.J. Harris, W.S., Shak, P.K., Mi yamoto A.T.M., Mat loff. J.M. and Swar, H.J.C.: Coronary sinus blood flow and sampling for detection of unrecognized myocardial ischemila and imjury.

Cardiovasc. Surg.: (Supp1. II) 58$61,1976$.

Griepp, R.B., Stinson, E.B., oyer, P.E., Copeland, $J . G$. and Shumway, N.E.: The superiarity of aortic cross-clamping with pround local hypothermia for myocardial protection during aorta-coronary bypass grafting.

1. Thorac. Cardiowasc. Surg. 70 : $995-1009,1975$.

Grower, F.L., Fewel, J.G., Ghidoni, J.J., Norton, J.B., Arom, K.V: and Trinkle, J.K.: Effects of ventricular fibrillation on coronary blood flow and mocardial metabolism. j. Thorac. Cardiowasc. Surg. 73: $616-624,1977$.

Guilbeau, E... Moore, L.K., Viole, A.d., Mathis, T.R. Switser, A.d., Brondon, T.A., Martin, M. and Fisk, R.L.: Effects of intermittent infusions of glucose - containing crystallaid cardioplegic solution on myocardial tissue lactic acid and recovery of contractility. J. Thorac. Cardilawasc. Surg. 86: $920-929,1984$.

Guyton, A.C.: Textbook of medilcal phys iollogy.

Philladelphia, W.B. Saunders Company, 1976.

Hattori, S., Weintraub, W.S., Agarwal, J.B.., Badenheimer, M.M., Banker, V.S. and Helfant, R.H.: contrasting ischemic contraction patterns by zone and layer in canine myocardium.

Am. J. Physiol. 243: H852-H855, 1982 .

Hearse, D.J.: Oxygen deprivation and early myocardial contractile failure: A reassessment of the possible role of adenosine triphosphate.

Am. J. Cardiol. 44: 1115-1121.

Hearse, D.J., Braimbridge, M.V. and Jynge, $P_{\text {.: }}$ Protection of the ischemic myocardium: Cardioplegia 1981. Rawen Press, New York.

Hearse, D.u., Stewart, D.A. and Braimbridge, M.W.: Cellular Protection during Myacardial Ischemia. Circulation 54: 193-202, 1976. 
Hendriks, F.F.A., Jonas, J., Van der Laarse, A. and Huysmans. M.A.: Cardioplegic arrest in isolated blood perfused working rat hearts. J. Surg. Res. $35: 41-50,1983$.

Hemens, W.Th. Willems, G.M. and Visser, M.P.: Quantification of circulating proteuns.

Martinus Nijhoff, 1982 .

The Hague/Boston/Londen.

Heymann, M.A., Payne, B.D., Hoffman, J.I.E. and Rudolph, A.M.: Blood flow measurements with radionuclide-labeled particles.

Prog. Cardiovasc. Dis. 20: 55-79, 1977.

Hollaar, L. and Van der Laarse, A.: Interference of the measurement of lactate dehydrogenase (LDH) activity in human serum and plasma by LDH from blood cells.

clin. Chim. Acta 99: 135-142, 1979.

Hottenrott, C.E., Maloney, J.V. and Buckberg, G.: Studies on the effects of ventricular fibrillation on the adequacy of regional myocardial flow: I Electrical vs. spontaneous fibrillation.

J. Thorac. Cardiovasc. Surg. 68: $615-625,1974$.

Hultgren, H. N., Miyagawa, M., Buck, W., Angel 1, W.W. and Alto, P.: Ischemic myocardial injury during coronary artery surgery.

An. Heart J. 82: 624-631, 1971.

Hurley, E.J., Lower, R.R., Dong, E., Pillsbury, R.C. and Shumway, N.E.: Clinical experience with local hypothermia in elective cardiac arrest.

J. Thorac. Cardiowase. Surg. 47: $50-65,1964$.

Imai, Sh. Katano, $Y_{*}$. Shimamoto, N. and Sakai, K.: Energy metabol ism in ischenic myocardium as studied in the isolated perfused guinea pig neart. n: Perspectives in cardiovascular research. Ischemic myocardium and antianginal drugs leds: M.M. Winbury, Y. Abiko). Raven Press, New York (1979), 185-199 (vol. 3).

Isom, 0.W*, Kutin, N.D., Falk, E.A. and Spencer, F.C.: Patuerns of myocardial metabolism during cardiopulmonary bypass and coranary perfusion.

J. Tharac. Cardiovasc. Surg. 64: $705-721,1973$.

Jalonen, J.: Cardiopulmonary bypass and myocardial oxygenation.

Scand. J. Thorac. Cardiovasc. Surg., Suppl. 27, 1980. (Acad. Dissert.).

Jalonen, J.: Myocardial oxygenation and recovery after topical cooling of the ischaemic heart and after hypothermic coronary perfusion.

Scand. J. Thorac Cardiovasc. Surg. 15: 49-56, 1981a.

Jalonen, J.: Is there any benefit. from adding single-dose cardioplegia to topical cooling of the ischemic myacardium in aprtic valve replacement operations.

Scand. $J$. Thor. Cardiovasc. Surg. 15: $75-81,1981 \mathrm{~b}$.

Jalonen, J., Havia, T., Inberg, M.V., Juva, K. and Laksomen, $V_{\text {. }}$ : Does nomothermia afford better conditions for myocardial oxygemation than hypothermia during artificial coromary perfuston.

Scand. J. Thor" . Cardiovase. Surg. $15: 57-65,1981 \mathrm{c}$.

Jalonen, J., Irjala, J., Vartinen, $E$. and Inberg, M.V.: Reduced lactate washout from the myocardium after combining $5 t$. Thomas I type cardioplegia with topical cooling of the heart.

Scand. J. Thor. cardiowasc. Surg. $15: 67-73,1981 d$. 
James, T.N." Anatomy of the coronary arteries, 1961 .

Harper and Row. publishers, Hagerstown, Maryland.

Jardetzky, 0. , Greene, E.A. and Lorber, $V_{\text {: }}$ Oxygen consumption of the completely isolated dog heart in fibirillation.

Circ. Res. 6: 144-147, 1956.

Jellinek, M. Standeven, J.W., Menz, L.J., Hahn, J.W. and Barner, H.B.: Cold blood potassium cardioplegia. Effects of increasing concentrations of potassium.

J. Thorac. Cardiovisc. Surg. 82: $26-37,1981$.

dennings, R.B.: Symposium on the pre-hospital phase of acute myocardial infarction. Part II. Early phase of myocardial ischemic injury and infarction.

Am. J. Cardiol. 24:753-765, 1969.

dennings, R.B., Hawkins, H.K., Lowe, J.E., Hill, M.L., Klotman, S. and Reimer, K.A.: Relation between high energy phosphate and lethal injury in myocardial ischemia in the dog.

Am. J. Patho1, 92: 187-215, 1978.

Jones, S.B.: Myocardial norepinephrine turnaver during induced hypothemia and rewarming.

J. Appl. Physiol. 50: 962-966, 1981 .

Jones, R.M., Attarian, D.E.* Currie, W.D., 01sen, C.O." Hili, R.C., Sink, J.D. and Wechsler, A.S.: Metabolic deterioration during global ischemila as a function of time in the intact nomal dog heart.

4. Thorac, Cardiovase. Surg. 81 : $264-273,1981$.

Jones, C.E. "Thomas, $J_{\text {.X. }}$. Parker, J.C. and Parker, J.E.: Acute changes in high energy phosphates. nucleotide derivatives, and con- tractile force in ischemic and non-ischemic canine myocardium following coronary occlusion.

Cardiovasc. Res. 10: 275-282, 1976.

dynge, P. Hearse, 0.J. , De Leilits, J. Feuvray, D. and Braimbridge, M. W.: Protection of the Ischemilc Myocardium.

1. Thorac. Cardiowasc. Surg. 76: $2-15,1978$.

Kao, R.L., conti, V.R. and Willians, E.H.: Effects of temperature during potassium arrest on myocardial metabolism and function. J. Thorac. Cardiovasc. Surg. 84: 243-249, 1982 .

Katz, A.M. and Messineo, F.C.: Lipid-membrane interactions and the pathogenesis of ischemic damage in the myocardium.

Circ. Res. 48: 1-17, 1981

Kawachi, $\gamma_{\text {., }}$ Tominaga, $\mathbb{R}_{\text {.. }}$, Yoshitoschi, M., Sese, A., Tokunaga, $K$. and Nakamura, $M_{\text {. : }}$ Influence of perfusion pressure on oxygen supply and demand in beating empty hypertrophied dog hearts.

J. Surg. Res. 33: 103-112, 1982.

Kayser, L., Berglund, B. and Carlson, L.A.: Changes in myocardial metabolisin in man by a new stimulator of carbohydrate oxidation.

Cheli. Pathol. Pharmacol. 26: 459$469,1979$.

Kim, J.D., Jones, M., Hauowell, S.T., Koch, J.L., Lees, D.E., Weise, $V$. and Kopui, I.J.: Changes in peripheral vascular and cardiac sympathetic activity before and after coromary artery bypass surgery-interrelationships with hemodynamic allerations.

Ani. Heart J. 102: 972-979, 1981.

King, H., Sheng Su, C., Bounous, G. Hardin, R., Deriu, F. and Schumacher, H.B.: Hypothermia in 
relation to low flow rates.
In: Exracorporeal circulation. Allen, J.G. (ed.) Charles C. Thomas Publ. Sprimgfield, 11 inois, USA, 193-203, 1958.

Kleber, A.G.: Extracellular potassium accumulation in acute myacardial ischentia.

J. Mol. Cel1. Cardiol. 16: 389-395, 1984.

Koster, J.K., Cohn, L.H., Collins, J.J., Sanders, J.H., Muller, J.E. and roung, E.: Continuous hypothermic arrest versus intermittent ischemia for myocardial protection during coronary revascularization. Am. Thorac. Surg. 24: 330-336, 1977.

Laguens, R.P., Weinschelbaum, R. and Favaloro, R.: Ultrastructural and morphometric study of the human heart musclie cell in acute coronary insufficiency.

Human Pathol. 10: 695-705, 1979.

Lamprecht, W., Steün, P., Heinz, F. and Weisser, H.: Determination of creatine phosphate.

In: Methods of enzymatic analysis. H.U. Bergmeyer, Ed., Academic Press, New York, N.Y., 1974, 1777-1781.

Lamprecht, W., and Trautschold, I.: Determination of adenosime triphosphatie.

In: Methods of enzymatic analysis. H.U. Bergmeyer, Ed., Acadenic Press, New Yark, N.Y., 1974 , 2101-2110.

Landaas, S., Urdal, P., Reikvam, $A$. and Semb, G.: The origin of creatine kinase $B B$ occuming in serum during aortacoronary bypass surge$r y *$

crin. Chim. Acta 111: 179-184, 1981 .

Lees, M.H., Herr, R.H., Hill, J.D., Morgan, E.L., Ochsner, A.J.,
Thomas, C., Vam Fleet, D.L. and Beaverton, B.A.: Distribution of systemic blood flow of the rhesus monkey during cardioputmonary bypass.

J. Thorac. Cardiovasc. Surg. 61: $570-586,1971$.

Lell, W.A., Walker* D.R., Blackstone, Kouchoukos, N.T., Allarde, R. and Roe, C.R.: Evaluation of myocardil damage in patients undergoing coronary-artery bypass procedures with halothane $N_{2} \mathrm{O}$ anesthesia and adjuvants.

Ahesth. Amalg. 56: $556-563,1977$.

Levinsky, L., Schimert, G. "Lajos, T.Z., Lee, A.B., Korenyi-Both, A., Vladutin, A., Montes, M. and Siegel, J.H.: The use of steroids as a potentiator of hypothermic myocardial preservation in man.

J. Surg. Res. 26: 629-651, 1979.

Levitsky, S. and Feinberg, H.: Biochemical changes of ischemia.

Ann. Thorac. Surg. 20: 21-29, 1975.

Levitisky, S. Wright, R.N., Rao, K.S., Holland, C., Roper, K., Engelmam, R. and Feinberg, $H_{\text {. }}$ : Does intermittent caromary perfusion offer greater myocardial protection than continuous aortic cross-clamping.

Surgery 82: $51-59,1977$.

Lewis, F.T. and Mansar, T.: Closure of atrial septal defects with the aid of hypothermia: experimental accomplishments and the report of on successful case.

Surgery 33: 52-59, 1953 .

Lillehei C.W., Cohen, M., Warden, H.E. and Varco, R.L.*: The direct vision intracardiac correction of congenital anomalies by controlled cross-circulation.

Surgery $38,11-29,1955$.

Linda 1, S., Myklebust "R., Sorlle, D. and Jorgensen, $L$.: Morphological 
changes in atrial myocardial cells after cold cardloplegic standstil and during reperfusion in coronary bypass surgery.

Sicand. J." Thorac. Cardovasc. Surg. 17: 109-119, 1983.

Lolley, D.M., Ray, U.F s Myers, W.O., Sauter, R.D. and Sheldon, G.: Is reperfusion injury from multiple aortic cross-clanping a curremt wyth of cardiac surgery.

Ann. Thorac. Surg. 30: 110-117. 1980.

Magrassi, P., Dumont, L., Stanley, P. and Chartrand, C.: Effects of cardiopulmonary bypass on the dymanics and coronary circulation of the nomal heart.

Chest 80: $80-84,1981$.

Manners, J.M. and Nielsem, M.S.: Magnesium flux during open heart surgery. The effect of st. Thomas Hospital cardioplegic solution. Anesthes a $36: 157-166,1981$.

Marco, J.D., Hahn, J.W., Barner, H.B. Topical cardiac hypothemia and phrenic nerve injury.

Ann. Thorac. Surg. 23: 235-237, 1977.

Marsboom, R.A., Verstraete, D., Thiempont, $D$. and Mattheeuws, 0. : The use of halo-anisone and fentanyl for neuroleptanalgesia in dogs. Br. Vet. J. 120: $466-468,1964$.

Mason, D.T.: Usefulness and limitathons of the rate of rise of intraventricular pressure (dp/dt) in the evaluation of myocardíal contractility in man.

Am. J. Cardiol. 23: 516-527, 1969.

Mason, D.T., Braunwald, E., Ross, J. and Morrow, A.G.: Diagnostjc value of the first and second derivatives of the arterial pressure pulse in aortic valve disease and in hypertrophic subaortitic stenosis.
Circulation 30: $90-100,1964$.

McAlpine, W.A.: Heart and coronary arteries.

Berlin, Springer Verlag, 1975.

Mcconnel1, D.H., Brazier, J.R., Cooper, N. and Buckberg, G.0.: Studies of the effects of hypothermia on regional myocardial blood flow and metabolism during cardiopulmonary bypass. II. Ischemia during moderate hypothemia in continually perfused beating hearts.

J. Tharac. Cardiovasc. Surg. 73 : $95-101,1977$.

McDonagh, P.F., Goldman, N. and Laks, H.: Transcaronary solute exchange in the beating versus fibrillating canine heart on cardiopulmonary bypass.

Microcircullation, $2: 45-72,1982$.

McFarland, J.A., Thomas, L.B., Gilbert, J.H. and Morrow, A.G.: Myocardial mecrosis following elective cardiac arrest induced with potassium citrate.

J. Thorac. Cardiovasc. Surg. 40: $200-208,1960$.

HcGovern, J.J., Jomes, A.P., and Steinberg, A.G.: The hematocrit of capillary blaod.

New Eng. J. Med. 253: 308- 〉, 1.955.

Meesmann, W., Van Krosigh, S., Meumanm, H., Martin, C., Hirsche, H., Marocek. Th. and Sautter, R.: Early shunting of $9 \mu \mathrm{m}$ and $15 \mathrm{\mu m}$ tracer microspheres from the acutely ischemic canine myocardium.

Basilc. Res. Cardiol. 78: 310-335, 1983.

Melrase, D.G. "Dreyer, B. Bentall, H.H. and Baher, J.B.E.: Elective cardiac arrest.

Lancet $i 1: 21-22,1955$.

Mercer, D.W. and Varat, M.A.: 
Detection of cardiac specific creatine kinase isoenzyme in sera with nomal or slightly increased total creatine kinase activity. Clin. Chem. 21: 1088-1092, 1975.

Merchant, F.J., Feinberg, H. and Lewitsky, 5.: Sequential analysis of altered myocardial metabolism and contractility induced by nomothemic arrest and reperfusion. J. Surg. Res. 16: 153-161, 1974.

Molina, J.E., Feiber, F., Sisk, A., Polem, T. and Collins, B.: Cardioplegia without fibrillation ar defibrillation in cardiac surgery. Surgery 81: 619-626, 1977 .

Moore, C.H., Gordon, F.T., Allums, U.A. Reeves, J., Lombardo, T.A., Barclay, G.W., Brady, A.B. and Sweet, R.L.: Diagnosis of perioperative myocardial infarction after coronary artery bypass.

Ann. Thorac. Surg. 24: 323-329, 1977.

Mori, A., Fabata, R., Matsuda, M., Nahamwia, $Y$, Takeuchi, T. and Okada, Y.: Carbohydrate metabolism during pulsatile cardiopumonamy bypass under profound hypothermia. Jpn. Circ. U. 47: 528-535, 1983.

Namin, D.H., Mayer, S.E. and Maltbie, M.: The role of potassium and calcium ions in the effect of epinephrine on cariac cyclic adenosine $3^{\prime}, 5^{\prime}$-monophosphate, phosphorylase kinase, and phosphorylase.

Mol. Fharmacol. 4: 522-530, 1968.

Nohara, Y.: Observations on myocardial ischemial.

dap. Circ. J. 47: 1983 .

Nugent, W.C., Lewine, F.H. Liapis, C.D., LaRaia, P.J., Tsai, C.-H., and Buckley, M.J.: Effect of the piH of cardioplegic solution on postarrest myocardial preservation. Circulation 66: (Suppt 1): $68-73$, 1982.
Oldhan, M.t., Roe, Ch.R., roung, W.G. and Diseon, S.H.: Intraopera tive detection of myocardial damage during coronary artery surgery by plasma creatine phosphokinase isoenzyme analysis.

Surgery 74: 917-925, 1973.

Dlin, C.L., Bonfin, V., Brudz, R., Kaijser, L., Strom, S.J. and Sylvem, C.H.: Myocardilial protection during aortic valwe replacenent. J. Thorac. Cardlowasc. Surg. 82: $837-847,1981$.

opie, L.H., Thomas, M. Cwen P. and Shuman, G.: Increased coronary venous imorganic phosphate concentrations during experimental myocardial ischemia.

Am. J. Cardiol. 30: 503-513, 1972.

Opie, L.H., Owen, P. and Riemersma, R.A.: Relative rates of oxidation of glucose and free fatty acids by ischenic and nonischemic myocardium after coronary artery ligation in the dog.

Eur. J. Clim. Invest. 3: 419-435. 1973.

Opie, L.H.: Effects of regional ischemia on metabolism of glucose and fatty acids. Relative rates of aerobic and anaerobic energy production during myocardial infarction and comparison with effects of anoxia.

Circ. Res. 38 (Suppl. I): 52-72, 1976.

Passomneau, J.W.: Lactate. Fluorimetric method.

In: Bergneyer, H.U. ed.: Methods of enzymatic analysis. Academic Press, New York 1468-1472, 1974.

Owen, P., Thomas, M. Young, W. and opie, L.H.: Comparison between metabolic changes in lacal venous and coronary sinus blood after acute experimental comonary arte. rial acclusion.

Aml. J. Cardio:. 25:562-579, 1970. 
Paul, M.H., Theilen, E.0., Gregg, 0.E. Marsh, U.B. and Casten, G.G. Cardic metabolism in experimental ventricular fibrillation.

Circ. Res. 2:573-57a, 1954.

Pepper, J.R., Lockey, E., CamhovicDarracott, 5 . and Braimbridge, M.H.: Cardioplegia wersus intermitttent ischaemic arrest in coronary bypass surgery.

Thorax 37: 887-892, 1982 .

Pewler, U.0. and Johnson, J.A.:

Sinultaneous single isotope radioenzymatic assay of plasma norepimephrine, epinephrine and dopamine.

Life Sci. $21: 625-533,1977$.

Pine, M. B., Biny, O.H.L., Weintraub, R.M. and Abelmann, H.H.: Myocardial volume regulation after normothermic and hypothermic ischenic arrest in dogs.

Am. J. Physiol. 240: H116-H126, 1981.

Piper, H.M., Schwartz, P., Spahr, R., Huetter, J.F. and Spieckermann, P.G.: Early enzyme release from myocardial cells is not due to Arreversible cell damage.

J. Mol. Cell. Cardiol. 16: 385-388, 1984.

Ponce-Hornos, J.E., Langer, G.A. and Nudd, L.M." Inorganic phosphate: its effects on $\mathrm{Ca}$-exchange and compartimentalization in cultured heart cells.

1.Moll. Cell. Cardiol. 14: 71-52, 1982.

Ponce-Hornas, J.E. and Langer, G.A.: Effects of inorganic phosphate on lon exchange, energy state, and contraction in maminalion heart.

Am. N. Physiol. 242: H79-HB8, 1982.

Prinzen, F.W.: Gradlents in myocardial blood flow, metabolism and mechanics across the ischemic left ventricular wall.
Ph.0.-thesis, University of Limburg, Mastricht, The Netherlands, 1982.

Prinzen, F.H., Arts, T. Van der Vusse, G.J., Coumans, $M . A$. and Reneman, R.S.: Gradients in fiber shortening and metabolism across the ischemic left ventricular wall. Subritted for publication.

Prinzen, F.W., Arts, T., Van der Vusse, G.J. and Reneman, R.S.: Fiber shortening in the inner layers of the left ventricular wall as assessed from epicardial deformation during normoxia and ischemia.

J. Biomech. 17: 801-811, 1984 .

Prinzen, F.W. Van der Vusse, G.J. and Reneman, R.S.: Blood flow distribution in the left ventricular free wall in open-chest dogs.

Basic Res. Candiol. 76: 431-437, 1981.

Race, D., stirling, G.R. and Morris, K.N.: Induced ventricular fibrillation in open heart surgery. J. Thorac. Cardiovasc. Surg. 47: $271-282,1964$.

Rau, E.E. and Langer, G.A.: Díssaciation of energetic state and potassium lass from anoxic myocardium.

Am. J. Physiol. 235: 1537-4543, 1978.

Ream, A.K. and Fogdall, R.P.: Acute cardiovascular management.

J.B. Lippincott Company, Philadelphia, Toronto, 1982.

Regan, T.J., Markow, A., 0ldewurtel, H.A. and Burke, W.M.: Myocardial metabolisin and function during ischaenia. Responce to L-noradrenaline.

Cardiowasc. Res. 4: 334-342, 1970.

Reimer, K.A., Jennings, R.B. and Hill, M.L.: Total ischemia in dog 
hearts in vitro. 2. High-energy phosphate depletion and associated effects in energy metabolism, cell volume regulation, and sarcolemul integrity.

Circ. Res. 49: 901-911, 1981.

Reneman, R.S., Jageneau, A.H.M., Van Gerven, W., Dony, J. and Beirnaert, $P$.: The radioactive microsphere method for the assessment of regional myocardial blood flow after coronary antery occlusion.

Pfluegers Arch, 353: 337-347, 1975.

Reneman, R.S. and Spencer: The use of diastolic reactive hyperemia to evaluate the coromary vascular system.

Ann. Thorac. Surg. 13: 477-487, 1972 .

Reneman, R.S. and Spencer, M.P.: The functional state of the coronary vascular system after aorta to - coronary bypass surgery.

In: Norman, J.C. (ed.) Coronary artery medicine and surgery: concepts and controversies. Appletion Centry Crofts, Mew York: $172-181,1975$.

Reneman, R.S. and Verheyen, A.: The radioactive microsphere method.

Bibl. Anat. 15: 15-19, 1977 .

Reul, G.J., Meyer, J., Sandiford, F.M., Wukasch, D.C., Noman, J.C. and cooley, D.A.: Comparison of mormothermic and hypothermic anoxic cardiac arrest in aortocoronary artery bypass.

In: Norman, J.C. (ed.) Coronary artery medicine and surgery: concepts and controversies. Appleton-Century-Crofts, New York, $\quad 560-570, \quad 2975$.

Reves, J.G., Buttner, E., Karp, R.B., Oparil, S., McDaniel, H.G. and Smith, L.R.: Elevated catecholamines during cardiac surgery: Consequences of reperfusion of the pastarrested heart.
Am. J. Cardiol. 53:722-131, 1984.

Roberts, A.J., Sanders, J.H., Moran, J.M. Kaplan, K.J.. Lichtenhal, P.R., spies, S.M. and Michaelis, L.L.: Nanrandomized matched Pair analysis of intermittent ischenic arrest versus potassium crystalloid cardioplegia during myocardial revascularization.

Anm. Thorac. Surg. 31: 502-511, 1981.

Robinson, L.A., Braimbridge, M.V. and Hearse, D.J.: Creative phosphate-anadditive myocardial protective and anti arrhythmic agent in cardioplegia.

J. Thorac. Cardiovasc. Surg. 87: $190-200,1984$.

Roe, B.B., Hutchinson, J.C., Fishman, N.H., Ullyot, D.J. and Smith, D.L.: Myocardial protection with cold, ischenic, potassium-induced cardioplegia.

J. Thorac. Cardiovasc. Surg. 73: $366-374,1977$.

Roe, Ch.R., wagner, G.S., Young, W.G., Curtis, S.E., Cobb, F.R. and Irvin, R.G.: Relation of creatine kinase isoenzyme $M B$ to postoperative electrocardiographic diagnosis in patients undergoing coronaryartery bypass surgery.

cl in. Cheln. 25: 93-99, 1979.

Rosenkranz, E.R. and Buckberg. G.D.: Myocardial protection during surgical coronary reperfusion.

J. An. Coll. Cardiol. 1: $1235-1247$, 1983.

Rudolph, A.M., and Heymanm, M.A.: The circulation of the fetus in utero. Methods for studying distribution of blood flow, cardiac output and organ blood flow.

Circ. Res. 21: 163-184, 1967.

Salerno, T.A. and Chiong, M.A.: Cardioplegic arrest in pigs. 
3. Thorac. Cardiovasc. Surg. 80. $929-933,1900$.

Sapstord, R.N., Backstone, E.M., Kirkith, J.H., Karp, R.B., Kouchoukos, N.I. "Pacifico, A.D." Roe, Ch.R. and Bradley, E.L.: Coronary perfusion versus cold schemic arrest during aortic valve surgery. A randomized study.

Circulation 49: 1190-1199, 1974 .

Schamhardt, H.C.: Regional myocardial perfustion and performance.

Ph. D. -thesis, Erasmus University, Rotterdam, 1980.

Schaper, J., Hehrlein, F., Schlepper, M. and Thiedemann, K.: Ultrastructural alerations during ischeniz and reperfusion in human hearts during cardlac surgery. J. Mol. Cell. Cardiol. 9: 175-189, 1977.

Schaper, J.: Ultrastucture of the myocardium in acute ischenia.

In: The pathophysiology of myocardial perfusion, Schaper, w. ed., Elsevier/North-Holl and Bionedical press, 1979.

Schaper W., (ed.): The collateral circulation of the heart. North- Holland Publ. Co., Amsterdam-London-New York (1971).

Schaper, W. Lew $\hat{f}$. P. and Jagemeas, A. H. W.: The detemination of the rate of change of the left ventricular pressure (dp/dt).

Arch. Kreislaufforsch. 46: 27-41, 1965 .

Schosser, R., Arfors, K. -E. and Messmer, K.: MIC-II: a program for the determination of cardiac output, arteriowenous shunt and regionl blood flow using the radioactive microsphere method.

Comput. Progr. Biomed. 9: 19-39, 1979.

Schuette, A.H., Huttemeier, P.C.,
Watkins, W.O. and Zapol, W.M.: Effect of Iung thromboxane generation on regional biaod flow during sheep bypass.

Ant d. Physiol 242: H462-4469, 1982.

Sebel, P.S., Bowill, J.G. Schellekens, A.P.M. and Hawker. C.D.: Homonal reponces to highdose fentanyl anaesthesia.

Br. J. Anaesth. 53: 941-947, 1981 .

Senning, A.: Ventricular fibrilTation during extracomporeal circuTation.

Acta Chirurg. Scand. Suppl. 171. 1952 (Acad. Dissert.).

Shapira, N.: Comparison of the effect of blood cardioplegia to crystalloid cardioplegia on myocardial contractility in man.

J. Thorac. Cardiovasc. Surg. 80: $647-655,1980$.

Shel1, W.E., Lavelle, J.F., Covell, J.W. and Sobel, B.E.: Early estimation of myocardial damage in conscious dogs and patiens with evolving acute myocardial infarction.

J. Clin. Invest. 52: 2579-2590, 1973.

Shragge, B.W., Drgermess, 5.B. and Blackstone, E.H.: Complete recavery of the heart following exposure to profound hypothemia.

J. Thorac. Cardiovasc. Surg. 81: $455-458,1981$.

Shumway, N.E., Lower, R.R. and Stofer, R.C.: Selective hypothemia af the heart in anaxic cardiac arrest.

Surgery, Gymecology and obstetrics 109: $750-754,1959$.

Siegenthaler, W.: Klinische pathophysiologie.

George Thieme Verlag, Stuttgart-New York, 1982.

Singh, A.K., Farrugia, R. Tepitiz, 
C. and Karlson, K.E.: Electrolyte versus blood cardioplegia - Randomized cinical and myocardial ultrastructural study.

Ann. Thorac. Surg. 33: 218-227, 1982 .

Sink, J.D., Pellom, G.L., Currie, W.D., Chitwood, W.R., Hill, R.C. and wechsler, A.S.: Protection of mitochondrial function during ischemia by potassium cardioplegia: correlation with ischenic contracture.

Circulation 60 (Supp 1. I): 158-163, 1979.

Snoeckx, L.H., Verheyen, J.L., Van de Water, A., Lewi, P. and Reneman, R.S.: On-line computation of cardiac output with the thernodilution method using a digital minicomputer.

Cardiavasc. Res. 10: 556-564, 1976.

Speicher, C.E., Ferrigan, L., wolfson, S.K. Yalav, E.H. arid Rawson, A.d.: Cold injury of myocardium and pericardium im cardiac hypothermita.

Surgery, Gynecology and abstetrics $114: 659-665,1962$.

Standeven, J.W., Jellinek, M., Menz, L.J., Kolata, R.J., and Barner, H.B.: Cald blood potassium diltiazen cardioplegia.

J. Thorac. Cardiovasc. Surg. 87: $201-212,1984$.

Strom, S., Bend $z$, R., $01 \mathrm{in}, \mathrm{C}$. and Lundberg, 5.: Serum enzymes with special reference to CK-MB follawing coronary bypass surgery.

Scand. J. Thorac. Cardiowasc. Surg. 13: $53-59,1979$.

Swan, H., Zeavin, I., Blount Jr.., S.G. and Virtue, R.H.: Surgery by direct vision in the open heart. during hypothermia.

J.A.M.A. 153: 1081-1085, 1953*

Sylven, J.C.N., Bomfim, V., Ivert,
T. and $01 \mathrm{in}, \mathrm{C.}$ : Mocardral and mon-myocardial release of myoglobin and creaine-kinase $M B$ following cardiac operations with hypothermic potassium cardioplegia.

Cardiovasc. Res. 16: 151-157, 1982.

Szekeres, 1. and Udvary, E.: Haemodynamic factors influencing myocardial ischaemia in a canine model of coronary artery stenosis: the effects of nitroglycerine.

Brit. J. of Pharmacol. 79: $337-347$, 1983.

Taylor, J., Schackk, N.A. and Downar, E.: Ultrastructural changes of ischemic injury due to coronary artery occlusion in the porcine heart.

J. Mol. Cel1. Cardial. 43: 79-95, 1984.

Theroux, P., Franklin, D., Ross Jr., J. and Kemper, W.S.: Reglional myocardial function during acute coronary artery occlusion and its modification by pharmacologlic agents in the dog.

Circ. Res. 35: 896-908, 1974.

Tyers, G.F.O., Maulley, M.d., Williams, E.H., Shaffer, C.W.* Williams, D.R. and Kurusz, M.: Preliminary clinical experience with isotonic hypothermic potassium-induced arrest.

J. Thorac. Cardiovasc. Surg. 74: $674-694,1977$.

Utley, J.R, Carlson, E.L., Hoffinan, J.I.E., Martinez, H.M. and Buckberg, G.0.: Total and regional myocardial blood flow measurements with 25 wn, 15 wn, 9 um and filtered 1-10 $\mu \mathrm{m}$ diameter microspheres and antipyrine in dogs and sheep. Clinc. Res. 34: $391-405,1974$.

Utley, J.R., Wachtel, C., Caín, R.B., Spaw, E.A., Collins, J.C. and Stephens, D.B.: Effects of hypothermia, hemodilutian, and pump oxygenation on organ water content. 
blood flow and oxygen dellivery, and renal function.

Ann. Thorac. Surg. 31: $121-133$, 1981.

Van Belle, $H_{1}$ : Mek and sensitive reaction for automatic determination of inorganic phosphate and its application to serum.

Anal. Btochem. 33: 132-142, 1970.

Van der Laarse, A., Dijkshourn, N.J. Hollaar, L. and Caspers, Th.: The (iso)enzyme activities of lactate dehydrogemase, a-hydroxybutyrate dehydrogenase, creatine kinase and aspartate aminotransferase in human myocardial biopisies and autopsies.

Clin. Chim. Acta, 104: 381-391, 1980.

Van der Schaar, P.J., Reneman, R.S. and Van der Bult, U.A.: A pump umit for perfusion of the coromary vessels.

Thorax 21: $382-384,1966$.

Van der Vusse, G.u. , Van Belle, H., Van Gerwen, W., Kruger, R. and Reneman, R.S.: Acute effect of fentanyl on hemodynamics and myocardial carbohydrate utilization and phosphate release during ischemia.

Br. U. Anesth. 51: 927-935, 1979.

Van der Vusse, G.J., Coumans, W.A., Van der Veen, E., Drake, A.J., Flameng, W. and Suy, R.: ATP, creatine phosphate and glycagen content in human miocardial biopsies: Markers for the effilcacy of cardiaprotection during aortocoronary bypass surgery.

Vasc. Surg. 18: 127-134, 1984.

Van der Vusse, G.d., Flameng, W., Coumans, W., Van der Veen, $E_{*}$, and Suy, R.: Myocardial ATP, creatine phosphate and gilycogen as markers for the efficacy of cardioprotection during aortocoronary bypass surgery. n: Protection of tissues against hypoxia. Wauquier, $A$. et al (ed.), Elsevier bianedical press-Ansterdam, $449-452,1982$.

Van der Vusse, G.J., Prinzen, F. W., Coumans, $W_{*} A_{*}$, Kruger, $\mathbb{R}_{*}$, Verlaan, C. and Reneman, R.S.: Assessment of myacardial ischemia using hemodynamic and biochemical variables with special reference to elevated arterial free fatty acid concentration by heparin.

Adw. Clin. Cardial. 1: 407-420, 1980 a.

Van der Vusse, G.J. and Reneman, R.S.: Glycogen and lipids (endogenous substrates).

In: Cardiac metabolism. (eds.) A.J. Drake-Holl and and M. I. M. Noble. John wiley and Sons Ltd, Chichester, England, 215-237, 1982.

Van Kampen, E.J. and Zijlstra, H.G.: Standardization of hemoglobinometry. I The hemoglobin cyanide method.

clin. Chim. ACta, 6:538, 1961.

Van Renterghen, R.J.: Aortic valve geometry during the cardiac cycle. Ph. 0.-thesis, Uniwersity of Limburg, Mastricht. The Netherlands, 1983.

Winas, J.F., Fewel, J.G., Arom, K.V., Trinkie, J.K. and Grower, F.L.: Effects of systemic hypothermia on myocardial metabolism and coronary blood flow in the fibrillating heart.

J. Thorac Cardiovasc. Surg. 77: $900-907,1979$.

Visser, M.P., Krill, M.T.A., Willems, G.M. and Hermens, W.Th.: Plasma volume determination by use of enzyme dilution in the dog. Lab. Animals, 16: 248-255, 1982.

Wallace, H.W., Rheinlander, H.F. and Sugerman, H.J.: Cardiac meta- 
bolism during extracorporeal circulation.

Arch. of surg. 82: 158-166, 1961.

Weber, D.0. and Yarnoz, $M_{*}$ : Hyperkalemia complicating cardiopulmonary bypass: analysis of rish factors.

Ann. Thorac. Surg. 34: 439-445, 1982.

Weintraub, W.S., Hattori, S., Agarwal, J.B., Bodenheimer, M.M., Banka, V.S. and Helfant, R.H.: The relationship between myocardial blood flow and contraction by myocardial layer in the canine left ventricle during ischemia.

Circ. Res. 48: 430-438, 1981.

Weisel, R.D., Hoy, F.B.J., Baird, R.J. Ivanov, J., Hilton, J.D., Burns, R.J., Mickle, D.A.G., Mickleborough, L.L., Scully, H.E., Goldman, B.S. and McLaugl in, P.R.: Comparison of alternative cardioplegic techniques.

J. Thorac. Cardiovasc. Surg. 86: (Suppl. I) 97-108, 1983.

Weisel, R.D., Lipton, I.H., Lyall, R.N. and Baird, R.J.: CardiaC metabolism and performance following cold potassium cardioplegia. Circulation 58: 217-226, 1978.

Willems, G.M., Muytjens, A.M.M., Lambi, F.H.H. and Hermens, W. Th.: Estimation of circulatory parameters in patients with acute myocardial infarction. Significance for calculation of enzymatic infarct size.

Cardiovasc. Res. 13: 578-587, 1979.

Willems, G.M., Van der Laarse, A., Hollaar, L., Davids, H.A. and Hermens, W.Th.: Models and inarker enzymes for the quantification of myocardial damage after cardiac surgery.

In: Advances in studies on heart netabollism. Caldarera, C.M. and Harris, P. (ed.), CLUEB,
Bologna (Italy), 395-400, $1982 \mathrm{~b}$.

Willens, G.M., Van der Veen, F.H., Huysmans, H.A., Flameng, H* De Meyere, R., Van der Laarse. A., Van der Vusse, G.J. and Hermens, W.Th.: Enzymatic assessment of myocardial necrosis after cardiac surgery. Differentiation from skeletal muscle damage, hemolysis and liver injury.

An. Heart J. (accepted for publication).

Willems, G.M., Visser, M.P., Krill, M.T.A. and Hermens, W.Th.: Quantitative analysis of plasma enzyme levels based upon simultameous. determination of different enzymes. Cardiavasc. Res. 16: 120-131, $1982 \mathrm{a}$.

Wil son, G.J., Robertson, J.M., Walters, F.d.M., Steward, D.J. and McGregor, D.C.: Intramyocardial pH during elective arrest of the heart: relative effect of hypothermia versus potassium cardioplegia on anaerobic metabolism.

Ann. Thorac. Surg. 30: 472-481, 1980.

Yipintsoi, T., Dobbs, H.A., Scanlon, P.D., Knopp, T.J. and Bassingthwaighte, J.B.: Regional distribution of diffusible tracers and carbonized microspheres in the left ventricle of isolated dog hearts.

Circ. Res. 33: 573-587, 1973.

Zerbe, G.0.: Randomization amalysis of the completely randomized design extended to growth and response curves.

J. Am. Stat. Assoc. 74: 215-221, 1979 , 
In this thesis three techniques of myocardial protection, which are routinely employed during aorto-coronary bypass surgery, were evaluated in a randomized clinical trial and in an experimental dog study. The three techniques of investigation were continuous aortic cross-clamping in combination with multidose ice-coll St. Thomas Hospital cardioplegia, and intermittent aortic cross-clamping at $34^{\circ} \mathrm{C}$ (normothermia) and at $25^{\circ} \mathrm{C}$ (hypothermia). On the average, the period of ischemia llasted 63 minutes in the cardioplegia group (heart temperature less than $18^{\circ} \mathrm{C}$ and body temperature $25^{\circ} \mathrm{C}$ ), and the single periods of aortic cross-clamping in the other two groups lasted 10 minutes and were followed by reperfusion periods of approximately 15 minutes. Since 4 to 7 anastomoses were performed, the mean total duration of ischemia was 42 and 45 minutes in the normothermia and hypothermia groups, respectiveiy. The dog study was performed to obtain more detailed information about specific questions raised in the clinical study.

The cllinical study revealed adequate hemodynamic recovery inmediately after weaning from extracorporeal circulation. These findings were confirmed in the dog study. Besides, the results in this part of the investigation also showed good recovery of subendo and subepicardial fiber shortening.

The cumulative release of heart-specific enzymes was very small and no marked ultrastructural changes in mitochondria of both the subendo and subepicardial layers of the left vertricular free wall could be detected in the patients. Both findings indicated that no substantial amount of cardiac tissue became damaged. Besides, no significant differences could be abserved between the three operation techniques. The evaluation of circulatory parameters in the dog experiments revealed a transient increase in plasma volume and apparent disappearance rate constant for circulating enzymes. Because these parameters had returned to control values within 4 hours and peak values of plasma enzyme activity were observed thereafter, the changes in ctrculatory parameters will not influence the calculation of cumulative enzyme release to a great extent. Cumulative creatine kinase release was found to be a sensitive parameter for the assessment of damage by the extracorporeal circulation procedure, rather than the ischemic insult.

Biochemical analysis of transmural left ventricular biopsies revealed that myocardilal ATP and glycogen contents were decreased in postischemic tis- 
sue in the intermittent aortic cross-clamp patient groups. This decrease was associated with release of lactate and inarganic phosphate, during the repetitive periods of reperfusion. In contrast no change in myocardial ATP and glycogen content could be observed in the cardioplegia group. The sustained metabolic activity during the periods of intermittent aortic cross-clamping was also observed in the dogs, irrespective of a reduction in myocardial temperature from $34^{\circ} \mathrm{C}$ to $25^{\circ} \mathrm{C}$. Pronounced changes of the tissue contents of creatine phosphate, inorganic phosphate and lactate could be observed during the periods of ischemia and reperfusion, but these ischemia induced changes appeared to be completely reversible. Although in both groups with intermittent aortic cross-clamping comparable metabolic disturbances were measured in the myocardial tissue, the release of lactate and inorganic phosphate as markers of the ischemic insult, was considerably reduced under hypothermic circumstances.

In general we conclude from both the clinical and the experimental study that

- hardly any sign of irreversible myocardial damage could be observed in the three groups under investigation.

- cardioplegia offered a better protection against the ischemic insuit than intermittent aortic cross-clamping, both on the basis of metabolic disturbances in the myocardial tissue and the release of metabolites during reperfusion.

- a decrease in myacardial metabolic activity during ischemia as the result of a reduced temperature in conditions of intemittent aortic cross-clamping did not result in a better preservation of high-energy phosphates and glycogen stores in patients. However, the release of lactate and inorganic phosphate during reperfusion was reduced in hypothermic conditions. 


\section{SAMENWATTING}

Eén van de methoden om een vernauwing van de kransslagaders te behandelen is het uftwoeren van een aorta-coronaire bypass operatie. Hierbij worden beenaders vrij geprepareerd en aangebracht tussen de aorta en de kransslagader voorbij de vernauwing. Op deze manjer ontstat een overbrugging om het bedreigde gedeel te van het hart dat door de betrokken kransilagader bevloeid wordt weer van bloed te voorzien. Tijdens het uitvoeren van deze operatie is het noodzakelijk dat het hart wordt stilgelegd en de doorbloeding van de hartspier gestopt wordt. Dit laatste gebeurt door het plaatsen van een klem op de aorta of grote lichaamsslagader. Stilleggen van het hart is mogelijk door de hart- en longfunctic over te laten nemen door een hart-longmachine (extracorporale circulatie).

Het stoppen wan de hartspierdoorbloeding is een potentieel gevaar, omdat er geen toevoer van zuurstof en voedingsstoffen meer plaatsvindt en afbraakprodukten niet meer worden afgevoerd. Deze amstandigheid wordt ischemie genoema. Na verloop van tijd kan de ischemie de hartspiercellen onherstelbaar beschadigen. Aangezien het regelmatig voorkomt dat meerdere overbruggingen aangebracht worden per patiënt, dienen maatregelen genomen te worden om de ischemieduur bimnen aanvaardbare grenzen te houden. Hiertoe kan men de aorta voor elke overbrugging apart afklemmen, warbij tussen de afk Temmingen het hartweefsel opnieuw doorbloed wordt om het weefsel te laten herstellen van de aangebrachte ischemie. De lichaams- en harttemperatuur kan ingesteld zijn op waarden wariërend wan $25^{\circ} \mathrm{C}$ tot $34^{\circ} \mathrm{C}$. Anderzijds wordt de techniek gehanteerd on de aorta continu af te $k 1$ emmen tijdens het plaatsen van de overbruggingen. In dit geval dienen aanvullende beschemende matregeien, bijvoorbeeld in de vom van cardioplegie, getroffen te worden. Hiertoe worden in het algemeen de kransslagaders doorstroomd met een ijskoude vloeistof met een hoog kaliumgehalte waardoor de hartactiviteit stopt. Nadat alle overbruggingen zijn aangebracht wordt de temperatuur van de patiënt weer teruggebracht tot de fysiologisch normale temperatuur en de hart-longmachine stilgezet zodra het hart zelf weer woldoende pompcapaciteit kan opbrengen.

In dit proefschrift is een onderzoek beschreven warin drie operatietechnieken met elkaar worden vergeleken. De drie technieken zijn: continue 
afklemming van de aorta en gelijktijdige behandeling met de zogenaamde st. Thomas Hospital cardioplegische vloeistof en intermitterende afklemming van de aorta bij een lichaamstemperatuur van $34^{\circ} \mathrm{C}$ (nornotherinie) of bij $25^{\circ} \mathrm{C}$ (hypothermiel. In het onderzoek is enerzijds een klinische studie uitgevoerd, waarbij aan de hand van de bloedsomloop, de hartspierstofwisseling en de structuur van de mitochondriën in de cel, drie groepen patiënten met elkaar zijn vergeleken gedurende een korte periode voor en na de operatie en tijdens de fase van de extracorporale circulatie. Anderzijds zijn de drie operatietechnieken bestudeerd in een proefdiemodel bij de hond. Van het proefdiermodel is gebruik gemaakt om enkele onopgeloste vragen ult de klinische studie in meer detail te kunnen onderzoeken.

In de kiinische studie zijn 72 patiënten willekeurig verdeeld over drie groepen, die behandeld zijn volgens de genoemde drie operatietechnieken: cardioplegie en intermitterende aorta-afklemming met normothermie of hypothermie. In de cardioplegie groep bleef de aorta gemiddeld 63 minuten afge$k 1$ emd, bij een harttemperatuur van minder dan $18^{\circ} \mathrm{C}$ en een 71 chaamstemperatuur van $25^{\circ} \mathrm{C}$. De $i \mathrm{jskoude}$ cardioplegische vioeistof met een relatief hoog kaliumgehalte (16 mo1. $\left.1^{-1}\right)$ en een normal calciumgehalte $\left(1.2\right.$ mmo $\left.1.1^{-1}\right)$ werd iedere 20 minuten door de kransslagaders gespoeld. In de normothermie en de hypothermie groepen werd de aorta voor het aanbrengen van iedere overbrugging germiddeld ongeveer 10 minuten afgek lemd. Tussen deze perioden vam afklemming werd de hartspier gedurende gemiddeld ongeveer 15 minuten doorblaed. De totale afklemtijd bedroeg in deze twee groepen respectievelijk 42 en 45 minuten. Per patiënt werden 4 tot 7 overbruggingen tussen de acrta en de kransslagaders aangebracht. Dit aantal was niet verschillend tussen de drie groepen.

In de proefdierstudie werden meerdere groepen honden bestudeerd volgens de protocollen die overeenkomen met die van de drie patiënten groepen. Tijdens de extracorporale circulatie (145 minuten) is in de normothermte en de hypothermie groepen de aorta intermitterend afgeklemd (4 mal 10 minuten) en de afklemmingen zijn afgewisseld door periaden van doorbloeding die 15 minuten duren. In de cardioplegie groep is de aorta 60 minuten afgeklemd en is de 5t. Thomas Hospital cardioplegische vloeistof tijdens de afklemming drie maal door de kranssiagaders gespoeld. 
Ha de operatie wa bij de patienten het herstiel van de hartfunktie en de bloedsomloop bevredigend. Er konden geen duidelijke verschillen tussen de drie groepen worden aangetoond. Het verhoogde hartrïtme, de daling in arteriêle bloeddruk en de stijging in cardiac index (de hoevee theid bloed die per minuut door het hart wordt uitgepampt gedeeld door het lichaamsoppervlak) zijn wellicht volledig toe te schrijwen aan de toegediende marcosemiddelen en de bloedwerdunning die plats vindt door het mengen van het bloed wan de patient met de vioeistofinhoud van de hart-longmachine. Ook de daling van de kracht waamee de linker hartkamer samentrekt was vergelijkbaar in de drie groepen. Het staat ter discussue of deze daling kan worden toegeschreven aan een direct effect van de toegediende marcosemiddelen op de nabelasting van het hart, of op de hartspier zelf. In het proefdiemodel is behalve een adequat herstel van de bloedsomloop en de hartfunctie ook wargenomen dat de hartsplierfunctie in het hart, na extracorporale circulatie niet verschiliend is tussen de groepen. Hieruit kan worden geconcludeerd dat de periode (n) vami ischemie geen aantoonbare blijvende invloed heeft gehad op de werking van de hartspier. De hogere plasma adrenalinespiegel die in de normothermie groep is gemeten na extracorporale circulatie, kan een positieve invloed hebben op het functioneren van het hart van deze patiënten en hierdoor een mogelijk negatief effect van het operatieprotocol maskeren.

Een in de kliniek weel gehanteerde parameter voor het vastsitellen van onherstelbare hartweefselbeschadiging na ischemie is het verlies van enzymen uit het hart, hetgeen gemeten wordt als eem stijging in de plasma-enzym activiteit na afloop van de operatie. In de klinische studie bleek in de drie groepen de plasma-activiteit van CK-MB en HBOH piekwaarden te bereiken van 4 tot 8 uur na de operatie, terwijl piekwaarden voor AST en creatine kinase pas na 12 tot 24 uur werden gevonden. Wit deze pllasma warden is de totale witstorting berekend door gebrük te maken wan bekende waarden woar de afbraksnelheid van de enzymen. Wervolgens is deze hoeveelheid uitgedrukt in gram equivalenten hartweefsel door van een bekende weefselenzyminhoud uit te gaan. Hierbij is rekening gehouden met het vrijkomen wan enzymen uit skeletspieren en wit de tijdens de extracorporale circulatie beschadigde rode bloedcellem. op deze wijze kon worden berekend dat minder dan $1 \%$ van de totale enzyminhoud van de hartspier in het bloed komt, hetgeen wijst op een geringe beschadiging van de hartspier.

Uyt de proefdierstudie is naar voren gekomen dat bij het meten van het 
wrijkomen van enzymen als maat woor weefselschade na extracorporale circulatie, rekening moet worden gehouden met veranderde waarden vall de parameters warmee de totale hoeveellheid wrijgekomen enzymen berekend wordt. Het plasmavolume bleek tot $150 \%$ te stijgen en de verdiwijningssnelhelid van de enzmen uit de bloedsomloop was aammerkelijk groter dan onder controle onstandigheden. Aangezien het plasmavolume en de verdwijningssnelheid van de enzynen binnen 4 uur na de operatie weer vergeljjkbaar wamen met de omstandigheden voor de extracorporale circulatie en het vrijokomen van de enzymen voorname7 ijk na 4 uur plaatsvond, zal de invlaed van deze parameters op de berekening van de totale uhtstorting gering zijn.

Marfologische veranderingen in de hartspiercel werden bestudeerd in biopten die vóor en ongeveer 20 minuten na de periodelnl van aorta afkleming werden genomen. In deze biopten werd de structuur van mitochondriên onderzocht met behulp van een electronemicroscoop. Het blleek dat vrijwel alle mitochondriën in de stukjes hartweefsel, die voor het afklemmen van de aorta waren verkregen, een normale structuur vertoonden en dat deze structuur na de perioden(n) van afkleming in alle drie de graepen behouden bleef.

De stofwisselling van de hartspier werd bestudeerd in stukjes hartweefsel, die in de klinische studie verkregen werden op dezelfde tijdstippen als de weefselstukjes voor electronenmicroscopisch onderzoek. In de hartspler bleek het gehalte aan ATP en glycogeen te zijm gedaald na de perioden wan ischemie in de nomothermie en hypothermie groepen, terwijl het gehalte aan creatine fosfaat niet veranderd bleek te zijn. In de cardioplegie groep werden geen veranderingen waargenomen. Bovendien werd het melkzuur, anorganisch fosfaat, kalium en zuurstofgehalte bepaald in het aderlijke bloed wit het hart, zowel voor als na de perioden van aorta afklemming. De concentratie wan deze substanties in het aderlijke bloed werd vergeleken met die in het slagaderlijke bloed en het concentratie verschill werd gebruikt als mat voor de ernst van de ischemische veranderingen ten gevolge wan de afkleming. Deze cancentratie verschillen werden in de proefdierstudie omigerekend tot opname en afgifte van deze chemische substanties per gram hartweefsel door gelijktijidige meting wan de hartspier doorblloeding. Het bleek dat direct na het losmaken van de aortaklem aanzienlijke hoeveelheden melkzuur en anorgarisch fosfat uit het hart stroomden in de nomotherme groep en de hypotherme groep, wat respectivelijk wijst op anaerobe glycolyse en de afbrak wan energierijke fosfaatverbindingen. In de met cardioplegie behandelde harten bleken deze veranderingen 
vrijwel niet op te treden, waaruit kan worden geconcludeerd dat de energiebehoefte in voldoende mate was verlaagd zodat de stofwisseling tijdens de periode van ischemie vrijwel geheel geremd was.

Berekening wan de hoeveelheld anorganisch fosfaat en melkzuur in de proefdierstudie geeft aan dat onder normotherme omstandigheden aanzientijk meer van deze substanties het hart verlaten. Daar tegenover staat dat de weefselconcentraties van deze stoffen aan het einde van de ischemie niet verschillend zijn tussen de normotherme en de hypotherme groepen. Dit geldt global ook voor de weefselconcentraties van stoffen met energierijke verbindingen zoals ATP, creatine fosfaat en glycogeen. Hieruit kan worden geconcludeerd dat verlaging wan de temperatuur van $34^{\circ} \mathrm{C}$ naar $25^{\circ} \mathrm{C}$ leidt tot een verlaging van de zuurstoficonsumptie tijdens normale doorbloeding van het hart. Daartegenover staat dat de afname van energierijke fosfaten en de stifging van melkzuur in het weefsel na ischemie niet minder was bij de lagere temperatuur van $25^{\circ} \mathrm{C}$. De bevinding dat bij een lagere temperatuur veel minder melkzuur en anorganisch fosfaat het hart verlaat mag daarom niet worden gezien als een gevolg van een verschil in stofwisseling, maar als een gevolg van een verminderde uitstroom wan deze stoffen bij een lagere temperatwur.

In het algemeen kan worden geconcludeerd dat bescherming van het hart door cardioplegie de voorkeur verdient boven de toepassing van intermitterende afklemming van de aorta. Dit is gebaseerd op de geringe veranderingen in de stofwisseling van de hartspier tijdens ischemie onder cardioplegische omstandigheden. Het is van belang om hier op te merken dat relatief korte perioden van ischemie zijn onderzocht. of tijdens de langere ischemieduur die bij andere soorten van openhartoperaties voorkomen dezelfde mate van bescherming door middel van cardioplegie gevonden wordt moet nog worden bevestigd. 
Nawoord.

Het onderzoek dat in dit proefschrift is beschreven werd uitgevoerd met steun van de Nederlandse Hartstichting (projectleider G.J. van der Vusse, projectnr. 79.098). Het $k 1$ inische deel van dit onderzoek is verricht in samenwerking met Prof. $\mathbb{R}$. Suy, Prof. dr. W. Flameng en Dr. R. Me Meyere op de afdeing Cardiovasculaire Chirurgie wan de Katholieke Uniwersiteit te Leuven in Belgie. Het dierexperimentele gedeelte wan deze studie, alsook de biochemische analyses en de datawerwerking zijn uitgevoerd op de Rijksuniversiteit Limburg te Maastricht.

Het electronenicroscopisch deel van dit onderzoek Merd door Marcel Borgers en Fred Xhonneux werricht bij Janssen Pharmaceutica (Beerse, Belgif). De calciunanalysator werd ter beschikking gesteld door Radiometer, Nederland.

Aan de computerverwerking hebben met name Lex Volovics. Henk Jas en Vic Dreessen meegewerkt. Peter willemsen en will coumans hebben een grote bijdrage geleverd tijdens de uitvoering vam respectievelijk de experimentele en de klinische studies, en daarnast de meeste biochenische analyses verricht. De analyse van plasma enzymactiviteitem is uitgevoerd door Marij Krill en Marie-Louise Boumans, en de mathematische uitwerking van deze data door Gearge Willems. De dierproeven zijn uitgevoend in samenwerking met Ruud Kruger, Theo van der Nagel, Inger Simons-Achtenberg en Jet Beekman. Huub Simons en Frans slangen hebben zorg gedragen voor de proefdieren. Aan de verwerking wan het manuscript hebben Mariel coenen, Emmy van Roosmalen en Lucienne de Boer meegewerkt. Vele discussies over de inhoud van dit proefschrift zijn gewoerd met Wim Hermens en Theo Arts.

Allen die hebben meegewerkt aan deze studie wil ik van harte bedanken voor de goede en prettige samenwerking die uiteindelijk heeft geleid tot het werschijnen van dit proefschrift.

In het bijzonder wil ik de referenten, Prof. H. Weliens, Prof. H. Huysmans en prof. W. Flaneng bedanken voor hun kritische commentaar.

Rob Reneman als promotor, en Ger van der Vusse als copromotor, hebben op een zeer stimulerende wijze vorm gegeven aan het anderzoek, en in menig opzicht aan de imhoud van dit proefschrift bijgedragen. Hiervoor wil ik jullie in het bijzonder bedanken.

De goede samenwerking met Frits Prinzen en Theo van der Nagel zijn onontbeerlijk geweest tijdens het witwoeren van het onderzoek, en zeer zeker bij het gereed maken van dit proefschrift in de afgelopen maanden. 
Curriculum witae

Erik van der Veen werd op 3 februari 1950 geboren te 's-Gravenhage. Na het behalen wan het HBS-b diploma aan het Erasmus Lyceum te A7me 70 (1969.) is hij in dat zelfde jaar aan de scheikunde studie begonnen te Groningen. Na een verplichte studie onderbreking op wiegbasis Twente (1970-1971) is hij in Wageningen begonnen met de studie Humane Voeding. Het kandidatsexamen met als verzwarde vakken celbiologie, dierfysiologie en levensmiddelenchemie werd in 1979 behaald. De 6-maands praktijktijd heeft hij gewerkt in het Central Food Technology and Research Institute in Mysore, Zuid-India. Het ingenieurs examen haalde hij met lof in september 1980, met de hoofdvakken humane voeding (Prof. dr. J.G.A.J. Hautvast) en celbiologie (Prof. dr. L.P.M. Timmermans).

Na 3 maanden studentassistentschappen te Wageningen is hij per 1 januari 1981 in dienst getreden als wetenschappelijk ambtenaar bij de capaciteitsgroep Fystollogie wan de Rijksuniversiteit Limburg te Mastricht. Tot 1 december 1983 heeft hij gewerkt in het projekt "Myocard protectie tijdens aorta-comaire bypass chirurgie" (projekt van de Nederlandse Hartstichting, nr. 79.098). De resultaten wan dat onderzoek zijn in dit proefschrift weergegeven. Sindsdien merkt his in de capaciteitsgroep Fysiologie voor de duur van drie jaar in het projekt "Schatting van hartspierschade en andere toepassingen van kwantificeringsmethoden voor circulerende eiwitten" (dr. W.Th. Hermens). 